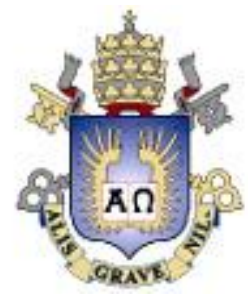

Eliot Pezo Zegarra

Sistema Pendular para Controle Passivo das Vibrações de Estruturas sob Excitação de Base

Tese apresentada como requisito parcial para obtenção do título de Doutor pelo Programa de Pós-Graduação em Engenharia Civil da PUC-Rio.

Orientador: Prof. Paulo Batista Gonçalves 
Eliot Pezo Zegarra

\section{Sistema Pendular para Controle Passivo das Vibrações de Estruturas sob Excitação de Base}

Tese apresentada como requisito parcial para obtenção do título de Doutor pelo Programa de Pós-Graduação em Engenharia Civil da PUC-Rio. Aprovada pela Comissão Examinadora abaixo assinada.

Prof. Paulo Batista Gonçalves Orientador Departamento de Engenharia Civil-PUC-Rio

Prof. Carlos Magluta Departamento de Engenharia Civil-COPPE/UFRJ

Profa. Eliane Maria Lopes Carvalho Departamento de Engenharia Civil-UFF

Prof. Raul Rosas e Silva Departamento de Engenharia Civil-PUC-Rio

Profa. Deane de Mesquita Roehl Departamento de Engenharia Civil-PUC-Rio

Prof. Marcio da Silveira Carvalho Coordenador Setorial do Centro Técnico Científico - PUC-Rio 
Todos os direitos reservados. É proibida a reprodução total ou parcial do trabalho sem autorização da universidade, do autor e do orientador.

Eliot Pezo Zegarra

Formou-se em Engenharia Civil na Universidad Nacional de San Antonio Abad del Cusco, Peru em 2006 e possui mestrado em Engenharia Civil pela Pontifícia Universidade Católica de Rio de Janeiro-PUC-Rio em 20012

Ficha Catalográfica

Zegarra, Eliot Pezo

Sistema pendular para controle passivo das vibrações de estruturas sob excitação de base / Eliot Pezo Zegarra ; orientador: Paulo Batista Gonçalves. - 2016.

192 f. : il. color. ; $30 \mathrm{~cm}$

Tese (doutorado)-Pontifícia Universidade Católica do Rio de Janeiro, Departamento de Engenharia Civil, 2016.

Inclui bibliografia

1. Engenharia civil - Teses. 2. Controle passivo de vibrações. 3. Vibrações não lineares. 4. Excitação de base. 5. Isolamento de base. I. Gonçalves, Paulo Batista. II. Pontifícia Universidade Católica do Rio de Janeiro. Departamento de Engenharia Civil. III. Título. 
A meus pais, Calixto e Martha. Irmãos, Yngrid, Mauro, Arturo, Magaly, Miluzca e Jhoel e sobrinhos, pelo acompanhamento incondicional. 


\section{Agradecimentos}

A Deus, por fortalecer-me para culminar mais uma etapa da minha vida.

A meus pais, irmãos e sobrinhos, que sempre estiveram pertos a traves de carinhos e motivações.

A meu orientador, Professor Paulo Batista Gonçalves, pela transmissão de seus conhecimentos

A professora Deane de Mesquita Roehl e Tecgraf PUC-Rio, pela oportunidade da aplicação dos conhecimentos adquiridos e da minha estabilidade econômica.

Aos professores do Departamento de Engenharia Civil, pela oportunidade de me permitir conhecer uma pequena parte da Engenharia Civil.

À PUC, por me acolher na sua infraestrutura para desenvolver a Tese.

A CNPq, pelo apoio econômico,

A todas as pessoas que acompanharam este trabalho.

A meus amigos que se tornaram a minha família no Brasil, Evelin, Thais, Sabrina, Helena, Roberta, Rosane, Lorena, Soraida, Deysi, Jesus, Luis Fernado, Elvis, Nicolas, John, Monica, Mario Alberto, Juan Pablo, Luisa e a todos os que estivaram na sala $607-\mathrm{C}$. 


\section{Resumo}

Pezo Zegarra, Eliot; Gonçalves, Paulo Batista. Sistema Pendular para Controle Passivo das Vibrações de Estruturas sob Excitação de Base. Rio de Janeiro, 2016. 192p. Tese de Doutorado - Departamento de Engenharia Civil, Pontifícia Universidade Católica do Rio de Janeiro.

O controle passivo de vibrações em edifícios usando absorsores pendulares tem sido bastante estudado na literatura técnica e usado na pratica em edifícios altos como o Taipei-101 em Taiwan. Como a frequência do pêndulo depende apenas do seu comprimento e da aceleração da gravidade, para sintonizar a frequência do pêndulo com a do edifício, tem-se como única variável de projeto o comprimento do pêndulo. Entretanto, em muitos casos, o comprimento necessário e o espaço requerido não se coadunam com o projeto. Nestes casos pode-se substituir o pêndulo clássico por um sistema pendular equivalente composto por uma massa que se movimenta sobre uma superfície curva, permitindo maior flexibilidade no projeto do absorsor, já que o comprimento do pêndulo torna-se irrelevante e a forma da superfície curva pode ser otimizada. Em virtude do movimento da massa sobre a superfície curva, novas forças de inércia e amortecimento não encontradas no pêndulo clássico podem aparecer. No presente trabalho um sistema pendular composto de uma massa que se desloca através de suportes rolantes sobre uma superfície curva é proposto para controle das oscilações de estruturas sob excitação de base. Este sistema pendular tem a vantagem de poder ser usado tanto como um amortecedor pendular de massa sintonizada (APMS) quanto como isolador de base pendular (IBP). Como o sistema pendular pode, em certos casos, apresentar grandes rotações, barreiras que limitam o movimento são propostas, gerando forças de impacto cuja eficiência no controle de vibrações é aqui investigada.

\section{Palavras-chave}

Controle passivo de vibrações; vibrações não lineares; excitação de base; isolamento de base. 


\section{Abstract}

Pezo Zegarra, Eliot; Gonçalves, Paulo Batista (Advisor). Pendulum system for the passive control of the vibrations of structures under base excitation. Rio de Janeiro, 2016. 192p. Doctoral Thesis Departamento de Engenharia Civil, Pontifícia Universidade Católica do Rio de Janeiro.

The passive vibration control of buildings using pendulum absorber has been extensively studied in the technical literature and used in high buildings such as the Taipei-101 in Taiwan. Since the frequency of the pendulum depends only on its length and the acceleration of gravity, to tune the frequency of the pendulum to that of the building, its length is the sole design variable. However, in many cases, the pendulum length and the space required for its installation are not consistent with the design. In these cases one can replace the classic pendulum with an equivalent pendulum system comprising a mass that moves on a curved surface, allowing greater flexibility in the absorber design as the length of pendulum becomes irrelevant and the shape of the curved surface can be optimized. Because of the mass movement on the curved surface, new inertia and stiffness forces not found in the classic pendulum may appear. In the present work a pendulum system comprising a mass that moves through rolling bearings on a curved surface is proposed for control of the oscillations of structures under base excitation. This pendulum system has the advantage of being used both as a pendulum tuned mass damper (APMS) and as a base isolation pendulum system (IBP). As the pendulum system can, in certain cases, display large rotations, barriers which limit its movement are proposed, generating impact forces whose efficiency in vibration control is here investigated.

\section{Keywords}

Passive vibration control; nonlinear vibrations; base excitation; base isolation. 


\section{Sumário}

1 Introdução $\quad 30$

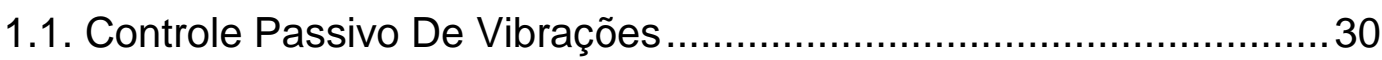

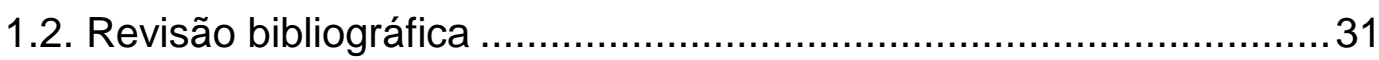

1.3. Objetivos da Tese e Contribuição ................................................ 42

1.4. Organização e Descrição da Tese .................................................43

2 Análise linear clássica $\quad 45$

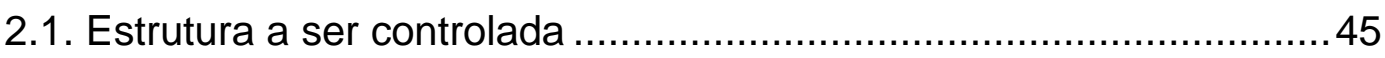

2.2. Estrutura com amortecedor de massa sintonizado (AMS) linear.......46

2.3. Valores ótimos do amortecimento e razão de frequências

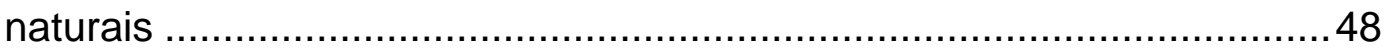

2.4. Estrutura com isolador de base linear .........................................52

2.5. Valores de amortecimento inerentes às estruturas $e$

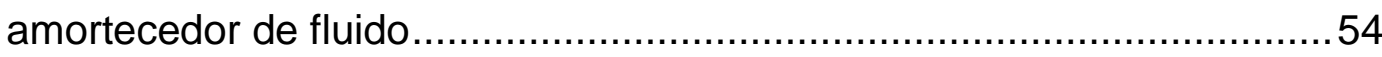

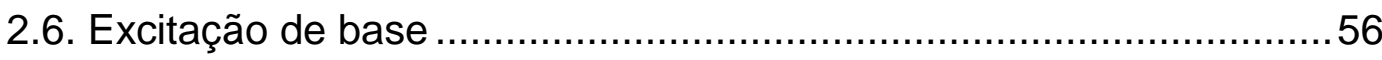

3 Sistema de controle passivo pendular 63

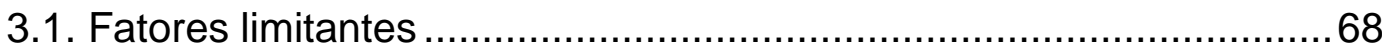

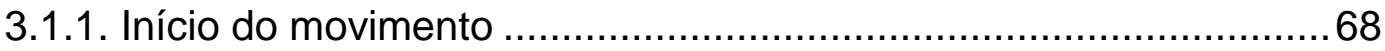

3.1.2. Rolamento sem deslizamento ............................................ 70

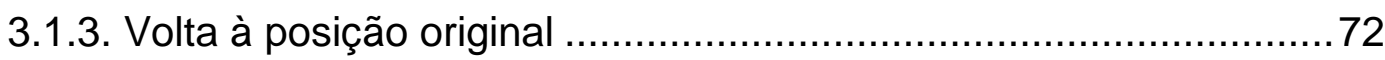

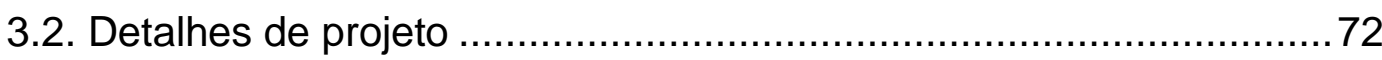

4 Controle passivo - amortecedor pendular de massa sintonizado $\mathbf{7 4}$

4.1. Estrutura com amortecedor pendular de massa sintonizada.............74

4.1.1. Equações de movimento na forma adimensional..........................76

4.2. Frequências e modos de vibração .................................................78 
4.3. Analise paramétrica da resposta permanente sob carga harmônica. 80

4.3.1. Análise paramétrica da influência da força de amortecimento do APMS na resposta da estrutura

4.3.2. Análise da resposta no tempo com carga harmônica e

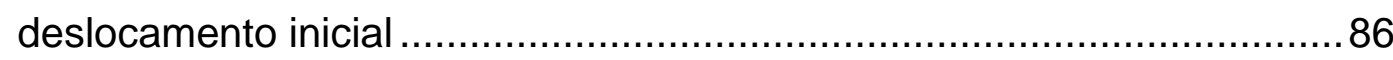

4.4. Análise da resposta no tempo com carga sísmica ........................91

4.5. Valores ótimos para o APMS linearizado ..................................... 98

5 Controle passivo - isolador de base pendular 102

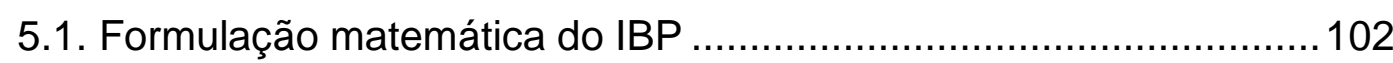

5.2. Equações de movimento na forma adimensional ......................... 103

5.3. Frequências naturais e modos de vibração do sistema

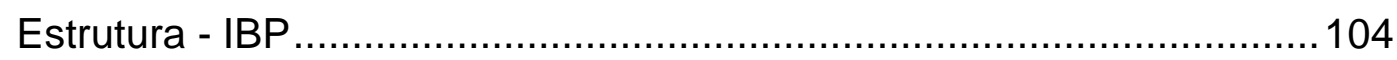

5.4. Análise paramétrica da resposta permanente sob carga

harmônica. 106

5.4.1. Análise paramétrica da não linearidade da força de amortecimento

5.5. Análise da resposta no tempo com carga harmônica e step load.

5.5.1. Resposta no tempo com carga harmônica ................................ 115

5.5.2. Resposta a um deslocamento inicial .......................................117

5.6. Análise da resposta no tempo com carga sísmica ........................118

6 Variação da curvatura 132

6.1. Variação do raio de curvatura ........................................... 132

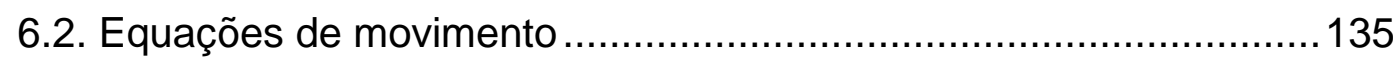

6.2.1. Formulação matemática da estrutura com APMS com superfície curva polinomial .................................................... 135

6.2.2. Isolador de base pendular ............................................. 136

6.3. Análise paramétrica em função do tipo de curva ...........................136

6.3.1. Estrutura com APMS ..................................................... 136

6.3.2. Estrutura com IBP ................................................... 141 
7.1. Forças de impacto e métodos de análise ....................................... 144

7.1.1. Impacto sobre superfícies flexíveis ............................................144

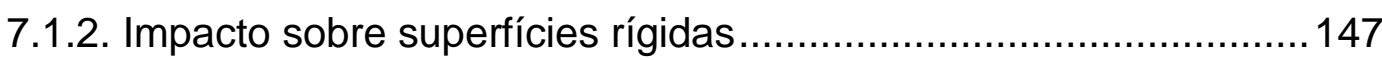

7.1.2.1. Coeficiente de restituição e energia cinética

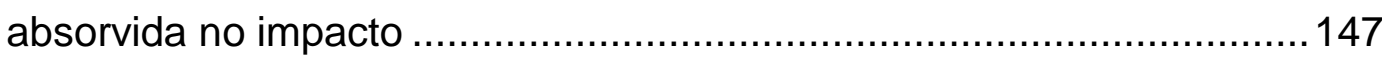

7.1.2.2. Vibração de uma massa com impacto rígido ............................. 148

7.2. Impacto entre duas massas em movimento .................................... 150

7.3. Efeito do impacto sobre as oscilações do APMS e do IBP...............153

7.3.1. Estrutura com APMS com rotação restrita ................................153

7.3.2. Isolamento pendular de base com rotação restrita........................ 164

7.4. Impacto no controle sísmico ............................................................. 171

8 Conclusões e sugestões do trabalho $\quad 174$

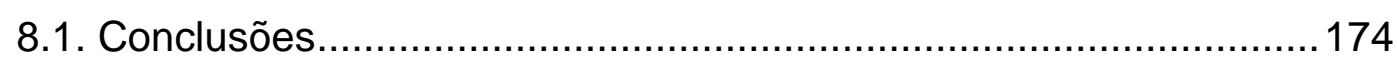

8.2. Sugestões de trabalhos futuros ................................................. 178

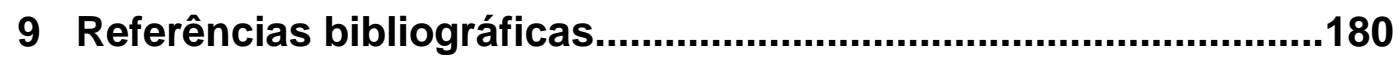

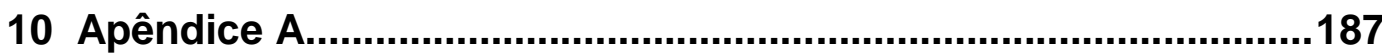

10.1. Equações de movimento do sistema pendular de massa sintonizada com curvas não circulares

10.2. Equações de movimento do isolador de base pendular para curvas não circulares. 


\section{Lista de figuras}

Figura 1-1 Torre Taipe 101 em Taipe, Taiwan, com amortecedor pendular de massa sintonizado

Figura 1-2 Alguns possíveis sistemas para controle de vibrações de estruturas (Matta e de Stefano (2009).

Figura 1-3 Sistema de isolamento de base com suporte de elastômero.

Figura 1-4 Isolamento de base com suporte de elastômero e amortecedores em duas direções

Figura 1-5 Isolamento de base com suporte rolante sobre

superfície plana em duas direções

Figura 1-6 Suporte rolante em uma ponte

Figura 2-1 Estrutura shear frame de um grau de liberdade sem controle (a), estrutura deformada após o deslocamento de base $\mathrm{xg}(\mathrm{b})$

Figura 2-2 Estrutura tipo shear frame com ams linear (a), estrutura

deformada pelo deslocamento de base $\mathrm{xg}$ (b)

Figura 2-3 Variação das frequências naturais em função dos

parâmetros adimensionais $\Delta$ e $\delta$.

Figura 2-4 Modos de vibração da estrutura com ams, primeiro modo (a), segundo modo (b)

Figura 2-5 Fator de amplificação em função de $\beta(\delta=0,05, \Delta=1)$

Soong \& Dargush, (1997)

Figura 2-6 Sistema de isolamento de base de linear (a), estrutura deformada pelo movimento de base $\mathrm{xg}$ (b)

Figura 2-7 Variação das duas frequências naturais da estrutura com isolamento de base linear em função de $\Delta$ para valores selecionados de $\delta$. 
Figura 2-8 Modos de vibração da estrutura com isolamento de base linear, primeiro modo (a), segundo modo (b)................................54

Figura 2-9 Amortecedor de fluido (Soong e Dargush, 1997;

Constantinou e Symans.1993b)

Figura 2-10 Aceleração no tempo (a), espectro de potências (b),

do terremoto el centro, componente ew

Figura 2-11 Acelerações no tempo (a), espectro de potências (b), do terremoto el centro, componente ns

Figura 2-12 Aceleração no tempo (a), espectro de potências (b), do terremoto loma prieta componente ew

Figura 2-13 Comparação dos períodos típicos de edifícios e respectivas frequências, determinados em função da altura. os valores são aproximados: o sistema estrutural, material e proporções geométricas também alteram o período (arnold, 2003)

Figura 2-14 Grupo vulnerável: cidade de méxico, 1985. os períodos das estruturas na faixa de 6 a 20 andares em ressonância com o conteúdo de frequências do terremoto (arnold, 2003)

Figura 2-15 Exemplo de espectro de resposta da ação sísmica, no regime elástico usado em projeto (em preto) e comparação com o conteúdo de frequências de diversos sismos.

Figura 3-1 Sistema de controle passivo pendular (a) posição inicial e (b) posição final após o deslocamento de base $\mathrm{xg}$

Figura 3-2 Cinemática da massa sobre a superfície curva. 64

Figura 3-3 relação não linear frequência-amplitude obtida por integração numérica (RK4 - em preto) e pela eq.3.14 (pasquetti (2008), em vermelho)

Figura 3-4 Diagrama de bifurcação dos deslocamentos da estrutura com ibp de curva circular.

Figura 3-5 Diagrama de corpo livre do apms (a) e relações geométricas (b) 68

Figura 3-6 Esquema simplificado do aparelho para o sistema pendular proposto por lee et al. (2009) 
Figura 3-7 Protótipo do sistema pendular

Figura 3-8 (a) Esquema simplificado do sistema pendular com superfície curva para controle de movimento em duas direções perpendiculares, (b) amortecedor de torção (http://www.vibromech.com/customer/presentation/veslfull\%20scope\%20supplier\%2020-nov-06.pdf)

Figura 4-1 Amortecedor pendular de massa sintonizada 74

Figura 4-2 Variação das frequências naturais em função dos parâmetros adimensionais $(\Delta \mathrm{e} \delta$ )

Figura 4-3 Modos de vibração da estrutura com APMS,

(a) primeiro modo e (b) segundo modo .79

Figura 4-4 Deslocamento da estrutura e rotação do APMS em função da razão de frequências $\Delta=0,7 ; 0,8 ; 0,9 ; 1,0 ; 1,1 ; 1,2 ; 1,3$ e $(\delta=0,01)$

Figura 4-5 Deslocamentos e acelerações máximas da estrutura com APMS e sem controle em função de $\Delta$

Figura 4-6 (a) Diagramas de bifurcação da estrutura, (b), do APMS e (c) comparação da resposta da estrutura sem controle, linearizada e sem linearizar. Para $\xi S=2 \%, \xi a=3,5 \%$ e $\delta=0.01$

Figura 4-7 (a) Diagramas de bifurcação da estrutura, (b) do APMS, para $\xi S=2 \%, \xi a=3.5 \%$

Figura 4-8 Influencia da variável $\alpha$ na resposta da estrutura e do APMS

Figura 4-9 Deslocamentos da estrutura no tempo $\beta=1,0 ; \delta=0,01$;

$\Delta=0,9$

Figura 4-10 Rotações do APMS no tempo $\beta=1,0 ; \delta=0,01 ; \Delta=0,9$

Figura 4-11 Deslocamentos da estrutura no tempo $\beta=1,0 ; \delta=0,01$;

$\Delta=1,0$

Figura 4-12 Rotações do APMS no tempo $\beta=1,0 ; \delta=0,01 ; \Delta=1,0$

Figura 4-13 Deslocamentos da estrutura no tempo $\beta=1,0 ; \delta=0,01$;

$\Delta=1,1$ 
Figura 4-14 Rotações do APMS no tempo $\beta=1,0 ; \delta=0,01 ; \Delta=1,1 \ldots \ldots \ldots . . .88$

Figura 4-15 Deslocamentos da estrutura no tempo $\delta=0,01 ; \Delta=0,9 \ldots \ldots .89$

Figura 4-16 Rotações do APMS no tempo $\delta=0,01 ; \Delta=0,9 \ldots \ldots \ldots \ldots \ldots . . . . . . . . .19$

Figura 4-17 Deslocamentos da estrutura no tempo $\delta=0,01 ; \Delta=1,0 \ldots \ldots .90$

Figura 4-18 Rotações do APMS no tempo $\delta=0,01 ; \Delta=1,0 \ldots \ldots \ldots \ldots \ldots \ldots . . . . . . . .90$

Figura 4-19 Deslocamentos da estrutura no tempo $\delta=0,01 ; \Delta=1,1 \ldots \ldots . .90$

Figura 4-20 Rotações do APMS no tempo $\delta=0,01 ; \Delta=1,0 \ldots \ldots \ldots \ldots \ldots . . . . . . .91$

Figura 4-21 Espectro de potências dos terremotos .............................92

Figura 4-22 Espectro de potência dos sismos na região de interesse ....92

Figura 4-23 Deslocamentos da estrutura com carga sísmica

$(\Delta=0,9 ; \delta=0,01 ; \xi S=2 \% ; \xi a=3,5 \%)$

Figura 4-24 Acelerações da estrutura com carga sísmica

$(\Delta=0,9 ; \delta=0,01 ; \xi S=2 \% ; \xi a=3,5 \%)$

Figura 4-25 Rotações do APMS com carga sísmica

$(\Delta=0,9 ; \delta=0,01 ; \xi S=2 \% ; \xi a=3,5 \%)$

Figura 4-26 Deslocamentos da estrutura com carga sísmica $(\Delta=0,9$;

$\delta=0,01 ; \xi S=2 \% ; \xi a=3,5 \%)$

Figura 4-27 Acelerações da estrutura com carga sísmica

$(\Delta=0,9 ; \delta=0,01 ; \xi S=2 \% ; \xi a=3,5 \%)$

Figura 4-28 Rotações do APMS com carga sísmica

$(\Delta=0,9 ; \delta=0,01 ; \xi S=2 \% ; \xi a=3,5 \%)$

Figura 4-29 Deslocamentos da estrutura com carga sísmica

$(\Delta=0,9 ; \delta=0,01 ; \xi S=2 \% ; \xi a=3,5 \%)$

Figura 4-30 Acelerações da estrutura com carga sísmica

$(\Delta=0,9 ; \delta=0,01 ; \xi S=2 \% ; \xi a=3,5 \%)$

Figura 4-31 Rotações do APMS com carga sísmica

$(\Delta=0,9 ; \delta=0,01 ; \xi S=2 \% ; \xi a=3,5 \%)$

Figura 4-32 (a)-Diagramas de bifurcação da estrutura,

(b)-do APMS e (c) comparação com a resposta sem controle.

$\xi S=2 \%$, para valores ótimos de $\xi a$ e $\Delta$

Figura 4-33 Deslocamentos da estrutura com carga sísmica.

Terremoto "El Centro-EW" 
Figura 4-34 Rotações do APMS com carga sísmica ( $\xi S=2 \%$ )

Figura 5-1 (a) Estrutura indeformada com isolador de base

pendular (IBP), (b) estrutura deformada com IBP pelo

deslocamento de base $\mathrm{Xg}$.

Figura 5-2 Frequências de vibração da estrutura com IBP em

função de $(\Delta)$

Figura 5-3 Modos de vibração da estrutura com IBP,

(a) primeiro e (b) segundo modo

Figura 5-4 (a) Curvas de bifurcação do deslocamento horizontal da

estrutura e (b) rotação do IBP. $\Delta=0,01$.

Figura 5-5 (a) Deslocamento horizontal da estrutura e

(b) rotação do IBP. $\Delta=0,1$

Figura 5-6 (a) Deslocamentos e (b) acelerações máximas da

estrutura com IBP em função de $(\Delta)$

Figura 5-7 Deslocamentos e acelerações máximas da estrutura com IBP em função de $(\Delta)$

Figura 5-8 Diagrama de bifurcação na vizinhança das frequências

de vibração $(\Delta=0,1)$ da estrutura com IBP.

Figura 5-9 Diagrama de bifurcação na vizinhança das frequências de vibração $(\Delta=0,3)$ da estrutura com IBP.

Figura 5-10 Deslocamento máximo da estrutura em função da

razão de massas.

Figura 5-11 (a) Influência no deslocamento da estrutura e

rotação do IBP e (b) das acelerações da estrutura da variável $\alpha$.

Para $\xi S=0,02 ; \xi a=0,035 ; \Delta=0,1 ; \delta=0,1$.

Figura 5-12 Deslocamento da estrutura com e sem controle, (b)

estrutura com IBP no tempo para $\beta=1 \delta=0,1 ; \Delta=0,1$

Figura 5-13 Rotações do IBP no tempo $\beta=1 \delta=0,1 ; \Delta=0,1$

Figura 5-14 (a) Deslocamento da estrutura com e sem controle, (b)

estrutura com IBP no tempo para $\beta=1 \delta=0,01 ; \Delta=0,9$

Figura 5-15 Rotações do IBP no tempo $\beta=1 \delta=0,01 ; \Delta=0,9$ 
Figura 5-16 Deslocamento da estrutura com IBP e sem controle no tempo $\delta=0,1 ; \Delta=0,1$

Figura 5-17 Variação da rotação do IBP no tempo em vibração

livre $\delta=0,1 ; \Delta=0,1$ 118

Figura 5-18 (a) Comparação dos deslocamentos da estrutura com e sem controle, (b) rotação do IBP e (c) deslocamento da estrutura com IBP, com carga sísmica $(\Delta=0,1 ; \delta=0,1 ; \xi S=2 \% ; \xi a=3,5 \%)$

Figura 5-19 Acelerações da estrutura com carga sísmica

$(\Delta=0,1 ; \delta=0,1 ; \xi S=2 \% ; \xi a=3,5 \%)$

Figura 5-20 Deslocamentos da estrutura (a) e rotação do IBP,

(b) com carga sísmica $(\Delta=0,1 ; \delta=0,1 ; \xi S=2 \% ; \xi a=3,5 \%)$

Figura 5-21 Acelerações da estrutura com carga sísmica

$(\Delta=0,1 ; \delta=0,1 ; \xi S=2 \% ; \xi a=3,5 \%)$

Figura 5-22 (a) Deslocamentos da estrutura e (b) rotação do

IBP com carga sísmica $(\Delta=0,1 ; \delta=0,1 ; \xi S=2 \% ; \xi a=3,5 \%)$.

Figura 5-23 Acelerações da estrutura com carga sísmica

$(\Delta=0,1 ; \delta=0,1 ; \xi S=2 \% ; \xi a=3,5 \%)$

Figura 5-24 Deslocamentos da estrutura com carga sísmica

$(\Delta=0,9 ; \delta=0,01 ; \xi S=2 \% ; \xi a=3,5 \%)$

Figura 5-25 Acelerações da estrutura com carga sísmica

$(\Delta=0,9 ; \delta=0,01 ; \xi S=2 \% ; \xi a=3,5 \%)$

Figura 5-26 Rotações do IBP sob carga sísmica

$(\Delta=0,9 ; \delta=0,01 ; \xi S=2 \% ; \xi a=3,5 \%)$

Figura 5-27 Deslocamentos da estrutura com carga sísmica

$(\Delta=0,4 ; \delta=0,01 ; \xi S=2 \% ; \xi a=3,5 \%)$

Figura 5-28 Acelerações da estrutura com carga sísmica

$(\Delta=0,4 ; \delta=0,01 ; \xi S=2 \% ; \xi a=3,5 \%)$

Figura 5-29 Rotações do IBP sob carga sísmica

$(\Delta=0,4 ; \delta=0,01 ; \xi S=2 \% ; \xi a=3,5 \%)$

Figura 5-30 Deslocamentos da estrutura com carga sísmica

$(\Delta=0,1 ; \delta=0,01 ; \xi S=2 \% ; \xi a=3,5 \%)$ 
Figura 5-31 Acelerações da estrutura com carga sísmica

$(\Delta=0,1 ; \delta=0,01 ; \xi S=2 \% ; \xi a=3,5 \%)$

Figura 5-32 Rotações do IBP sob carga sísmica

$(\Delta=0,1 ; \delta=0,01 ; \xi S=2 \% ; \xi a=3,5 \%)$

Figura 5-33 Deslocamentos da estrutura com carga sísmica

$(\Delta=0,1 ; \delta=0,01 ; \xi S=2 \% ; \xi a=3,5 \%)$

Figura 5-34 Acelerações da estrutura com carga sísmica

$(\Delta=0,1 ; \delta=0,01 ; \xi S=2 \% ; \xi a=3,5 \%)$

Figura 5-35 Rotações do IBP sob carga sísmica

$(\Delta=0,1 ; \delta=0,01 ; \xi S=2 \% ; \xi a=3,5 \%)$

Figura 5-36 Deslocamentos da estrutura com carga sísmica

$(\Delta=0,1 ; \delta=0,01 ; \xi S=2 \% ; \xi a=3,5 \%)$

Figura 5-37 Acelerações da estrutura com carga sísmica

$(\Delta=0,1 ; \delta=0,01 ; \xi S=2 \% ; \xi a=3,5 \%)$

Figura 5-38 Rotações do IBP sob carga sísmica

$(\Delta=0,1 ; \delta=0,01 ; \xi S=2 \% ; \xi a=3,5 \%)$

Figura 5-39 Deslocamentos máximos da estrutura em função

de $\Delta$ para $\delta=0,1$

Figura 5-40 Acelerações máximas da estrutura em função de $\Delta$

para $\delta=0,1$

Figura 5-41 Rotações máximas do IBP em função de $\Delta$ para $\delta=0,1 \ldots . .129$

Figura 5-42 Deslocamentos (a) e Acelerações máximas (b) da estrutura; rotações máximas do IBP (c) gerados pelo terremoto "Loma Prieta-EW-0,15g"

Figura 5-43 Deslocamentos (a) e Acelerações máximas (b) da estrutura; rotações máximas do IBP (c) gerados pelo terremoto "El Centro-EW-0,21g".

Figura 5-44 Deslocamentos (a) e Acelerações máximas (b) da estrutura; rotações máximas gerados pelo terremoto

"El Centro-NS-0,35g".

Figura 6-1 Superfícies curvas quadráticas usadas para o pêndulo de raio variável. 
Figura 6-2 Superfície de quarto grau usada para gerar o pêndulo

Figura 6-3 Curvas quadráticas modificadas em função da variável $(\phi)$

Figura 6-4 Funções que descrevem o pêndulo virtual (a), rigidez

efetiva $\left(d^{2} Z a / d X_{a}^{2}\right)$ para os tipos de curva (b), para

$R c=1, \phi=10, H=0.25, n=1 ; m=800$

Figura 6-5 Diagramas de bifurcação da estrutura (a) e do

APMS (b) para os diferentes tipos de curvas $(\Delta=0,9)$

Figura 6-6 Diagramas de bifurcação da estrutura (a) e do APMS (b) para os diferentes tipos de curvas $(\Delta=1,0)$

Figura 6-7 Diagramas de bifurcação da estrutura (a) e do APMS (b) para os diferentes tipos de curvas $(\Delta=1,1)$

Figura 6-8 (a) Diagramas de bifurcação da estrutura com IBP
e sem controle, (b) e da estrutura com IBP, (c) deslocamento

horizontal do IBP; em função da variação da curva, $\delta=0,1 ; \Delta=0,1$

Figura 7-1 (a) e (b)-Impacto de uma estrutura sobre uma superfície flexível como isolador de base, (c) e (d)- amortecedor de massa sintonizado 145

Figura 7-2 Variação do amortecimento Cc em função da penetração. . 146 Figura 7-3 Plano fase da estrutura com impacto sobre superfície flexível

Figura 7-4 Trabalho $W c$ feito pela força normal de contato $\mathrm{F}$ entre os corpos durante o período de compressão, e o trabalho $W f-W c$ recuperado durante a restituição, como função do deslocamento normal relativo $\mathrm{D}$ no ponto de contato. (b) Trabalho da força normal de contato relacionado com alterações na velocidade relativa normal durante o período de compressão $(p<p c)$ e restituição $(p c<p<p f)$. 148

Figura 7-5 (a) e (b)-Estrutura com controle de vibrações

com IB, (c) e (d)- estrutura impacto rígido 149

Figura 7-6 Plano face da estrutura com impacto rígido $(e=1)$ 150

Figura 7-7 Modelo proposto por Blazejczyk e Kapitaniak, (1996) 
Figura 7-8 Curva de bifurcação do sistema de 2GL sem impacto

Figura 7-9 Diagrama de bifurcação do oscilador principal com impacto e $\delta=0,1$

Figura 7-10 Diagrama de bifurcação do oscilador principal com impacto e $\delta=0,25$

Figura 7-11 Diagrama de bifurcação do oscilador principal com impacto.

Figura 7-12 Estrutura com APMS com rotação restrita sem deformar e deformada pelo deslocamento de base $\mathrm{Xg}$

Figura 7-13 Diagramas de bifurcação da estrutura (a) e do APMS (b) com $\theta$ lim $=10^{\circ}$

Figura 7-14 Plano de fase da estrutura como e sem impacto. (a), APMS (b) com limite de $\theta=10^{\circ}$ e a seção de Poincaré (c) para

$\delta=0,01 ; \Delta=0,9 ; \mathrm{e}=0,6$ e $\beta=0,883$

Figura 7-15 Plano de fase da estrutura (a) e do APMS (b) com

limite de $\theta=10^{\circ}$ para $\delta=0,01 ; \Delta=0,9 ; \mathrm{e}=0,6$ e $\beta=0,883$

Figura 7-16 Deslocamentos da estrutura com e sem impacto

para $e=0,6 ; \delta=0,01 ; \Delta=0,9$ e $\beta=0,883$

Figura 7-17 Deslocamentos da estrutura com e sem impacto

para $e=0,6 ; \delta=0,01 ; \Delta=0,9$ e $\beta=0,883$

Figura 7-18 Plano de fase da estrutura com e sem impacto. (a),

APMS (b) com limite de $\theta=10^{\circ}$ e a seção de Poincaré (c) para

$\delta=0,01 ; \Delta=0,9 ; \mathrm{e}=0,6$ e $\beta=1$

Figura 7-19 Plano de fase da estrutura (a) e do APMS (b) com

limite de $\theta \lim =10^{\circ}$ para $\delta=0,01 ; \Delta=0,9 ; e=0,6$ e $\beta=1$

Figura 7-20 Deslocamentos da estrutura com e sem impacto com

$\theta \lim =10$, para $e=0,6 ; \delta=0,01 ; \Delta=0,9$ e $\beta=1,0$

Figura 7-21 Rotações do APMS com e sem impacto para

$e=0,6 ; \delta=0,01 ; \Delta=0,9$ e $\beta=1,0$

Figura 7-22 Diagramas de bifurcação da estrutura (a) e

do APMS (b) com limite de $\theta=15^{\circ}$ 
Figura 7-23 Plano de fase da estrutura como e sem impacto. (a), APMS (b) com limite de $\theta=15^{\circ}$ e a seção de Poincaré (c) para $\delta=0,01 ; \Delta=0,9 ; e=0,6$ e $\beta=0,883$

Figura 7-24 Deslocamentos da estrutura com e sem impacto

para $e=0,6 ; \delta=0,01 ; \Delta=0,9$ e $\beta=0,883$

Figura 7-25 Rotações do APMS com e sem impacto, para

$e=0,6 ; \delta=0,01 ; \Delta=0,9$ e $\beta=0,883$

Figura 7-26 Plano de fase da estrutura como e sem impacto. (a),

APMS (b) com limite de $\theta=15^{\circ}$ e a seção de Poincaré (c) para

$\delta=0,01 ; \Delta=0,9 ; \mathrm{e}=0,6$ e $\beta=1,0$

Figura 7-27 Plano de fase da estrutura (a), do APMS (b) com

limite de $\theta=15^{\circ}$ e a seção de Poincaré (c)

Figura 7-28 Deslocamentos da estrutura com e sem impacto

para $e=0,6 ; \delta=0,01 ; \Delta=0,9$ e $\beta=1,0$

Figura 7-29 Rotações do APMS com e sem impacto para

$e=0,6 ; \delta=0,01 \Delta=0,9$ e $\beta=1,0$

Figura 7-30 Diagramas de bifurcação da estrutura (a) e do

APMS (b) com limite de $\theta=30^{\circ}$

Figura 7-31 Plano de fase da estrutura (a) e do APMS (b) com

$\theta_{\text {lim }}=30^{\circ}$, para $\delta=0,01 ; \Delta=0,9 ;$ e $=0,6$ e $\beta=1$

Figura 7-32 Deslocamento no tempo da estrutura com

$\theta_{\text {lim }}=30^{\circ}$, para $\delta=0,01 ; \Delta=0,9 ; \mathrm{e}=0,6$ e $\beta=1$

Figura 7-33 Rotações do pêndulo no tempo com limite de

$\theta \lim =30^{\circ}$, para $\delta=0,01 ; \Delta=0,9 ; \quad e=0,6$ e $\beta=1$

Figura 7-34 Estrutura com IBP com deslocamento restrito,

(a) na posição inicial e (b) após o deslocamento de base Xg

Figura 7-35 Diagramas de bifurcação da estrutura (a) e do IBP (b)

com e sem impacto a $\theta$ Lim $=5,16^{\circ}$.

Figura 7-36 Diagramas de bifurcação da estrutura (a) e do IBP (b)

sem e com impacto de $\theta \operatorname{Lim}=1^{\circ}$, para e $=0,6 ; \delta=0,1$ e $\Delta=0,1$

Figura 7-37 Diagrama de ressonância das acelerações da estrutura com e sem impacto para $\theta \mathrm{Lim}=1^{\circ}$ para e $=0,6 ; \delta=0,1$ e $\Delta=0,1$ 
Figura 7-38 Diagramas de bifurcação da estrutura (a) e (b), e do IBP (c) sem e com impacto para $\theta$ Lim $=0,5^{\circ}$;

$e=0,6 ; \delta=0,1$ e $\Delta=0,1$

Figura 7-39 Plano fase da estrutura (a) e do IBP (b) para

$\beta=0,099 ; \mathrm{e}=0,6 ; \delta=0,1$ e $\Delta=0,1$

Figura 7-40 Plano de fase da estrutura (a) e do IBP (b) para

$\beta=1,2 ; e=0,6 ; \delta=0,1$ e $\Delta=0,1$

Figura 7-41 Plano de fase da estrutura (a) e do IBP (b) para

$\beta=3,33 ; \mathrm{e}=0,6 ; \delta=0,1$ e $\Delta=0,1$

Figura 7-42 Deslocamento da estrutura no tempo para IBP

com e sem impacto $\theta_{\text {Lim }}=0.5^{\circ}$

Figura 7-43 Rotação do IBP no tempo para IBP com e sem

impacto $\theta_{\text {Lim }}=0,5^{\circ}$

Figura 7-44 Velocidades da estrutura no tempo para IBP com e

sem impacto $\theta_{\text {Lím }}=0,5^{\circ}$

Figura 7-45 Acelerações da estrutura no tempo para IBP com e sem impacto $\theta \mathrm{Lim}=0,5^{\circ}$

Figura 7-46 Curvas de ressonância em função do coeficiente de

restituição (e) $\Delta=0,9 ; \delta=0,01 \theta \mathrm{Lim}=10^{\circ}$

Figura 7-47 Deslocamento da estrutura no tempo em função do coeficiente de restituição (e), para $\theta \operatorname{Lim}=10^{\circ}$ e $\beta=1,1$

Figura 7-48 Deslocamentos no tempo da estrutura com IBP, sob carregamento sísmico

Figura 7-49 Acelerações no tempo da estrutura com IBP, sob

carregamento sísmico

Figura 7-50 Rotações no tempo do IBP com carregamento sísmico ....172

Figura 10-1 Diferença geométrica da curva quadrática e da modificada 188

Figura 10-2 Curva de quarto grau para gerar o pêndulo 189 


\section{Lista de tabelas}

Tabela 1-1 Estruturas com ams (gerb-vibration control systems) 33

Tabela 1-2 Estruturas esbeltas com ams pendular segundo Pirner, (2002) 36

Tabela 2-1 Valores ótimos dos parâmetros $\Delta \mathrm{e} \xi S$.

(Warburton e Ayonride, 1982) 50

Tabela 2-2 Amortecimentos inerentes às estruturas segundo

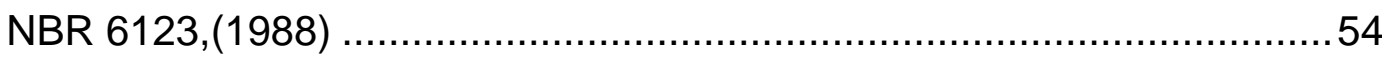

Tabela 2-3 Representação analítica do amortecimento 56

Tabela 2-4 Terremotos notáveis

(https://en.wikipedia.org/wiki/Peak_ground_acceleration)

Tabela 2-5 Correlação da intensidade instrumental com aceleração pico do solo

(https://en.wikipedia.org/wiki/Peak_ground_acceleration).

Tabela 3-1 Coeficientes de atrito rolante para diferentes tipos de material

Tabela 3-2 Coeficiente de atrito estático e cinemático de alguns materiais

Tabela 4-1 Valores básicos dos parâmetros da análise modal da estrutura tipo Shear frame (Avila, 2002) .80

Tabela 4-2 Eficiência do APMS em função do valor de $\Delta$ 82

Tabela 4-3 Deslocamentos e acelerações máximas da estrutura

e AMS. $\Delta=0,9 \xi S=2 \%, \xi a=3,5 \%$, (Figura 4-7)

Tabela 4-4 Influência da variável $(\alpha)$ do amortecimento na resposta da estrutura com APMS .86

Tabela 4-5 Deslocamentos, acelerações máximas da estrutura e rotações máximas do APMS em função de $\Delta$ 
Tabela 4-6 Deslocamentos, acelerações máximas da estrutura e rotações máximas do APMS em função de $(\delta)$

Tabela 4-7 Valores ótimos da razão de frequências e fator de amortecimento do APMS em função da razão de massas 98

Tabela 4-8 Deslocamentos e acelerações máximas da estrutura sem e com APMS para valore ótimos de $\xi a$ e $\Delta$, excitação de base harmônica. 99

Tabela 5-1 Frequências naturais de vibração da estrutura com IBP (Adimensional)

Tabela 5-2 Eficiência do IBP em função do valor de $\Delta, \Delta=0,01$.

$d^{2} \bar{X}_{g} / d \tau^{2}=0,01 \Delta^{2} \beta^{2} \operatorname{sen}(\beta \tau)$

Tabela 5-3 Eficiência do IBP em função do valor de $\Delta, \Delta=0,1$. $d^{2} \bar{X}_{g} / d \tau^{2}=0,01 \Delta^{2} \beta^{2} \operatorname{sen}(\beta \tau)$ 109

Tabela 5-4 Valores máximos dos deslocamentos e acelerações da estrutura e rotações do IBP $\Delta=0,1$.

Tabela 5-5 Valores máximos dos deslocamentos e acelerações da estrutura e rotações do IBP $\Delta=0,3$.

Tabela 5-6 Valores máximos dos deslocamentos e acelerações da estrutura e rotações do IBP $\Delta=0,9$.

Tabela 5-7 Influência da variável $(\alpha)$ do amortecimento na resposta do sistema Estrutura - IBP-2GL $\xi S=0,02 ; \xi a=0,035 ; \Delta=0,1 ; \delta=0,1$

Tabela 5-8 Eficiência do IBP no controle de vibrações sob carga sísmica El centro-EW $\delta=0,01$

Tabela 5-9 Eficiência do IBP no controle de vibrações sob carga sísmica El centro-NS $\delta=0,01$

Tabela 5-10 Eficiência do IBP no controle de vibrações sob carga sísmica Loma Prieta-EW $\delta=0,01$ 128

Tabela 5-11 Eficiência do IBP no controle de vibrações sob carga sísmica "Loma Prieta-EW" $\delta=0,1$ 
Tabela 5-12 Eficiência do IBP no controle de vibrações sob carga sísmica "El centro-EW" $\delta=0,1$

Tabela 5-13 Eficiência do IBP no controle de vibrações sob carga sísmica "El centro-NS" $\delta=0,1$

Tabela 6-1 Deslocamentos e acelerações máximas para cada tipo de curva $(\delta=0,01 ; \Delta=0,9)$

Tabela 6-2 Deslocamentos e acelerações máximas para

cada tipo de curva $(\delta=0,01 ; \Delta=1,0)$.

Tabela 6-3 Deslocamentos e acelerações máximas para cada tipo de curva $(\delta=0,01 ; \Delta=1,1)$

Tabela 6-4 Valores máximos de deslocamentos e acelerações

da estrutura e deslocamentos do IBP

Tabela 7-1 Deslocamentos e acelerações máximas com e sem impacto do APMS $\delta=0,01 ; \Delta=0,9$

Tabela 7-2 Deslocamentos e acelerações máximas da estrutura na vizinhança da primeira frequência com diferentes limites de $\theta$, para $e=0,6 ; \delta=0,1$ e $\Delta=0,1$ 166

Tabela 7-3 Deslocamentos e acelerações máximas da estrutura e rotações máximas do IBP com e sem impacto. 


\section{Lista de símbolos}

\section{Português Maiúscula}
A
Amplitude da forca de excitação
$\mathrm{C}_{\mathrm{S}}$
Coeficiente de amortecimento da estrutura principal
$\mathrm{C}_{\mathrm{a}} \quad$ Coeficiente de amortecimento do amortecedor linear e pendular
$\mathrm{C}_{\mathrm{b}} \quad$ Coeficiente de amortecimento do isolador de base linear e pendular
Coeficiente de amortecimento do amortecedor
$\mathrm{C}_{\mathrm{ma}}$
Coeficiente de amortecimento máximo
$\mathrm{C}_{\mathrm{C}}$
Coeficiente de amortecimento
$\mathrm{F}_{\mathrm{c}}$
Força centrípeta
$\mathrm{F}_{\mathrm{N}}$
Força de atrito
$\mathrm{F}_{\mathrm{o}}$
Força estática
$\mathrm{F}_{\mathrm{N}}$
Força normal
FT
Força de torção
$\mathrm{F}_{\mathrm{s}}$
Força de atrito rolante
$\mathrm{H}$
Razão dos coeficientes geométricos
I
Momento de inércia da massa do cilindro
$\mathrm{K}_{\mathrm{S}}$
Rigidez lateral da estrutura principal
$\mathrm{K}_{\mathrm{b}}$
Rigidez linear do isolador de base
$\mathrm{K}_{\mathrm{a}}$
Rigidez lateral do amortecedor
$\mathrm{K}_{\mathrm{ad}}$
Rigidez lateral adicional do amortecedor pendular
$\mathrm{M}_{\mathrm{a}}$
Massa do amortecedor
$\mathrm{M}_{\mathrm{S}}$
Massa da estrutura principal
$\mathrm{M}_{\mathrm{b}}$
Massa do isolador de base
$\mathrm{M}_{\mathrm{r}}$
Massa do cilindro rolante
$\mathrm{P}_{\mathrm{v}}$
Força no amortecedor na linear 
$\mathrm{R}_{\mathrm{c}}$

$\mathrm{R}_{\mathrm{D}}$

R

$\mathrm{R}_{\mathrm{S}}$

$\mathrm{R}_{\mathrm{a}}$

$\mathrm{T}_{\mathrm{a}}$

$\mathrm{T}_{\mathrm{S}}$

$\mathrm{T}_{\mathrm{b}}$

$T$

$\mathrm{U}_{\mathrm{a}}$

$\mathrm{U}_{\mathrm{S}}$

V

$\mathrm{V}_{\mathrm{c}}$

$V_{a}$

$\mathrm{V}_{\mathrm{b}}$

$\mathrm{V}_{\mathrm{T}}$

$V_{S}$

$\mathrm{V}_{\mathrm{A}}, \mathrm{V}_{\mathrm{B}}$

$\mathrm{V}_{\mathrm{A}}^{\prime}, \mathrm{V}_{\mathrm{B}}^{\prime}$

$\mathrm{W}_{\mathrm{c}}, \mathrm{W}_{\mathrm{f}}$

$\mathrm{X}_{\mathrm{S}}$

$\overline{\mathrm{X}}_{\mathrm{S}}$

$\dot{\mathrm{X}}_{\mathrm{S}}$

$\dot{\bar{X}}_{\mathrm{S}}$

$\ddot{X}_{S}$

$\ddot{\bar{X}}_{S}$

$\dot{\mathrm{X}}_{\mathrm{g}}$

$\ddot{X}_{\mathrm{g}}$

$\mathrm{X}_{\mathrm{b}}$

$\overline{\mathrm{X}}_{\mathrm{b}}$
Raio de curvatura da superfície curva

Fator de amplificação dinâmica

Energia interna de amortecimento

Energia interna de amortecimento da estrutura principal

Energia interna de amortecimento do amortecedor pendular

Energia cinética do pêndulo

Energia cinética da estrutura principal

Energia cinética da base

Energia cinética do cilindro rolante

Energia interna de deformação do sistema pendular

Energia interna de deformação da estrutura principal

Energia potencial do pêndulo

Velocidade relativa do pistão do amortecedor

Potencial do carregamento externo do sistema pendular

Potencial do carregamento externo do isolador pendular

Potencial do carregamento total do sistema

Potencial do carregamento externo da estrutura principal

Velocidades das massas antes do impacto

Velocidades das massas após o impacto

Trabalho feito pela força de contato, durante o impacto

Deslocamento horizontal da massa da estrutura principal

Deslocamento horizontal na forma adimensional

Velocidade horizontal da massa da estrutura principal

Velocidade horizontal na forma adimensional

Aceleração horizontal da massa da estrutura principal

Aceleração horizontal na forma adimensional

Velocidade da base (Solo) gerada pelo sismo

Aceleração da base (Solo) gerada pelo sismo

Deslocamento horizontal da massa do isolador de base linear e pendular

Deslocamento horizontal na forma adimensional 
$\dot{\mathrm{X}}_{\mathrm{b}} \quad$ Aceleração horizontal da massa do isolador de base linear e pendular

$\dot{\overline{\mathrm{X}}}_{\mathrm{b}} \quad$ Velocidade horizontal na forma adimensional

$\ddot{\mathrm{X}}_{\mathrm{b}}$ Aceleração horizontal da massa do isolador linear e pendular

$\ddot{\bar{X}}_{\mathrm{b}} \quad$ Aceleração horizontal na forma adimensional

$\mathrm{X}_{\mathrm{a}} \quad$ Deslocamento horizontal da massa do amortecedor linear e pendular

$\overline{\mathrm{X}}_{\mathrm{a}} \quad$ Deslocamento horizontal na forma adimensional

$\dot{\mathrm{X}}_{\mathrm{a}} \quad$ Velocidade horizontal da massa do amortecedor linear e pendular

$\dot{\overline{\mathrm{X}}}_{\mathrm{a}} \quad$ Velocidade horizontal na forma adimensional

$\ddot{X}_{\mathrm{a}} \quad$ Aceleração horizontal da massa do amortecedor linear e pendular

$\ddot{\bar{X}}_{\mathrm{a}} \quad$ Aceleração horizontal na forma adimensional

$\mathrm{X}_{1}, X_{2} \quad$ Modos de vibração

$\mathrm{Z}_{\mathrm{a}} \quad$ Deslocamento vertical da massa do amortecedor pendular

$\dot{\mathrm{Z}}_{\mathrm{a}} \quad$ Velocidade vertical da massa do amortecedor pendular

$\mathrm{Z}_{\mathrm{b}} \quad$ Deslocamento vertical da massa do isolador pendular

$\dot{\mathrm{Z}}_{\mathrm{b}} \quad$ Velocidade vertical da massa da fundação

\section{Português Minúscula}
$\mathrm{a}, \mathrm{b} \quad$ Coeficientes numéricos
e Coeficiente de restituição no impacto
$f \quad$ Distância focal da curva quadrática
g Aceleração da gravidade
$h \quad$ Coeficiente que define uma superfície curva
$m \quad$ Coeficiente que define uma superfície curva
$\mathrm{m}_{\mathrm{A}}, \mathrm{m}_{\mathrm{B}} \quad$ Massas
$n \quad$ Coeficiente que define uma superfície curva
$\mathrm{p}_{\mathrm{c}}, \mathrm{p}_{\mathrm{f}}, \mathrm{p} \quad$ Impulso no instante do impacto 


$\begin{array}{ll}\mathrm{q}_{\mathrm{i}} & \text { i-ésima coordenada generalizada } \\ r & \text { Raio de curvatura do cilindro rolante } \\ t & \text { Tempo } \\ \mathrm{v}_{\mathrm{o}} & \text { Velocidade inicial do impacto } \\ \mathrm{v}_{\mathrm{f}} & \text { Velocidade final de impacto } \\ \mathrm{x} & \text { Deslocamento horizontal } \\ \mathrm{x}_{\text {máx }} & \text { Deslocamento dinâmico máximo } \\ \mathrm{x}_{\text {sta }} & \text { Deslocamento estático }\end{array}$

\section{Grego Maiúscula}

$\Gamma \quad$ Razão de coeficientes de amortecimento

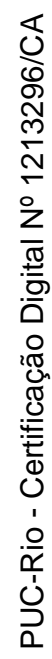
$\Delta$
Razão de frequências naturais
$\Omega$
Frequência de excitação
$\Lambda \quad$ Coeficiente na forma de porcentagem
$\Pi$
Energia potencial total

\section{Grego Minúscula}
$\alpha \quad$ Variável que define 0 grau de não linearidade do amortecedor
$\beta \quad$ Razão de frequências de excitação
$\delta \quad$ Razão de massas
$\varepsilon \quad$ Folga da massa do amortecedor linear
$\theta \quad$ Rotação da massa do sistema pendular
$\dot{\theta} \quad$ Velocidade angular
$\ddot{\theta} \quad$ Aceleração angular
$\lambda \quad$ Autovalor
$\mu_{\mathrm{s}} \quad$ Coeficiente de atrito estático
$\mu_{\mathrm{r}} \quad$ Coeficiente de atrito de rolamento
$\xi_{\mathrm{S}} \quad$ Taxa de amortecimento da estrutura principal


$\xi_{\mathrm{b}} \quad$ Fator de amortecimento do isolador de base linear e pendular

$\omega_{\mathrm{a}}$

$\omega_{\mathrm{i}}$

$\bar{\omega}_{\mathrm{i}}$

$\omega_{\mathrm{b}}$

$\bar{\omega}_{\mathrm{b}}$ $\omega_{\mathrm{p}}$

$\omega_{\mathrm{sp}}$

$\omega_{\mathrm{S}}$

Siglas

\section{AMS}

$\mathrm{AMH}$

APMS

EW

IBP

NBR

NS
Taxa de amortecimento do amortecedor linear e pendular

Tempo na forma adimensional

Coeficiente que define uma superfície curva

Aceleração angular

Frequência natural do amortecedor linear e pendular

Frequências de vibração do sistema Estrutura-(AMS, APMS ou (BP)

Frequências naturais na forma adimensional da estrutura(AMS, APMS ou IBP)

Frequência natural de vibração do isolador de base linear e pendular

Frequência natural de vibração na forma adimensional

Frequência natural do pêndulo

Frequência natural do sistema pendular

Frequência natural da estrutura principal

Amortecedor de massa sintonizada

Amortecedor de massa hibrida

Amortecedor pendular de massa sintonizada

Leste-Oeste

Isolador de base pendular

Norma Brasileira

Norte-Sul 


\section{Introdução}

\section{1.}

\section{Controle Passivo De Vibrações}

À medida que as estruturas se tornam mais leves e esbeltas, a frequência fundamental da estrutura diminui e aproxima-se dos valores das frequências de excitação associadas a carregamentos ambientais, tais como ventos, ondas e terremotos. Com isto as estruturas podem apresentar níveis indesejados de vibração, provocando desconforto aos usuários, danos em elementos estruturais e, em casos extremos, a ruina da estrutura. Isto é bastante comum em regiões de alta sismicidade onde a excitação sísmica oferece perigo para edifícios, pontes, torres e chaminés, independentemente de sua altura. Sistemas de controle passivo têm sido estudados analítica e experimentalmente por diferentes pesquisadores e usados em vários tipos de estruturas com o objetivo de minimizar os efeitos da vibração sobre a estrutura. No caso de sismos, o controle passivo de vibrações pode ser obtido usando-se atenuadores que geram forças de controle sobre a estrutura que se opõem à excitação, ou através de mecanismos de isolamento de base (Soong e Dargush, 1997). Em geral sistemas de isolamento de base são mais apropriados para estruturas sob excitação de base, reduzindo a quantidade de energia que é transmitida do solo para a estrutura. Entretanto, em estruturas já existentes, pode ser conveniente o uso de amortecedores de massa sintonizada para diminuir as vibrações na estrutura. Existem diversos tipos de isolamento de base e sistemas de controle passivo. Descrições detalhadas destes mecanismos podem sem encontradas em, dentre outras, Kelly (1993), Soong e Dargush (1997), Rivin (2003), Kelly e Constantinou (2011), e Soong e Costantinou (2014). 


\section{2.}

\section{Revisão bibliográfica}

Um mecanismo que tem sido utilizado como um amortecedor de massa sintonizada é o pêndulo clássico. Um exemplo bastante conhecido é o pêndulo usado para o controle de vibrações do edifício Taipei 101 em Taiwan, ilustrado na Figura 1-1 (Li, Q. S., et al. 2010). Como a frequência do pêndulo depende apenas do seu comprimento e da aceleração da gravidade, para sintonizar a frequência do pêndulo com a do edifício, tem-se como única variável de projeto o seu comprimento. Entretanto, em muitos casos, o comprimento necessário e o espaço requerido não se coadunam com o projeto. Nestes casos pode-se substituir o pêndulo clássico por um sistema pendular, composto por uma massa que se movimenta sobre uma superfície curva, permitindo grande flexibilidade no projeto do absorsor, já que o comprimento do pêndulo torna-se irrelevante e a forma da superfície curva pode ser otimizada. Este sistema pode ser usado como amortecedor pendular de massa sintonizada (APMS), gerando forças contrárias ao movimento da estrutura, ou desacoplando o movimento da base do movimento da estrutura, no caso de ser usado como isolador pendular de base (IBP).

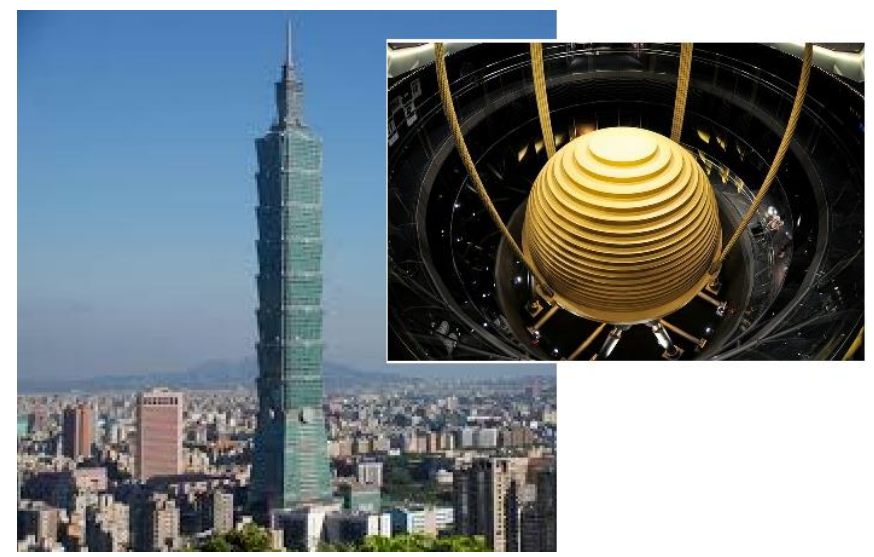

Figura 1-1 Torre Taipe 101 em Taipe, Taiwan, com amortecedor pendular de massa sintonizado

Diversas pesquisas relacionadas ao movimento de uma massa sobre uma superfície curva são encontradas na literatura técnica. Alguns destes trabalhos têm como objetivo o controle de vibrações. A seguir apresenta-se uma revisão bibliográfica enfocando diversos aspectos relevantes para esta tese.

Trabalhos analíticos e experimentais para o entendimento dos movimentos oscilatórios em diferentes tipos de superfícies curvas foram realizados no passado 
recente. Shaw e Haddow (1992) desenvolveram diversos modelos experimentais tipo montanha russa para modelar osciladores não lineares com não linearidade quadrática ou cúbica. $\mathrm{O}$ objetivo foi identificar a superfície capaz de modelar cada tipo de oscilador. Em particular, foi modelada a equação de escape (não linearidade quadrática) e dois osciladores tipo Duffing (não linearidade cúbica). Gottwald et al. (1992) desenvolveram diversas estudos analíticos e experimentais com o objetivo de estudar o comportamento da equação de Duffing, através de um corpo rígido que se desloca sobre uma superfície curva com dois vales potenciais, simulando a equação de Duffing com perda de rigidez. Usando este modelo, investigaram diversos fenômenos não lineares como histerese, sensibilidade às condições iniciais, oscilações subharmônicas e caos. Mais adiante, Gottlieb (1997) derivou a função potencial de uma superfície curva sobre a qual se movimenta uma esfera pela influência da gravidade de modo a reproduzir um oscilador linear ou não linear.

Diversos sistemas de controle de vibrações para minimizar deslocamentos de estruturas por efeito de carregamentos dinâmicos gerados pelo vento foram propostos na literatura, em particular sistemas de controle passivo. Dentre estes, o amortecedor de massa sintonizada (AMS) tem sido usado com bastante frequência em virtude de sua facilidade de instalação. A Tabela 1-1 mostra uma série de estruturas com amortecedores de massa sintonizados. Pinheiro (1997) estudou analiticamente o absorsor pendular clássico não linear, ligado à estrutura por uma mola rotacional. $\mathrm{O}$ absorsor apresentou bons resultados no controle de vibrações em estruturas esbeltas. Mudanças na forma do pêndulo clássico foram também sugeridas pelo autor. Ávila (2002) pesquisou o efeito de múltiplos amortecedores de massa sintonizados, a influência não linear da rigidez do AMS no comportamento da estrutura principal e a eficiência de um sistema híbrido (AMH) em relação ao AMS. Nucera et al. (2008) investigaram, através de um estudo experimental e numérico, como o conceito de transferência dirigida de energia através de um acoplamento não linear (nonlinear targeted energy transfer) pode ser usado para mitigar as vibrações de uma estrutura de três andares tipo "shear frame" sob a excitação sísmica. 
Tabela 1-1 Estruturas com AMS (GERB-Vibration Control Systems)

\begin{tabular}{|c|c|c|c|c|c|}
\hline País & Estrutura & $\begin{array}{c}\text { Freq. } \\
\text { natural } \\
(\mathrm{Hz})\end{array}$ & $\begin{array}{c}\text { Massa } \\
\text { do } \\
\text { AMS }\end{array}$ & $\begin{array}{c}\text { Tipo } \\
\text { de } \\
\text { Amort. }\end{array}$ & Ano \\
\hline Brasil & REFAB 2 Chaminé & 0,7 & $2 \times 5.000$ & horiz. & 2003 \\
\hline \multirow{2}{*}{ Dinamarca } & Passarela & 4,1 & $3 \times 200$ & vert. & 1999 \\
\hline & Nykredit's New Domicil, Laje & 6,8 & $3 \times 1.000$ & vert. & 2001 \\
\hline \multirow{3}{*}{ França } & Paris, Passarela & $1,8-2,1$ & $3 \times 2.050-2.800$ & vert. & 1997 \\
\hline & La Hague, SGN, Chaminé & 1,4 & $2 \times 200$ & horiz. & 1999 \\
\hline & Paris, Passarela Solferino & $0,8-2,2$ & $14 \times 1.900-2.500$ & $\begin{array}{l}\text { horiz. / } \\
\text { vert. }\end{array}$ & 2000 \\
\hline \multirow{20}{*}{ Alemanha } & $\begin{array}{l}\text { Hannover exhibition Centre, } \\
\text { Ponte }\end{array}$ & 5 & $4 \times 170$ & vert. & 1984 \\
\hline & $\begin{array}{l}\text { Berlin, Arc de } 124,4^{\circ}, \text { Escultura } \\
\text { de aço }\end{array}$ & 1,1 & 75 & horiz. & 1988 \\
\hline & Munich, BMW, Laje da fabrica & 13 & $20 \times 380$ & vert. & 1988 \\
\hline & $\begin{array}{l}\text { Solingen, Henckels } \\
\text { Zwillingweke, Laje da fabrica }\end{array}$ & 14 & $6 \times 400$ & vert. & 1989 \\
\hline & Dorsten, Passarela & 1,9 & $2 \times 1.700$ & vert. & 1990 \\
\hline & $\begin{array}{l}\text { Munich, Babcock, Estrutura de } \\
\text { aço }\end{array}$ & 12 & $2 \times 200$ & vert. & 1993 \\
\hline & Göttingen, Chaminé & 0,7 & 1.100 & horiz. & 1994 \\
\hline & $\begin{array}{l}\text { Regensburg, Siemens, Laje do } \\
\text { escritório }\end{array}$ & 7,5 & $11 \times 160$ & vert. & 1996 \\
\hline & Hamburg, Chaminé & 0,7 & 780 & horiz. & 1996 \\
\hline & Karlsruhe, Estrutura de edifício & $2,8-3,0$ & $24 \times 250-500$ & vert. & 1997 \\
\hline & $\begin{array}{l}\text { Scholven, Ventiladores de torres } \\
\text { de refrigeração }\end{array}$ & 14 & $22 \times 100$ & horiz. & 1998 \\
\hline & Kassel, Passarela & 0,7 & 2.000 & vert. & 1998 \\
\hline & Berlin, Schwedter Str., Passarela & 1,9 & $4 \times 900$ & vert. & 1999 \\
\hline & $\begin{array}{l}\text { Berlin, Reichstag, Varandas para } \\
\text { espectadores }\end{array}$ & 4,5 & $18 \times 700$ & vert. & 1999 \\
\hline & $\begin{array}{l}\text { Berlin, Bundeskanzleramt, } \\
\text { Passarela }\end{array}$ & $1,7-3,3$ & $6 \times 1.500-2.200$ & vert. & 2000 \\
\hline & $\begin{array}{l}\text { MS Deutschland, Navio de } \\
\text { cruzeiro }\end{array}$ & $3,4-13,5$ & $4 \times 200-10.000$ & $\begin{array}{l}\text { horiz. / } \\
\text { vert. }\end{array}$ & 2001 \\
\hline & Berlin, Britzer Damm, Passarela & 5,9 & $2 \times 500$ & vert. & 2001 \\
\hline & Freilassing, Passarela & 2,3 & $4 \times 820$ & vert. & 2002 \\
\hline & Marl, transportadora & 12,3 & 550 & vert. & 2003 \\
\hline & Dresden, Neue Terassen, Laje & 2,4 & $8 \times 5.000$ & vert. & 2003 \\
\hline \multirow{5}{*}{$\begin{array}{c}\text { Grã- } \\
\text { Bretanha }\end{array}$} & Inverness, Ponte Kessock & 0,5 & $8 \times 2.000$ & vert. & 1989 \\
\hline & $\begin{array}{l}\text { London, Millennium Done, } \\
\text { Estrutura de Aço }\end{array}$ & 2,4 & $3 \times 600$ & vert. & 1999 \\
\hline & $\begin{array}{l}\text { London, Stakis Metropole, } \\
\text { Edifício do Hotel }\end{array}$ & 4,4 & $7 \times 14.500$ & vert. & 2000 \\
\hline & London, Ponte Millennium & $0,8-2,2$ & $\begin{array}{l}58 \times 1.000- \\
\quad 2.500\end{array}$ & $\begin{array}{l}\text { horiz. / } \\
\text { vert. }\end{array}$ & 2001 \\
\hline & Coventry, Passarela & 1 & $3 \times 670$ & vert. & 2003 \\
\hline Islândia & Passarela & 2,6 & $4 \times 350$ & vert. & 1999 \\
\hline Itália & Barberino del Mugello, Passarela & 2,3 & $2 \times 100$ & vert. & 2002 \\
\hline
\end{tabular}




\begin{tabular}{|c|c|c|c|c|c|}
\hline & $\begin{array}{l}\text { Sardinia, Sarlux, Ventilador de } \\
\text { torre de refrigeração }\end{array}$ & 11 & $24 \times 700$ & horiz. & 2000 \\
\hline Japão & Ube, Chaminé & 3,1 & 300 & horiz. & 2000 \\
\hline $\begin{array}{l}\text { Coréia do } \\
\text { Sul }\end{array}$ & Seoul, Passarela Sun You & $0,8-2$ & $\begin{array}{c}4 \times 1.500- \\
1.650\end{array}$ & $\begin{array}{l}\text { horiz. / } \\
\text { vert. }\end{array}$ & 2002 \\
\hline \multirow{4}{*}{ Noruega } & North Trondelag, Ponte & 0,5 & 10.000 & vert. & 1989 \\
\hline & Ponte Mjasundet & 0,6 & 6.000 & vert. & 1992 \\
\hline & Budandet/Vaerladet, 3 Pontes & $0,8-2$ & $\begin{array}{c}5 \times 5.000- \\
10.000\end{array}$ & vert. & 2002 \\
\hline & Bergen, Laje de academia & 3,8 & $2 \times 2.000$ & vert. & 2003 \\
\hline Polônia & Wroclaw, Passarela & $1,2-1,5$ & $3 \times 450-500$ & vert. & 2003 \\
\hline Suíça & Rümlang, Passarela & 2 & 1.000 & vert. & 1992 \\
\hline Singapura & $\begin{array}{l}\text { Singapore, Aeroporto Changi, } \\
\text { Passarela }\end{array}$ & 0,9 & $2 \times 500$ & horiz. & 2003 \\
\hline \multirow[t]{2}{*}{ Tailândia } & Bangkok, Ponte Chao Phya & $0,3-0,7$ & $18 \times 4500$ & $\begin{array}{l}\text { horiz. / } \\
\text { vert. }\end{array}$ & 1985 \\
\hline & Bangkok, Chaminé & 0,8 & 3.500 & horiz. & 1999 \\
\hline \multirow{3}{*}{$\begin{array}{c}\text { Emirados } \\
\text { Árabes } \\
\text { Unidos }\end{array}$} & $\begin{array}{l}\text { Dubai, Burj AL Arab, Armação } \\
\text { de açõ e pináculo }\end{array}$ & $0,8-2$ & $11 \times 5.000$ & horiz. & 1997 \\
\hline & $\begin{array}{l}\text { Dubai, Emirates Towers, } \\
\text { Pináculo }\end{array}$ & 0,9 & $6 \times 1.200$ & horiz. & 1999 \\
\hline & $\begin{array}{l}\text { Dubai, 21st Century tower, } \\
\text { Pináculo }\end{array}$ & 1,1 & $2 \times 500$ & horiz. & 2003 \\
\hline
\end{tabular}

Matta e De Stefano (2009) estudaram, mediante uma simulação numérica como um absorsor de massa sintonizado, comumente usados em estruturas flexíveis sob excitação do vento ou de tráfego, pode ser usado em um edifício sob excitação sísmica. Para o estudo usaram dois tipos de superfície curva para o amortecedor pendular, chegando a demostrar que a curva circular apresenta melhores resultados no controle do edifício, quando este é submetido a um movimento de base harmônico. A eficácia do controle sob cargas impulsivas é condicionada ao uso de uma elevada relação de massas entre a estrutura e o absorsor. Neste trabalho eles mostram esquematicamente diferentes tipos de amortecedores, alguns já estudados na literatura. Estes são ilustrados na Figura 1-2. Posteriormente Matta et. al. (2009-b) estudaram o uso de um sistema pendular em duas direções para a proteção sísmica de edifícios. Legeza (2013) propõe um amortecedor pendular que consiste em um pêndulo clássico invertido onde a massa se movimenta sobre uma curva do tipo isócrono. Ele comenta que uma grande vantagem deste amortecedor é que a frequência natural de vibração é independente da amplitude do movimento. 

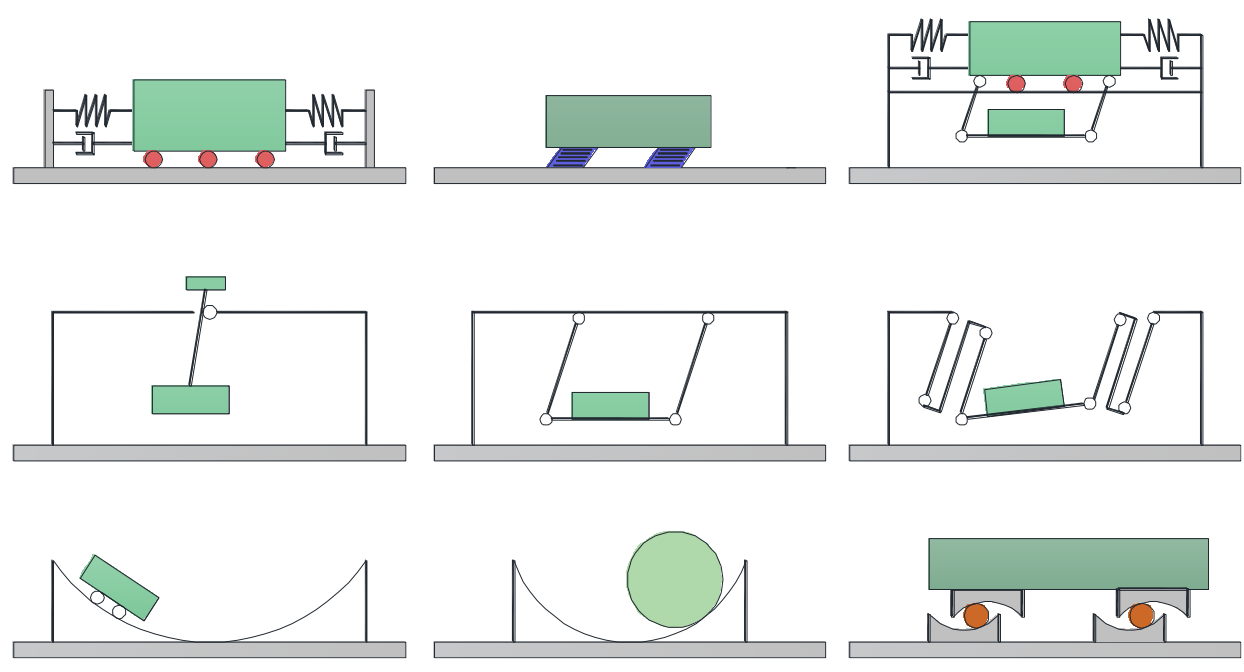

Figura 1-2 Alguns possíveis sistemas para controle de vibrações de estruturas (Matta e De Stefano (2009).

Chen e Georgakis (2013), preocupados com os efeitos dinâmicos do vento nas torres eólicas, propuseram um sistema de controle passivo que consiste em uma ou mais esferas que se deslocam sobre uma superfície esférica no topo da torre, criando um amortecedor multidirecional. Um modelo em escala reduzida foi testado em uma mesa vibratória. A absorção de energia ocorre tanto devido ao movimento das esferas quanto ao impacto entre as mesmas. Este sistema havia sido anteriormente estudado por Pirner (2002), que realizou estudos teóricos e experimentais e instalou um AMS composto de uma esfera dentro de um recipiente esférico em uma torre de televisão na República Checa.

Orlando e Gonçalves (2013) estudaram um sistema híbrido para controle de vibrações de estruturas de torres esbeltas. O controle híbrido é baseado no uso simultâneo de um absorsor pendular com uma força externa, dependente da velocidade, tipo on-off, aplicada na conexão torre-pêndulo, aumentando assim a eficiência do pêndulo no controle de vibrações. Já Garrido et al. (2013) propuseram um sistema de controle de vibrações chamado de AMS de dupla inércia rotacional.

Pirner (2002) estudou diversos sistemas pendulares. Na Tabela 1-2 ele ilustra uma série de estruturas esbeltas com AMS pendular. 
Tabela 1-2 Estruturas esbeltas com AMS pendular segundo Pirner, (2002)

\begin{tabular}{|c|c|c|c|c|}
\hline & Estrutura & $\begin{array}{c}\text { Frequência } \\
\text { natural }\end{array}$ & $\begin{array}{c}\text { Razão de } \\
\text { massas } \\
\delta\end{array}$ & Amortecedor \\
\hline 1 & $\begin{array}{l}\text { Torre de TV, } \\
\text { altura } 67 \mathrm{~m}\end{array}$ & $\begin{array}{l}1,27 \\
1,70\end{array}$ & $1 / 20$ & $\begin{array}{c}\text { Amortecedor } \\
\text { pendular }(840-\mathrm{Kg})\end{array}$ \\
\hline 2 & $\begin{array}{l}\text { Torre estaiada, } \\
\text { altura } 109 \mathrm{~m}\end{array}$ & $\begin{array}{c}0,75 \\
1,442 \\
2,386 \\
4,079\end{array}$ & $1 / 10$ & $\begin{array}{c}\text { Absorsor } \\
\text { pendular }(650-\mathrm{Kg})\end{array}$ \\
\hline 3 & $\begin{array}{l}\text { Torre estaiada, } \\
\text { altura } 179 \mathrm{~m}\end{array}$ & $\begin{array}{l}0,585 \\
0,735 \\
0,810 \\
1,183 \\
1,184\end{array}$ & $1 / 20$ & $\begin{array}{c}\text { Absorsor } \\
\text { pendular }(1000-\mathrm{Kg})\end{array}$ \\
\hline 4 & $\begin{array}{l}\text { Torre de TV, } \\
\text { altura } \\
88 \mathrm{~m}\end{array}$ & $\begin{array}{l}0,613 \\
2,329 \\
3,213\end{array}$ & $1 / 6,5$ & $\begin{array}{c}\text { Absorsor } \\
\text { pendular }(800-\mathrm{Kg})\end{array}$ \\
\hline 5 & $\begin{array}{l}\text { Torre estaiada, } \\
\text { altura } 42,28 \mathrm{~m}\end{array}$ & $\begin{array}{c}0,667 \\
2,530 \\
5,73\end{array}$ & $1 / 10$ & $\begin{array}{c}\text { Absorsor } \\
\text { pendular }(400-\mathrm{Kg})\end{array}$ \\
\hline 6 & $\begin{array}{c}\text { Torre de TV, } \\
\text { altura } \\
193 \mathrm{~m} \\
145 \mathrm{~m} 1500 \\
\text { Kg na altura de } \\
193 \mathrm{~m}\end{array}$ & $\begin{array}{c}0,283 \\
0,672 \\
1,439 \\
2,839 \\
4,3544\end{array}$ & $1 / 10$ & $\begin{array}{l}\text { Absorsores } \\
\text { pendular em cada } \\
\text { altura }(2.500-\mathrm{Kg})\end{array}$ \\
\hline 7 & $\begin{array}{c}\text { Torre de TV, } \\
\text { altura } \\
183 \mathrm{~m}\end{array}$ & $\begin{array}{l}0,373 \\
0,921 \\
1,400 \\
2,173\end{array}$ & $1 / 8$ & $\begin{array}{c}\text { Absorsor } \\
\text { pendular }(500-\mathrm{Kg})\end{array}$ \\
\hline 8 & $\begin{array}{c}\text { Torre estaiada, } \\
\text { altura } 179 \mathrm{~m}\end{array}$ & $\begin{array}{l}0,463 \\
0,725 \\
1,125\end{array}$ & $1 / 25$ & $\begin{array}{c}\text { Absorsor } \\
\text { pendular }(3.000- \\
\mathrm{Kg})\end{array}$ \\
\hline 9 & $\begin{array}{l}\text { Pilares do } \\
\text { ponte }\end{array}$ & 0,200 & $1 / 100$ & $\begin{array}{l}\text { Amortecedor } \\
\text { pendular }\end{array}$ \\
\hline 10 & $\begin{array}{l}\text { Torre com } \\
\text { altura de } 20 \mathrm{~m}\end{array}$ & 1,85 (em torção) & $1 / 10$ & $\begin{array}{l}\text { Amortecedor } \\
\text { pendular }(2 \times 312- \\
\mathrm{Kg})\end{array}$ \\
\hline
\end{tabular}

Quando os movimentos oscilatórios dos amortecedores ultrapassam os deslocamentos permitidos, barreiras rígidas ou flexíveis podem ser instaladas para limitar os deslocamentos, gerando forças de impacto que podem adicionalmente aumentar a dissipação de energia do amortecedor. Na literatura encontram-se diversos trabalhos que estudam o efeito de forças de impacto nas oscilações não lineares e controle de vibrações de diversos sistemas mecânicos. 
Chatterjee et al. (1995) estudaram o efeito de um amortecedor com impacto elástico e inelástico nas vibrações de um oscilador tipo Duffing com ganho de rigidez sob excitação harmônica. O projeto ótimo é baseado em uma solução estável de pequena amplitude prevista pelo método de balanço harmônico. O uso de um amortecedor de impacto tipo on-off como controlador para uma transição entre a resposta ressonante e não ressonante do oscilador não linear é proposta. Mitić (1997) estudou um sistema de um grau de liberdade, descrito pela equação diferencial de Duffing, sob excitação harmônica, com impacto unilateral ou bilateral com um anteparo rígido, integrando numericamente a equação diferencial através do método de Runge-Kutta de quarta ordem. Andreaus e Casini (2000) estudaram a resposta dinâmica de um sistema linear de um grau de liberdade com impacto contra um anteparo com comportamento histerético que permite a simulação do comportamento de diversos tipos de impacto. A distinção entre contato rígido ou flexível é feita em concordância com a natureza impulsiva ou não impulsiva da reação de contato. Para o caso de contato rígido, um coeficiente de restituição é proposto.

Blazejczyk-Okolewska (2001) estudou a influência do impacto no controle de vibrações de estruturas através de um sistema de dois graus de liberdade com a massa do amortecedor submetida a impactos contra um anteparo rígido. Ele argumenta que o AMS com impacto pode ser mais eficiente que o AMS clássico.

Dimentberg e Iourtchenko (2004) apresentaram uma revisão da literatura de sistemas com vibrações randômicas sujeitos a impacto. Vários métodos são apresentados e aplicados a sistemas de dois graus de liberdade descritos por equações diferenciais estocásticas.

Narkhede e Sinha (2012) analisaram amortecedores com fluidos viscosos para o controle de forças de impacto. Amortecedores convencionais de fluido viscoso linear podem dissipar somente uma quantidade limitada de energia, e não são eficientes como os amortecedores não lineares para forças de impacto. A formulação matemática e o desempenho relativo de estruturas sujeitas a excitações de curta duração e pulsos são discutidos. A influência da não linearidade do amortecedor é também avaliada.

Embora vários trabalhos tenham pesquisado a eficiência de amortecedores de massa sintonizada em estruturas sob excitação de base, a melhor forma de redução dos deslocamentos das estruturas sujeitas a movimentos de base, em 
especial aqueles gerados pelos sismos são por meio de isoladores de base. $\mathrm{Na}$ literatura técnica encontram-se diferentes sistemas de isolamento de base, especialmente projetados para estruturas de edifícios, pontes e obras de arte.

Nagarajaiah et al. (1991) desenvolveram um modelo analítico e algoritmos para análise dinâmica tridimensional de estruturas isoladas com suportes de elastômeros, apoios deslizantes, molas e/ou amortecedores. Algoritmos capazes de capturar o complexo comportamento não linear do atrito em apoios deslizantes são implementados. Um exemplo envolvendo um edifício de concreto armado com seis andares é estudado.

Kelly (1993) publicou uma coletânea de pesquisas sobre isoladores de base com suportes de elastômero. Testes foram realizados usando somente apoios de borracha e com a adição de diferentes tipos de mecanismos de dissipação de energia para melhorar o amortecimento. De acordo com os resultados, o aumento do amortecimento nem sempre leva a uma diminuição da resposta da estrutura e a melhor maneira de aumentar o amortecimento é fornecê-lo através da deformação do próprio aparelho de apoio. Um nível alto de amortecimento pode ser prejudicial para a estrutura a ser controlada. Exemplos de suportes de elastômeros são apresentados nas Figura 1-3 e Figura 1-4.

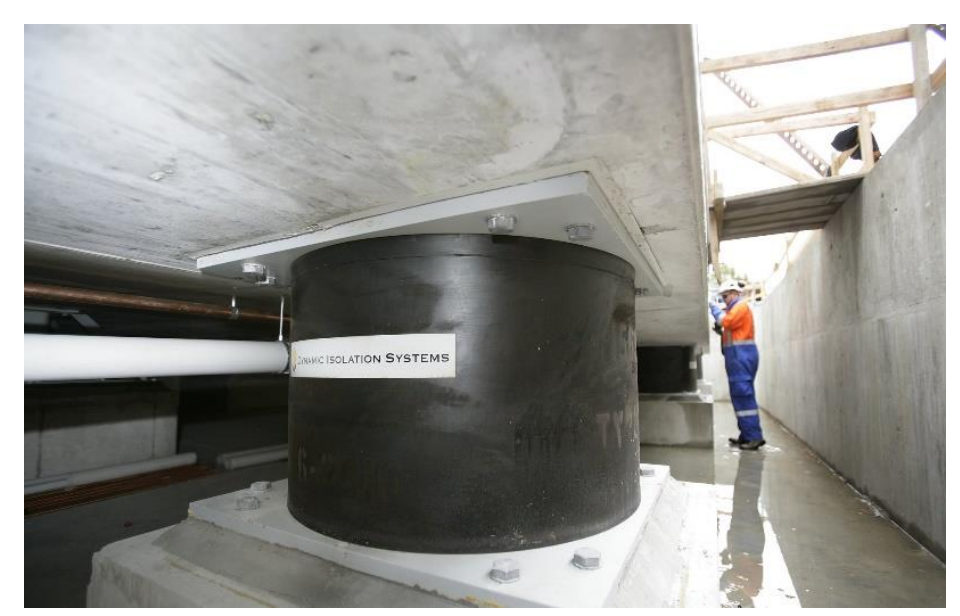

Figura 1-3 Sistema de isolamento de base com suporte de elastômero 


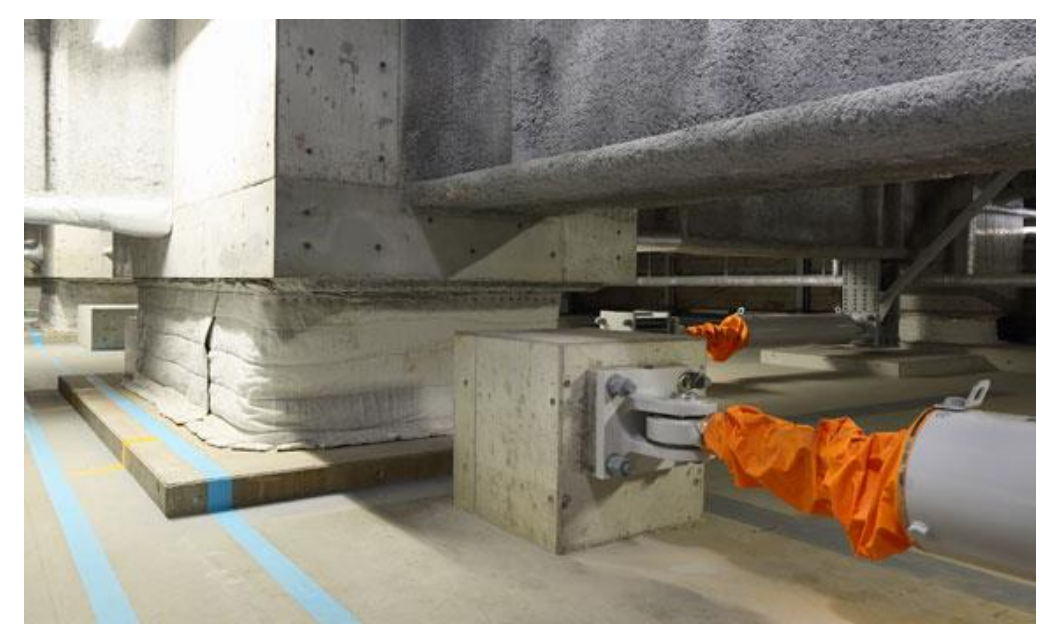

Figura 1-4 Isolamento de base com suporte de elastômero e amortecedores em duas direções

Naeim e Kelly (1999) apresentam o estado da arte e uma completa revisão dos sistemas de isolamento de base. Os conceitos básicos de isolamento sísmico e dos princípios fundamentais de projeto de isolamento sísmico seguidos de exemplos numéricos são discutidos. Ênfase é dada aos isoladores de base com suporte de elastômero.

Mokha et al. (1991) estudaram experimentalmente, com base em estudos teóricos anteriores, um sistema de isolamento de base pendular com massa deslizante, onde a energia é dissipada por atrito, instalado em uma estrutura de seis andares em escala de 1:4 sobre uma mesa vibratória. Dois tipos de materiais são estudados, o primeiro com coeficiente de atrito de 0,075 e o segundo de 0,095. Em testes usando o sinal do "El Centro", a estrutura isolada não teve nenhum dano. Shustov (1993) desenvolveu um modelo analítico de um sistema de isolamento de base pendular com atrito onde uma esfera rugosa é colocada em uma cavidade esférica, enquanto Jangid e Londhe (1998) pesquisaram em um novo sistema de isolamento de base, formado por cilindros de seção elíptica localizados entre a base e a fundação da estrutura, verificando a sua eficácia no isolamento de base de edifícios sob efeito de forças sísmicas. Diferentes excentricidades dos rolamentos foram testadas, mostrando que os rolamentos elípticos são bastante efetivos na redução da resposta sísmica. Um trabalho semelhante foi presentado por Lin, et al. (1995) que desenvolveram um trabalho analítico e experimental de um sistema de isolamento de base usando um sistema de rolamentos em uma superfície horizontal sob a fundação. A estrutura de um só andar de $326 \mathrm{Kg}$ é testada em uma mesa vibratória, usando uma faixa de valores 
para o coeficiente de atrito cinemático de rolamento entre 0,0007 para 0,0016, obtendo boa correlação entre resultados analíticos e experimentais. Entretanto o sistema leva a um deslocamento de corpo rígido após a excitação. Um exemplo deste tipo de suporte é ilustrado na Figura 1-5.

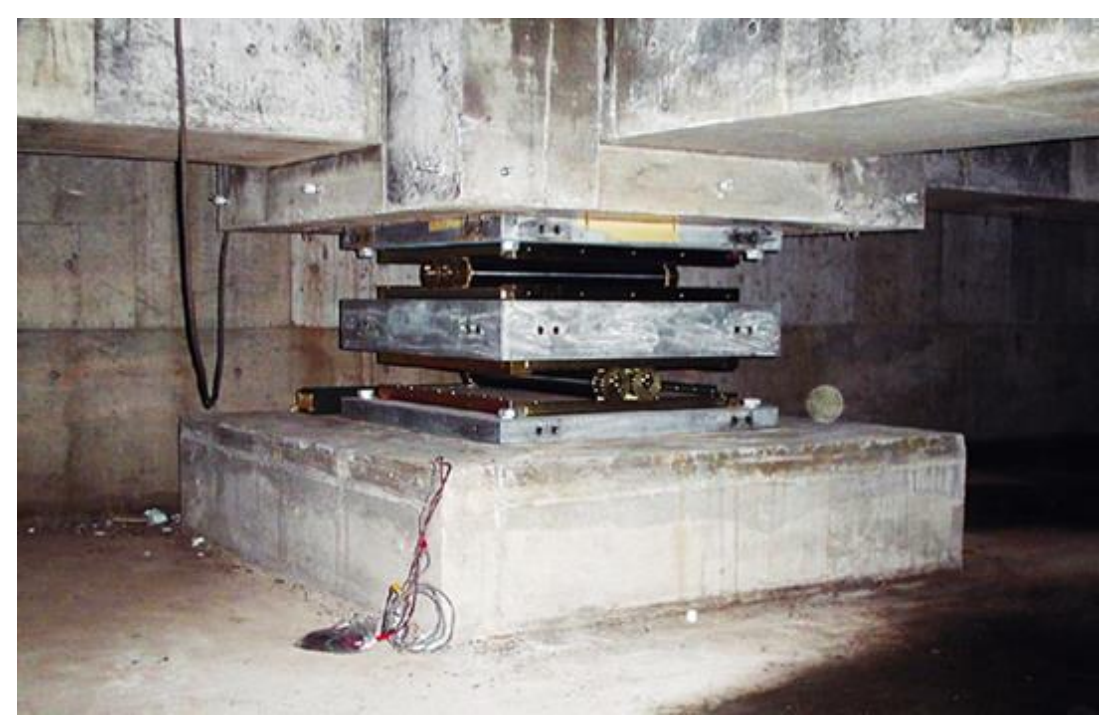

Figura 1-5 Isolamento de base com suporte rolante sobre superfície plana em duas direções

Jangid (2000) pesquisou a resposta aleatória de uma estrutura de vários andares do tipo shear-frame com isolamento de base com sistema rolante, sob efeito do sismo "El Centro".

Ueda et al. (2004) estudam o uso do isolamento de base na proteção de vitrines de exposição e obras de arte usando um sistema de isolamento com rolamentos formado por duas placas que permite o movimento em duas direções perpendiculares. Testes em mesa vibratória foram realizados, mostrando bom desempenho do sistema de isolamento.

Bratosin (2004) apresenta um método para determinar mudança de períodos usando funções de amplificação dinâmica linear ou não linear. Para a determinação das funções não lineares é usada o modelo não linear de KelvinVoigt (modelo NKV) para estruturas isoladas, que tem a capacidade de modelar efeitos não lineares do solo e do isolamento de base.

Uma análise experimental de um modelo de uma ponte com isolamento de base por apoios rolantes em escala 1:75 é realizada por Tsai et al. (2006). Além disso, uma expressão analítica aproximada para a aceleração pico da ponte isolada é derivada. Os resultados dos testes revelam que a força sísmica transmitida pelo 
apoio é independente da intensidade do terremoto quando o movimento do cilindro sobre a base inclinada é iniciado.

Hoang et al. (2008) trabalharam no reforço sísmico de uma ponte treliçada de grande vão existente no Japão. O apoio existente é substituído por um novo sistema de isolamento com laje deck, onde a laje e o sistema de isolamento juntos podem ser vistos como um AMS gigante. A grande razão de massas leva a um AMS ótimo com uma menor frequência de sintonização e alto valor de amortecimento. Para grandes relações de massas, o AMS é muito eficiente na redução da resposta da estrutura principal e robusto em relação a incertezas nos parâmetros do sistema.

Ibrahim (2008) apresentou uma revisão detalhada de sistemas de isolamento de base com ênfase nos isoladores não lineares, apresentando os conceitos básicos e características de isoladores não lineares e os fenômenos não lineares inerentes a esta classe de sistemas.

Taniguchi et al. (2008) estudaram o efeito de um AMS pendular nos deslocamentos de uma estrutura com isolamento de base, levando a uma redução de $15 \%$ a $25 \%$ nos deslocamentos da estrutura isolada. Lee et al. (2009) pesquisaram analítica e experimentalmente um novo sistema de isolamento para pontes rodoviárias com cilindros apoiados em uma superfície inclinada na forma de V. Minda et al. (2012) estudaram um sistema pendular onde uma massa desliza sobre uma superfície descrita por uma função polinomial, sendo a energia dissipada por atrito.

Pezo (2012) estudou analiticamente a influência de um amortecedor magneto reológico do tipo Bouc-Wen no controle de vibrações. O amortecedor é caracterizado por um comportamento histérico não linear que leva em geral a uma grande dissipação de energia.

Cano (2013) desenvolveu um modelo numérico para a análise sísmica de edifícios com sistema de isolamento de base através de suportes de elastômero e suportes rolantes que se deslocam sobre planos inclinados, validando os resultados com ensaios experimentais em um modelo físico em escala. $\mathrm{O}$ modelo tem quatro andares e foi submetida a excitação de base gerada por uma mesa vibratória.

Uma análise do isolamento de base para a proteção de obras de arte é apresentada por Contento e Di Egidio (2012). Eles modelam o comportamento 
dinâmico de corpos rígidos, especificamente de obras de arte, tais como estátuas, obeliscos e fontes sujeitas a excitação sísmica sobre um isolador de base clássico, levando em conta a não simetria dos objetos que geram uma excentricidade entre o centro de massa e o geométrico. Os estudos foram conduzidos considerando dois tipos de excitações: impulso e carregamento sísmico. Equações exatas de movimento são escritas para descrever diferentes fases de movimento, ou seja, contato total, deslizamento, rotação e deslizamento com rotação. Comparações entre resultados obtidos do movimento do corpo rígido com e sem isolador de base mostram a eficácia do isolador de base.

\section{3.}

\section{Objetivos da Tese e Contribuição}

Este trabalho faz parte da linha de pesquisa em Instabilidade e Dinâmica das Estruturas do Departamento de Engenharia Civil da PUC-Rio. É uma continuação natural dos trabalhos desenvolvidos por Pinto (1999), Ávila (2002), Orlando (2006) e Pezo (2012) sobre controle ativo, passivo e híbrido de estruturas flexíveis submetidas a carregamentos dinâmicos.

O objetivo do presente trabalho é analisar a influência de um sistema pendular passivo no controle de vibrações de estruturas, quando este é incorporado à estrutura principal como amortecedor de massa sintonizado ou como isolador de base para minorar as vibrações de estruturas submetidas a movimento de base, em particular carregamentos sísmicos. O sistema pendular consiste em uma massa que se movimenta sobre uma superfície curva, gerando forças similares ao pêndulo clássico. Este sistema não é encontrado na literatura e tem diversas vantagens sobre os sistemas já existentes, tais como facilidade de construção, voltar naturalmente à posição original, ter um pequeno amortecimento inerente ao sistema e entrar facilmente em movimento, levando a grandes reduções de deslocamentos e acelerações. Como em certas condições de carregamento o sistema pendular pode sofrer rotações elevadas, um mecanismo composto de barreiras flexíveis ou rígidas é proposto, levando a forças adicionais de dissipação através de impactos. O sistema pendular pode ser usado não só em estruturas, mas também para controle de vibrações de equipamentos sensíveis em laboratórios e hospitais e na proteção de obras de arte. Cabe ressaltar que a 
tecnologia para construção do sistema pendular está bem estabelecida sendo a mesma usada para o projeto de aparelhos de apoio de pontes e grandes estruturas, em particular suportes rolantes, como ilustra a Figura 1-6.

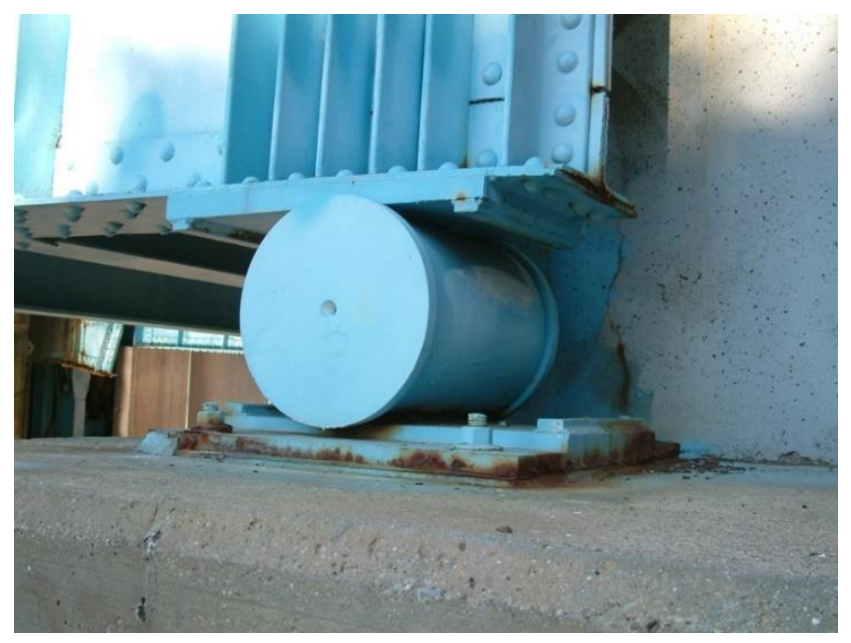

Figura 1-6 Suporte rolante em uma ponte

\section{4.}

Organização e Descrição da Tese

Esta tese está dividida em oito capítulos, sendo o primeiro esta introdução. O Capítulo 2 contém um resumo dos conceitos e equações referentes ao amortecedor de massa sintonizada e isolador de base linear. Valores ótimos dos parâmetros das equações de movimento e sinais dos terremotos usados para a análise do sistema passivo proposto são também apresentados. No Capítulo 3, apresenta-se a formulação do sistema pendular e apresentam-se os fatores limitantes que devem ser levados em consideração no projeto deste sistema de controle. No Capítulo 4 é estudado o uso do sistema pendular como amortecedor pendular de massa sintonizada (APMS) com superfície circular instalado em um edifício tipo shear-frame. Apresenta-se a seguir uma detalhada análise paramétrica do sistema estrutura-APMS sob carregamento harmônico, perturbações iniciais e carregamento sísmico, com o objetivo de verificar a eficiência do APMS no controle de deslocamentos e acelerações. O efeito do amortecimento na resposta da estrutura também é investigado. No Capítulo 5 é investigada a eficiência do sistema pendular como isolador de base pendular (IBP), considerando uma superfície circular. Apresenta-se inicialmente a 
modelagem do problema, seguida da análise paramétrica considerando carregamento harmônico e sísmico. No Capítulo 6 analisa-se a influência da forma da superfície do sistema pendular, considerando diversas funções polinomiais com ganho ou perda de rigidez. No Capítulo 7 estuda-se como a consideração do impacto do sistema pendular como mecanismo de dissipação de energia influencia a eficiência do APMS e do IBP. Finalmente, no Capítulo oito são apresentadas as conclusões do presente trabalho e sugestões para trabalhos futuros. A bibliografia e os apêndices com as equações explícitas do APMS e do IBP para curvas não circulares completam o presente volume. 


\section{2}

\section{Análise linear clássica}

\section{1.}

\section{Estrutura a ser controlada}

A estrutura do tipo shear frame de um grau de liberdade, ilustrada na Figura 2-1, é usada como referência para avaliar a eficiência dos sistemas de controle passivo de vibrações sob a ação de movimento de base, propostos no presente trabalho.
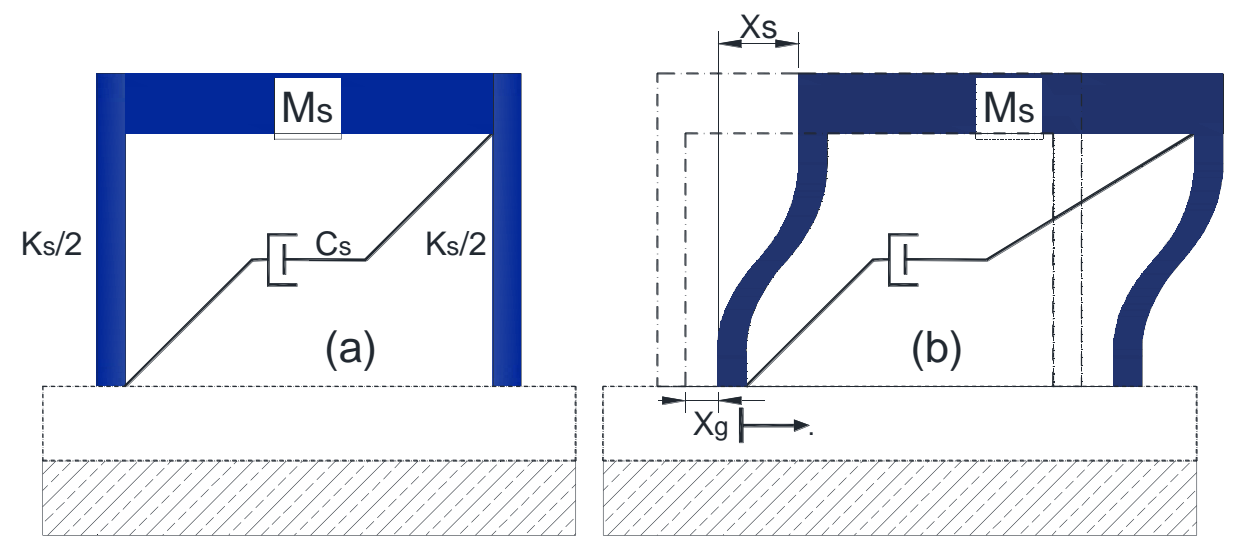

Figura 2-1 Estrutura Shear Frame de um grau de liberdade sem controle (a), estrutura deformada após o deslocamento de base Xg (b)

A equação diferencial de movimento que representa o comportamento dinâmico da estrutura sob uma excitação de base, $X_{g}(t)$, é dada por:

$$
M_{S} \ddot{X}_{S}+C_{S} \dot{X}_{S}+K_{S} X_{S}=-M_{S} \ddot{X}_{g}
$$

onde $M_{S}$ é a massa, $C_{S}$ é o coeficiente de amortecimento, $K_{S}$ é a rigidez, $X_{S}$ é o deslocamento horizontal relativo à base, $\dot{X}_{S}$ é a velocidade, $\ddot{X}_{S}$ é a aceleração da estrutura e $\ddot{X}_{g}$ é a aceleração da base, sendo $(\dot{X})=d X / d t$ e $t$ é o tempo. Para um edifício de $n$ pavimentos, os valores de $M_{S}, C_{S}$ e $K_{S}$ podem ser tomados, em uma primeira aproximação, como a massa, amortecimento e rigidez modal relativa ao primeiro modo de vibração.

Definindo os seguintes parâmetros, 


$$
\begin{aligned}
& \omega_{S}^{2}=\frac{K_{S}}{M_{S}} ; \quad \frac{C_{S}}{M_{S}}=2 \xi_{S} \omega_{S} ; \quad \bar{X}_{g}=\frac{X_{g}}{R_{c}} ; \quad \bar{X}_{S}=\frac{X_{S}}{R_{c}} ; \quad \bar{X}_{S}=\frac{X_{S}}{R_{c}} ; \tau=t \omega_{S} \\
& \frac{d \bar{X}_{S}}{d \tau}=\frac{1}{\omega_{S}} \frac{d X_{S}}{d t} ; \quad \frac{d^{2} \bar{X}_{S}}{d \tau^{2}}=\frac{1}{\omega_{S}^{2}} \frac{d^{2} X_{S}}{d t^{2}}
\end{aligned}
$$

onde $\omega_{S}$ é a frequência natural de vibração da estrutura, $\xi_{S}$ é a taxa de amortecimento da estrutura e $R_{c}$ é uma dimensão característica do problema que, nos capítulos seguintes, será tomada como o raio de curvatura da superfície curva usada nos sistemas de controle passivo propostos no presente trabalho

Usando estes parâmetros, a Eq.2.1 é reescrita na seguinte forma adimensional:

$$
\frac{d^{2} \bar{X}_{S}}{d \tau^{2}}+2 \xi_{S} \frac{d \bar{X}_{S}}{d \tau}+\bar{X}_{S}=-\frac{d^{2} \bar{X}_{g}}{d \tau^{2}}
$$

Pode-se observar que a Eq.2.3 encontra-se em função de um só parâmetro adimensional, a taxa de amortecimento $\xi_{S}$. A frequência natural de referência na forma adimensional é unitária.

\section{2. \\ Estrutura com amortecedor de massa sintonizado (AMS) linear}

Um amortecedor de massa sintonizado (AMS) clássico é composto de uma massa $M_{a}$ localizada no topo da estrutura ligada à mesma através de uma mola de rigidez linear $K_{a}$ e um amortecedor viscoso linear com constante de amortecimento $C_{a}$, como ilustra a Figura 2-2, formando assim o sistema estruturaAMS com dois graus de liberdade.
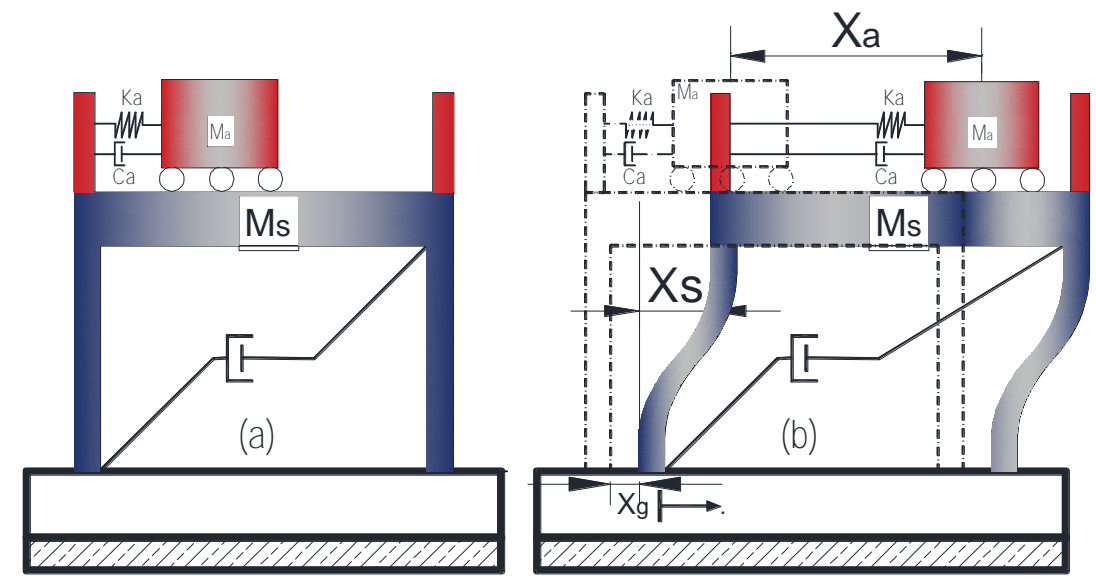

Figura 2-2 Estrutura tipo shear frame com AMS linear (a), Estrutura deformada pelo deslocamento de base Xg (b) 
O sistema de equações diferenciais que descreve o comportamento dinâmico da estrutura com AMS tem forma (Soong \& Dargush, 1997):

$$
\begin{aligned}
& M_{s} \ddot{X}_{S}+C_{s} \dot{X}_{S}+K_{S} X_{S}=C_{a} \dot{X}_{a}+K_{a} X_{a}-M_{s} \ddot{X}_{g} \\
& M_{a} \ddot{X}_{a}+C_{a} \dot{X}_{a}+K_{a} X_{a}=-M_{a} \ddot{X}_{S}-M_{a} \ddot{X}_{g}
\end{aligned}
$$

onde $X_{S}$ é o deslocamento da estrutura relativo à base e $X_{a}$ é o deslocamento da massa adicional com respeito à estrutura.

A frequência natural de vibração do AMS, $\omega_{a}$, é definida como

$$
\omega_{a}^{2}=\frac{K_{a}}{M_{a}}
$$

Definindo os seguintes parâmetros adimensionais

$$
\delta=\frac{M_{a}}{M_{S}} ; \quad \Delta=\frac{\omega_{a}}{\omega_{S}} ; \quad \frac{C_{a}}{C_{S}}=\delta \Delta \frac{\xi_{a}}{\xi_{S}}
$$

e substituindo os parâmetros adimensionais da Eq. 2.2 e 2.6 na Eq. 2.4, obtém-se o seguinte sistema:

$$
\begin{gathered}
\frac{d^{2} \bar{X}_{S}}{d \tau^{2}}+2 \xi_{S} \frac{d \bar{X}_{S}}{d \tau}+\bar{X}_{S}=2 \Delta \delta \xi_{a} \frac{d \bar{X}_{a}}{d \tau}+\delta \Delta^{2} \bar{X}_{a}-\ddot{\bar{X}}_{g} \\
\delta \frac{d^{2} \bar{X}_{a}}{d \tau^{2}}+2 \delta \Delta \xi_{a} \frac{d \bar{X}_{a}}{d \tau}+\delta \Delta^{2} \bar{X}_{a}=-\delta \frac{d^{2} \bar{X}_{S}}{d \tau^{2}}-\delta \ddot{\bar{X}}_{g}
\end{gathered}
$$

onde $\xi_{a}=C_{a} / 2 M_{a} \omega_{a}$ é taxa de amortecimento do AMS.

As duas frequências naturais do sistema estrutura-AMS são obtidas a partir das Eqs.2.7 e 2.8. As duas frequências de vibração na forma adimensional são dadas por

$$
\bar{\omega}_{i}=\frac{1}{2} \sqrt{2 \delta \Delta^{2}+2 \Delta^{2}+2 \mp 2 \sqrt{\delta^{2} \Delta^{4}+2 \delta \Delta^{4}+\Delta^{4}+2 \delta \Delta^{2}-2 \Delta^{2}+1}}
$$

Observa-se que as duas frequências dependem apenas de dois parâmetros, a razão de massas, $\delta=M_{a} / M_{S}$, e a razão de frequências, $\Delta=\omega_{a} / \omega_{S}$.

A Figura 2-3 mostra a variação das duas frequências naturais em função da razão de frequências para valores selecionados da razão de massas, enquanto a Figura 2-4 ilustra os dois modos de vibração. O primeiro modo corresponde a um pequeno movimento da estrutura em comparação com o movimento do AMS, se deslocando as duas massas no mesmo sentido, que é o comportamento esperado em uma estrutura com um absorsor de vibrações. Para o segundo modo, tem-se que as duas massas se movem em direções opostas, com o AMS apresentando os 
maiores deslocamentos. Para valores usuais de $\delta$, a primeira frequência cresce suavemente com $\Delta$, a partir de zero, enquanto a segunda permanece praticamente constante até atingir o valor $\Delta=1$ quando as duas frequências normalizadas se aproximam do valor unitário (valor ideal para o AMS clássico). A partir deste ponto, as duas frequências invertem o comportamento, crescendo a segunda frequência de forma praticamente linear enquanto a primeira tende a um valor constante.

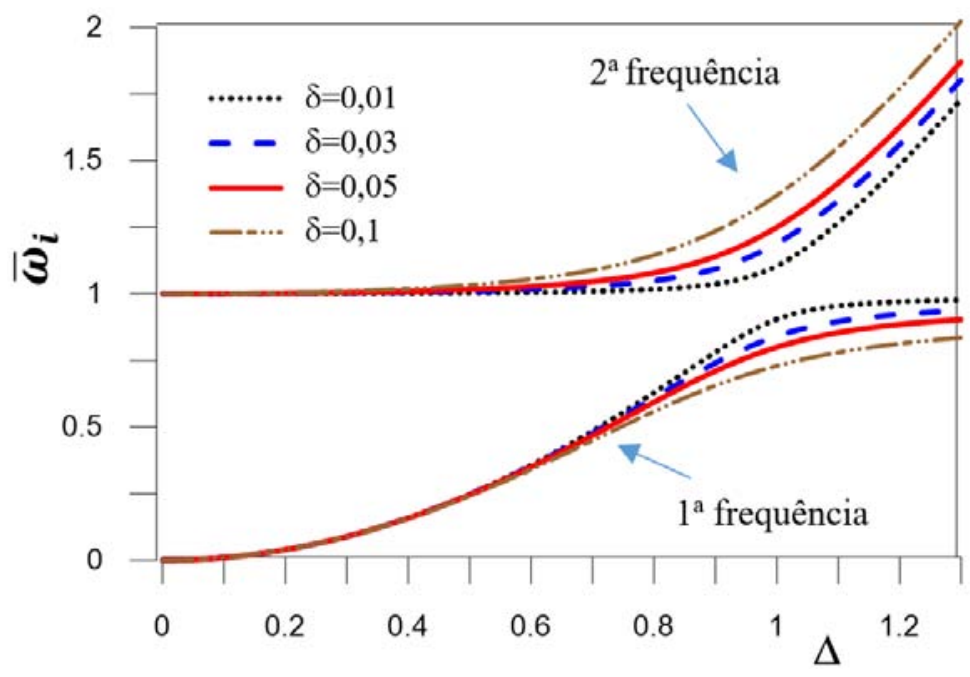

Figura 2-3 Variação das frequências naturais em função dos parâmetros adimensionais $\Delta \mathrm{e}$ $\delta$.
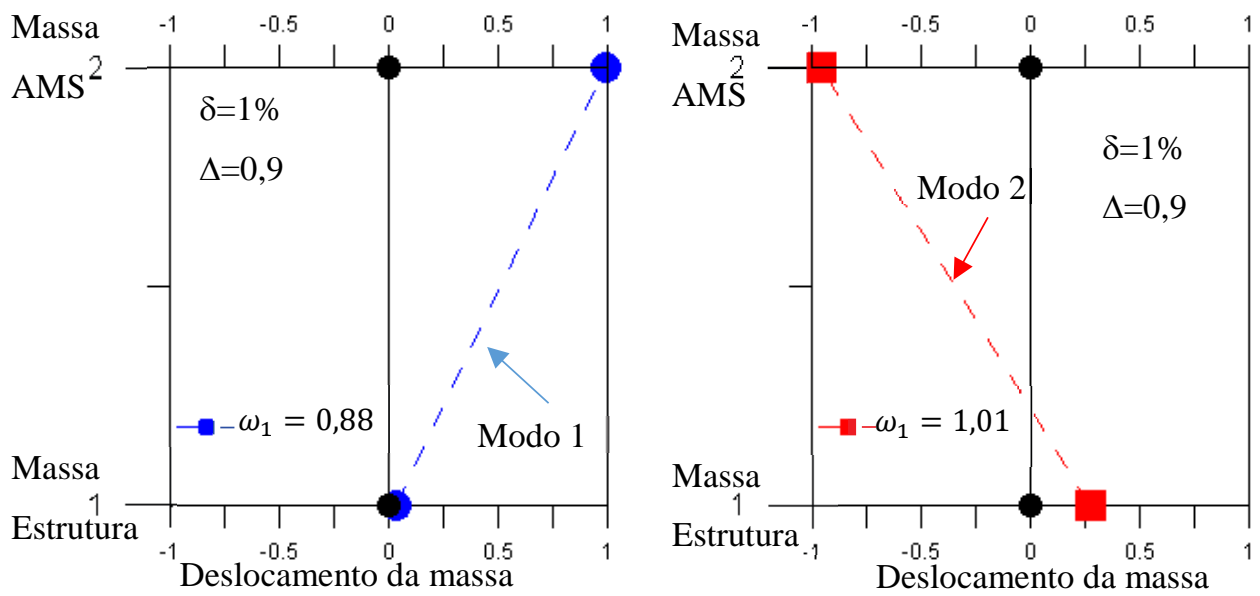

Figura 2-4 Modos de vibração da estrutura com AMS, Primeiro modo (a), segundo modo (b)

\section{3.}

\section{Valores ótimos do amortecimento e razão de frequências naturais}

Den Hartog (1956) obteve a solução do sistema Eq.2.4, onde a estrutura principal é não amortecida $\left(C_{s}=0\right)$ e está submetida a uma força senoidal $f(t)=$ 
A sen $(\Omega t)$ com frequência de excitação $\Omega$ e magnitude A. Os efeitos dinâmicos do AMS são medidos através do fator de amplificação dinâmica da estrutura dado por

$$
R_{D}=\frac{x_{\max }}{x_{s t a}}=\sqrt{\frac{\left(\Delta^{2}-\beta^{2}\right)^{2}+\left(2 \xi_{a} \Delta \beta\right)^{2}}{\left(\left(\Delta^{2}-\beta^{2}\right)\left(1-\beta^{2}\right)-\Delta^{2} \beta^{2} \delta\right)^{2}+\left(2 \xi_{a} \Delta \beta\right)^{2}\left(1-\beta^{2}+\beta^{2} \delta\right)^{2}}}
$$

onde $x_{s t a}=A / K_{S}$ é o deslocamento estático e $\beta=\Omega / \omega_{s}$ é razão entre a frequência de excitação e a frequência natural da estrutura não controlada. Verifica-se que o fator de amplificação dinâmica depende, neste caso, não só dos parâmetros $\delta$ e $\Delta$, mas também de $\beta$ e $\xi_{a}$.

A Figura 2-5 mostra a variação do fator de amplificação dinâmica, $R_{D}$, em função da frequência de excitação $\beta$, para valores selecionados do fator de amortecimento do AMS, $\xi_{a}, \delta=0,05$ e $\Delta=1$. Para um valor de $\xi_{a}=0$, a amplitude da resposta da estrutura é infinita para as duas frequências de ressonância do sistema estrutura-AMS. Por outro lado, a amplitude da resposta da estrutura é nula para $\Delta=1$ (anti-ressonância). Quando o amortecimento do AMS tende a infinito, o sistema se reduz a $1 \mathrm{GL}$ com massa $\left(M_{s}+M_{a}\right)$, de modo que a amplitude na frequência de ressonância torna-se de novo infinita. Para qualquer valor entre os dois extremos a solução apresenta dois picos finitos que dependem do valor de $\xi_{a}$. Todas as curvas passam por dois pontos denotados por P e Q na Figura 2-5.

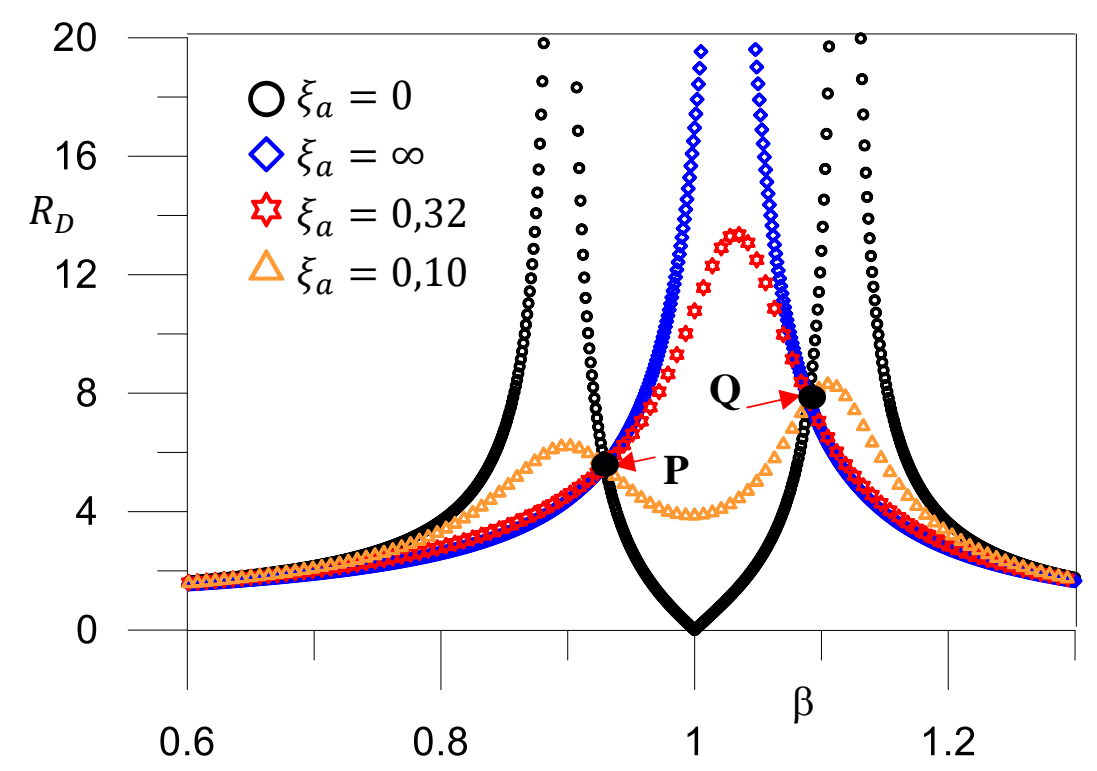

Figura 2-5 Fator de amplificação em função de $\beta(\delta=0,05, \Delta=1)$ Soong \& Dargush, (1997) 
Os dois picos da resposta tornam-se mínimos quando (Brock, 1946):

$$
\xi_{a}=\sqrt{\frac{3 \delta}{8(1+\delta)}}
$$

Warburton e Ayonride (1982) conduziram uma análise detalhada para determinar os parâmetros ótimos de amortecimento e da relação de frequências $\Delta$ em função da relação de massas $\delta$, considerando tanto excitação harmônica quanto aleatória. Os resultados são mostrados na Tabela 2-1. Em geral, as diversas expressões para cálculo de $\Delta$ ótimo leva a valores entre 0,9 e 1,0. Já o valor do amortecimento ótimo é em geral elevado, exigindo o uso de amortecedores especialmente projetado para este fim. Embora um amortecimento elevado diminua os picos da resposta permanente na região de ressonância, este pode ter um efeito adverso na fase transiente, diminuindo a eficiência do AMS, o que deve ser uma preocupação na presença de cargas de curta duração como as cargas sísmicas. No terremoto de San Fernando, em 1971, o período em que as acelerações de base ultrapassaram 0,05g foi de apenas 6 segundos. Nos terremotos de Loma Prieta e Northridge este patamar foi ultrapassado em 10 segundos, causando, contudo, grandes danos. Entretanto, no terremoto de San Francisco em 1906, vibrações severas ocorreram durante 45 segundos e, no Alasca, em 1964, por mais de 3 minutos (Arnold, 2003).

Tabela 2-1 Valores ótimos dos parâmetros $\Delta$ e $\xi_{\boldsymbol{s}}$. (Warburton e Ayonride, 1982)

\begin{tabular}{|c|c|c|c|c|}
\hline Caso & Excitação & $R_{D}$ & $\Delta_{\text {ótimo }}$ & 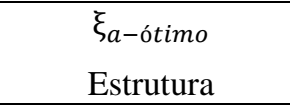 \\
\hline 1 & $\begin{array}{c}\text { A } e^{i \Omega t} \\
\text { Força } \\
\text { harmônica }\end{array}$ & $\sqrt{1+\frac{2}{\delta}}$ & $\frac{1}{1+\delta}$ & $\sqrt{\frac{3 \delta}{8(1+\delta)}}$ \\
\hline 2 & $\begin{array}{c}\ddot{X}_{g} e^{i \Omega t} \\
\text { Aceleração de } \\
\text { base harmônica }\end{array}$ & $\sqrt{\frac{2}{\delta}}(1+\delta)$ & $\frac{\sqrt{1-\frac{\delta}{2}}}{1+\delta}$ & $\sqrt{\frac{3 \delta}{8(1+\delta)\left(1-\frac{\delta}{2}\right)}}$ \\
\hline 3 & Força aleatória & $\sqrt{\frac{1+\frac{3 \delta}{4}}{\delta(1+\delta)}}$ & $\frac{\sqrt{1+\frac{\delta}{2}}}{1+\delta}$ & $\sqrt{\frac{\delta\left(1+\frac{3 \delta}{4}\right)}{4(1+\delta)\left(1+\frac{\delta}{2}\right)}}$ \\
\hline 4 & $\begin{array}{c}\text { Aceleração de } \\
\text { base } \\
\text { Aleatória }\end{array}$ & $(1+\delta)^{3 / 2} \sqrt{\frac{1}{\delta}}-\frac{1}{4}$ & $\frac{\sqrt{1-\frac{\delta}{2}}}{1+\delta}$ & $\sqrt{\frac{\delta\left(1-\frac{\delta}{4}\right)}{4(1+\delta)\left(1-\frac{\delta}{2}\right)}}$ \\
\hline
\end{tabular}


Considerando os efeitos das frequências características dos solos nos parâmetros ótimos Hoang et al., (2008) apresentam fórmulas para diferentes valores de frequências de excitação. Para $1<\beta<3$, tem-se:

$$
\Delta_{\text {ótimo }}=\frac{\sqrt{1-\frac{\beta \delta}{6}}}{1+\delta}
$$

Para $\beta=1$, quando a frequência de excitação é igual à frequência da estrutura, eles propõem o uso dos seguintes valores

$$
\begin{aligned}
& \Delta_{\text {ótimo }}=\frac{\sqrt{(1-0.6 \delta)\left(1+\delta^{2}\right)}}{1+\delta} \\
& \xi_{\text {a-ótomo }}=\frac{\sqrt{\delta\left(1+2.5 \delta+2 \delta^{2}\right)}}{2(1+2.7 \delta)}
\end{aligned}
$$

Além disso, incorporando o efeito do fator de amortecimento da estrutura principal, $\xi_{s}$, nos valores ótimos, para valores de $\beta=1$ se tem

$$
\Delta_{\text {б́timo }}=\frac{\sqrt{(1-0.6 \delta)\left(1+\delta^{2}\right)}}{1+\delta}-0.7 \xi_{S}
$$

Para $1<\beta<3$, tem-se

$$
\begin{gathered}
\Delta_{\text {ótimo }}=\frac{\sqrt{1-\frac{\beta \delta}{6}}}{1+\delta}-\frac{0.7 \xi_{S}}{1-\frac{\delta}{2}} \\
\xi_{a-\text { ótimo }}=\sqrt{\frac{\delta\left(1-\frac{\delta}{4}\right)}{4(1+\delta)\left(1-\frac{\delta}{2}\right)}+0.25 \delta \xi_{S}}
\end{gathered}
$$

e para valores de $\beta>3$ se tem

$$
\Delta_{\text {ótimo }}=\frac{\sqrt{1-\frac{\delta}{2}}}{1+\delta}-\frac{0.7 \xi_{S}}{1-\frac{\delta}{2}}
$$




$$
\xi_{a-o ́ t i m o}=\sqrt{\frac{\delta\left(1-\frac{\delta}{4}\right)}{4(1+\delta)\left(1-\frac{\delta}{2}\right)}}+0.25 \delta \xi_{S}
$$

\section{4.}

\section{Estrutura com isolador de base linear}

Considera-se agora que a estrutura possui um sistema de isolamento de base linear com rigidez $K_{b}$ e amortecimento $C_{b}$, tendo a fundação uma massa total $M_{b}$, como mostra a Figura 2-6, sendo o conjunto submetido a um deslocamento de base $X_{g}$. Os deslocamentos relativos da estrutura e da base são denotados por, respectivamente, $X_{s}$ e $X_{b}$.

O sistema de equação de movimento que representa o comportamento dinâmico do sistema é dado por (Naeim e Kelly, 1999):

$$
\begin{gathered}
\left(M_{S}+M_{b}\right) \ddot{X}_{b}+M_{S} \ddot{X}_{S}+C_{b} \dot{X}_{b}+K_{b} X_{b}=-\left(M_{S}+M_{b}\right) \ddot{X}_{g} \\
M_{S} \ddot{X}_{b}+M_{S} \ddot{X}_{S}+C_{S} \dot{X}_{S}+K_{s} X_{S}=-M_{S} \ddot{X}_{g}
\end{gathered}
$$
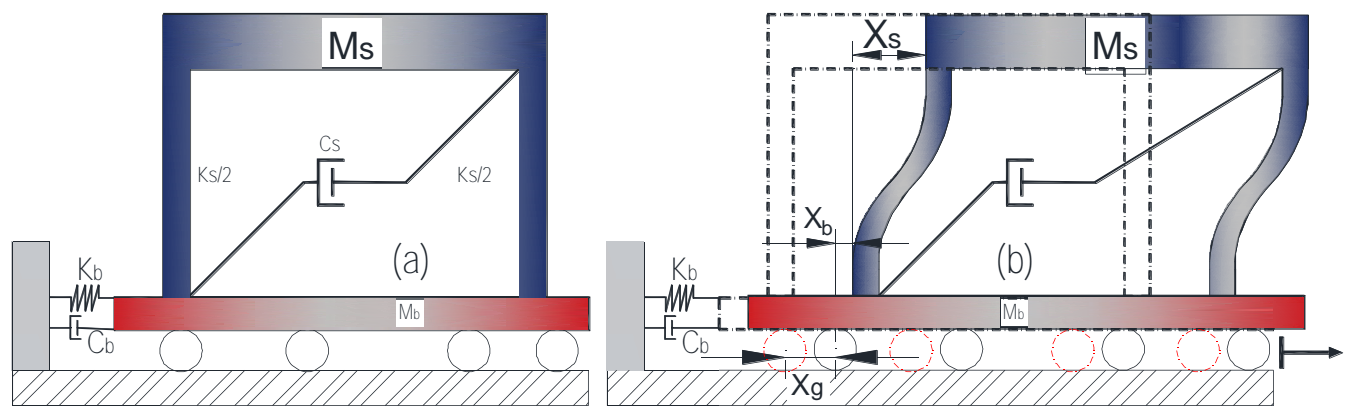

Figura 2-6 Sistema de isolamento de base de linear (a), estrutura deformada pelo movimento de base $\mathrm{Xg}$ (b)

A frequência natural de vibração da base da estrutura, $\omega_{b}$, é dada por

$$
\omega_{b}^{2}=\frac{K_{b}}{M_{b}},
$$

e o fator de amortecimento $\xi_{b}$ por

$$
\frac{C_{b}}{M_{b}}=2 \xi_{b} \omega_{b}
$$

Redefinindo a razão de frequências para este caso na forma 


$$
\Delta=\frac{\omega_{b}}{\omega_{S}}
$$

tem-se que as Eqs.2.20 e 2.21 podem ser reescritas em termos dos parâmetros adimensionais das Eqs.2.2, 2.23 e 2.24, tomando a forma

$$
\begin{gathered}
(1+\delta) \frac{d^{2} \bar{X}_{b}}{d \tau^{2}}+\frac{d^{2} \bar{X}_{S}}{d \tau^{2}}+2 \delta \Delta \xi_{b} \frac{d \bar{X}_{b}}{d \tau}+\delta \Delta^{2} \bar{X}_{b}=-(1+\delta) \frac{d^{2} \bar{X}_{g}}{d \tau^{2}} \\
\frac{d^{2} \bar{X}_{S}}{d \tau^{2}}+\frac{d^{2} \bar{X}_{b}}{d \tau^{2}}+2 \xi_{S} \frac{d \bar{X}_{S}}{d \tau}+\bar{X}_{S}=-\frac{d^{2} \bar{X}_{g}}{d \tau^{2}}
\end{gathered}
$$

As frequências naturais de vibração obtidas das Eq. 2.25 e 2.26 são dadas por

$$
\bar{\omega}_{b}=\frac{\sqrt{2}}{2} \sqrt{\frac{\delta \Delta^{2}+\delta+1 \pm \sqrt{\Delta^{4} \delta^{2}-2 \Delta^{2} \delta^{2}+2 \Delta^{2} \delta+\delta^{2}+2 \delta+1}}{\delta}}
$$

A Figura 2-7 mostra a variação das duas frequências naturais em função da razão de frequências, $\Delta$, para valores selecionados da razão de massas, $\delta$, e a Figura 2-8 mostra os respectivos modos de vibração. Verifica-se que o primeiro modo de vibração corresponde a aproximadamente um movimento de corpo rígido da estrutura principal, com pequeno deslocamento entre as duas massas, o que é desejado em um sistema de isolamento de base, enquanto o segundo modo leva a um movimento relativo entre as duas massas. Verifica-se que, para uma dada razão de massas, $\delta$, a primeira frequência cresce de uma forma quase linear $\operatorname{com} \Delta$, a partir do valor nulo (movimento de corpo rígido para $\Delta=0$ ). Já a segunda frequência é praticamente insensível ao valor de $\Delta$. À medida que $\delta$ cresce, a primeira frequência aumenta enquanto a segunda diminui.

Cabe destacar que a massa da base em estruturas reais pode levar a valores elevados de $\delta$, o que é um fator positivo para o controle de vibrações onde, em geral, a eficiência cresce com $\delta$. 


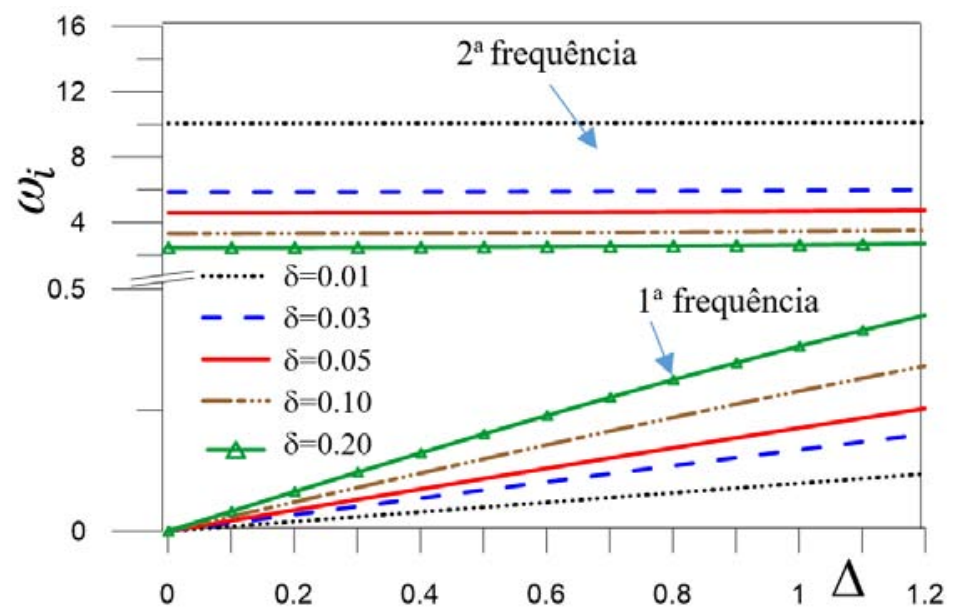

Figura 2-7 Variação das duas frequências naturais da estrutura com isolamento de base linear em função de $\Delta$ para valores selecionados de $\delta$.
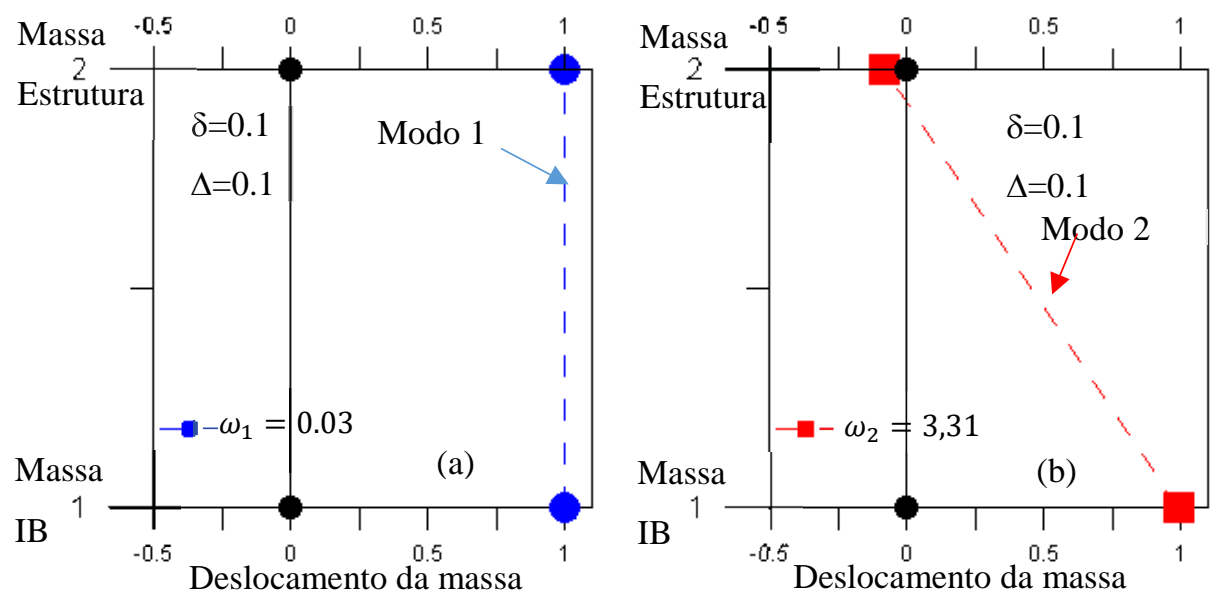

Figura 2-8 Modos de vibração da estrutura com isolamento de base linear, Primeiro modo (a), segundo modo (b)

\section{5 .}

Valores de amortecimento inerentes às estruturas e amortecedor de fluido

As forças de amortecimento são função principalmente dos materiais que compõem a estrutura, das ligações entre os elementos estruturais, dos travamentos e sistemas de amortecimento incorporados (amortecedores fluidos, etc), entre outros fatores. Em geral, a força de amortecimento é alterada muito pouco com as frequências naturais, que, por sua vez, são função da massa e rigidez da estrutura. Em relação ao amortecimento estrutural, segundo a NBR 6123, (1988), seu valor é geralmente muito pequeno, gerando grandes deslocamentos nas estruturas quando são solicitadas por forças externas nas regiões de ressonância. A Tabela 2-2 mostra valores de referência do fator de amortecimento da estrutura, $\xi_{s}$, para 
algumas estruturas civis, juntamente com valores esperados do período fundamental de vibração, T1, em função da altura da estrutura, h.

Tabela 2-2 Amortecimentos inerentes às estruturas segundo NBR 6123,(1988)

\begin{tabular}{lcc}
\hline Tipo de edificação & $\xi_{s}$ & T1=1/f1 \\
\hline $\begin{array}{l}\text { Edifícios com estrutura aporticada de concreto, sem } \\
\text { cortinas }\end{array}$ & 0,020 & $\begin{array}{c}0,05 \mathrm{~h}+0,015 \mathrm{~h} \\
\text { (h em metros) }\end{array}$ \\
$\begin{array}{l}\text { Edifícios com estrutura de concreto, com cortinas para } \\
\text { absorção de forças horizontais }\end{array}$ & 0,015 & $0,05 \mathrm{~h}+0,012 \mathrm{~h}$ \\
$\begin{array}{l}\text { Torres e chaminés de concreto, seção variável } \\
\text { Torres, mastros e chaminés de concreto, seção uniforme }\end{array}$ & 0,015 & $0,02 \mathrm{~h}$ \\
Edifícios com estrutura de aço soldada & 0,010 & $0,015 \mathrm{~h}$ \\
Torres e chaminés de aço, seção uniforme & 0,008 & $0,29 \sqrt{h}-0,49$ \\
Estruturas de madeira & 0,030 & \\
\hline
\end{tabular}

Uma maneira de aumentar o amortecimento da estrutura ou introduzir uma parcela de amortecimento nos sistemas de controle é usar amortecedores viscosos. Eles dissipam energia através do deslocamento de um pistão em uma câmara preenchida por fluido altamente viscoso e a sua capacidade de dissipação depende da transformação de energia mecânica em calor. O que gera o amortecimento é a dissipação de energia durante a passagem do fluido através dos furos do pistão, onde se encontram válvulas responsáveis por controlar o movimento e pela própria válvula da base que controla a passagem de óleo do tubo de pressão para o tubo reservatório, como ilustra a Figura 2-9.

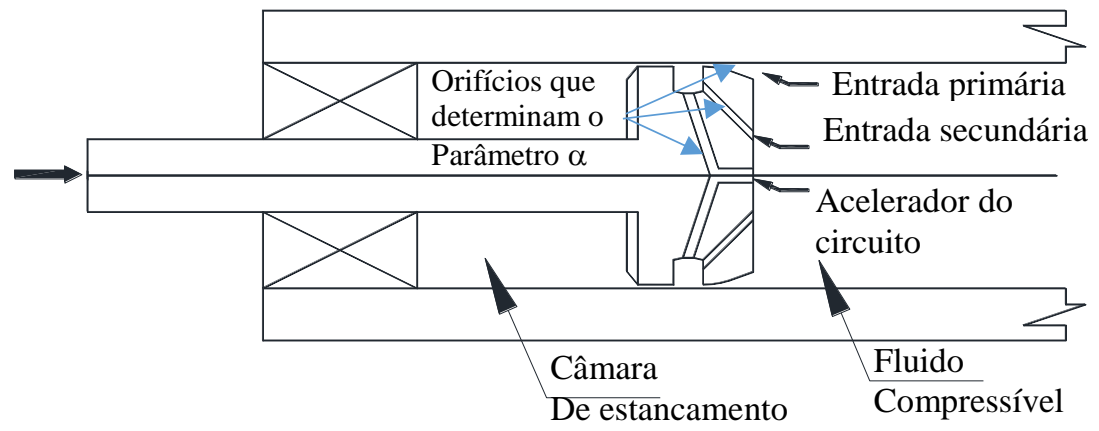

Figura 2-9 Amortecedor de fluido (Soong e Dargush, 1997; Constantinou e Symans.1993b)

Os amortecedores com líquidos altamente viscosos podem ser projetados com pistões cujos orifícios podem ser especialmente desenhados para se obter um 
dado coeficiente de amortecimento que otimiza o desempenho do amortecedor e permitem um comportamento não linear, segundo a expressão:

$$
P_{v}=C_{V}\left|V_{c}\right|^{\alpha} \operatorname{sgn}\left(V_{c}\right)
$$

onde $C_{v}$ é coeficiente de amortecimento, $V$ é a velocidade relativa do pistão e $\alpha$ é uma variável que pode variar de 0,5 a 2 segundo Constantinou, et al., (1993). Segundo Taylor (1999), para estruturas submetidas a sismos devem ser usados valores de 0,4 a 0,5 e para estruturas submetidas a cargas de vento devem ser usados valores de 0,5 a 1,0 .

Existem outros modelos de amortecimento usados em sistemas de controle. A Tabela 2-2 mostra algumas das leis constitutivas encontradas na literatura.

Tabela 2-3 Representação analítica do amortecimento

\begin{tabular}{|c|c|c|}
\hline Caso & $g\left(\frac{d x}{d t}, x\right)$ & Fonte \\
\hline I & $C_{1} \frac{d x}{d t}$ & Viscoso ou meio ambiente \\
\hline II & $C_{0}|x|\left(\operatorname{sign}\left(\frac{d x}{d t}\right)\right)$ & $\begin{array}{c}\text { Material ou atrito } \\
\text { (deslizamento) }\end{array}$ \\
\hline III & $C_{2}\left(\frac{d x}{d t}\right)^{2}\left(\operatorname{sign}\left(\frac{d x}{d t}\right)\right)$ & Meio ambiente \\
\hline IV & $C_{3}|x| \frac{d x}{d t}$ & Material \\
\hline V & $C_{1}\left(1+\alpha x^{2}\right) \frac{d x}{d t}$ & Global \\
\hline
\end{tabular}

\section{6.}

\section{Excitação de base}

Assumindo um deslocamento de base do tipo harmônico

$$
X_{g}=A \operatorname{sen}(\Omega t)
$$

a aceleração de base tem a forma

$$
\frac{d^{2} X_{g}}{d t^{2}}=\mathrm{A} \Omega^{2} \operatorname{sen}(\Omega t)
$$

onde $A$ é amplitude do deslocamento da base e $\Omega$ é a frequência de excitação.

Escrevendo, como é costume na análise sísmica, a magnitude da aceleração em termos da aceleração da gravidade $g$, tem-se: 


$$
\frac{d^{2} X_{g}}{d t^{2}}=\Lambda g \operatorname{sen}(\Omega t)
$$

onde $A \Omega^{2}=\Lambda g$.

No caso de sismos geralmente são usados acelerogramas registrados em alguns eventos sísmicos ou são gerados sinais aleatórios a partir de um dado espectro de frequências (Paullo, 2015). Um dos sinais mais usados na literatura se refere aos sinais registrados para os sismos El Centro ocorrido no Imperial Valley localizado no sudeste da Califórnia, Estados Unidos, no ano de 1940 que chegou a registrar uma magnitude de 6,9 na escala de momento e uma intensidade de 10 na escala de Mercalli e, em termos de aceleração, chegou a uma aceleração máxima de 0,21g na componente EW (Figura 2-10) e uma aceleração máxima de 0,35g para a componente NS (Figura 2-11), com seus respectivos conteúdos de frequências (espectros de potência).
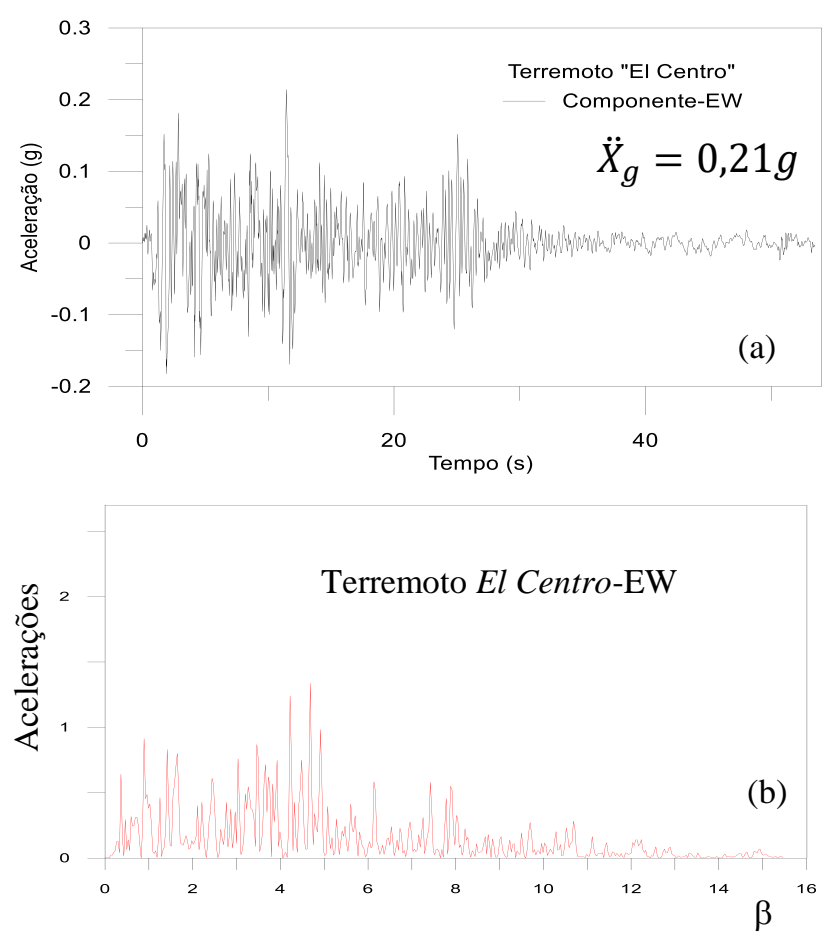

Figura 2-10 Aceleração no tempo (a), Espectro de potências (b), do terremoto El Centro, componente EW 

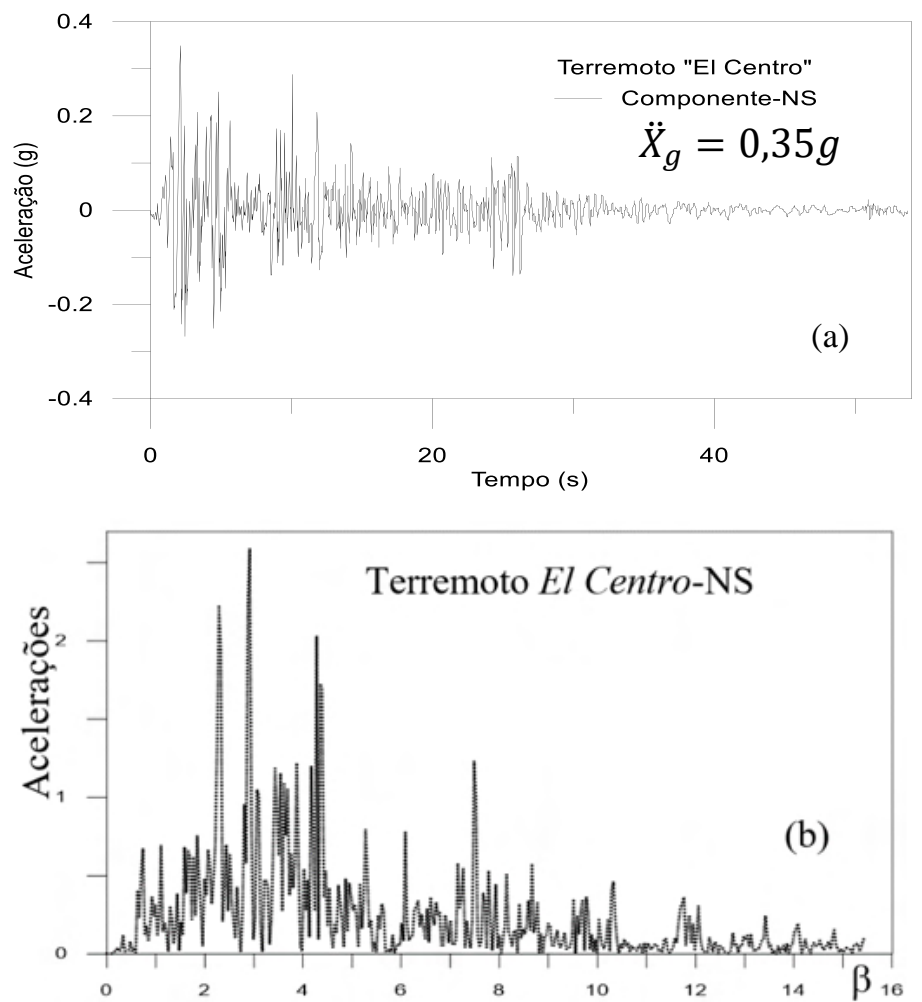

Figura 2-11 Acelerações no tempo (a), espectro de potências (b), do terremoto El Centro, componente NS

Outro sinal bastante usado na literatura é o do terremoto Loma Prieta ocorrido no ano de 1989, na baía de São Francisco, Califórnia, Estados Unidos, com uma aceleração máxima de 0,15g na componente EW (Figura 2-12).
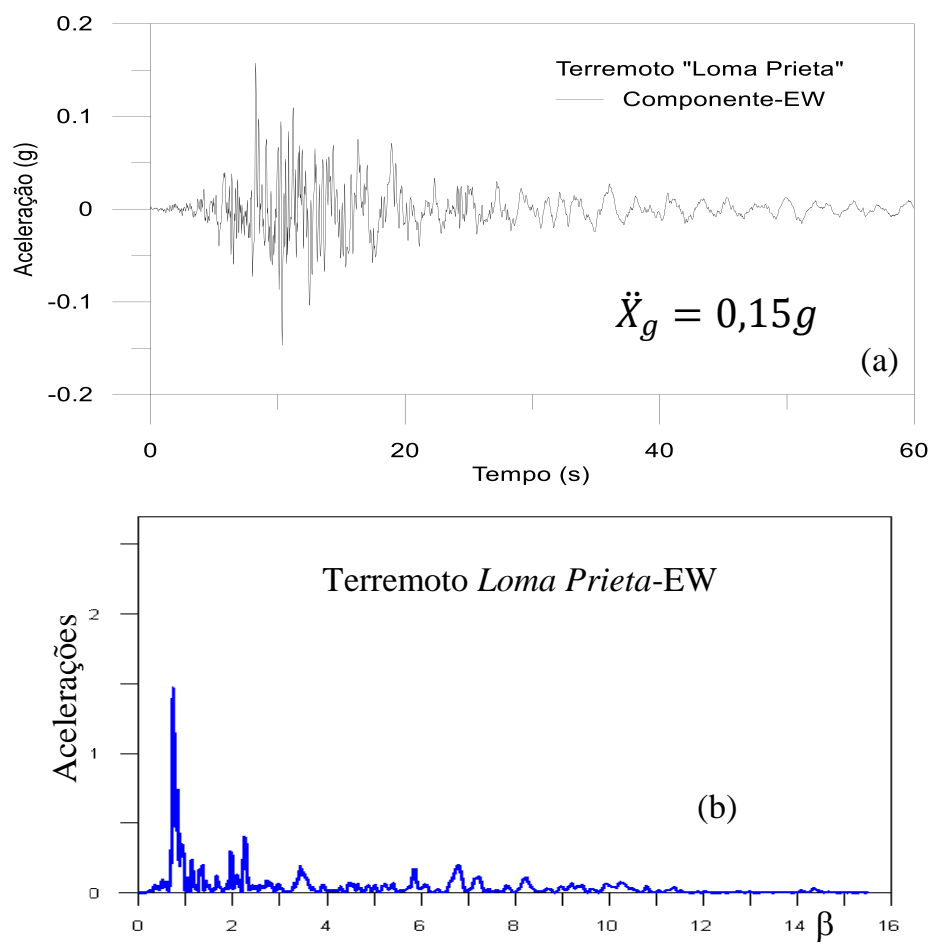

Figura 2-12 Aceleração no tempo (a), espectro de potências (b), do terremoto Loma Prieta componente EW 
Estes sinais serão usados, sem perda de generalidade, para testar a eficiência dos sistemas de controle propostos nesta tese. A Tabela 2-4 mostra a aceleração máxima de alguns sinais conhecidos, mostrando a variabilidade das mesmas (https://en.wikipedia.org/wiki/Peak_ground_acceleration).

A Tabela 2-5 mostra a correlação da intensidade instrumental com aceleração pico do solo, percepção do fenômeno e potência de dano. A maioria dos sismos apresentam acelerações máximas menores que 1g, mas em alguns sinais este valor pode ser bem superior, chegando no caso do sismo Iwate-Miyagi Nairiku, ocorrido no Japão em 2008 a um valor superior a 4g, que pode ser classificado, como ilustra a Tabela 2-6, como um evento extremo, gerando danos consideráveis (https://en.wikipedia.org/wiki/Peak_ground_acceleration). No terremoto de Northridge, em 1994, uma estação a 8km do epicentro registrou um pico de aceleração de 1,92g (Arnold, 2003).

Tabela 2-4 Terremotos notáveis (https://en.wikipedia.org/wiki/Peak_ground_acceleration)

\begin{tabular}{|c|c|c|c|c|c|}
\hline $\begin{array}{c}\text { Aceler. } \\
\text { pico do } \\
\text { solo } \\
\end{array}$ & $\begin{array}{c}\text { Soma } \\
\text { vetorial } \\
(\mathrm{NS}, \mathrm{EW} \text { e V) } \\
\end{array}$ & Mag. & Profund. & Fatalidades & Terremoto \\
\hline $2,7 \mathrm{~g}$ & $2,99 \mathrm{~g}$ & 9,0 & $30 \mathrm{~km}$ & $>15.000$ & $\begin{array}{l}\text { Sismo e tsunami de Tohoku de } \\
2011\end{array}$ \\
\hline $2,2 \mathrm{~g}$ & & 6,3 & $5 \mathrm{~km}$ & 185 & $\begin{array}{c}\text { Sismo Christchurch em } \\
\text { Fevereiro de2011 }\end{array}$ \\
\hline $2,13 \mathrm{~g}$ & & 6,4 & $6 \mathrm{~km}$ & 1 & $\begin{array}{c}\text { Sismo Christchurch em Junio } \\
\text { de2011 }\end{array}$ \\
\hline $1,7 \mathrm{~g}$ & & 6,7 & $19 \mathrm{~km}$ & 57 & Sismo Los Angeles de 1994 \\
\hline $1,26 g$ & & 7,1 & $10 \mathrm{~km}$ & 0 & Sismo Canterbury de 2010 \\
\hline $1,0 \mathrm{~g}$ & & 6,0 & $8 \mathrm{~km}$ & 0 & $\begin{array}{l}\text { Sismo Christchurch em } \\
\text { Decembro de } 2011\end{array}$ \\
\hline $1,01 \mathrm{~g}$ & & 7,3 & $8 \mathrm{~km}$ & 2.415 & Sismo Jiji em 1999 \\
\hline $1,01 \mathrm{~g}$ & & 6,6 & $10 \mathrm{~km}$ & 11 & $\begin{array}{l}\text { Sismo no mar Chuetsu em } \\
2007\end{array}$ \\
\hline $0,8 \mathrm{~g}$ & & 6,8 & $16 \mathrm{~km}$ & 6.434 & Sismo Kobe em 1995 \\
\hline $0,78 g$ & & 8,8 & $23 \mathrm{~km}$ & 521 & Sismo Chile em 2010 \\
\hline $0,6 g$ & & 6,0 & $10 \mathrm{~km}$ & 143 & Sismo Atenas 1999 \\
\hline $0,5 g$ & & 7,0 & 13 km & $\begin{array}{l}92.000- \\
316.000\end{array}$ & Sismo Haiti em 2010 \\
\hline $0,51 \mathrm{~g}$ & & 6,4 & & 612 & Sismo Zarand em 2005 \\
\hline $0,4 \mathrm{~g}$ & & 5,7 & $8 \mathrm{~km}$ & 0 & Sismo Christchurch em 2016 \\
\hline $0,438 g$ & & 7,7 & $44 \mathrm{~km}$ & 27 & $\begin{array}{c}\text { Sismo de Miyagi (Sendai) em } \\
1978\end{array}$ \\
\hline $0,367 \mathrm{~g}$ & & 5,2 & $1 \mathrm{~km}$ & 9 & Sismo Lorca 2011 \\
\hline $\begin{array}{l}0,25- \\
0,3 g\end{array}$ & & 9,5 & $33 \mathrm{~km}$ & 1.655 & Sismo Valdivia 1960 \\
\hline $0,24 \mathrm{~g}$ & & 6,4 & & 628 & Sismo Morocco 2004 \\
\hline \multirow[t]{3}{*}{$0,18 \mathrm{~g}$} & & 9,2 & $23 \mathrm{~km}$ & 143 & Sismo Alaska 1964 \\
\hline & $4,36 g$ & $6,9 / 7,2$ & $8 \mathrm{~km}$ & 12 & Sismo Iwate-Miyagi 2008 \\
\hline & 1,47 & 7,1 & $42 \mathrm{~km}$ & 4 & Sismo Miyagi Abril 2011 \\
\hline
\end{tabular}


Tabela 2-5 Correlação da intensidade instrumental com aceleração pico do solo (https://en.wikipedia.org/wiki/Peak_ground_acceleration)

\begin{tabular}{ccccc}
\hline $\begin{array}{c}\text { Intensidade } \\
\text { instrumental }\end{array}$ & $\begin{array}{c}\text { Aceleração } \\
(\mathbf{g})\end{array}$ & $\begin{array}{c}\text { Velocidade } \\
(\mathbf{c m} / \mathbf{s})\end{array}$ & Percepção & $\begin{array}{c}\text { Potência } \\
\text { do } \\
\text { dano }\end{array}$ \\
\hline I & $<0,0017$ & $<0,1$ & Não percebida & Nenhuma \\
II-III & $0,0017-0,014$ & $0,1-1,1$ & Fraco & Nenhuma \\
IV & $0,014-0,039$ & $1,1-3,4$ & Leve & Nenhuma \\
V & $0,039-0,092$ & $3,4-8,1$ & Moderado & Muito leve \\
VI & $0,092-0,18$ & $8,1-16$ & Forte & Leve \\
VII & $0,18-0,34$ & $16-31$ & Muito forte & $\begin{array}{c}\text { Moderado } \\
\text { Moderada } \\
\text { VIII }\end{array}$ \\
IX & $0,34-0,65$ & $31-60$ & Grave & $\begin{array}{c}\text { a forte } \\
\text { Forte }\end{array}$ \\
X+ & $>1,24$ & $>116$ & Extremo & Muito forte \\
\hline
\end{tabular}

O efeito da excitação de base é função não só da sua intensidade e conteúdo de frequências, mas também das frequências naturais, em particular da frequência fundamental da estrutura a ser analisada. A Figura 2-13 mostra uma comparação dos períodos e frequências naturais de edifícios em função da altura. Os valores são aproximados, já que eles dependem do sistema estrutural, material e proporções geométricas (Arnold, 2003).

No caso de movimento de base gerado por sismos, deve-se levar em consideração o conteúdo de frequências do sismo, que pode ser obtido através da transformada de Fourier do sinal. A Figura 2-14 ilustra considerando o sinal do sismo ocorrido na cidade de México em 1985 a faixa de edificações vulneráveis. Neste caso, os períodos das estruturas na faixa de 6 a 20 andares entram em ressonância com as frequências do terremoto. 


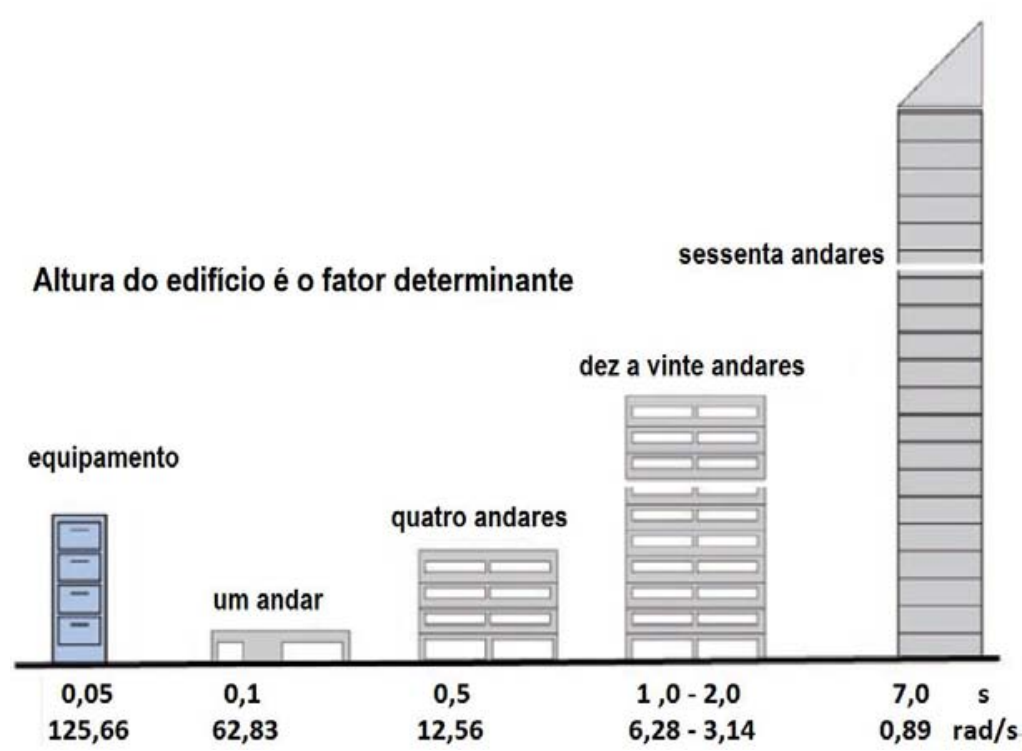

Figura 2-13 Comparação dos períodos típicos de edifícios e respectivas frequências, determinados em função da altura. Os valores são aproximados: o sistema estrutural, material e proporções geométricas também alteram o período (Arnold, 2003).

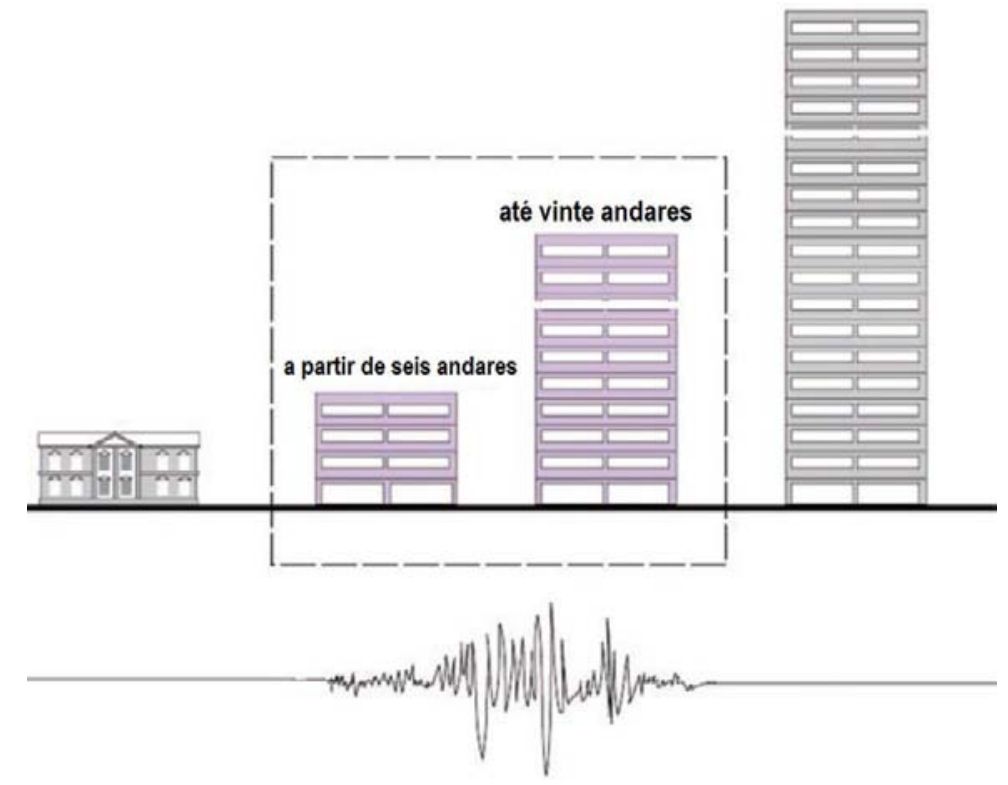

Figura 2-14 Grupo vulnerável: Cidade de México, 1985. Os períodos das estruturas na faixa de 6 a 20 andares em ressonância com o conteúdo de frequências do terremoto (Arnold, 2003)

Para análise sísmica de estruturas, geralmente se adota, com base nas características geológicas da região, um espectro de respostas da ação sísmica para dimensionamento da estrutura no regime elástico. Em geral este espectro mostra a variação da aceleração espectral normalizada com respeito à aceleração da gravidade (g) em função do período em segundos e consiste em um trecho inicial linear, seguido de um trecho constante que corresponde à região de 
máximas acelerações e, finalmente, um trecho não linear onde a aceleração espectral decresce, sendo inversamente proporcional ao período. A Figura 2-15 ilustra um exemplo de espectro de resposta para projeto (curva em preto) e compara este com o espectro de vários sismos, mostrando a consistência do procedimento. Verifica-se que os picos dos sismos aqui ilustrados se encontram em uma faixa de períodos que vai de zero a um segundo. A partir de um dado espectro o engenheiro pode gerar sismos artificiais que podem ser usados em análises numéricas para testar o comportamento de uma dada estrutura (Paullo, 2015). Com base no espectro característico de uma dada região, o engenheiro pode projetar a estrutura de modo que os períodos naturais associados aos modos mais baixos não coincidam com o período de máxima resposta. Esta informação também é útil no projeto de sistemas de isolamento de base, onde se deve aumentar o período do primeiro modo de vibração, afastando a estrutura da zona de máximas acelerações.

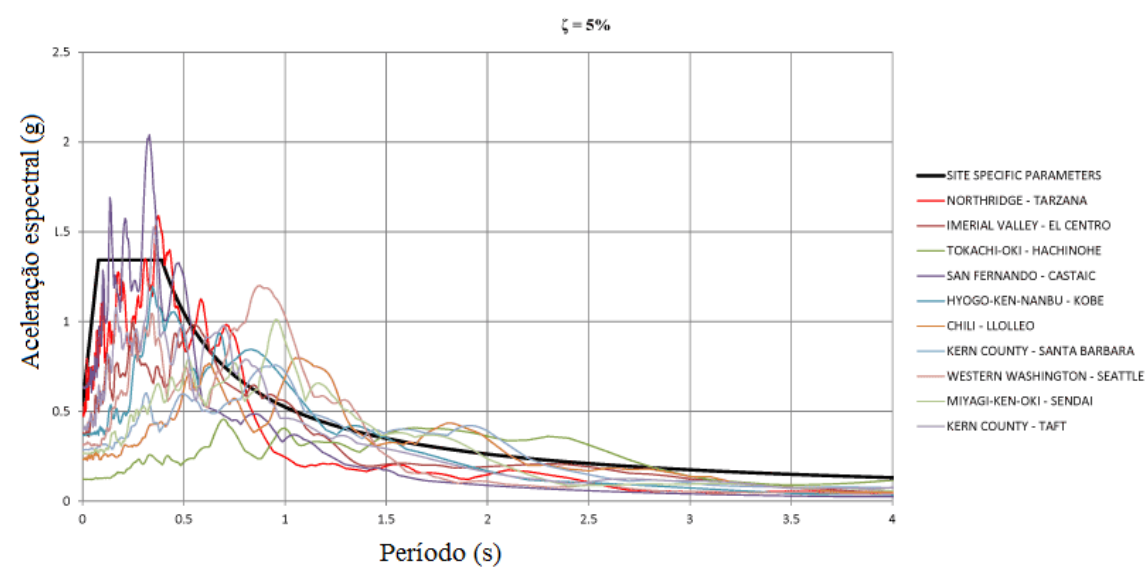

Figura 2-15 Exemplo de espectro de resposta da ação sísmica, no regime elástico usado em projeto (em preto) e comparação com o conteúdo de frequências de diversos sismos. 


\section{3 \\ Sistema de controle passivo pendular}

O controle de vibrações de estruturas para mitigar os efeitos de movimento de base produzidos por agentes externos, tem demostrado alta eficiência, reduzindo os deslocamentos laterais relativos e, consequentemente, os esforços e os danos nas estruturas Kelly, (1993), Naeim e Kelly (1999) e Pezo, (2012). O sistema de controle passivo pendular aqui proposto, ilustrado na Figura 3-1, pode ser usado como isolador pendular de base (IBP) ou, alternativamente, como amortecedor pendular de massa sintonizada (APMS). Este se constitui de uma massa $M_{a}$ que se desloca sobre uma superfície curva com curvatura constante ou variável. Este sistema gera forças não lineares similares às do pêndulo clássico, mas tem a vantagem de ocupar pouco espaço, permitir de forma simples a variação do raio de curvatura, e, quando desestabilizado, voltar automaticamente à posição inicial de equilíbrio por efeito da componente vertical do peso próprio do mecanismo, o que não ocorre com muitos sistemas de isolamento. Além disto, sendo uma superfície suave, não apresenta descontinuidades nas forças de restauração, como ocorre nos sistemas deslizantes (stick-slip) e nas bases em forma de planos inclinados.

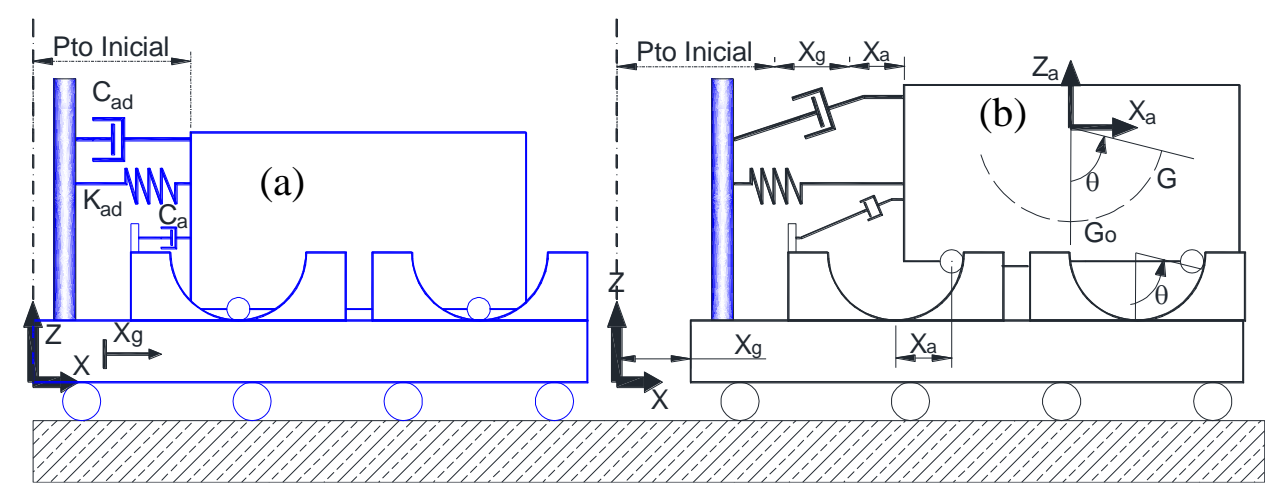

Figura 3-1 Sistema de controle passivo pendular (a) posição inicial e (b) posição final após o deslocamento de base $\mathrm{Xg}$

O sistema pendular pode ter, adicionalmente, uma mola de rigidez $K_{a d}$, coeficiente de amortecimento inerente ao isolador de base $C_{a d}$ e o coeficiente de 
amortecimento adicional $C_{a d}$, como é ilustrado na Figura 3-1, permitindo maior flexibilidade no projeto. O sistema está submetido a um movimento de base $X_{g}$. A massa $M_{a}$ se desloca sobre cilindros de raio $r$, cujo peso e inércia são considerados desprezíveis em comparação com aqueles gerados pela massa $M_{a}$. O deslocamento de base pode ser produzido por uma excitação harmônica ou aleatória.

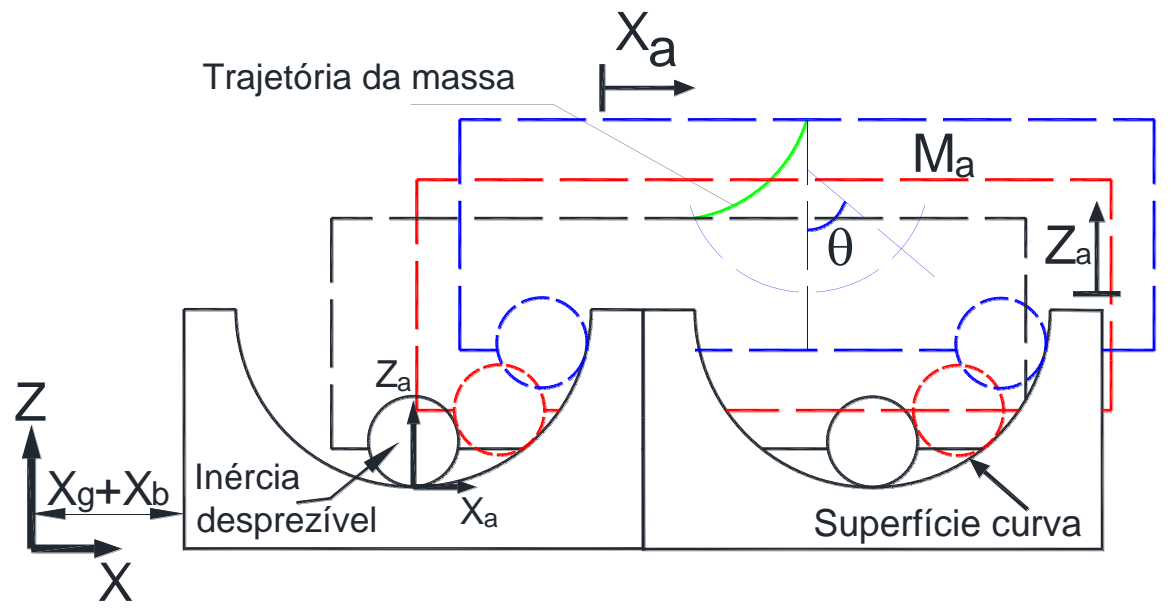

Figura 3-2 Cinemática da massa sobre a superfície curva.

A Figura 3-2 mostra a cinemática da massa $M_{a}$ ao se deslocar sobre uma superfície curva. A posição do pêndulo em um dado instante é definida pelas coordenadas horizontal e vertical da massa $M_{a}$, respectivamente $X_{a}$ e $Z_{a}$. Dependendo do tipo de curva e da variável que descreve a curva, é definida a coordenada generalizada ou grau de liberdade do pêndulo.

A energia cinética do pêndulo é dada por

$$
T_{a}=\frac{1}{2} M_{a}\left(\left(\dot{X}_{g}+\dot{X}_{a}\right)^{2}+\dot{Z}_{a}^{2}\right)
$$

A energia interna de deformação do pêndulo é definida como

$$
U_{a}=\frac{1}{2} K_{a d} X_{a}^{2}
$$

O potencial das cargas externas é dado pela expressão

$$
V_{a}=M_{a} Z_{a} g
$$

A energia potencial total é, portanto, dado por

$$
\Pi=U_{a}+V_{a}
$$


A função de Rayleigh do sistema pendular é dada, considerando um amortecimento viscoso linear, por

$$
R=\frac{1}{2} C_{a}\left(\dot{X}_{a}^{2}+\dot{Z}_{a}^{2}\right)+\frac{1}{2} C_{a d} \dot{X}_{a}^{2}
$$

Aplicando o Princípio de Hamilton, as equações de Euler-Lagrange são dadas por

$$
\frac{d}{d t}\left(\frac{\partial T}{\partial \dot{q}_{i}}\right)-\frac{\partial T}{\partial q_{i}}+\frac{\partial \Pi}{\partial q_{i}}+\frac{\partial R}{\partial \dot{q}_{i}}=0
$$

onde $q_{i}$ é a $i$-ésima coordenada generalizada do sistema.

A forma da superfície pode ser otimizada para se obter um sistema de controle de vibrações com melhor rendimento, neste trabalho usaremos quatro tipos de curvas para o sistema pendular.

Incialmente considere-se uma superfície circular de raio de curvatura constante $R_{c}$, tendo-se assim um pêndulo clássico. O deslocamento horizontal e vertical da massa é definido em função da rotação $\theta$, dependente do tempo $t$, medida a partir da vertical, como mostra a Figura 3-2.

Tem-se assim que o deslocamento horizontal da massa é dado por

$$
X_{a}=R_{c} \sin (\theta)
$$

enquanto o deslocamento vertical da massa é dado por

$$
Z_{a}=R_{c}(1-\cos (\theta))
$$

Neste caso, o movimento do sistema pendular é definido pela rotação $\theta$ (grau de liberdade do sistema) e a Eq.(3.6) tem a forma seguinte:

$$
\frac{d}{d t}\left(\frac{\partial T}{\partial \dot{\theta}}\right)-\frac{\partial T}{\partial \theta}+\frac{\partial \Pi}{\partial \theta}+\frac{\partial R}{\partial \dot{\theta}}=0
$$

Após desenvolver cada parcela da Eq.(3.9), é obtida a seguinte equação diferencial de movimento:

$$
\begin{aligned}
& \left(\begin{array}{l}
\frac{d X_{a}}{d \theta} \ddot{X}_{g}+\left(\frac{d X_{a}}{d \theta}\right)^{2} \ddot{\theta}+\frac{d Z_{a}}{d \theta} \frac{d^{2} Z_{a}}{d \theta^{2}}(\dot{\theta})^{2}+ \\
\frac{d X_{a}}{d \theta} \frac{d^{2} X_{a}}{d \theta^{2}}(\dot{\theta})^{2}+g \frac{d Z_{a}}{d \theta}+\left(\frac{d Z_{a}}{d \theta}\right)^{2} \ddot{\theta}
\end{array}\right) M_{a}+K_{a d} X_{a} \frac{d X_{a}}{d \theta}+ \\
& C_{a}\left(\left(\frac{d X_{a}}{d \theta}\right)^{2}+\left(\frac{d Z_{a}}{d \theta}\right)^{2}\right) \dot{\theta}+C_{a d}\left(\frac{d X_{a}}{d \theta}\right)^{2} \dot{\theta}=0
\end{aligned}
$$

ou seja 


$$
M_{a} R_{c}\left(R_{c} \ddot{\theta}+g \sin (\theta)+\cos (\theta) \ddot{X}_{g}\right)+R_{c}^{2}\left(\begin{array}{l}
C_{a} \dot{\theta}+C_{a d} \sin (\theta) \cos (\theta) \dot{\theta}+ \\
K_{a d} \sin (\theta) \cos (\theta)
\end{array}\right)=0
$$

cuja frequência natural é dada por $\omega_{0}=\sqrt{g / R_{c}+K_{a d} / M_{a}}=\sqrt{\omega_{p}^{2}+\omega_{a d}^{2}}$. A rigidez adicional pode ser usada para dar maior flexibilidade ao projeto do sistema pendular, permitindo a escolha de um valor apropriado para $R_{c}$.

Não considerando a rigidez e o amortecimento adicional, tem-se:

$$
M_{a} R_{c}^{2} \ddot{\theta}+R_{c}^{2} C_{a} \dot{\theta}+M_{a} R_{c} g \sin (\theta)=-M_{a} R_{c} \cos (\theta) \ddot{X}_{g}
$$

que corresponde à equação clássica de um pêndulo com frequência natural $\omega_{p}=\sqrt{g / R_{c}}$ submetido a um deslocamento horizontal de base. Na forma adimensional tem-se

$$
\ddot{\theta}+2 \xi_{a} \dot{\theta}+\omega_{p}^{2} \sin (\theta)=-\cos (\theta) \ddot{X}_{y} / R_{c}
$$

Pasquetti (2008) desenvolveu um procedimento analítico com base em séries de Taylor e, com base neste procedimento, derivou de forma bastante precisa a relação não linear frequência-amplitude do pêndulo, válida para grandes amplitudes, sendo esta dada por:

$$
\begin{aligned}
& \theta_{0} \omega^{8}-\frac{\pi^{2}}{8} \sin \left(\theta_{0}\right) \omega^{6}+\frac{\pi^{4}}{384} \cos \left(\theta_{0}\right) \sin \left(\theta_{0}\right) \omega^{4}- \\
& \frac{\pi^{6}}{46080} \sin \left(\theta_{0}\right)\left(4 \cos ^{2}\left(\theta_{0}\right)-3\right) \omega^{2}+ \\
& \frac{\pi^{8}}{10321920} \cos \left(\theta_{0}\right) \sin \left(\theta_{0}\right)\left(34 \cos ^{2}\left(\theta_{0}\right)-33\right)=0
\end{aligned}
$$

onde $\theta_{0}$ é a amplitude de vibração e $\omega$ a frequência não linear.

A Figura 3-3 mostra a relação frequência-amplitude dada pela Eq.(3.14) e a comparação da mesma com a solução numérica obtida pelo método de RungeKutta de quarta ordem (RK4). O pêndulo exibe um comportamento não linear com perda de rigidez (softening) onde a frequência tende a zero quando a amplitude de vibração $\theta_{0} \rightarrow \pm \pi$, que corresponde ao pêndulo na posição invertida (configuração instável). 


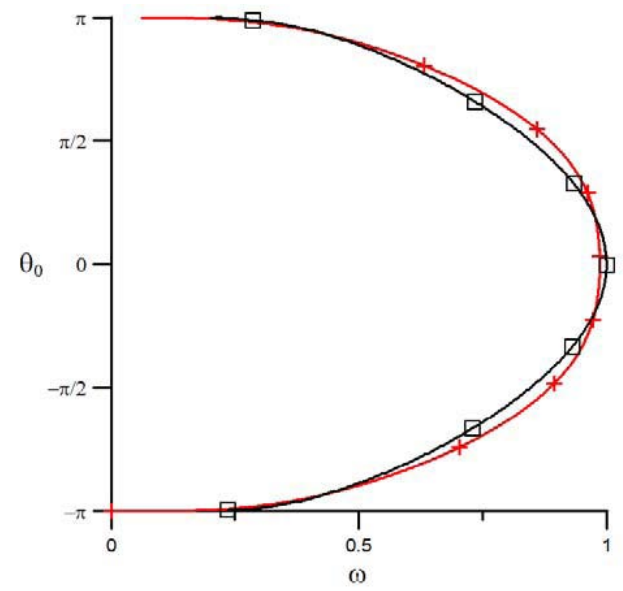

Figura 3-3 Relação não linear frequência-amplitude obtida por integração numérica (RK4 em preto) e pela Eq.(3.14) (Pasquetti (2008), em vermelho)

A Figura 3-4 mostra o diagrama de bifurcação do sistema pendular descrito pela equação (3.11), na forma adimensional (curva de ressonância) considerando uma excitação harmônica de base $\left(d^{2} \bar{X}_{g} / d \tau^{2}=0,121 \beta^{2} \operatorname{sen}(\beta \tau)\right)$, onde se mostra que o pêndulo apresenta um comportamento não linear com perda de rigidez e pode apresentar mudanças bruscas de amplitude em virtude de bifurcações nó-sela ao longo da curva de ressonância não linear.

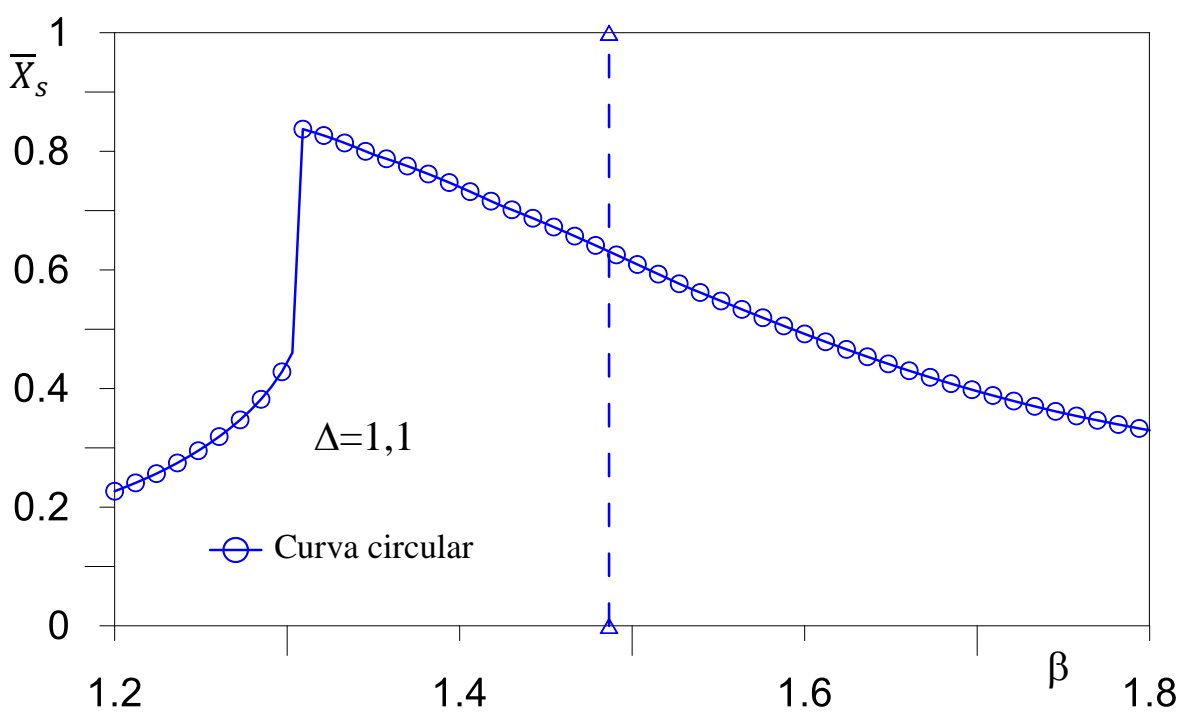

Figura 3-4 Diagrama de bifurcação dos deslocamentos da estrutura com IBP de curva circular. 


\section{1.}

\section{Fatores limitantes}

\subsection{1.}

\section{Início do movimento}

Para a massa $M_{a}$ entrar em movimento, é necessária uma força mínima que seja capaz de ultrapassar a força de atrito gerada pelo contato do material do cilindro com o material da superfície curva. Tsai et al. (2006) verificaram que a resistência ao rolamento é em geral bem menor que a resistência ao deslizamento na mesma superfície na maioria dos aparelhos de apoio. Eles estudaram a aceleração de base que inicia o movimento em um isolador de base com um cilindro que se desloca sobre um plano inclinado (superfície na forma de "V"). Aqui se considera o caso de uma superfície circular.

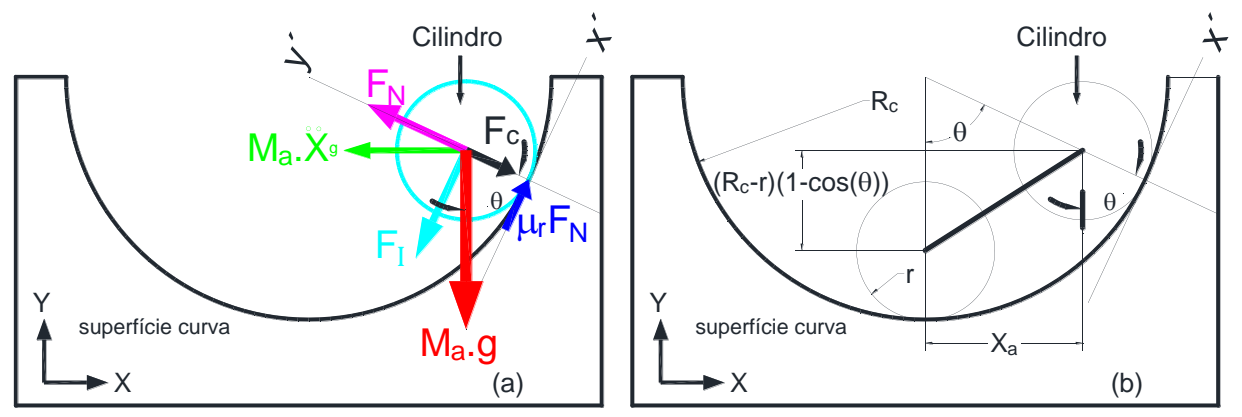

Figura 3-5 Diagrama de corpo livre do APMS (a) e relações geométricas (b)

Na Figura 3-5 é mostrado o diagrama de corpo livre de um cilindro de raio $r$ que se movimenta sobre uma superfície curva de raio de curvatura $R_{c}$, submetido a uma aceleração horizontal $\ddot{X}_{g}$. Fazendo-se o somatório de forças na direção X, se tem a seguinte equação:

$$
M_{a} \ddot{X}_{g}+F_{I} \cos (\theta)+F_{N} \sin (\theta)+\mu_{r} F_{N} \cos (\theta) \operatorname{sign}(\dot{\theta})-F_{c} \sin (\theta)=0
$$

onde $F_{c}=M_{a} R_{c}(\dot{\theta})^{2}$ é a força centrípeta, $F_{I}=M_{a} R_{c} \ddot{\theta}$ é a força de inércia devida ao movimento pendular e $F_{N}$ é a força normal da massa em movimento. O coeficiente de atrito $\mu_{r}$ é definido como a razão do coeficiente de resistência ao rolamento e o raio do rolamento (Shames, 1996).

Fazendo-se somatório de forças na direção $\mathrm{Y}^{\prime}$, obtém-se para a força normal: 


$$
F_{N}=F_{c}+M_{a} g \cos (\theta)-M_{a} \ddot{X}_{g} \sin (\theta)
$$

Cabe ressaltar que a massa na Eq.(3.16) no caso do APMS é a massa total $M_{a}$ divida pelo número de pontos de apoio, que depende do número de cilindros e do número de pontos de contato de cada cilindro com as guias circulares (ver Figura 3-5).

Considerando $\theta \geq 0$ e $\dot{\theta} \geq 0$, o pico da aceleração da estrutura é igual a

$$
\begin{aligned}
& S_{a}=R_{c} \ddot{\theta}=R_{c} \mu_{r}(\dot{\theta})^{2}+\cos (\theta) \mu_{r} g-\sin (\theta) \mu_{r} \ddot{X}_{g}+\sin (\theta) g- \\
& \tan (\theta) \sin (\theta) g+\sec (\theta) \ddot{X}_{g}
\end{aligned}
$$

Para o caso de uma superfície circular, a mínima força horizontal para o início do movimento de rolamento $\left(S_{a}=0\right)$ é

$$
\begin{aligned}
& \left|\ddot{X}_{g}\right| \geq \cos (\theta) \sin (\theta) \mu_{r} R_{c} g-\cos (\theta) R_{c} \mu_{r}(\dot{\theta})^{2}+\mu_{r} g \cos (\theta)^{2} \\
& +g \sin (\theta)(\sin (\theta)-\cos (\theta))
\end{aligned}
$$

Estudos anteriores (Wu et al. 2004) indicam que o principal parâmetro é o valor de $\theta$. No caso da superfície circular, quando o sistema se encontra na posição de equilíbrio estático ( $\theta=0)$, tem-se, $\left|\ddot{X}_{g}\right| \geq \mu_{r}\left(g-R_{c}(\dot{\theta})^{2}\right)$.

Considerando que a velocidade inicial é nula, tem-se que, $\left|\ddot{X}_{g}\right| \geq \mu_{r} g$. O coeficiente de atrito para um suporte rolante de aço é aproximadamente 0,0018 (http://www.tribology-abc.com/abc/cof.htm). Lin et al. (1995), em seu estudo sobre sistemas de isolamento de base, adotaram para o coeficiente de atrito cinemático de rolamento valores entre 0,0007 para 0,0016, obtendo boa correlação entre resultados analíticos e experimentais. Verifica-se, pois, que uma aceleração de base da ordem de 0,0018g seria suficiente para iniciar o rolamento do sistema pendular, estando este valor, de acordo com a Tabela 3-1, no limite de percepção de uma aceleração de base. Uma descrição do atrito em sistemas rolantes pode ser encontrada em https://en.wikipedia.org/wiki/Rolling resistance, onde se encontra também uma detalhada bibliografia sobre este assunto. 
Tabela 3-1 Coeficientes de atrito rolante para diferentes tipos de material

\begin{tabular}{ll}
\hline \multicolumn{1}{c}{$\mu_{r}$} & Descrição \\
\hline $0,0003-0,0004$ & Resistencia ao rolamento puro - Roda de aço do trem sobre trilho de aço \\
$0,001-0,0015$ & Rolamentos de esferas de aço endurecido sobre aço \\
$0,001-0,0024$ & Roda de aço do trem sobre trilho de aço -Vagão de passageiros cerca de 0,0020 \\
$0,0019-0,0065$ & Roda de ferro do carro de mina sobre trilho de aço \\
$0,0022-0,005$ & Pneus de bicicleta em 120 psi e 50 km/h \\
0,0025 & Carro solar Michelin/Eco-marathon pneus \\
$0,0045-0,008$ & Pneus de caminhão grande \\
0,0055 & Pneus de bicicleta BMX usados para carros solares \\
$0,0062-0,015$ & Medido no pneu de carro \\
$0,010-0,015$ & Pneus de carros comuns sobre concreto \\
$0,0385-0,073$ & Carruagem (século 19) na estrada de terra, neve macia na estrada \\
0,3 & Pneus de carros comuns na areia \\
\hline
\end{tabular}

\subsection{2.}

\section{Rolamento sem deslizamento}

Para garantir o rolamento do cilindro sobre a superfície circular sem que este deslize, o torque que gera a força de atrito no centro do cilindro precisa ser maior que o torque que gera o movimento rotatório do cilindro. Defina-se o torque do cilindro como a variação do momento angular

$$
\frac{d(I \omega)}{d t}=\frac{d}{d t}\left(\frac{I}{r} \frac{d X_{a}}{d t}\right)=\frac{I}{r} \frac{d^{2} X_{a}}{d t^{2}}
$$

onde $I$ é o momento de inércia de massa do cilindro e $r$ é o raio do cilindro. $\mathrm{O}$ torque devido à força de atrito no centro de gravidade do cilindro é

$$
F T=\mu_{s} F_{N} r=\mu_{s}\left(M_{a} R_{c}(\dot{\theta})^{2}+M_{a} g \cos (\theta)-M_{a} \ddot{X}_{g} \sin (\theta)\right) r
$$

$\log 0$

$$
F T \geq \frac{I}{r} \frac{d^{2} X_{a}}{d t^{2}}
$$

Considerando a massa adicional do amortecedor pendular concentrada no cilindro, o momento de inércia rotacional é definido por

$$
I=\frac{2}{5}\left(M_{a}+M_{r}\right) r^{2}
$$

Como a massa $M_{a} \gg M_{r}$, então $M_{a}+M_{r} \cong M_{a}$, e da Eq.((3.21)) se tem que: 


$$
\mu_{s} \geq \frac{2}{5} \frac{r \ddot{X}_{a}}{\dot{X}_{a}^{2}-R_{c} \ddot{X}_{a} \sin (\theta)+g R_{c} \cos (\theta)}
$$

A energia cinética total do cilindro é definida como

$$
\begin{aligned}
& T=\frac{1}{2} M_{a}\left(\dot{X}_{a}\right)^{2}+\frac{1}{2} I\left(\frac{\dot{X}_{a}}{r}\right)^{2} \\
& T:=\frac{1}{10} M_{a} \dot{X}_{a}^{2}\left(\frac{5 R_{c}^{2}+2 r^{2}}{R_{c}^{2}}\right)
\end{aligned}
$$

A energia potencial do sistema é definida como

$$
V=g M_{a}\left(R_{c}-r\right)(1-\cos (\theta))
$$

Considerando que a energia é conservada (quando o cilindro não escorrega), a energia cinética total do cilindro é transformada em energia potencial e tem-se

$$
\dot{X}_{a}^{2}=\frac{10 g R_{c}^{2}\left(R_{c}-r\right)(1-\cos (\theta))}{5 R_{c}^{2}+2 r^{2}}
$$

Derivando a Eq.(3.26) em função do tempo, se obtém a seguinte equação

$$
\ddot{X}_{a}=\frac{\mathrm{R}_{c} \mu_{r} \mathrm{~g} \cos (\theta)^{2}-\sin (\theta)\left(\mathrm{R}_{c} \mathrm{~g} \cos (\theta)-\dot{X}_{a}^{2}\right)+\dot{X}_{a}^{2}\left(\mu_{r} \cos (\theta)+1\right)}{R_{c}\left(\mu_{r} \sin (\theta) \cos (\theta)+\cos (\theta)^{2}\right)}
$$

Substituindo a Eq.(3.26) e Eq.(3.27) na Eq.(3.23), obtém-se o coeficiente de atrito mínimo entre o cilindro e a superfície curva para ter rolamento e não deslizamento:

$$
\begin{aligned}
& 5 R_{c}^{2} r(\sin (2 \theta)-4 \cos (\theta)-4 \sin (\theta)+4)+ \\
& \mu_{s} \geq \frac{10 R_{c} r^{2}(-\sin (2 \theta)+2 \cos (\theta)+2 \sin (\theta)-2)-2 r^{3} \sin (2 \theta)}{5 R_{c}^{2} r(\cos (2 \theta)-5 \sin (2 \theta)+6 \cos (\theta)+10 \sin (\theta))+} \\
& 10 R_{c} r^{2}(-\cos (2 \theta)+3 \cos (\theta)-1)-r^{3}(2 \cos (2 \theta)+2)+ \\
& 25 R_{c}^{3}(\sin (2 \theta)-\cos (\theta)-2 \sin (\theta)+2)
\end{aligned}
$$

Cabe ressaltar que o deslizamento causa o aparecimento de forças não lineares de difícil descrição. A Tabela 3-2 mostra valores do coeficiente de atrito estático e cinemático para o contato entre diferentes tipos de materiais. Verifica-se que estes valores são bem superiores ao atrito em suportes rolantes (http://www.tribology-abc.com/abc/cof.htm). 
Tabela 3-2 Coeficiente de atrito estático e cinemático de alguns materiais

\begin{tabular}{lcccc}
\hline & \multicolumn{2}{c}{ Estático } & \multicolumn{2}{c}{ Cinemático } \\
\cline { 2 - 5 } \multicolumn{1}{c}{ Material } & $\begin{array}{c}\text { Seco e } \\
\text { limpo }\end{array}$ & Lubrificado & $\begin{array}{c}\text { Seco e } \\
\text { limpo }\end{array}$ & Lubrificado \\
\hline Aço - Aço & 0,74 & 0,16 & 0,57 & \\
Alumínio - Aço & 0,61 & & 0,47 & \\
Cobre - Aço & 0,53 & & 0,36 & \\
Borracha - Concreto & 1,0 & 0,3 (molhado) & 0,8 & 0,45 (molhado) \\
Metal lubrificado - metal & 0,15 & & 0,06 & \\
Teflon - Teflon & 0,04 & 0,04 & 0,04 & \\
Bronze - Aço & 0,35 & 0,19 & 0,44 & \\
Polietileno - Aço & 0,2 & 0,2 & & \\
Aço - Teflon & 0,04 & 0,04 & & 0,04 \\
\hline
\end{tabular}

\subsection{3.}

\section{Volta à posição original}

A volta da massa adicional $M_{a}$ à posição inicial após o deslocamento pelo efeito do movimento de base é função da força restauradora, e necessita ser maior do que a força de atrito deslizante. A AASHTO(2000) exige que a força restauradora seja maior ou igual do que 1,05 vezes a resistência característica de rolamento.

$$
F_{s} \geq 1,05 \mu_{r} F_{N}
$$

Portanto, a máxima força de atrito permissível é

$$
\mu_{r} F_{N}=\frac{F_{S}}{1.05}
$$

\section{2.}

\section{Detalhes de projeto}

A Figura 3-6 mostra o projeto do sistema de apoio proposto por Lee et. al. (2009) onde o cilindro se desloca sobre uma superfície em V. Na Figura 3-8 é mostrado um pequeno protótipo de um sistema pendular com superfície curva. O sistema proposto por Lee et. al. (2009) tem a desvantagem de introduzir uma descontinuidade na declividade que gera uma não linearidade indesejável e exigir forças elevadas para o início do movimento em função da declividade inicial das duas rampas, o que não acontece com o sistema aqui proposto. Cabe ressaltar que o sistema pendular pode ser projetado para controle do movimento em duas direções perpendiculares, como ilustra a Figura 3-6, o que é interessante no caso 
de sismos. Sendo o amortecimento pequeno em virtude do baixo coeficiente de atrito, seu valor pode ser aumentado através do uso de amortecedores viscosos de torção que podem ser acoplados ao eixo de cada cilindro, Figura 3-8-(b) (Nestorides, 1958).

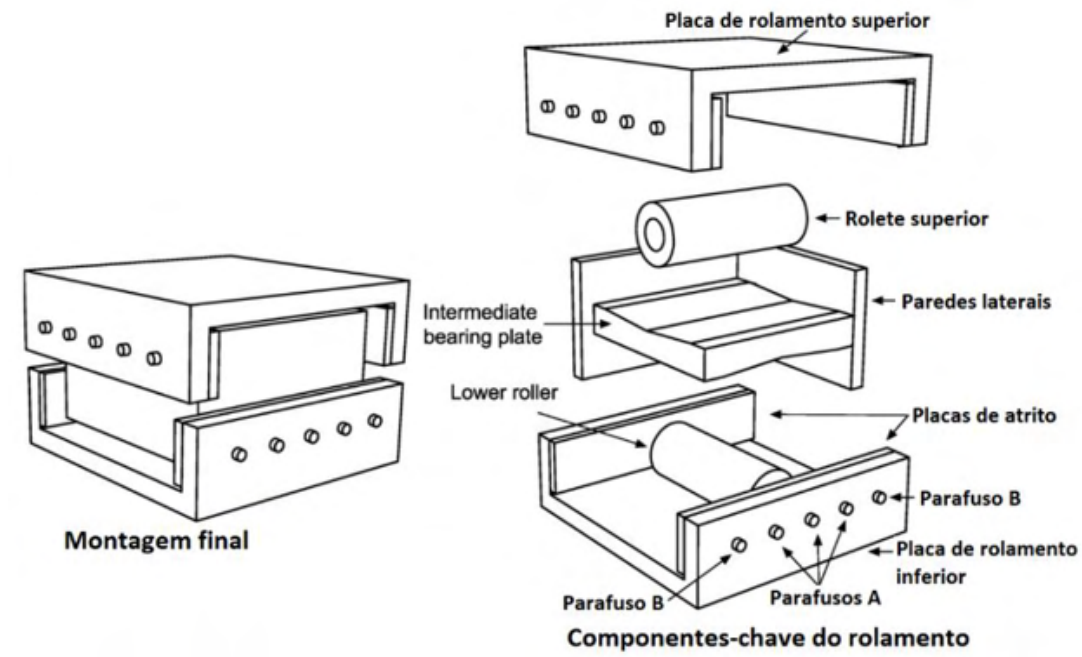

Figura 3-6 Esquema simplificado do aparelho para o sistema pendular proposto por Lee et al. (2009)
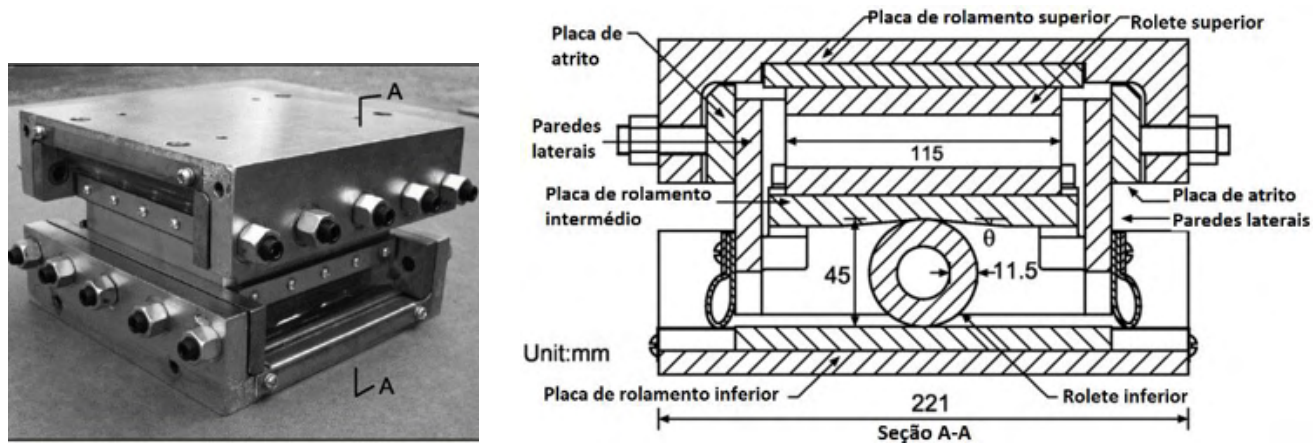

Figura 3-7 Protótipo do sistema pendular

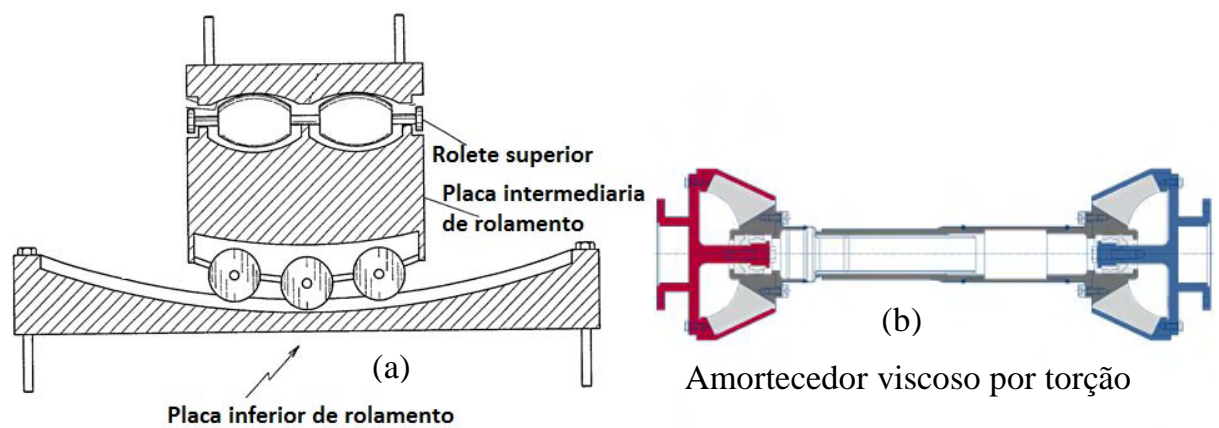

Figura 3-8 (a) Esquema simplificado do sistema pendular com superfície curva para controle de movimento em duas direções perpendiculares, (b) amortecedor de torção (http://www.vibromech.com/customer/presentation/VESL-

Full\%20Scope\%20Supplier\%2020-Nov-06.pdf) 


\section{4 \\ Controle passivo - amortecedor pendular de massa sintonizado}

O controle de vibrações em estruturas de edificações novas ou existentes tem demostrado nos últimos anos ser uma solução ótima para evitar danos ou colapso durante na presença de cargas dinâmicas. Apresenta-se neste capítulo uma proposta de controle passivo de vibrações através do amortecedor pendular de massa sintonizada (APMS) apresentado no capítulo anterior.

O sistema dinâmico é formado por uma estrutura principal, neste caso, uma estrutura tipo shear frame de massa $M_{S}$, rigidez lateral $K_{S}$ e coeficiente de amortecimento $C_{S}$, submetida a um movimento de base $X_{g}$, com o amortecedor pendular localizado no topo da estrutura principal, como ilustrado na Figura 4-1(a). O amortecedor pendular é por sua vez é constituído por uma massa adicional $M_{a}$ que se desloca sobre uma superfície côncava Figura 4-1-(b), com coeficiente de amortecimento $C_{a}$ formado assim um sistema de dois graus de liberdade Emiliano et al -(2009).

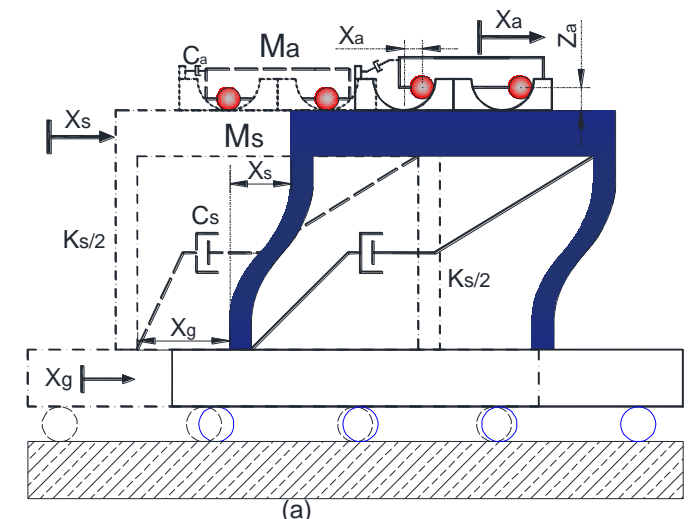

(a)

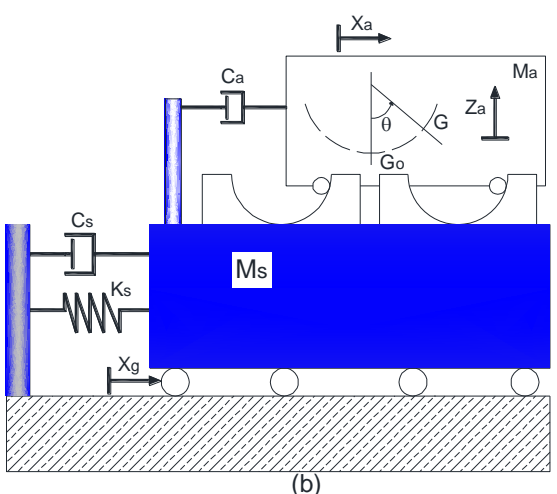

(b)

Figura 4-1 Amortecedor pendular de massa sintonizada

\section{1.}

\section{Estrutura com amortecedor pendular de massa sintonizada}

O movimento da estrutura principal é caracterizado pela coordenada generalizada $X_{S}$, enquanto o movimento pendular do amortecedor é descrito pela componente horizontal da massa adicional $X_{a}$ e pela componente vertical $Z_{a}$. 
Estas duas componentes são correlacionadas através da equação que descreve a superfície côncava.

A seguir, apresenta-se a dedução das equações de movimento considerando uma superfície curva circular de raio de curvatura $R_{c}$. No Capítulo 6 outros tipos de superfície com curvatura variável e seu efeito no controle de vibrações são estudados.

Energia cinética da estrutura é dada por:

$$
T_{S}=\frac{1}{2} M_{s}\left(\dot{X}_{g}+\dot{X}_{s}\right)^{2}
$$

A energia cinética do sistema pendular é por sua vez dada por

$$
T_{a}=\frac{1}{2} M_{a}\left(\left(\dot{X}_{g}+\dot{X}_{s}+\dot{X}_{a}\right)^{2}+\dot{Z}_{a}^{2}\right)
$$

A energia interna de deformação da estrutura é dada em função do seu deslocamento e da sua rigidez lateral, ou seja:

$$
U_{s}=\frac{1}{2} K_{s} X_{s}^{2}
$$

A energia potencial da massa gravitacional do amortecedor pendular é dada por

$$
V_{a}=M a \cdot g \cdot Z_{a}
$$

Considerando-se um amortecimento viscoso linear, as forças de amortecimento são função do coeficiente de amortecimento e da velocidade da estrutura e da massa adicional. A função de Rayleigh neste caso é dada por

$$
\begin{gathered}
R_{s}=\frac{1}{2} C_{s}\left(\dot{X}_{s}\right)^{2} \\
R_{a}=\frac{1}{2} C_{a}\left(\dot{X}_{a}^{2}+\dot{Z}_{a}^{2}\right)
\end{gathered}
$$

O deslocamento horizontal e vertical da massa para uma superfície circular é dado pelas seguintes expressões

-Deslocamento horizontal da massa:

$$
X_{a}=R_{c} \sin (\theta)
$$

-Deslocamento vertical da massa:

$$
Z_{a}=R_{c}(1-\cos (\theta))
$$

Definida o parâmetro que descreve a curva do pêndulo; o sistema estruturaAPMS é definido pelo grau de liberdade da estrutura principal $X_{S}$ e do pêndulo $\theta$. 
A energia cinética total do sistema em função dos dois graus de liberdade tem a seguinte forma:

$$
T=\frac{1}{2} M_{s}\left(\dot{X}_{g}+\dot{X}_{s}\right)^{2}+\frac{1}{2} M_{a}\left(\left(\dot{X}_{g}+\dot{X}_{s}+\frac{d X}{d \theta} \dot{\theta}\right)^{2}+\left(\frac{d Z_{a}}{d \theta} \dot{\theta}\right)^{2}\right)
$$

A energia potencial total do sistema é

$$
\Pi=\frac{1}{2} K_{s} X_{s}^{2}+M a \cdot g \cdot R(1-\cos (\theta))
$$

A função de dissipação de Rayleigh é dada por

$$
R=\frac{1}{2} C_{a}\left(\left(\frac{d X_{a}}{d \theta} \dot{\theta}\right)^{2}+\left(\frac{d Z_{a}}{d \theta} \dot{\theta}\right)^{2}\right)+\frac{1}{2} C_{s}\left(\dot{X}_{s}\right)^{2}
$$

A equação de Euler-Lagrange para a estrutura a ser controlada com o sistema passivo é definida da forma seguinte.

$$
\frac{d}{d t}\left(\frac{\partial T}{\partial \dot{X}_{s}}\right)-\frac{\partial T}{\partial X_{s}}+\frac{\partial \pi}{\partial X_{s}}+\frac{\partial R}{\partial \dot{X}_{s}}=0
$$

enquanto a equação de Euler -Lagrange para o APMS é dada por

$$
\frac{d}{d t}\left(\frac{\partial T}{\partial \dot{\theta}}\right)-\frac{\partial T}{\partial \theta}+\frac{\partial \pi}{\partial \theta}+\frac{\partial R}{\partial \dot{\theta}}=0
$$

Calculando cada parcela das equações de Euler-Lagrange, Eq.4.12 e Eq. 4.13, obtém-se o sistema de equações diferenciais que descreve o comportamento dinâmico do sistema em análise, a saber:

$$
\begin{aligned}
& M_{s}\left(\ddot{X}_{g}+\ddot{X}_{s}\right)+M_{a}\left(\ddot{X}_{g}+\ddot{X}_{s}+R \cos (\theta) \ddot{\theta}-R \sin (\theta)(\dot{\theta})^{2}\right)+ \\
& C_{s} \dot{X}_{s}+K_{s} X_{s}=0 \\
& \left(M_{a}\left(\cos (\theta) \ddot{X}_{g}+R \ddot{\theta}+g \sin (\theta)+\cos (\theta) \ddot{X}_{s}\right)+C_{a} R \dot{\theta}\right) R=0
\end{aligned}
$$

\subsection{1.}

\section{Equações de movimento na forma adimensional}

Os parâmetros adimensionais para expressar as Eqs.4.14 e 4.15 foram definidos nos dois capítulos anteriores, itens 2.4, 2.6 e 3.1. Neste caso redefinimos o parâmetro $\delta$ agora em função da massa adicional $M_{a}$ e da massa da estrutura principal $M_{S}$, ou seja:

$$
\delta=\frac{M_{a}}{M_{S}}
$$


O sistema de equações diferenciais Eq.4.14 e 4.15 na forma adimensional é obtido substituindo os parâmetros adimensionais anteriormente definidos, obtendo-se as seguintes equações:

$$
\begin{aligned}
& (\delta+1)\left(\frac{d^{2} \bar{X}_{S}}{d \tau^{2}}+\frac{d^{2} \bar{X}_{g}}{d \tau^{2}}\right)+\delta \cos (\theta) \frac{d^{2} \theta}{d \tau^{2}}+2 \xi_{s} \frac{d \bar{X}_{S}}{d \tau}- \\
& \delta \sin (\theta)\left(\frac{d \theta}{d \tau}\right)^{2}+\bar{X}_{s}=0 \\
& \delta \cos (\theta)\left(\frac{d^{2} \bar{X}_{S}}{d \tau^{2}}+\frac{d^{2} \bar{X}_{g}}{d \tau^{2}}\right)+\delta \frac{d^{2} \theta}{d \tau^{2}}+2 \delta \Delta \xi_{a} \frac{d \theta}{d \tau}+ \\
& \Delta^{2} \delta \sin (\theta)=0
\end{aligned}
$$

As equações de movimento na forma adimensional Eqs.4.16 e 4.17 encontram-se em função de 4 parâmetros, taxa de amortecimento da estrutura e APMS, $\xi_{s} e \xi_{a}$, respectivamente, a razão de massas $\delta$ e razão de frequências naturais $\Delta$. A principal variável em termos de projeto deste tipo de sistemas é o parâmetro $\delta$. Definido o valor $\delta$, podem ser calculados os valores ótimos para $\xi_{a}$, $\xi_{S}$ e $\Delta$ em função de $\delta$.

A parcela da força de amortecimento nas equações de movimento do sistema tem muita influência na resposta da estrutura em termos de deslocamento, aceleração e rotações do APMS. No Cap-2.5 é definido a força de amortecimento com comportamento não linear, Eq.2.28. Modificando a parcela de amortecimento do APMS na Eq.4.15 em função da Eq. 2.29, chega-se à seguinte expressão para a equação de movimento de movimento:

$$
\begin{aligned}
& \delta \cos (\theta)\left(\frac{d^{2} \bar{X}_{S}}{d \tau^{2}}+\frac{d^{2} \bar{X}_{g}}{d \tau^{2}}\right)+\delta \frac{d^{2} \theta}{d \tau^{2}}+2 \delta \Delta \xi_{a} R_{c}^{\alpha-1} \omega_{S}^{\alpha-1} \frac{d \theta}{d \tau}+ \\
& \Delta^{2} \delta \sin (\theta)=0
\end{aligned}
$$

Na Eq.4.18, a variável $\alpha$ faz com que o amortecedor tenha um comportamento não linear, para $\alpha \neq 1$. 


\section{2.}

\section{Frequências e modos de vibração}

Da linearização das Eqs.4.14 e 4.15, obtém-se o problema de autovalor generalizado:

$$
\left[\begin{array}{cc}
K_{s}-\lambda\left(M_{a}+M_{s}\right) & -\lambda R \cdot M_{a} \\
-\lambda M_{a} & M_{a} \cdot g-\lambda R \cdot M_{a}
\end{array}\right]\left\{\begin{array}{l}
X_{1} \\
X_{2}
\end{array}\right\}=\left\{\begin{array}{l}
0 \\
0
\end{array}\right\}
$$

onde $\lambda=\omega_{i}^{2}$ e os autovalores e autovetores representam respectivamente as frequências naturais e modos de vibração do sistema em análise. As frequências naturais são dadas em termos da rigidez da estrutura principal, das massas da estrutura principal e do APMS e da aceleração da gravidade por:

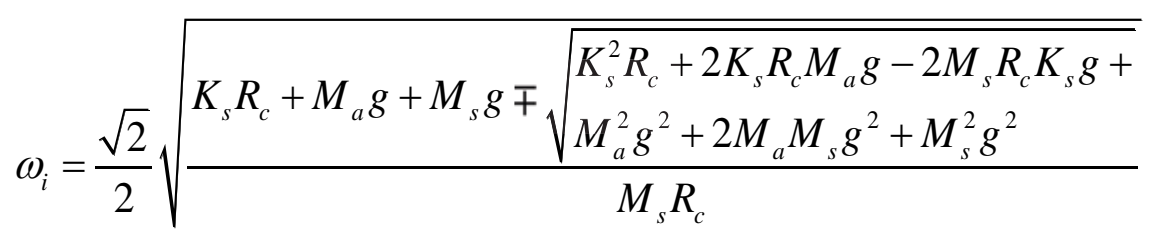

As duas frequências naturais do sistema em função dos parâmetros adimensionais, tomam a forma seguinte:

$$
\bar{\omega}_{i}=\frac{1}{2} \sqrt{2 \delta \Delta^{2}+2 \Delta^{2}+2 \mp 2 \sqrt{\delta^{2} \Delta^{4}+2 \delta \Delta^{4}+\Delta^{4}+2 \delta \Delta^{2}-2 \Delta^{2}+1}}
$$

Pode-se observar que, as duas frequências naturais dependem somente da razão de massas $\delta$ e frequências $\Delta$. Como esperado, na forma adimensional, a Eq. 4.21 é similar à Eq. 2.9, embora sejam diferentes na forma dimensional. Isto é, o sistema linearizado depende igualmente dos mesmos parâmetros adimensionais. A Figura 4-2 mostra a variação das duas frequências naturais em função da razão de frequências $\Delta$ para valores selecionados da razão de massas $\delta$. Para valores usuais de $\delta$, a primeira frequência cresce suavemente com $\Delta$, a partir de zero (raio de curvatura infinito), enquanto a segunda permanece praticamente constante e igual a unidade até atingir o valor $\Delta=1$, quando as duas frequências normalizadas se aproximam do valor unitário (valor ideal para o AMS clássico). A partir deste ponto, as duas frequências invertem o comportamento, crescendo a segunda frequência de forma praticamente linear enquanto a primeira tende a um valor constante. 


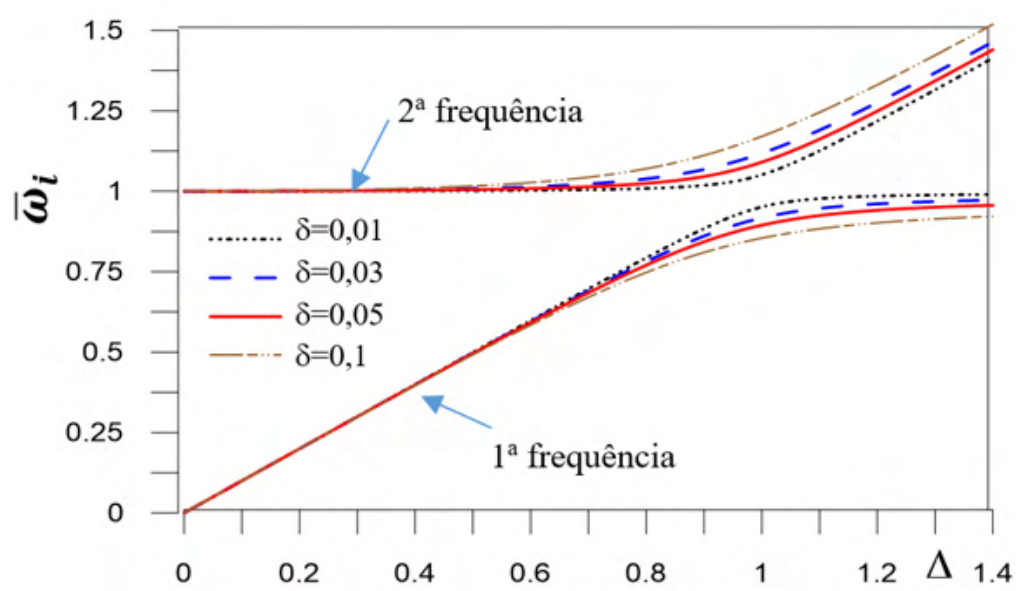

Figura 4-2 Variação das frequências naturais em função dos parâmetros adimensionais ( $\Delta \mathrm{e}$ $\delta)$.
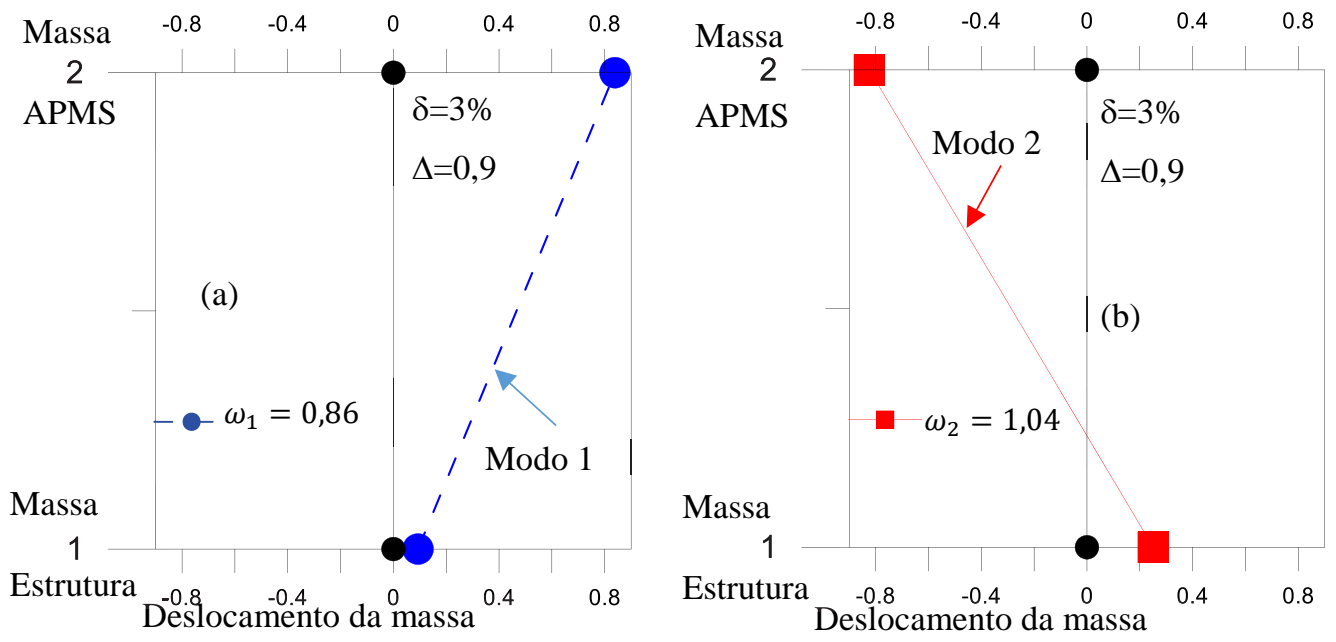

Figura 4-3 Modos de vibração da estrutura com APMS, (a) primeiro modo e (b) segundo modo

A Figura 4-3 mostra o primeiro e segundo modo de vibração do sistema estrutura-APMS, pode-se ver que no primeiro modo a estrutura (Massa-1) desloca-se na mesma direção que o APMS (Masssa-2), como é mostra o autovetor $X_{1}=\{0,0930,837\}^{T}$, além disso, a massa do APMS tem um deslocamento muito maior do que a massa da estrutura. No segundo modo de vibração, as massas deslocam-se em sentidos opostos segundo o autovetor $X_{2}=\{0,25-0,823\}^{T}$. Os modos de vibração demostram que a energia gerada pelo deslocamento de base da estrutura é absorvida em sua maior parte pelo APMS.

O raio do APMS é função da frequência da estrutura, da aceleração da gravidade e da frequência do sistema adicional mola-amortecedor, caso este seja 
considerado, sendo dado por $R_{c}=g /\left(\Delta^{2} \omega_{s}^{2}-\omega_{a d}^{2}\right)$. Tomando como um exemplo o edifício analisado por Ávila, (2002) (ver Tabela 4-1), obtém-se, considerando-se apenas o sistema pendular e $\Delta=1, R_{c}=0,98 m\left(g=9,8 \mathrm{~m} / \mathrm{s}^{2}\right)$. Caso se deseje aumentar o raio, pode-se fazer uso da rigidez adicional $K_{a d}$ (veja Figura 3.1) e/ou diminuir o valor de $\Delta$. O edifício Citicorp Tower em Nova York tem um período natural $\mathrm{T}=6,5 \mathrm{~s}$, que corresponde a uma frequência natural de $0,15 \mathrm{~Hz}$, ou seja, 0,94rad/s o que leva a $R_{c}=11 \mathrm{~m}$ para o APMS (Conner, 2001). Este edifício apresentou sérios problemas de vibração que foram minorados com o uso de um AMS. Veja que neste caso o uso de um pêndulo clássico seria difícil em virtude do espaço exigido para sua instalação.

Tabela 4-1 Valores básicos dos parâmetros da análise modal da estrutura tipo Shear frame (Avila, 2002)

\begin{tabular}{|c|c|c|l|}
\hline Massa modal & $M_{s}$ & 506617,43 & $\mathrm{Kg}$ \\
\hline Rigidez modal & $K_{s}$ & $5,1045 \mathrm{E}+06$ & $\mathrm{~N} / \mathrm{m}$ \\
\hline Frequência fundamental & $\omega_{s}$ & 3,17 & $\mathrm{Rad} / \mathrm{s}$ \\
\hline
\end{tabular}

\section{3. \\ Analise paramétrica da resposta permanente sob carga harmônica}

A análise paramétrica é focada em dois parâmetros: a razão de massas dentro de uma faixa de valores de $0,01 \leq \delta \leq 0,05$, e a razão de frequências naturais dentro de uma faixa de valores de $0,1 \leq \Delta \leq 1,3$, mantendo fixos os outros dois parâmetros relacionados com a taxa de amortecimento ( $\xi_{S}=$ $\left.0,02 e \xi_{a}=0,035\right)$. A força excitadora é harmônica definida como $d^{2} \bar{X}_{g} / d \tau^{2}=0,01 \Delta^{2} \beta^{2} \operatorname{sen}(\beta \tau)$.

Definidos todos os parâmetros das equações de movimento, Eq.4.16 e 4.17, é feita a integração do sistema de equações de movimento pelo método de RungeKuta de quarta ordem. Para obtenção dos diagramas de bifurcação usa-se o método da força bruta (Parker e Chua, 1989) tendo como variável de controle a frequência de excitação adimensional $\beta$. 


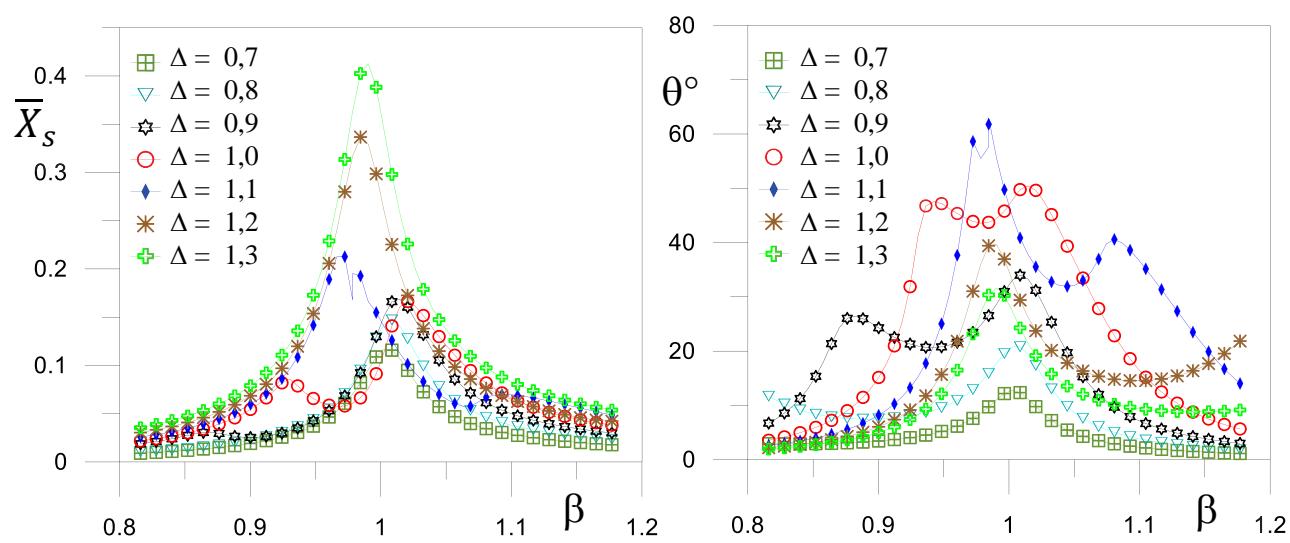

Figura 4-4 Deslocamento da estrutura e rotação do APMS em função da razão de frequências $\Delta=0,7 ; 0,8 ; 0,9 ; 1,0 ; 1,1 ; 1,2 ; 1,3$ e $(\delta=0,01)$

Na Figura 4-4 é mostrada a variação do deslocamento máximo da estrutura e rotação máxima do APMS durante o regime permanente em função do parâmetro $\Delta$ (curvas de ressonância). Para a interpretação correta dos resultados cabe lembrar que a força de excitação adimensional é dependente de $\Delta^{2}$. A Figura 4-5 mostra a variação do deslocamento máximo e aceleração máxima adimensional da estrutura com e sem APMS em função de $\Delta$. A eficiência do APMS é ilustrada na Tabela 4-2.
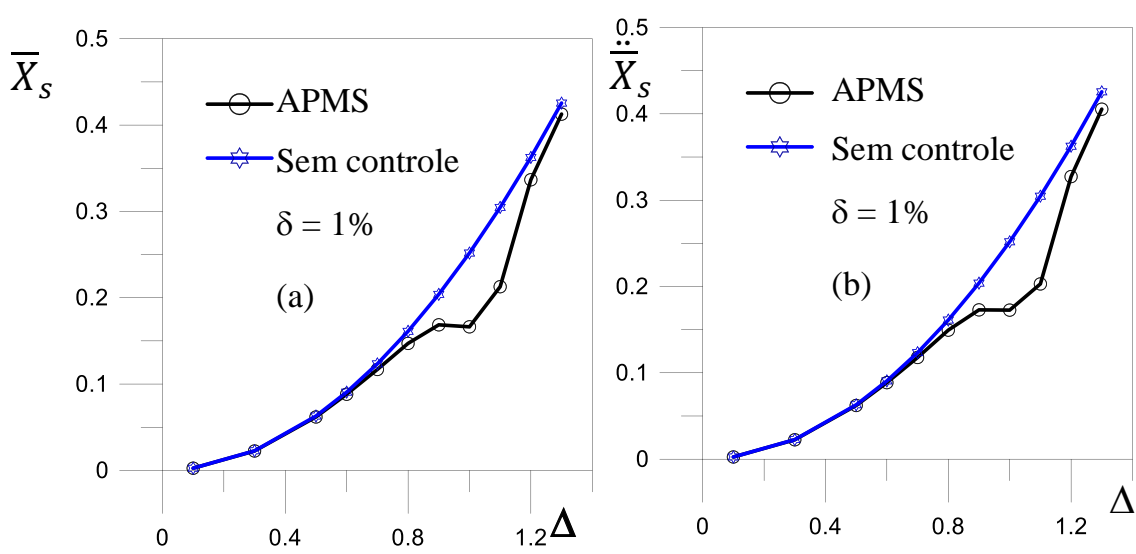

Figura 4-5 Deslocamentos e acelerações máximas da estrutura com APMS e sem controle em função de $\Delta$

Após o estudo do efeito do parâmetro $\Delta$ na estrutura sem controle e com APMS, verifica-se que a maior eficiência na redução de deslocamentos Figura 4-5-(a) e na redução das acelerações Figura 4-5-(b), acontece para valores do parâmetro $0,9 \leq \Delta \leq 1,1$. Este é o intervalo onde estão localizados os diversos 
valores ótimos encontrados na literatura. O APMS chega a diminuir os deslocamentos em até $33,95 \%$ para $\Delta=1,0$ e as acelerações em $33,33 \%$ para um valor de $\Delta=1,1$. As maiores rotações do APMS ocorrem para $\Delta=1,1$, atingindo $63^{0}$.

Tabela 4-2 Eficiência do APMS em função do valor de $\Delta$

\begin{tabular}{|c|c|c|c|c|c|c|c|c|}
\hline \multirow{3}{*}{$\begin{array}{c}\text { TIPO } \\
\text { DE } \\
\text { CURVA }\end{array}$} & \multirow{3}{*}{$\begin{array}{c}\text { Razão } \\
\text { de } \\
\text { freq. }\end{array}$} & \multicolumn{3}{|c|}{ Estrutura-APMS } & \multirow{2}{*}{\multicolumn{2}{|c|}{ Sem controle }} & \multirow{2}{*}{\multicolumn{2}{|c|}{$\begin{array}{c}\text { Eficiência } \\
(\%)\end{array}$}} \\
\hline & & \multicolumn{2}{|c|}{ Estrutura Principal } & \multirow{2}{*}{$\begin{array}{c}\text { APMS } \\
\left(\theta^{\circ}\right)\end{array}$} & & & & \\
\hline & & $\left(\bar{X}_{s}\right)$ & $\left(\ddot{\bar{X}}_{s}\right)$ & & $\left(\overline{\boldsymbol{X}}_{s}\right)$ & $\left(\ddot{\bar{X}}_{s}\right)$ & $\left(\overline{\boldsymbol{X}}_{\boldsymbol{s}}\right)$ & $\left(\ddot{\bar{X}}_{s}\right)$ \\
\hline \multirow{11}{*}{ Circular } & 0,1 & 0,00250 & 0,00251 & 0,15 & 0,00252 & 0,00252 & 0,636 & $\mathbf{0 , 0 8 5}$ \\
\hline & 0,3 & 0,02245 & 0,02245 & 1,41 & 0,02266 & 0,02265 & $\mathbf{0 , 9 5 2}$ & 0,897 \\
\hline & 0,5 & 0,06186 & 0,06216 & 4,69 & 0,06294 & 0,06291 & 1,726 & 1,185 \\
\hline & 0,6 & 0,08821 & 0,08864 & 7,80 & 0,09064 & 0,09059 & 2,682 & 2,155 \\
\hline & 0,7 & 0,11691 & 0,11780 & 12,76 & 0,12337 & 0,12330 & 5,237 & 4,458 \\
\hline & 0,8 & 0,14710 & 0,14945 & 20,80 & 0,16114 & 0,16105 & 8,710 & 7,200 \\
\hline & 0,9 & 0,16861 & 0,17294 & 33,99 & 0,20394 & 0,20383 & 17,324 & 15,155 \\
\hline & 1,0 & 0,16628 & 0,17264 & 50,45 & 0,25178 & 0,25164 & 33,956 & 31,391 \\
\hline & 1,1 & 0,21278 & 0,20297 & 63,01 & 0,30465 & 0,30448 & 30,156 & 33,339 \\
\hline & 1,2 & 0,33667 & 0,32733 & 39,66 & 0,36256 & 0,36235 & 7,139 & 9,665 \\
\hline & 1,3 & 0,41268 & 0,40540 & 31,59 & 0,42550 & 0,42526 & 3,014 & 4,671 \\
\hline
\end{tabular}

A Figura 4-6 mostra o comportamento da estrutura e do APMS para os três valores de $\Delta=0,9 ; 1,0$ e 1,1. As linhas verticais são os valores das frequências naturais de vibração do sistema estrutura-APMS, obtidas da Eq. 4.21. No caso da resposta da estrutura para $\Delta=0,9$ o maior pico dos deslocamentos acontece para a segunda frequência, mas o segundo pico é muito pequeno e encontra-se deslocado para a esquerda da primeira frequência de vibração. Para $\Delta=1,0$, o valor do pico também é para a segunda frequência, mas acontece fora do valor da frequência deslocando-se para a esquerda, mas desta vez o segundo pico é 48,1 \% menor que o segundo, também deslocado na esquerda do valor da primeira frequência. Finamente, para $\Delta=1,1$; o maior deslocamento passa a ser na vizinhança da primeira frequência de vibração, ocorrendo próximo ao valor da frequência natural, e o segundo pico é o 32,5 \% menor que primeiro. Em relação às rotações do APMS, quanto maior é o valor de $\Delta$, maior é o valor máximo da rotação neste trecho. Os deslocamentos dos picos para a esquerda são consequência da não linearidade do APMS que, como visto no Cap. 3, é do tipo softening. Verifica-se 
que a não linearidade aumenta com $\Delta$, em função do aumento do aumento das rotações do pêndulo. A Figura 4-6(c) compara para $\Delta=1,1$ a resposta controlada considerando as equações não lineares (em azul) e o sistema linearizado (em preto) com o sistema sem controle (em vermelho). Nota-se que a não linearidade tem uma influência benéfica no controle diminuindo ainda mais as amplitudes máximas de vibração na região de ressonância.
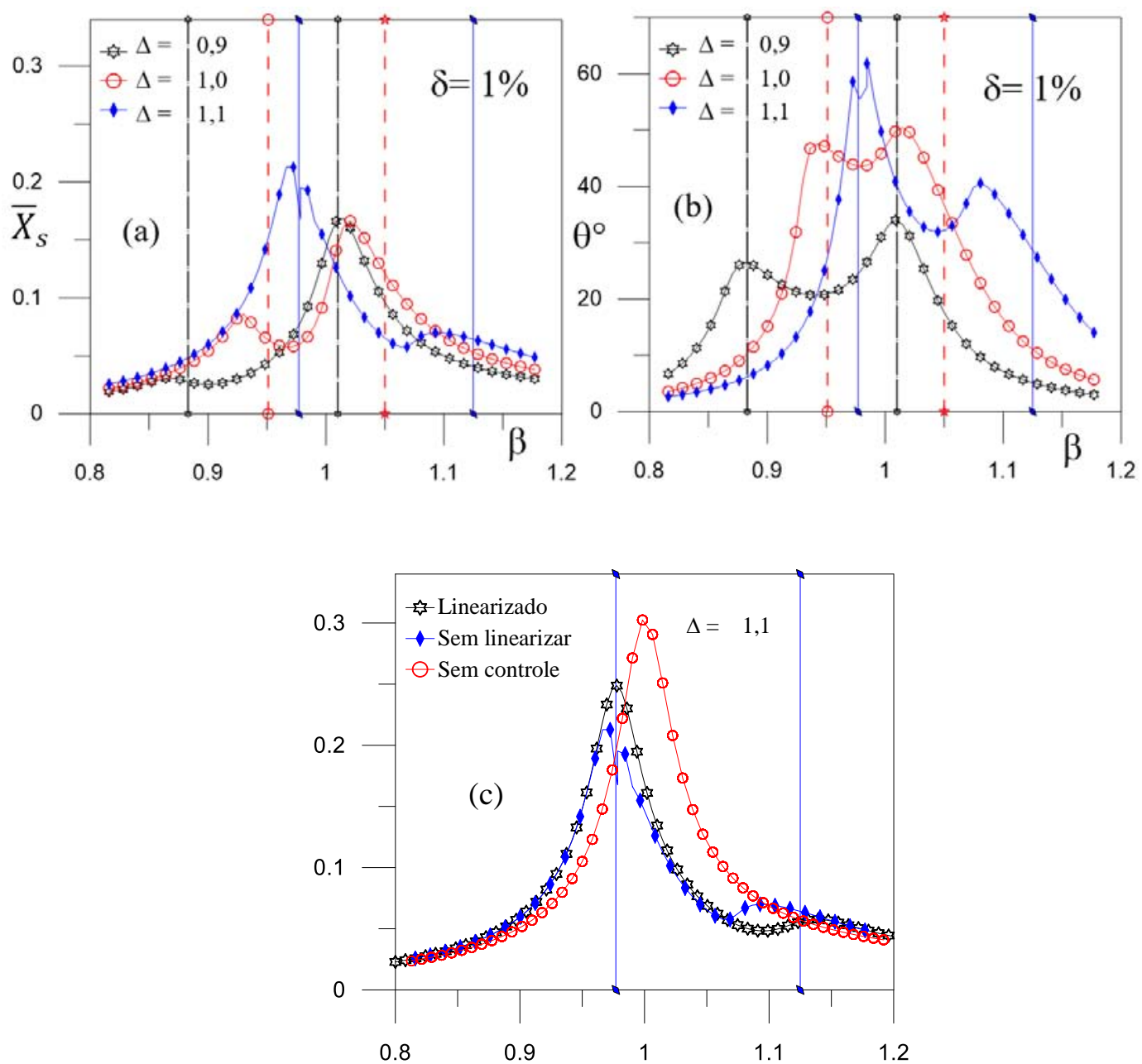

Figura 4-6 (a) Diagramas de bifurcação da estrutura, (b), do APMS e (c) comparação da resposta da estrutura sem controle, linearizada e sem linearizar. Para $\xi_{\boldsymbol{s}}=2 \%, \xi_{\boldsymbol{a}}=3,5 \%$ e $\delta=0,01$

A seguir, analisa-se a influência do parâmetro da razão de massas $\delta$, fixando-se $\Delta=0,9$. Considerando que o peso do APMS não deve sobrecarregar os elementos estruturais com o acréscimo da massa adicional no topo do prédio, um o valor máximo de $\delta=5 \%$ é adotado. 

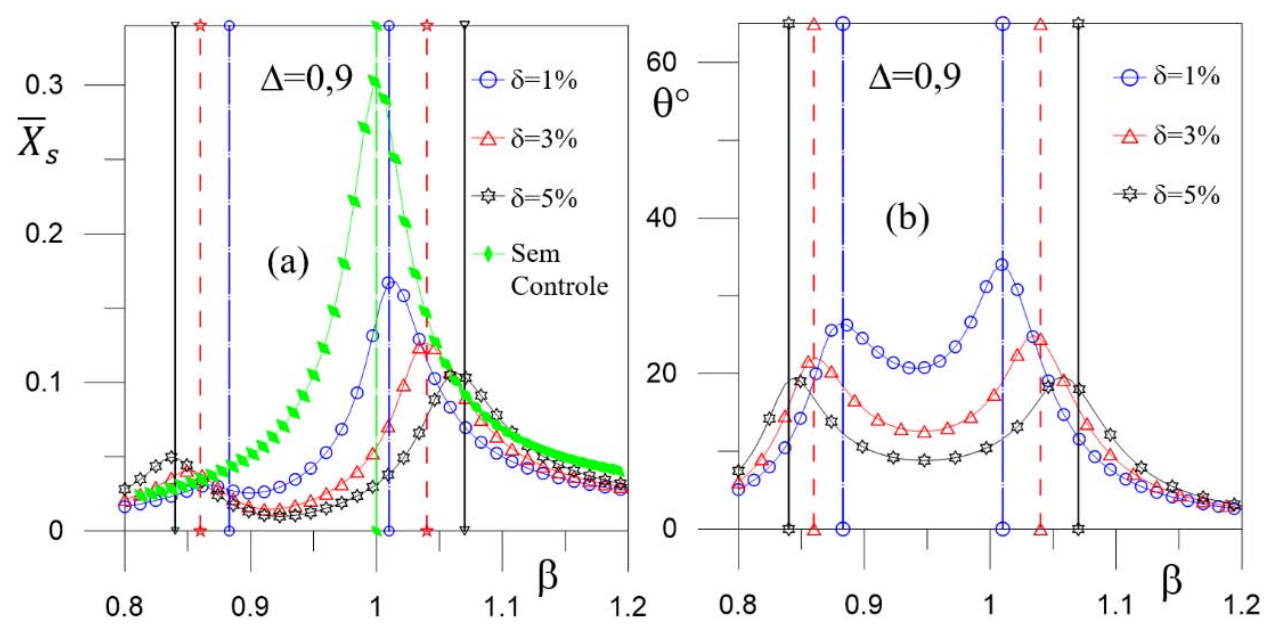

Figura 4-7 (a) Diagramas de bifurcação da estrutura, (b) do APMS, para $\xi_{\boldsymbol{s}}=2 \%, \xi_{\boldsymbol{a}}=3,5 \%$

A influência da razão de massas $\delta$ no controle de vibrações é mostrada na Figura 4-7. Verifica-se que o aumento de $\delta$ reduz tanto os deslocamentos da estrutura quanto as rotações do APMS. Comparando-se com a resposta da estrutura sem controle (em verde) observa-se claramente o efeito benéfico do APMS no controle da estrutura.

Tabela 4-3 Deslocamentos e acelerações máximas da estrutura e AMS. $\Delta=0,9 \xi_{\mathrm{s}}=$ $2 \% ; \xi_{\mathrm{s}}=3,5 \%$, (Figura $4-7$ )

\begin{tabular}{|c|c|c|c|c|c|}
\hline \multicolumn{6}{|c|}{ Estrutura-APMS } \\
\hline \multirow[b]{2}{*}{ Controle } & & \multirow{2}{*}{$\begin{array}{c}\text { Razão } \\
\text { de } \\
\text { massas }\end{array}$} & \multicolumn{2}{|c|}{ Estrutura Principal } & \multirow{2}{*}{$\begin{array}{c}\text { APMS } \\
\text { Rotação } \\
\left(^{\circ}\right)\end{array}$} \\
\hline & & & Deslocamento & Aceleração & \\
\hline \multirow{3}{*}{$\begin{array}{c}\text { AMS } \\
\text { Circular }\end{array}$} & $A$ & $1 \%$ & 0,169 & 0,173 & 34,00 \\
\hline & $\boldsymbol{B}$ & $3 \%$ & 0,127 & 0,136 & 24,87 \\
\hline & $C$ & $5 \%$ & 0,106 & 0,119 & 19,59 \\
\hline $\begin{array}{c}\text { Sem } \\
\text { Controle }\end{array}$ & $D$ & & 0,204 & 0,204 & \\
\hline \multirow{3}{*}{$\underset{\%}{\text { Redução }}$} & $D-A$ & & 17,32 & 15,15 & \\
\hline & $D-B$ & & 37,84 & 33,26 & \\
\hline & $D-C$ & & 48,01 & 41,61 & \\
\hline
\end{tabular}

A eficácia do amortecedor é apresentada na Tabela 4-3. Para $\delta=1 \%$ há uma redução de 17,32 \% em termos de deslocamento e de 15,15 \% nas acelerações da estrutura. Já para $\delta=5 \%$ a redução nos deslocamentos aumenta para $48 \%$ e nas acelerações para $41,6 \%$. 


\subsection{1.}

\section{Análise paramétrica da influência da força de amortecimento do APMS na resposta da estrutura}

O comportamento não linear do amortecedor é dado pela variável $\alpha$ que cuja influência é estudada dentro da faixa de $0,2 \leq \alpha \leq 2$. As equações de movimento usadas para avaliar a influência do parâmetro $\alpha$ são Eq. 4.16 e 4.18. Consideram-se os parâmetros $\Delta=0,9$ e $\delta=0,01$.

É apresentada na Figura 4-8 a influência da variável $\alpha$ em comparação com o valor da resposta da estrutura quando $\alpha=1$ (amortecedor linear). No eixo horizontal e representada a variável $\alpha$ e no vertical os incrementos ou reduções da resposta da estrutura e APMS. Pode-se ver que, para valores de $\alpha<1$, os deslocamentos e acelerações da estrutura e rotações do APMS são maiores que o caso linear, mas para valores de $\alpha>1$, as respostas da estrutura e APMS são menores que no caso linear.

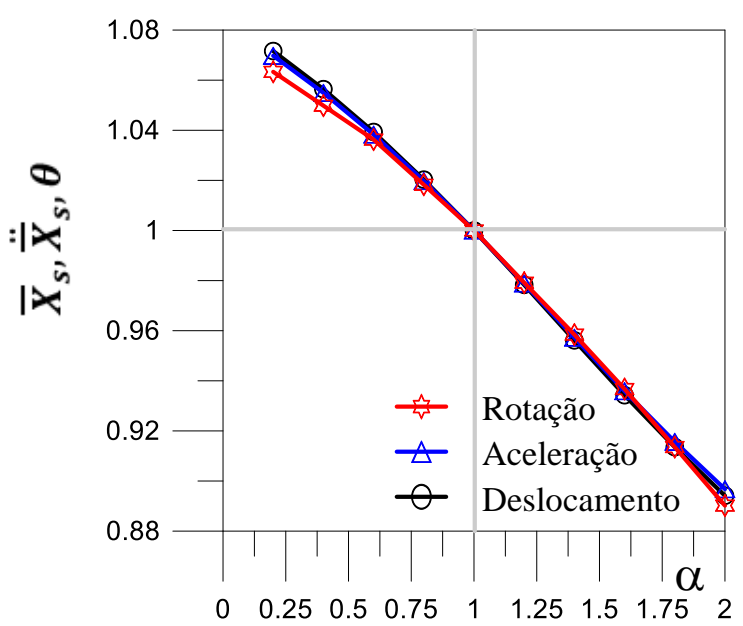

Figura 4-8 Influencia da variável $\alpha$ na resposta da estrutura e do APMS

Numericamente a influência da variável $\alpha$ é mostrada na Tabela 4-4. A referência neste caso são os valores obtidos quando $\alpha=1$. Para $\alpha=0,2$ os deslocamentos, acelerações da estrutura e rotação do APMS são 1,07 vezes os valores lineares. A eficiência melhora com o aumento de $\alpha$, ocasionando um redução de $10 \%$ para $\alpha=2$. 
Tabela 4-4 Influência da variável $(\alpha)$ do amortecimento na resposta da estrutura com APMS

\begin{tabular}{|c|c|c|c|c|c|c|c|}
\hline \multirow{3}{*}{$\begin{array}{c}\text { TIPO } \\
\text { DE } \\
\text { CURVA }\end{array}$} & \multirow{3}{*}{$\begin{array}{c}\text { Variável } \\
(\alpha)\end{array}$} & \multicolumn{6}{|c|}{ Estrutura-APMS } \\
\hline & & \multicolumn{4}{|c|}{ Estrutura Principal } & \multicolumn{2}{|c|}{ APMS } \\
\hline & & $\left(\bar{X}_{s}\right)$ & $\begin{array}{c}\text { Variação } \\
\left(\bar{X}_{s}\right)\end{array}$ & $\left(\ddot{\bar{X}}_{s}\right)$ & $\begin{array}{c}\text { Variação } \\
\left(\ddot{\bar{X}}_{s}\right)\end{array}$ & $\left(\theta^{\circ}\right)$ & $\begin{array}{c}\text { Variação } \\
\left(\theta^{\circ}\right)\end{array}$ \\
\hline \multirow{10}{*}{ Circular } & 0,2 & 0,181 & 1,07 & 0,185 & 1,07 & 36,14 & 1,06 \\
\hline & 0,4 & 0,178 & 1,06 & 0,182 & 1,05 & 35,68 & 1,05 \\
\hline & 0,6 & 0,175 & 1,04 & 0,180 & 1,04 & 35,22 & 1,04 \\
\hline & 0,8 & 0,172 & 1,02 & 0,176 & 1,02 & 34,61 & 1,02 \\
\hline & 1,0 & 0,169 & 1,00 & 0,173 & 1,00 & 33,99 & 1,00 \\
\hline & 1,2 & 0,165 & 0,98 & 0,169 & 0,98 & 33,28 & 0,98 \\
\hline & 1,4 & 0,161 & 0,96 & 0,166 & 0,96 & 32,58 & 0,96 \\
\hline & 1,6 & 0,158 & 0,93 & 0,162 & 0,94 & 31,84 & 0,94 \\
\hline & 1,8 & 0,154 & 0,91 & 0,158 & 0,92 & 31,05 & 0,91 \\
\hline & 2,0 & 0,151 & $\mathbf{0 , 8 9}$ & 0,155 & 0,90 & 30,26 & $\mathbf{0 , 8 9}$ \\
\hline
\end{tabular}

\subsection{2. \\ Análise da resposta no tempo com carga harmônica e deslocamento inicial}

A análise anterior no domínio da frequência levou em consideração apenas as reduções no regime permanente da resposta da estrutura. Sabe-se que, dependendo nas condições iniciais e do carregamento, os valores extremos podem ocorrer tanto na fase transiente quanto na fase permanente. Aqui e nos itens seguintes analisa-se a eficiência do APMS ao longo do tempo. Inicialmente considera-se uma carga harmônica com uma frequência de excitação igual à frequência natural de vibração da estrutura sem controle $(\beta=1)$, fixando-se os parâmetros $\delta=0,01, \xi_{S}=2 \% e \xi_{a}=3,5 \%$, e considerando-se $\Delta=0,9,1,0$ e 1,1 e $d^{2} \bar{X}_{g} / d \tau^{2}=0,01 \Delta^{2} \beta^{2} \operatorname{sen}(\beta \tau)$. O comportamento da estrutura e do APMS sob uma excitação de base harmônica (vibração forçada) é mostrado nas Figura 4-9 a Figura 4-14. 


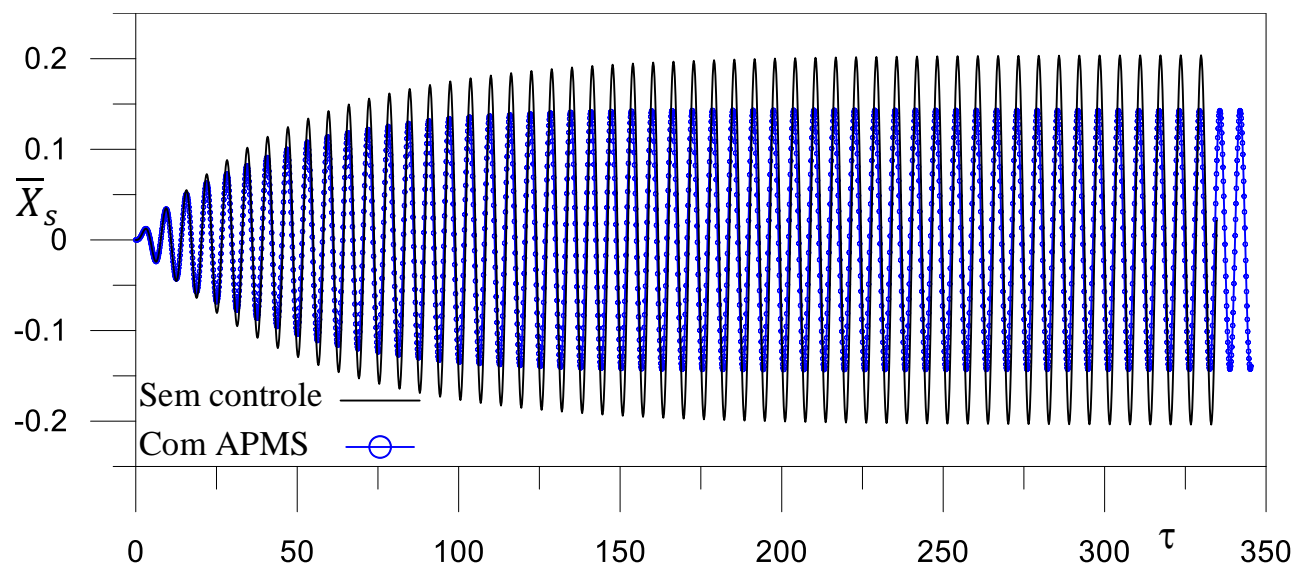

Figura 4-9 Deslocamentos da estrutura no tempo $\beta=1,0 ; \delta=0,01 ; \Delta=0,9$

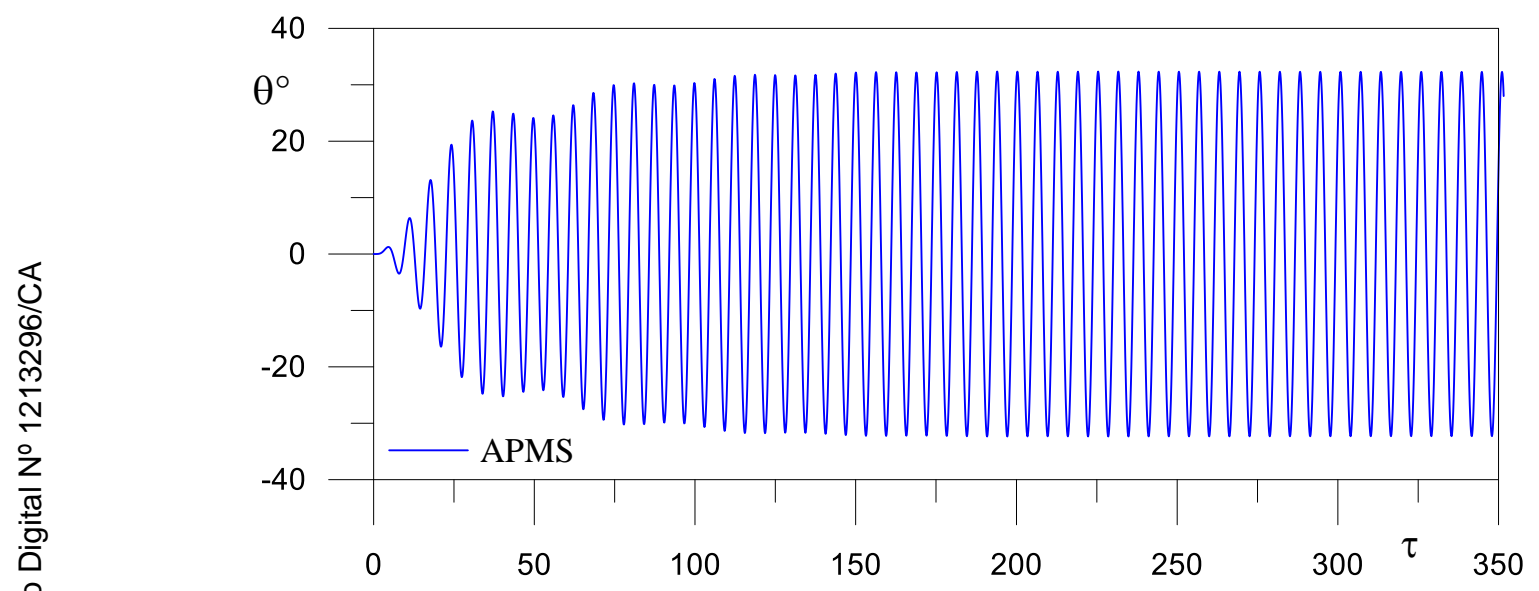

Figura 4-10 Rotações do APMS no tempo $\beta=1,0 ; \delta=0,01 ; \Delta=0,9$

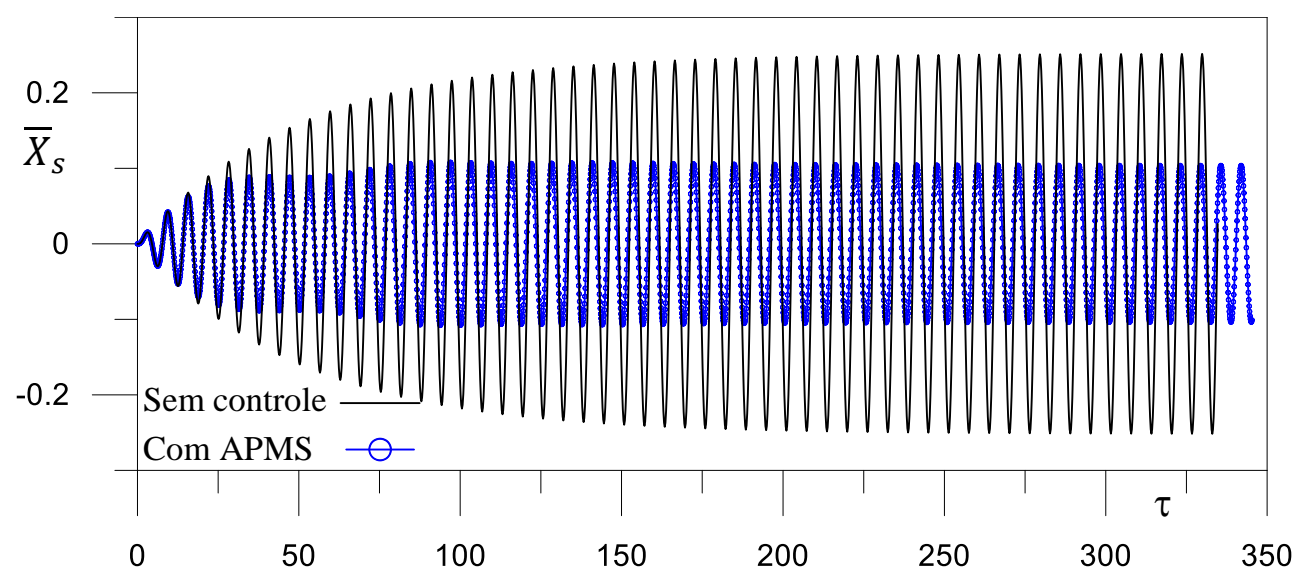

Figura 4-11 Deslocamentos da estrutura no tempo $\beta=1,0 ; \delta=0,01 ; \Delta=1,0$ 


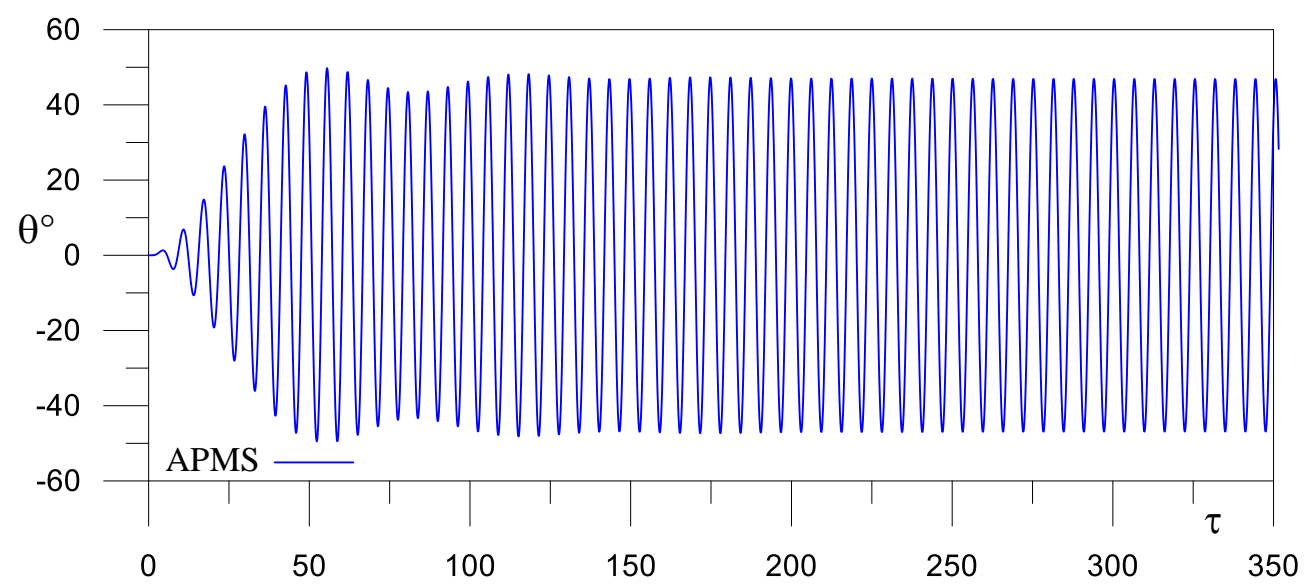

Figura 4-12 Rotações do APMS no tempo $\beta=1,0 ; \delta=0,01 ; \Delta=1,0$

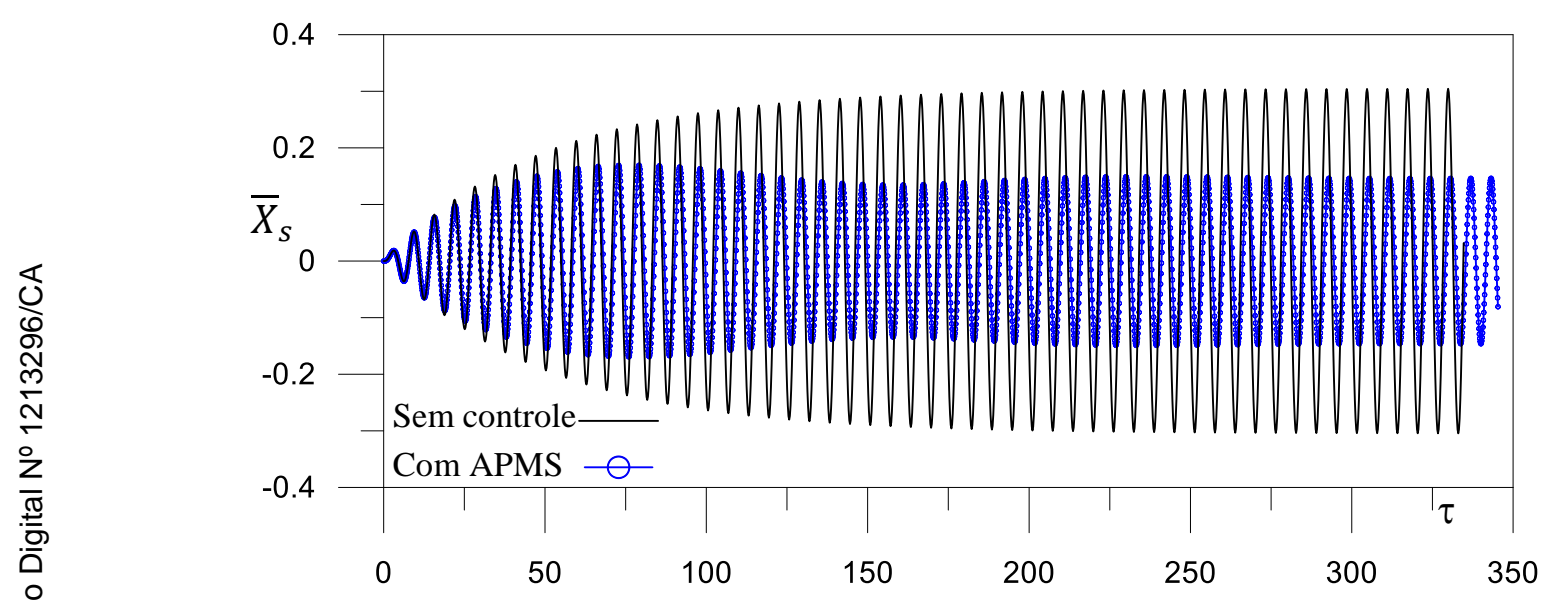

Figura 4-13 Deslocamentos da estrutura no tempo $\beta=1,0 ; \delta=0,01 ; \Delta=1,1$

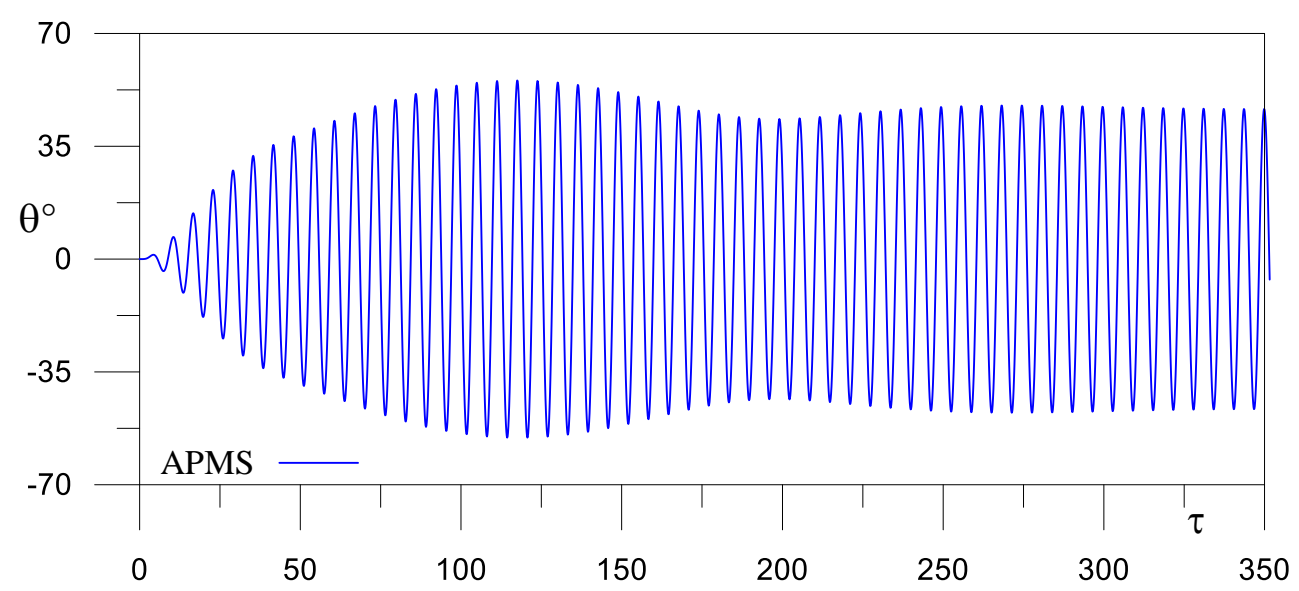

Figura 4-14 Rotações do APMS no tempo $\beta=1,0 ; \delta=0,01 ; \Delta=1,1$

No caso da estrutura com controle, o comportamento forçado para valores de $\Delta=0,9$ e 1,0 tanto a estrutura como o APMS experimentam o maior 
deslocamento e rotação no regime permanente, porém, para $\Delta=1,1$ os maiores deslocamentos e rotações da estrutura ocorrem na fase transiente. No caso da estrutura sem controle os maiores deslocamentos ocorrem na fase permanente em todos os casos. O efeito do APMS se faz sentir logo nos primeiros ciclos de vibração, sendo as oscilações da estrutura controlada consistentemente menores que as da estrutura controlada nas duas fases da resposta dinâmica.

O comportamento de vibração livre da estrutura e APMS e mostrado nas Figura 4-15 a Figura 4-20 para $\Delta=0,9 ; 1,0$ e 1,1. Os parâmetros adimensionais das equações de movimento Eq. 4.16 e 4.17 são os mesmos valores usados na vibração forçada, mas a força de excitação é nula $\left(d^{2} \bar{X}_{g} / d \tau^{2}=0\right)$. É imposto um valor inicial no deslocamento da estrutura $\bar{X}_{S}=0,1$.

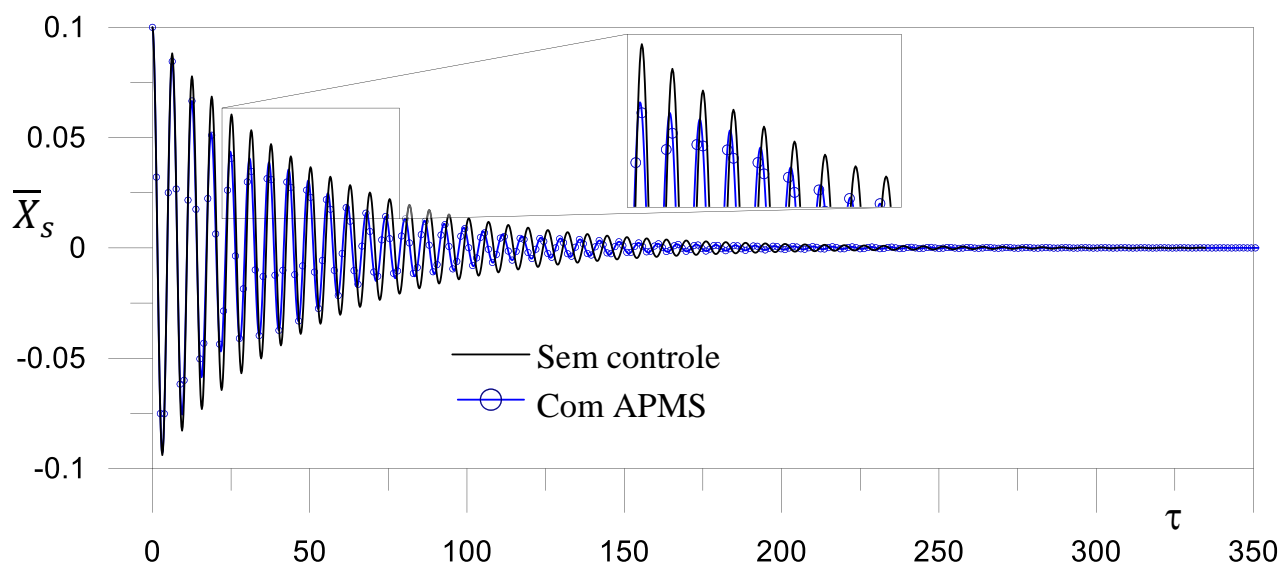

Figura 4-15 Deslocamentos da estrutura no tempo $\delta=0,01 ; \Delta=0,9$

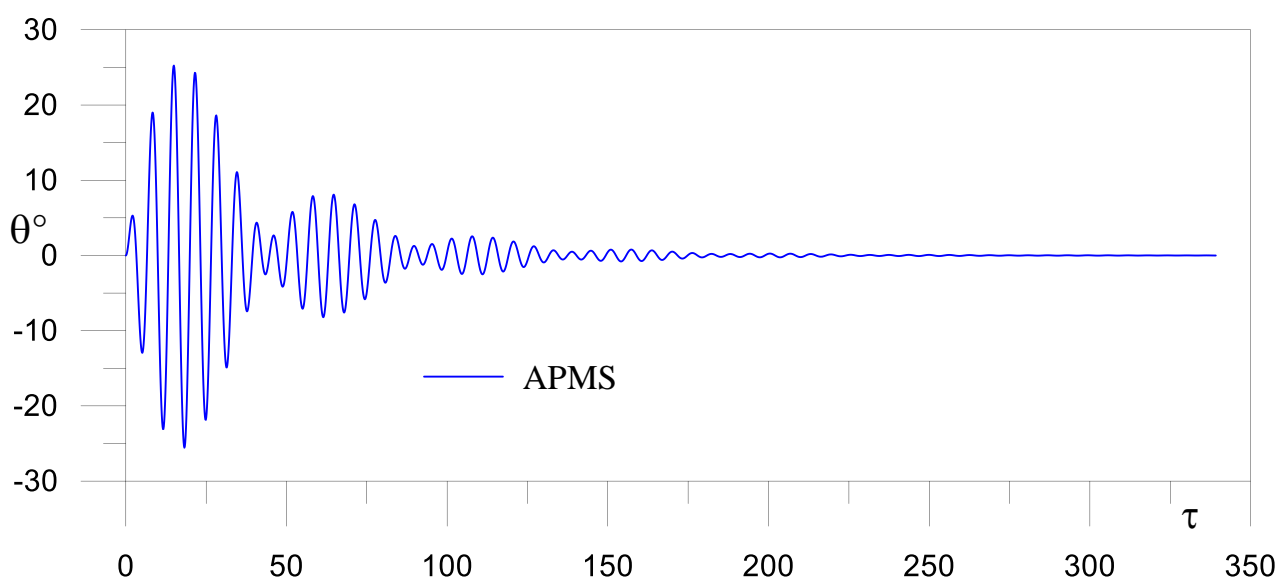

Figura 4-16 Rotações do APMS no tempo $\delta=0,01 ; \Delta=0,9$ 


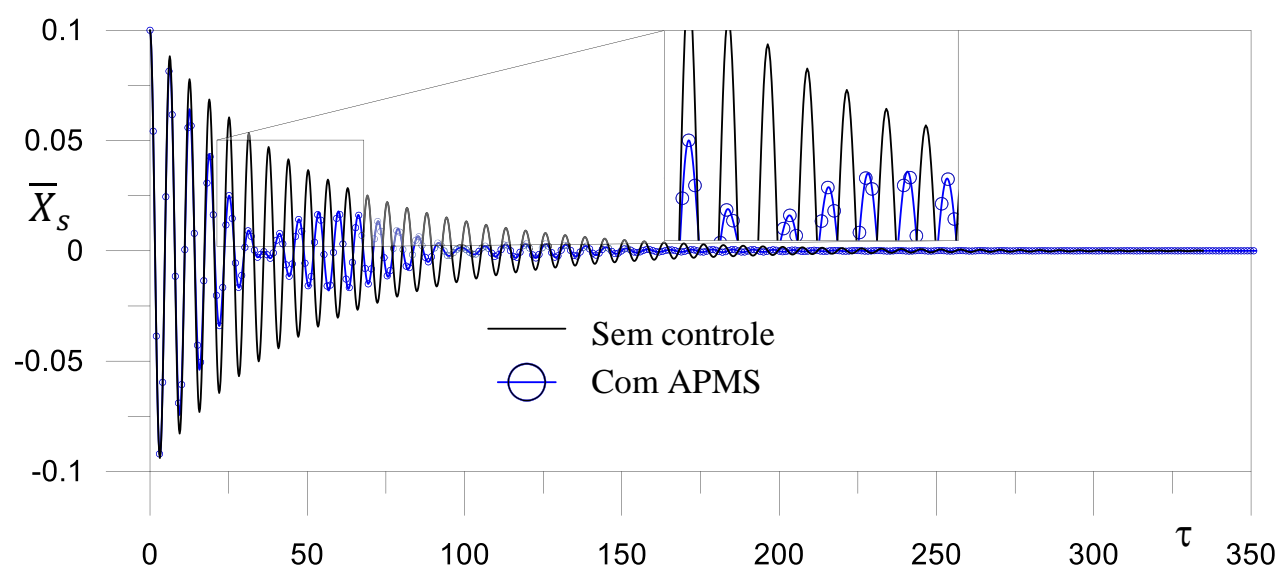

Figura 4-17 Deslocamentos da estrutura no tempo $\delta=0,01 ; \Delta=1,0$

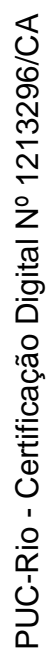

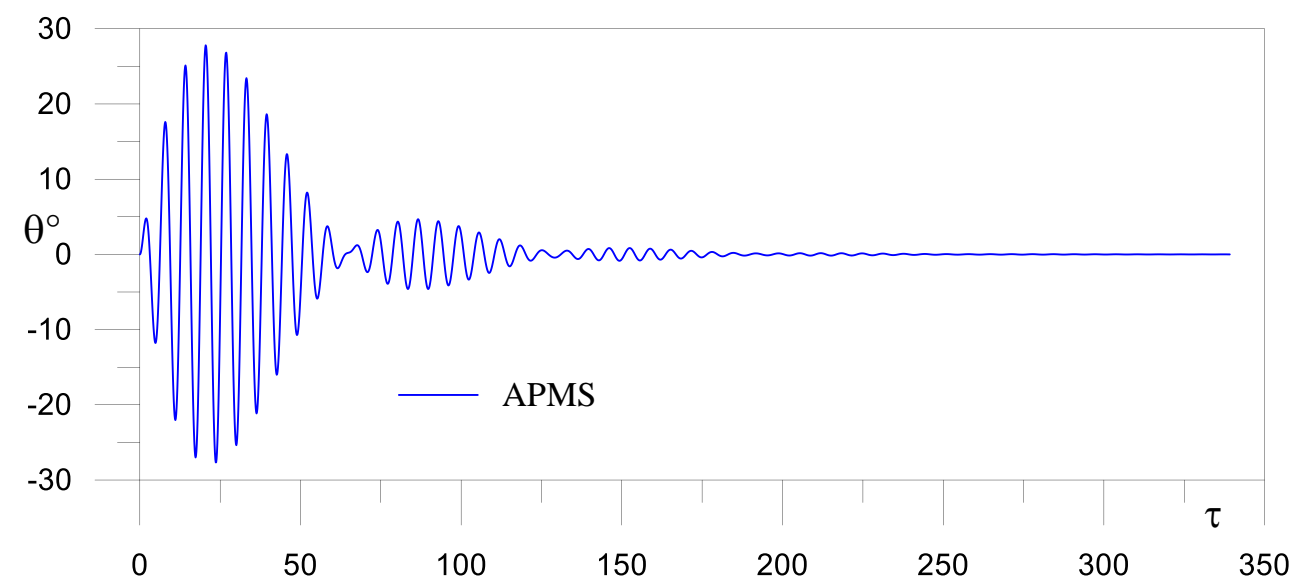

Figura 4-18 Rotações do APMS no tempo $\delta=0,01 ; \Delta=1,0$

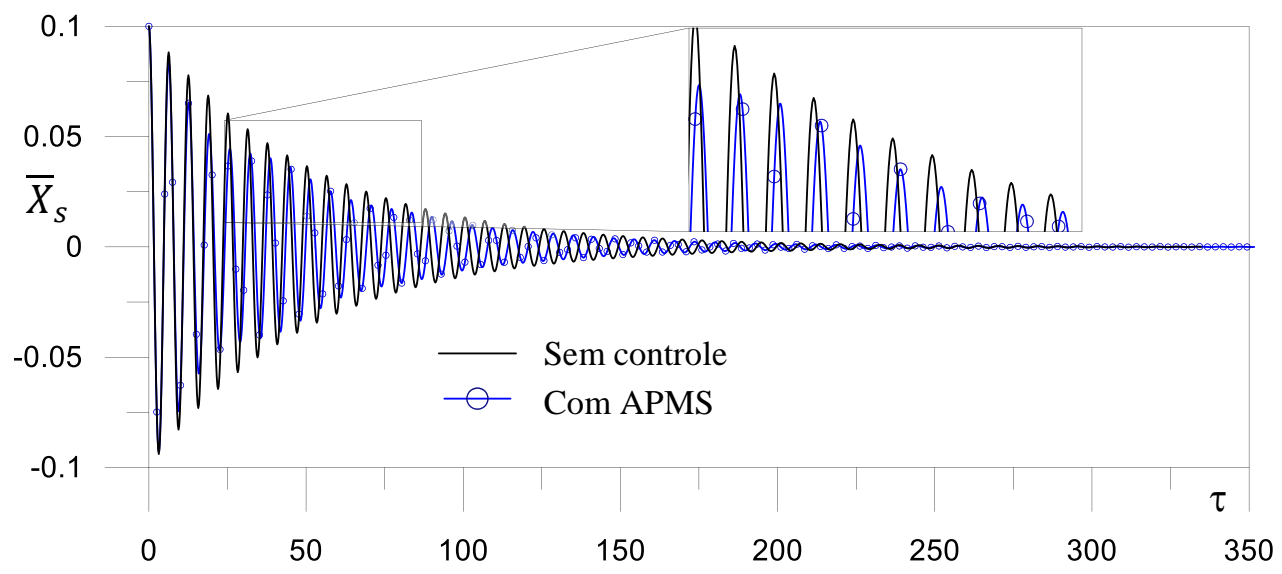

Figura 4-19 Deslocamentos da estrutura no tempo $\delta=0,01 ; \Delta=1,1$ 


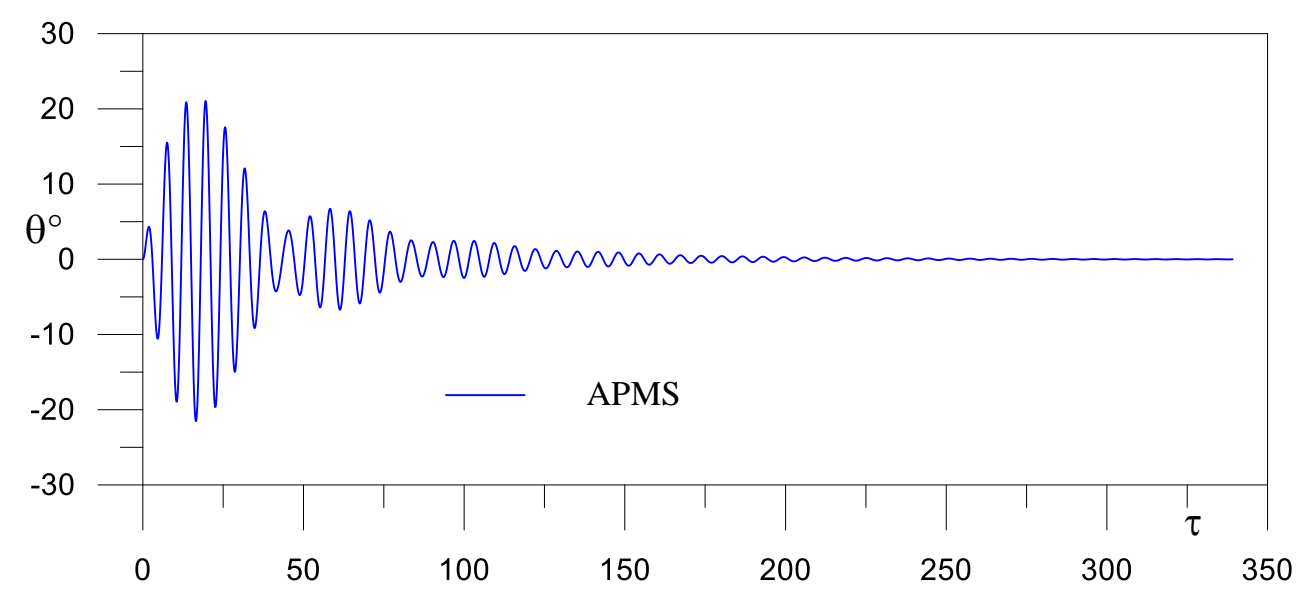

Figura 4-20 Rotações do APMS no tempo $\delta=0,01 ; \Delta=1,0$

O comportamento da estrutura em vibração livre sem controle tem um decremento de deslocamentos na forma exponencial, como esperado. Embora ambas as respostas da estrutura tenham os mesmos valores iniciais, logo o efeito do APMS, cujo deslocamento inicial é nulo, se faz sentir e as oscilações da estrutura controla diminuem com maior rapidez, voltando à posição inicial.

\section{4.}

\section{Análise da resposta no tempo com carga sísmica}

A resposta dinâmica das estruturas dos edifícios sob ação sísmica varia bastante dependendo das relações entre as frequências naturais de vibração da estrutura e o conteúdo de frequências do sismo. A Figura 4-1 apresenta o espectro de potência dos três sismos usados para testar a influência do APMS (ver Figuras 2.10 a 2.12). Considera-se, sem perda de generalidade, os espectros normalizados com relação à frequência natural de vibração da estrutura sem controle para que fiquem compatíveis com a formulação adimensional. 


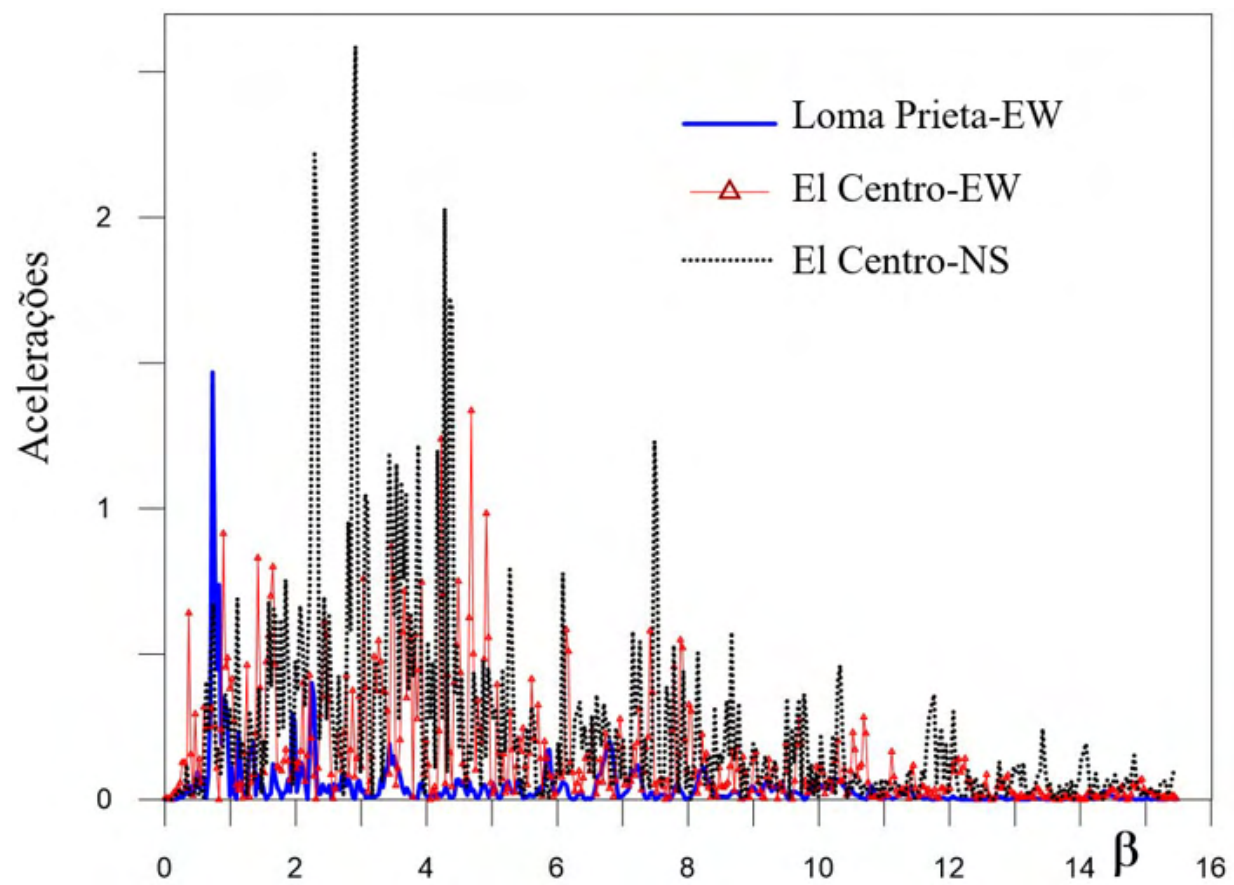

Figura 4-21 Espectro de potências dos terremotos

A Figura 4-22 mostra um detalhe em torno do valor unitário do espectro normalizado.

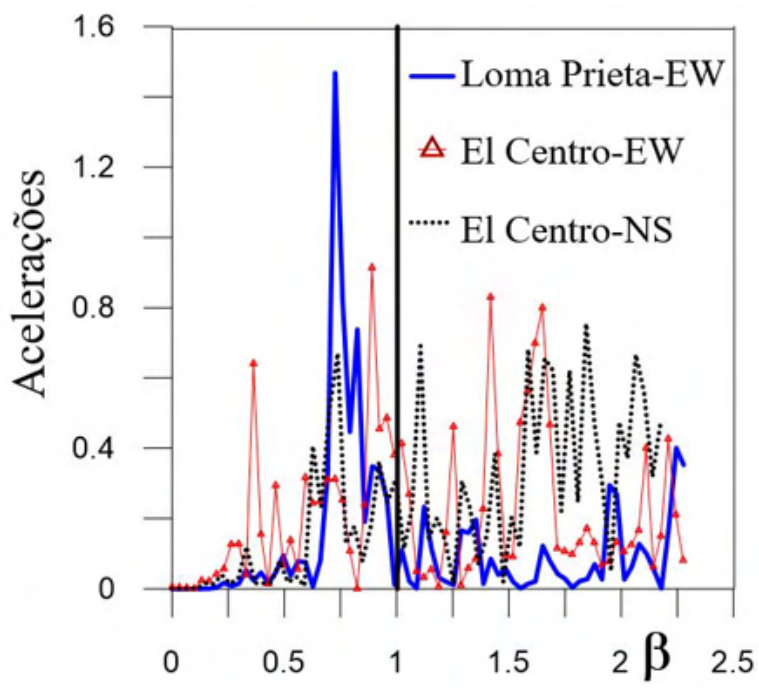

Figura 4-22 Espectro de potência dos sismos na região de interesse

A análise da estrutura sem controle e com APMS sob carga sísmica é feita para os três sinais do sismo (El Centro, componentes EW e NS, e Loma Prieta, componente EW). Os valores dos parâmetros adimensionais das equações de movimento Eq. 4.16 e 4.17 para a estrutura com controle passivo e Eq. 2.3 para a estrutura sem controle, são fixados em $\xi_{s}=2 \%, \xi_{a}=3,5 \% e \delta=0,05$. A força 
de excitação é $d^{2} \bar{X}_{g} / d \tau^{2}=\ddot{\bar{X}}_{g}$, tendo os sinais as magnitudes mostradas no Cap. 2. Apresentam-se a seguir as resposta da estrutura sem e com APMS em termos do deslocamento e aceleração e a rotação do APMS para três valores de $\Delta$ ( $\Delta=0,9$; 1,0 e 1,1). Para fins de ilustração, as Figuras 4.23 a 4.31 mostram as respostas no tempo para $\Delta=0,9$. Verifica-se em todos os casos um bom desempenho do APMS, reduzindo ao longo das respostas tanto os deslocamentos quanto as acelerações da estrutura. Verifica-se também que as rotações do APMS permanecem dentro de limites aceitáveis.

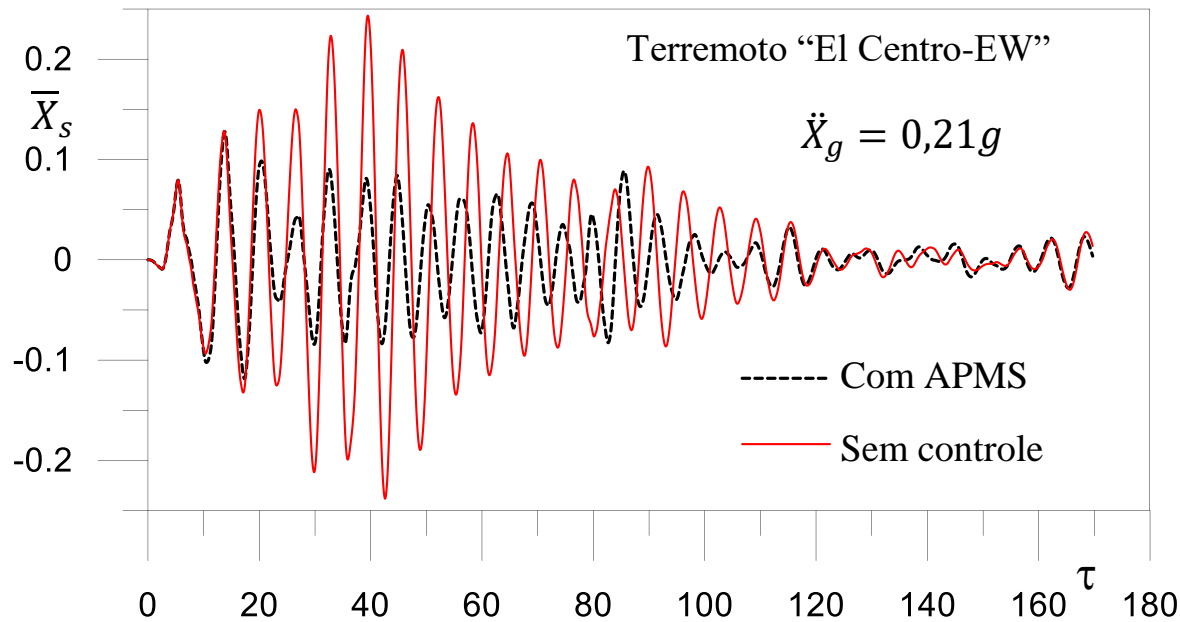

Figura 4-23 Deslocamentos da estrutura com carga sísmica $\left(\Delta=0,9 ; \delta=0,01 ; \xi_{s}=2 \%\right.$; $\xi_{s}=$ $3,5 \%)$

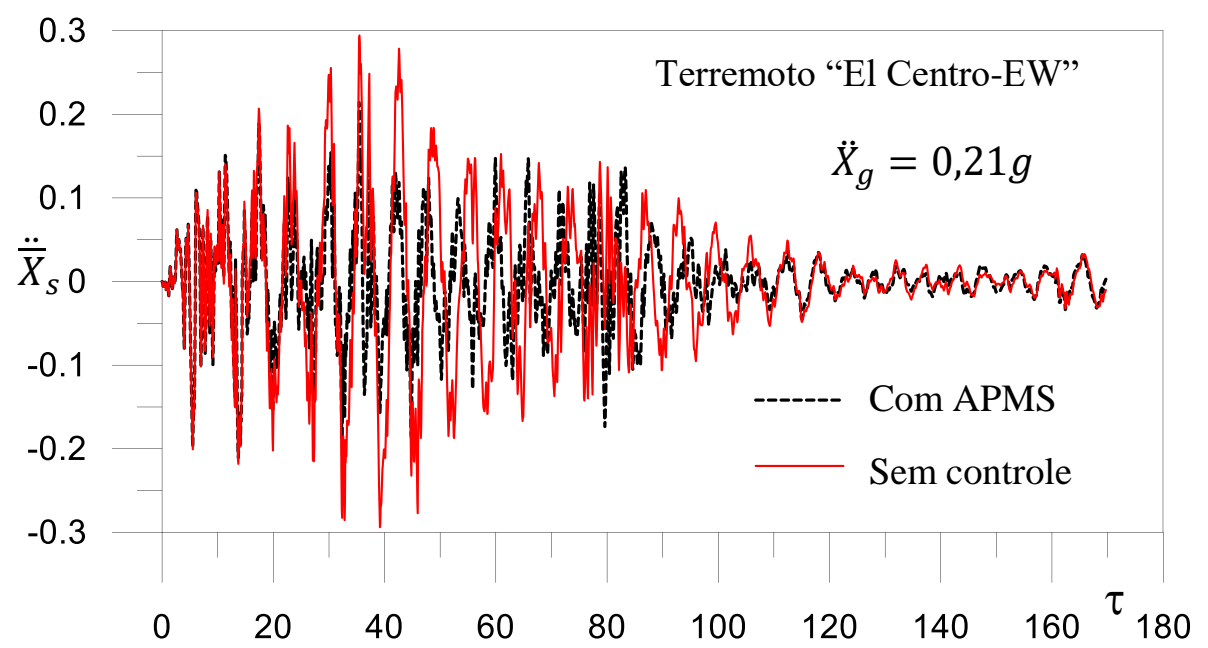

Figura 4-24 Acelerações da estrutura com carga sísmica $\left(\Delta=0,9 ; \delta=0,01 ; \xi_{s}=2 \% ; \xi_{s}=\right.$ $3,5 \%)$ 


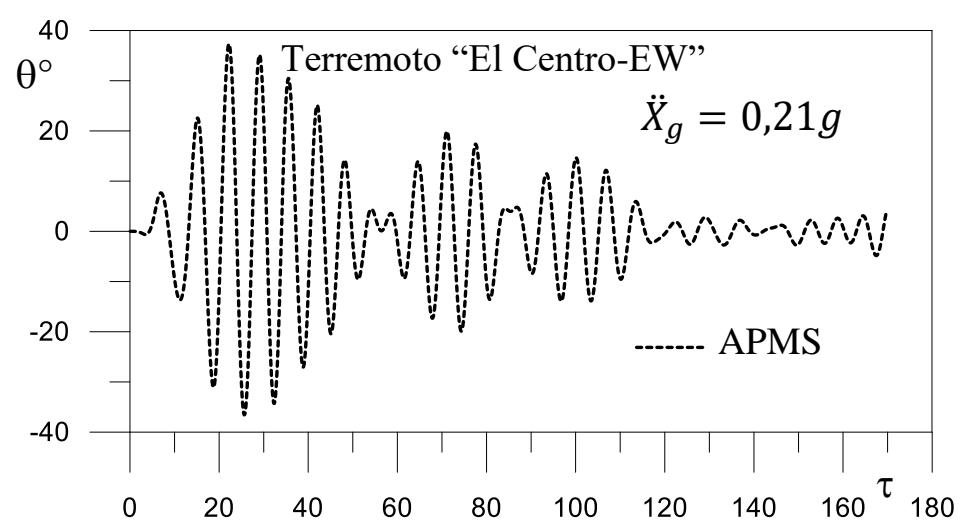

Figura 4-25 Rotações do APMS com carga sísmica $\left(\Delta=0,9 ; \delta=0,01 ; \xi_{s}=2 \% ; \xi_{s}=3,5 \%\right)$

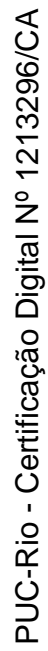

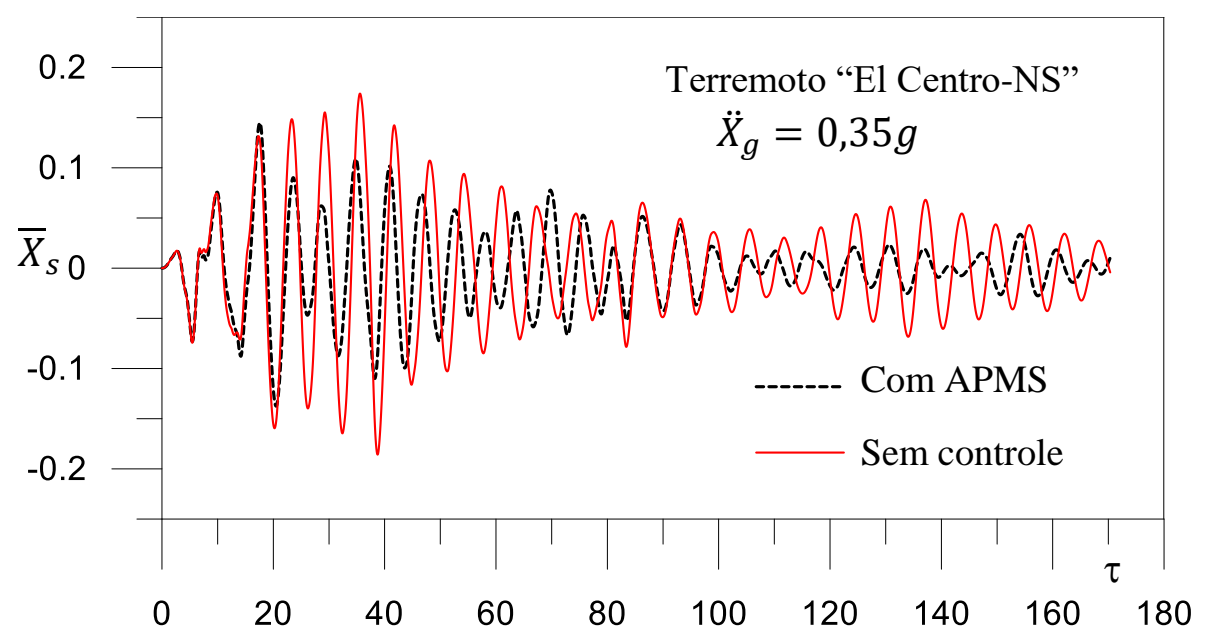

Figura 4-26 Deslocamentos da estrutura com carga sísmica $\left(\Delta=0,9 ; \delta=0,01 ; \xi_{s}=2 \% ; \xi_{s}=\right.$ $3,5 \%)$

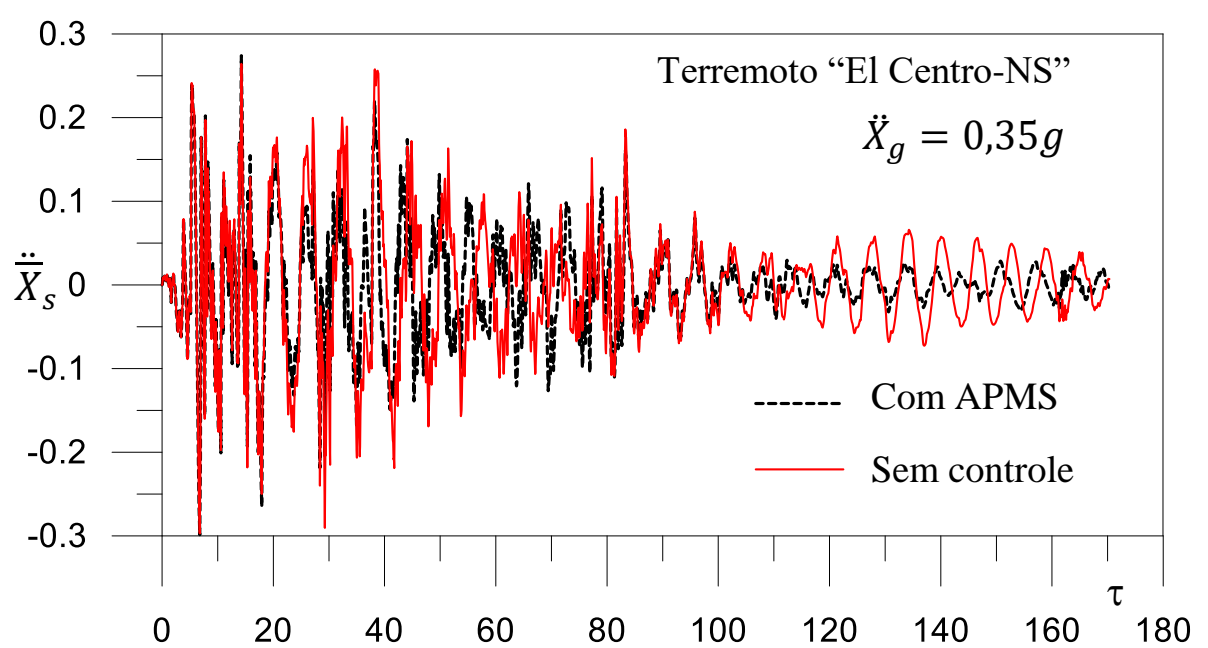

Figura 4-27 Acelerações da estrutura com carga sísmica $\left(\Delta=0,9 ; \delta=0,01 ; \xi_{s}=2 \%\right.$; $\xi_{s}=$ $3,5 \%)$ 


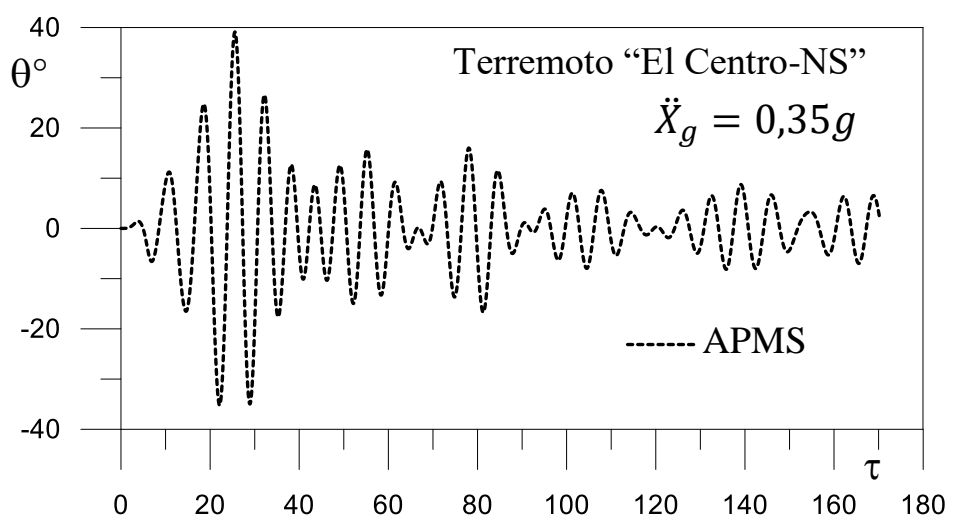

Figura 4-28 Rotações do APMS com carga sísmica $\left(\Delta=0,9 ; \delta=0,01 ; \xi_{s}=2 \% ; \xi_{s}=3,5 \%\right)$

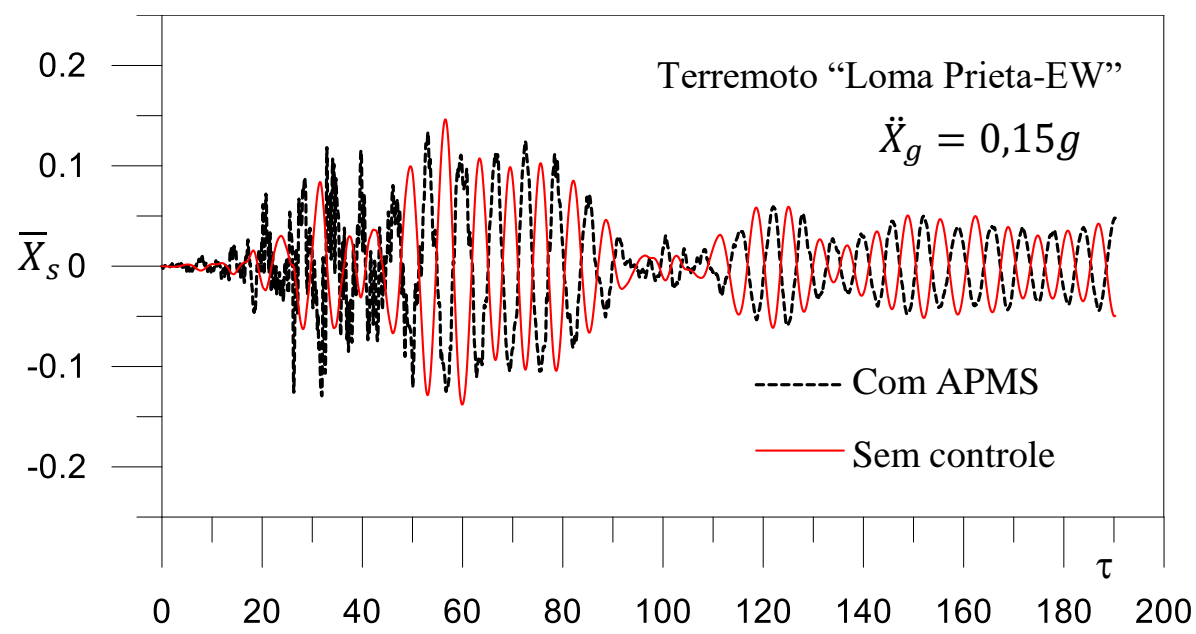

Figura 4-29 Deslocamentos da estrutura com carga sísmica $\left(\Delta=0,9 ; \delta=0,01 ; \xi_{s}=2 \%\right.$; $\xi_{s}=$ $3,5 \%)$

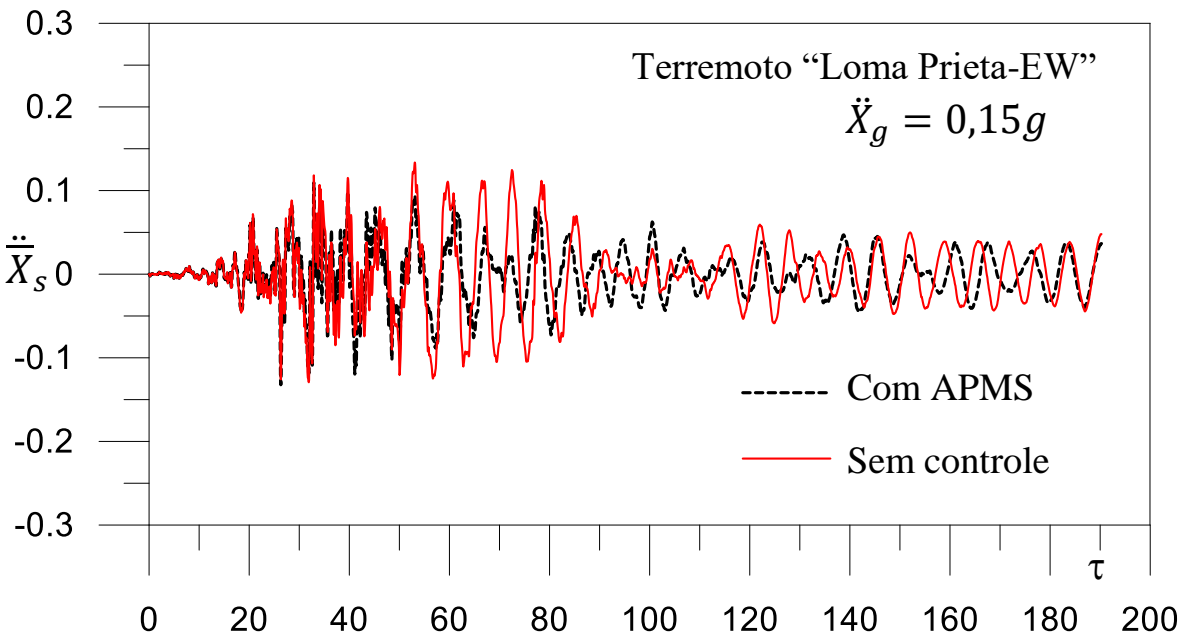

Figura 4-30 Acelerações da estrutura com carga sísmica $\left(\Delta=0,9 ; \delta=0,01 ; \xi_{s}=2 \% ; \xi_{s}=\right.$ $3,5 \%)$ 


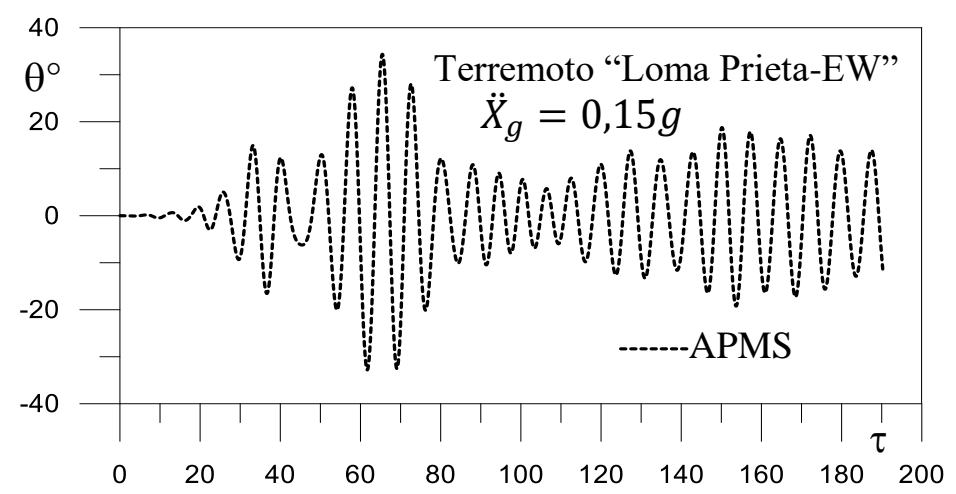

Figura 4-31 Rotações do APMS com carga sísmica $\left(\Delta=0,9 ; \delta=0,01 ; \xi_{s}=2 \% ; \xi_{s}=3,5 \%\right)$

Em todos os casos observa-se uma redução dos deslocamentos, mas em alguns exemplos nota-se um pequeno aumento nas acelerações, em particular para o sismo de $E l$ Centro-NS, Tabela 4-5, mostra, para os três valores de $\Delta$, a eficiência do APMS. Verifica-se uma grande variabilidade na redução dos deslocamentos e acelerações em função dos diferentes conteúdos de frequência e magnitude dos três sinais utilizados. Isto mostra a menor eficiências do APMS na presença de cargas aleatórias, já que seu desempenho depende de uma boa sintonia entre as diversas frequências existentes nos sinais de terremotos e do sistema estrutura-APMS. A maior redução nos deslocamentos foi de $47 \%$ para o sismo de $E l$ Centro-EW e $\Delta=0,9$. A maior redução nas acelerações foi de $32 \%$, também para o sismo de $E l$ Centro-EW, e $\Delta=1,0$. Como esperado, neste caso ocorrem as maiores rotações do APMS atingindo o valor de pico de 48,7. Em todos os casos observa-se uma redução nos deslocamentos, mas em alguns exemplos nota-se um pequeno aumento nas acelerações, em particular para o sismo de El Centro-NS. 
Tabela 4-5 Deslocamentos, acelerações máximas da estrutura e rotações máximas do APMS em função de $\Delta$

\begin{tabular}{|c|c|c|c|c|c|c|c|c|}
\hline \multirow{3}{*}{$\begin{array}{l}\text { Sinal do } \\
\text { Sismo }\end{array}$} & \multirow{3}{*}{$\begin{array}{c}\text { Razão } \\
\text { de } \\
\text { freq. } \\
(\Delta)\end{array}$} & \multicolumn{3}{|c|}{$\begin{array}{c}\text { Estrutura-APMS } \\
\delta=5 \%\end{array}$} & \multirow{2}{*}{\multicolumn{2}{|c|}{ Sem controle }} & \multirow{2}{*}{\multicolumn{2}{|c|}{$\begin{array}{c}\text { Eficiência } \\
(\%)\end{array}$}} \\
\hline & & \multicolumn{2}{|c|}{$\begin{array}{l}\text { Estrutura } \\
\text { Principal } \\
\end{array}$} & \multirow{2}{*}{$\begin{array}{c}\text { APMS } \\
\left(\boldsymbol{\theta}^{\circ}\right)\end{array}$} & & & & \\
\hline & & $\left(\bar{X}_{s}\right)$ & $\left(\ddot{\bar{X}}_{s}\right)$ & & $\left(\bar{X}_{s}\right)$ & $\left(\ddot{\bar{X}}_{s}\right)$ & $\left(\bar{X}_{s}\right)$ & $\left(\ddot{\bar{X}}_{s}\right)$ \\
\hline $\begin{array}{l}\text { Loma } \\
\text { Prieta-EW }\end{array}$ & & 0,111 & 0,109 & 34,356 & 0,146 & 0,134 & 24,092 & 18,155 \\
\hline $\begin{array}{l}\text { El Centro- } \\
\text { EW }\end{array}$ & 0,9 & 0,128 & 0,214 & 37,317 & 0,243 & 0,294 & 47,497 & 27,263 \\
\hline El Centro-NS & & 0,145 & 0,274 & 39,115 & 0,174 & 0,264 & 16,728 & $-3,708$ \\
\hline $\begin{array}{l}\text { Loma } \\
\text { Prieta-EW }\end{array}$ & & 0,143 & 0,139 & 28,127 & 0,181 & 0,165 & 20,608 & 15,935 \\
\hline $\begin{array}{l}\text { El Centro- } \\
\text { EW }\end{array}$ & 1,0 & 0,168 & 0,247 & 48,708 & 0,300 & 0,363 & 44,072 & 32,135 \\
\hline El Centro-NS & & 0,196 & 0,349 & 40,134 & 0,215 & 0,326 & 8,734 & $-6,891$ \\
\hline $\begin{array}{l}\text { Loma Prieta- } \\
\text { EW }\end{array}$ & & 0,208 & 0,192 & 28,857 & 0,219 & 0,200 & 4,784 & 3,793 \\
\hline $\begin{array}{l}\text { El Centro- } \\
\text { EW }\end{array}$ & 1,1 & 0,328 & 0,467 & 44,986 & 0,364 & 0,440 & 9,729 & $-6,190$ \\
\hline El Centro-NS & & 0,242 & 0,428 & 40,444 & 0,260 & 0,395 & 6,709 & $-8,488$ \\
\hline
\end{tabular}

A eficiência do APMS aumenta quando o valor da razão de massas aumenta, como é mostrado na Tabela 4-6 para três valores de $\delta$.

Tabela 4-6 Deslocamentos, acelerações máximas da estrutura e rotações máximas do APMS em função de $(\delta)$

\begin{tabular}{|c|c|c|c|c|c|c|c|c|}
\hline \multirow[t]{2}{*}{$\begin{array}{l}\text { Sinal do } \\
\text { Sismo }\end{array}$} & \multirow{2}{*}{$\begin{array}{c}\text { Razão } \\
\text { de } \\
\text { massas } \\
(\delta)\end{array}$} & $\begin{array}{r}\text { Estrut } \\
\text { Est } \\
\text { Pri } \\
\end{array}$ & $\begin{array}{l}a-A P M \\
\text { ura } \\
\text { pal } \\
\end{array}$ & $\begin{array}{l}\Delta=0,9 \\
\text { APMS }\end{array}$ & \multicolumn{2}{|c|}{ Sem controle } & \multicolumn{2}{|c|}{$\begin{array}{c}\text { Eficiência } \\
(\%)\end{array}$} \\
\hline & & $\left(\bar{X}_{s}\right)$ & $\left(\ddot{\bar{X}}_{s}\right)$ & $\left(\theta^{\circ}\right)$ & $\left(\bar{X}_{s}\right)$ & $\left(\ddot{\bar{X}}_{s}\right)$ & $\left(\bar{X}_{s}\right)$ & $\left(\ddot{\bar{X}}_{s}\right)$ \\
\hline $\begin{array}{l}\text { Loma } \\
\text { Prieta-EW }\end{array}$ & & 0,128 & 0,120 & 44,226 & 0,146 & 0,134 & 12,299 & 10,527 \\
\hline $\begin{array}{l}\text { El Centro- } \\
\text { EW }\end{array}$ & 0,01 & 0,205 & 0,273 & 52,892 & 0,243 & 0,294 & 15,927 & 7,254 \\
\hline $\begin{array}{l}\text { El Centro- } \\
\text { NS }\end{array}$ & & 0,149 & 0,266 & 47,022 & 0,174 & 0,264 & 14,325 & $-0,831$ \\
\hline $\begin{array}{l}\text { Loma } \\
\text { Prieta-EW }\end{array}$ & & 0,111 & 0,112 & 36,954 & 0,146 & 0,134 & 24,106 & 16,098 \\
\hline $\begin{array}{l}\text { El Centro- } \\
\text { EW }\end{array}$ & 0,03 & 0,133 & 0,239 & 42,801 & 0,243 & 0,294 & 45,262 & 18,714 \\
\hline $\begin{array}{l}\text { El Centro- } \\
\text { NS }\end{array}$ & & 0,140 & 0,270 & 42,846 & 0,174 & 0,264 & 19,657 & $-2,357$ \\
\hline $\begin{array}{l}\text { Loma } \\
\text { Prieta-EW }\end{array}$ & & 0,111 & 0,109 & 34,356 & 0,146 & 0,134 & 24,092 & 18,155 \\
\hline $\begin{array}{l}\text { El Centro- } \\
\text { EW }\end{array}$ & 0,05 & 0,128 & 0,214 & 37,317 & 0,243 & 0,294 & 47,497 & 27,263 \\
\hline $\begin{array}{l}\text { El Centro- } \\
\text { NS }\end{array}$ & & 0,145 & 0,274 & 39,115 & 0,174 & 0,264 & 16,728 & $-3,708$ \\
\hline
\end{tabular}




\section{5. Valores ótimos para o APMS linearizado}

No Capítulo 2 foram mostrados os valores ótimos para o AMS linear clássico que são os mesmos considerando as equações para o APMS linearizadas. Faz-se aqui uma análise considerando os valores ótimos da razão de frequências e do fator de amortecimento em função da razão de massas considerando os valores deduzidos por Warburton e Ayonride (1982) para aceleração de base harmônica e aleatória. Na Tabela 4-7 são mostrados estes parâmetros para três valores da razão de massas, $(\delta=0,01 ; 0,03$ e 0,05$)$. Como esperado, os valores ótimos do parâmetro $\Delta$ encontram-se entre 0,9 e 1,0 decrescendo com o valor de $\delta$. Já a taxa de amortecimento ótima do APMS, $\xi_{a}$, para excitação de base harmônica, cresce com o valor de $\delta$ atingindo a taxa de $13,53 \%$ do valor crítico para $\delta=0,05$. O mesmo ocorre para a excitação de base aleatória.

Tabela 4-7 Valores ótimos da razão de frequências e fator de amortecimento do APMS em função da razão de massas

\begin{tabular}{cccc}
\hline $\begin{array}{c}\text { Razão de } \\
\text { massas } \\
\boldsymbol{\delta}\end{array}$ & $\begin{array}{c}\text { Razão de } \\
\text { frequências }\end{array}$ & \multicolumn{2}{c}{$\begin{array}{c}\text { Fator de amortecimento } \\
\text { ótimo }\left(\boldsymbol{\xi}_{\boldsymbol{a} \text {-ótimo }}\right)\end{array}$} \\
\cline { 3 - 4 } & $\boldsymbol{\Delta}$ & Harmônico & Aleatório \\
\hline 0,01 & 0,987 & 0,0610 & 0,0490 \\
0,03 & 0,963 & 0,1053 & 0,0850 \\
0,05 & 0,940 & 0,1353 & 0,1098 \\
\hline
\end{tabular}

A Figura 4-32 mostra os diagramas de bifurcação da estrutura e do APMS para $\xi_{\mathbf{S}}=2 \%$, considerando os valores ótimos da razão de frequências $\Delta$ e taxa de amortecimento do APMS, $\xi_{a}$ para excitação de base harmônica (caso 2 da Tabela2.2), com $\delta=0,01 ; 0,03 ; 0,05$. A Tabela $4-8$ compara os deslocamentos e acelerações máximas da estrutura sem e com APMS sob excitação de base harmônica para valore ótimos de $\xi_{a}$ e $\Delta$. Verifica-se que estes valores levam a reduções consideráveis, crescendo a eficiência com a razão de massas e o consequente aumento no valor do amortecimento ótimo. Observa-se também que as rotações do APMS decrescem com a razão de massas. Verifica-se que para $\delta=0,05$ os valores máximos são aproximadamente constantes em uma larga faixa de b, o que leva a uma menor sensibilidade a incertezas nos parâmetros de projeto. 
A Figura 4-32 (c) compara a resposta da estrutura controlada com a resposta não controlada considerando os valores ótimos para excitação de base harmônica.
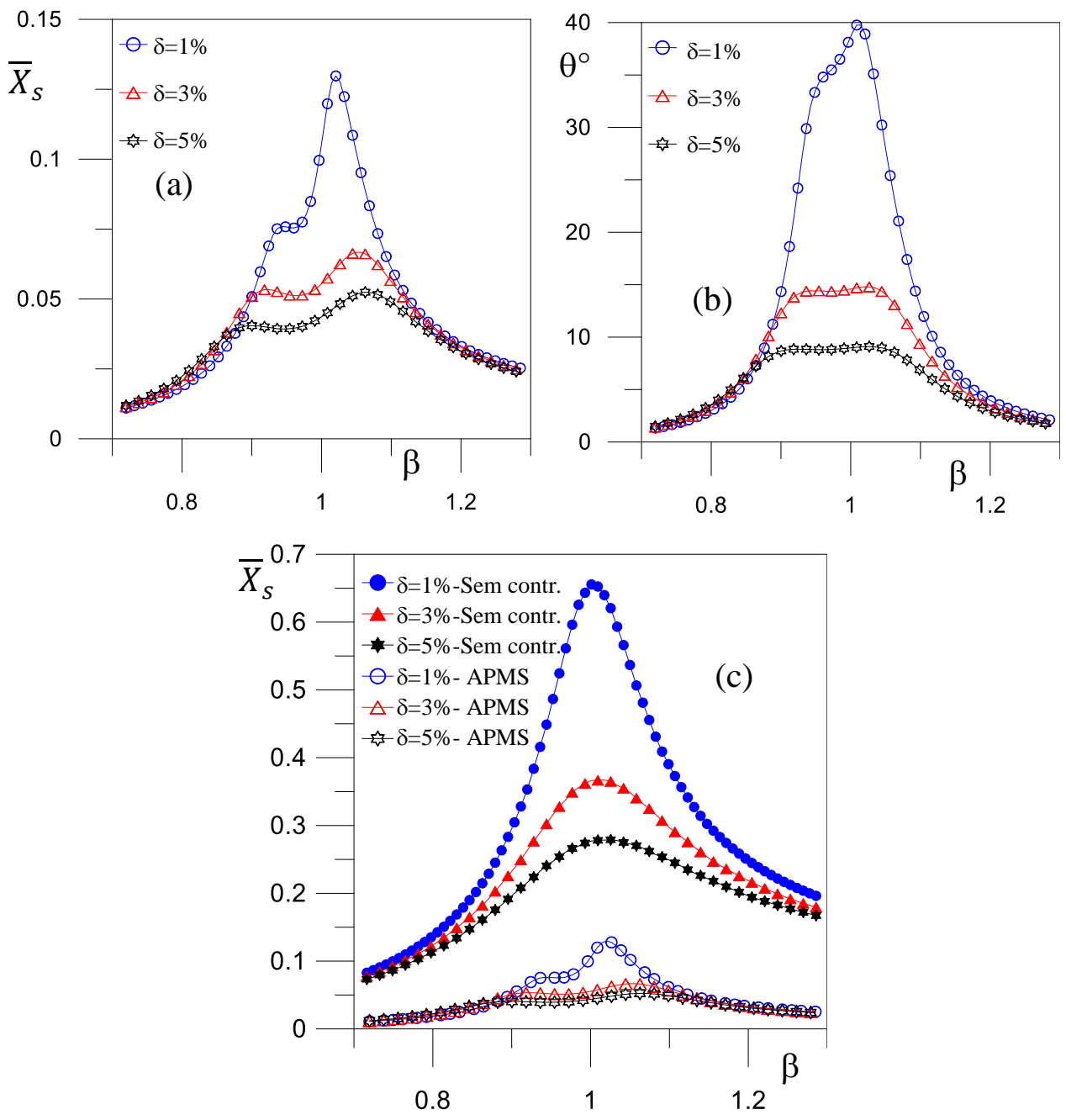

Figura 4-32 (a)-Diagramas de bifurcação da estrutura, (b)-do APMS e (c) comparação com a resposta sem controle. $\xi_{s}=2 \%$, para valores ótimos de $\xi_{a}$ e $\Delta$

Tabela 4-8 Deslocamentos e acelerações máximas da estrutura sem e com APMS para valore ótimos de $\xi_{a}$ e $\Delta$, excitação de base harmônica.

\begin{tabular}{|c|c|c|c|c|c|c|c|}
\hline \multicolumn{4}{|c|}{ Estrutura com APMS } & \multirow{2}{*}{\multicolumn{2}{|c|}{$\begin{array}{l}\text { Estrutura } \\
\text { sem controle }\end{array}$}} & \multirow{2}{*}{\multicolumn{2}{|c|}{$\begin{array}{c}\text { Eficiência } \\
(\%)\end{array}$}} \\
\hline \multirow{2}{*}{$\begin{array}{c}\text { Razão de } \\
\text { massas } \\
\delta\end{array}$} & \multicolumn{2}{|c|}{ Estrutura } & \multirow{2}{*}{$\begin{array}{c}\text { APMS } \\
\theta\end{array}$} & & & & \\
\hline & $\bar{X}_{S}$ & $\ddot{\bar{X}}_{S}$ & & $\bar{X}_{S}$ & $\ddot{\bar{X}}_{S}$ & $\bar{X}_{S}$ & $\ddot{\bar{X}}_{S}$ \\
\hline 0,01 & 0,150 & 0,136 & 39,761 & 0,246 & 0,246 & 47,18 & $4+, 04$ \\
\hline 0,03 & 0,067 & 0,095 & 14,807 & 0,234 & 0,234 & 71,48 & $\mathbf{5 9 , 5 4}$ \\
\hline 0,05 & 0,052 & 0,090 & 9,105 & 0,223 & 0,223 & 76,46 & $\mathbf{5 9 , 5 3}$ \\
\hline
\end{tabular}


A seguir estuda-se o comportamento da estrutura sob excitação sísmica considerando os valores ótimos da razão de frequências $\Delta$ e taxa de amortecimento do APMS, $\xi_{a}$, para excitação de base aleatória (caso 4 da Tabela2.1). A Figura 4-33 compara a resposta no tempo dos deslocamentos da estrutura submetida à componente Leste-Oeste do terremoto "El Centro" da estrutura sem e com APMS para $\delta=0,01 ; 0,03$ e 0,05 . A Figura 4-34 compara as rotações do APMS com carga sísmica para os três valores de $\delta$. Verifica-se novamente que a eficiência do APMS cresce com a razão de massas e o consequente aumento no valor do amortecimento ótimo.

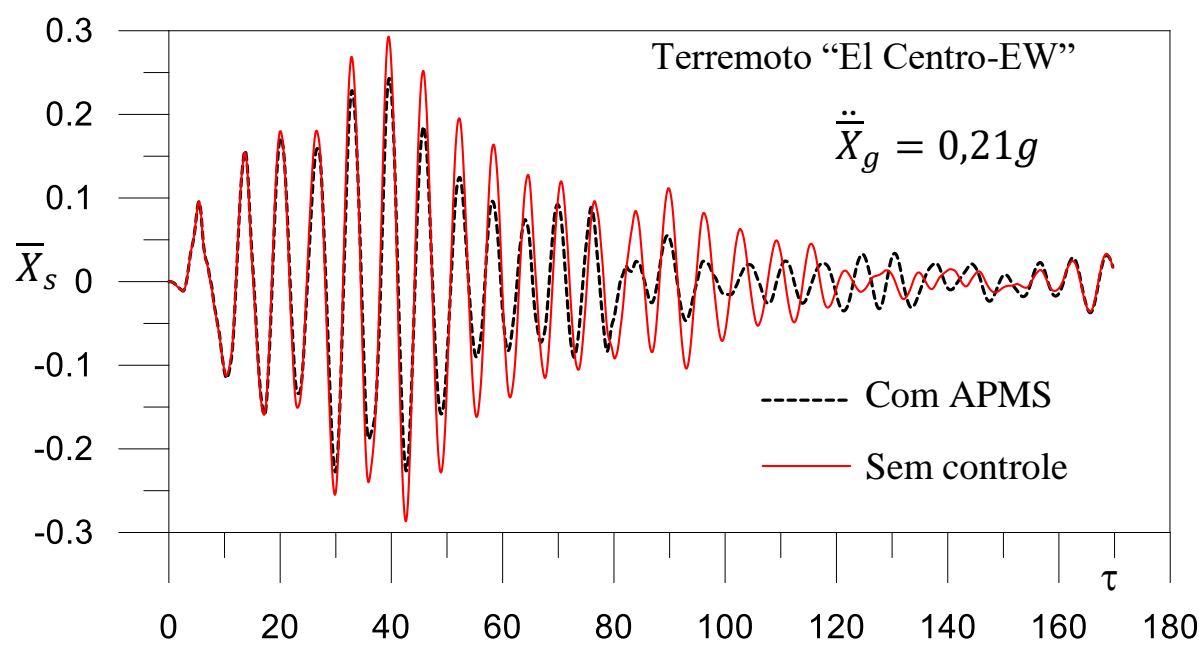

(a) $\delta=0,01 ; \Delta=0,987, \xi_{s}=2 \% ; \xi_{s}=4,9 \%$

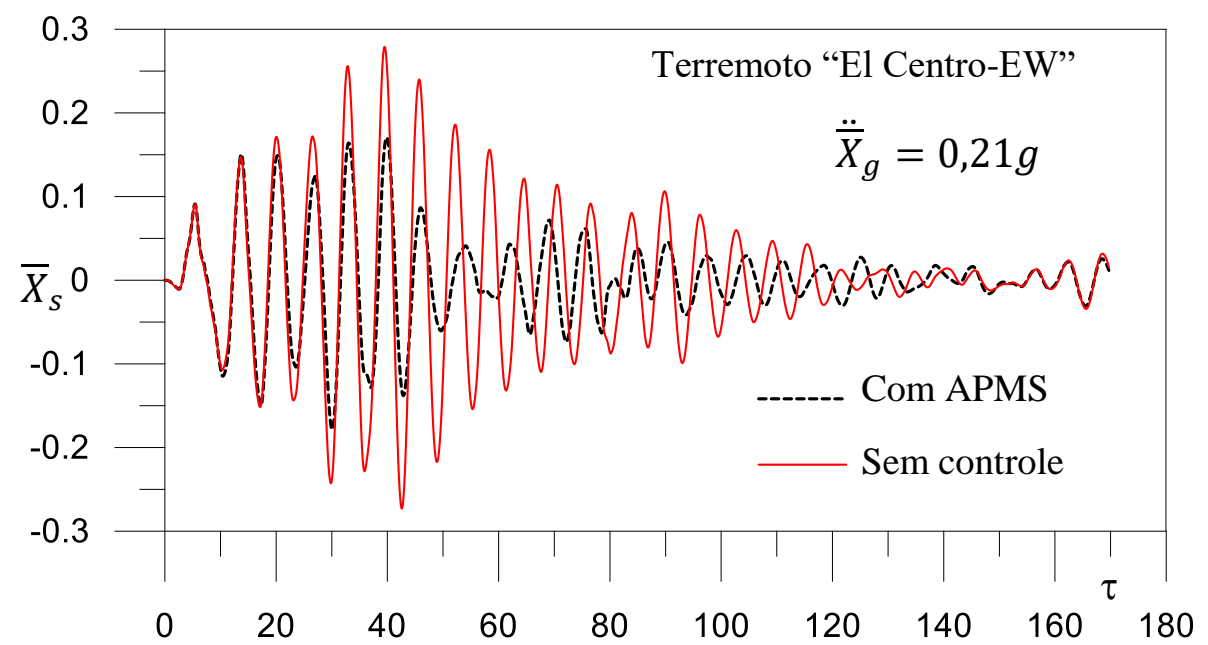

(b) $\delta=0,03 ; \Delta=0,963 ; \xi_{s}=2 \% ; \xi_{s}=8,5 \%$ 


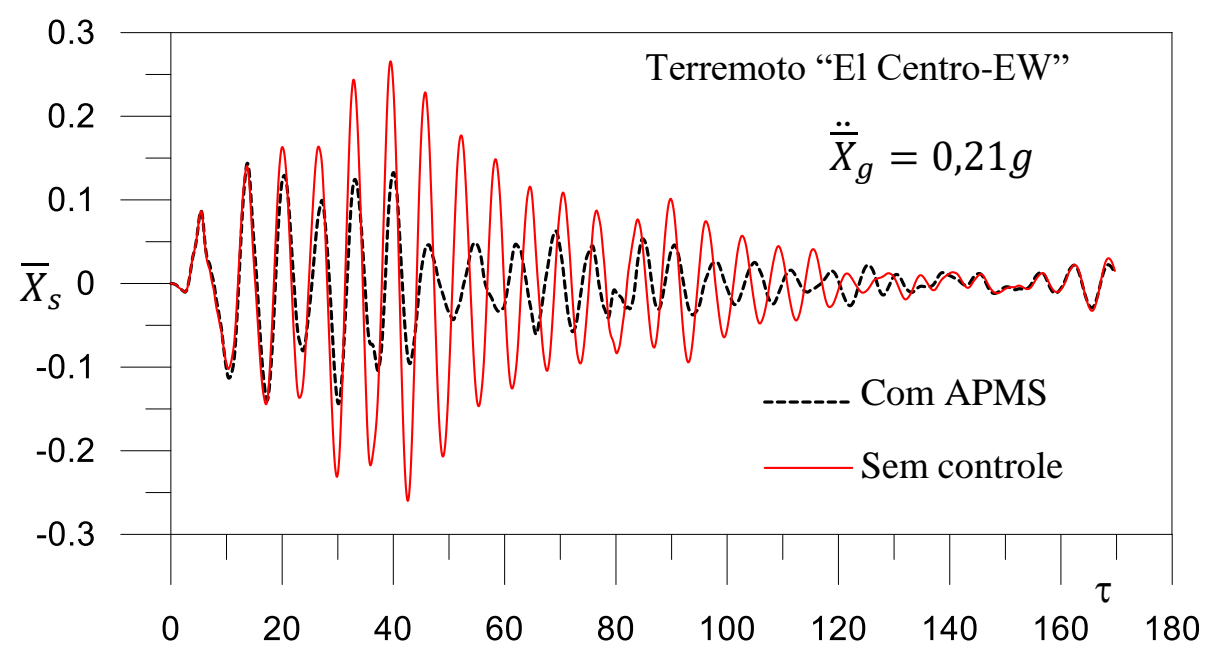

(c) $\delta=0,05 ; \Delta=0,940 ; \xi_{s}=2 \% ; \xi_{s}=10,98 \%$

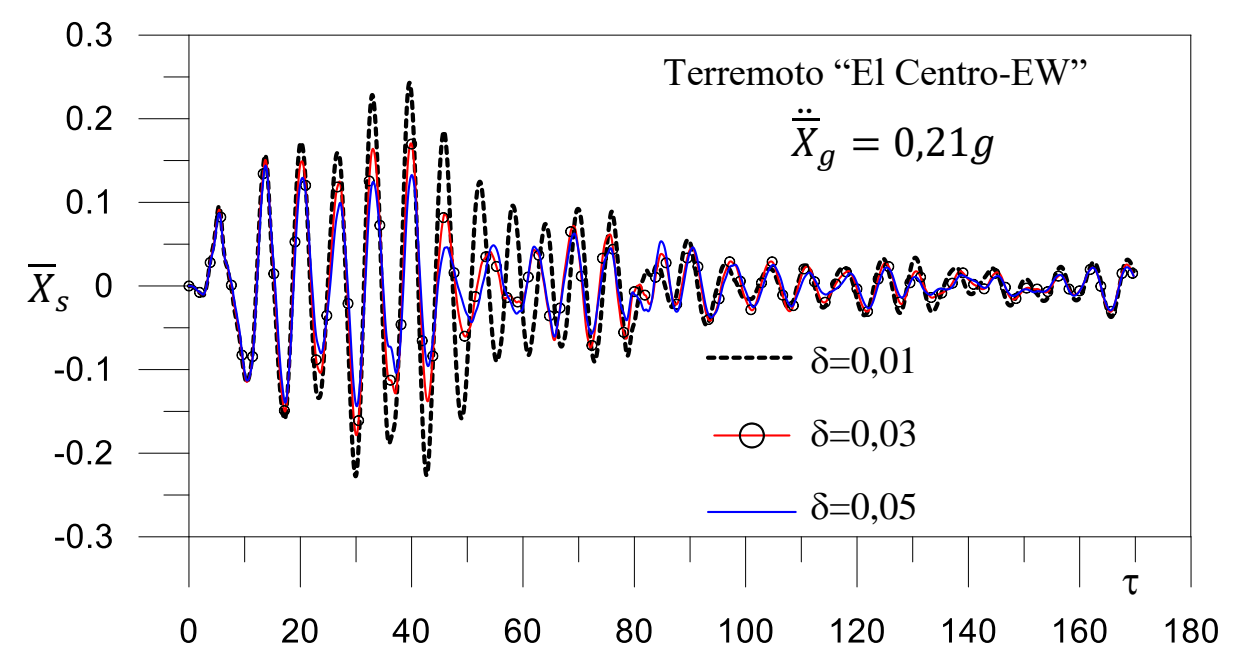

(d) Comparação dos resultados

Figura 4-33 Deslocamentos da estrutura com carga sísmica. Terremoto "El Centro-EW".

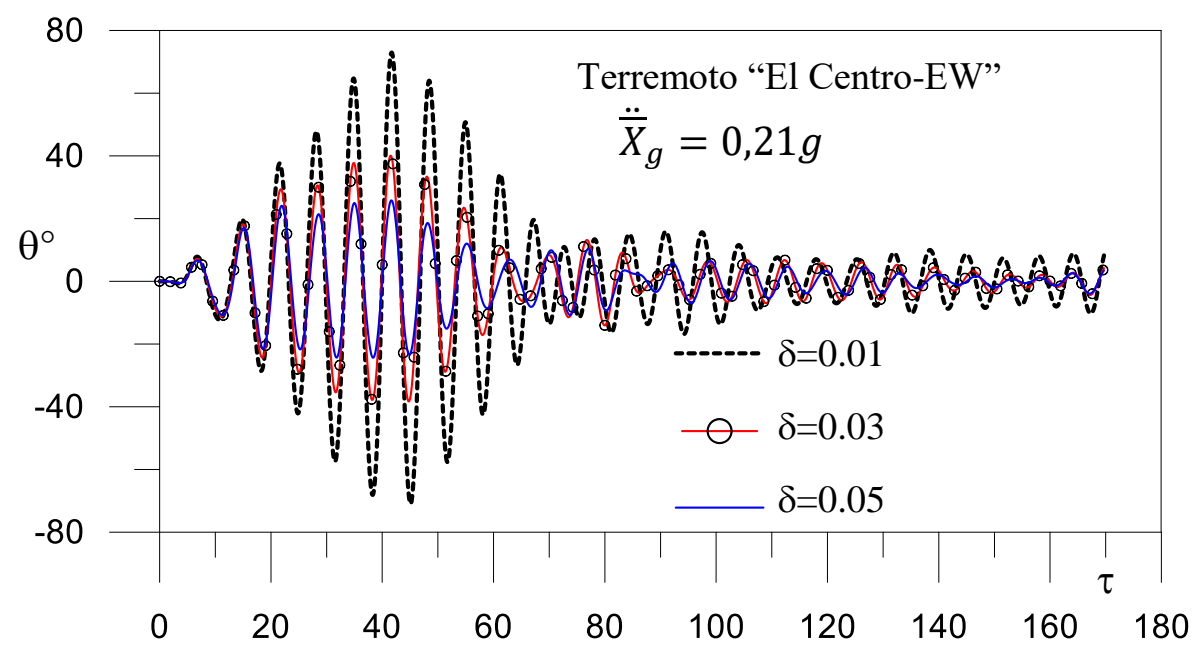

Figura 4-34 Rotações do APMS com carga sísmica $\left(\xi_{s}=2 \%\right)$ 


\section{Controle passivo - isolador de base pendular}

Estuda-se neste capítulo o comportamento dinâmico de uma estrutura sujeita a movimento de base com um isolador de base pendular (IBP), como ilustra a Figura 5-1, onde $\mathrm{X}_{\mathrm{b}}$ representa o grau de liberdade da base e $M_{b}$ representa a massa da base acima do isolador.

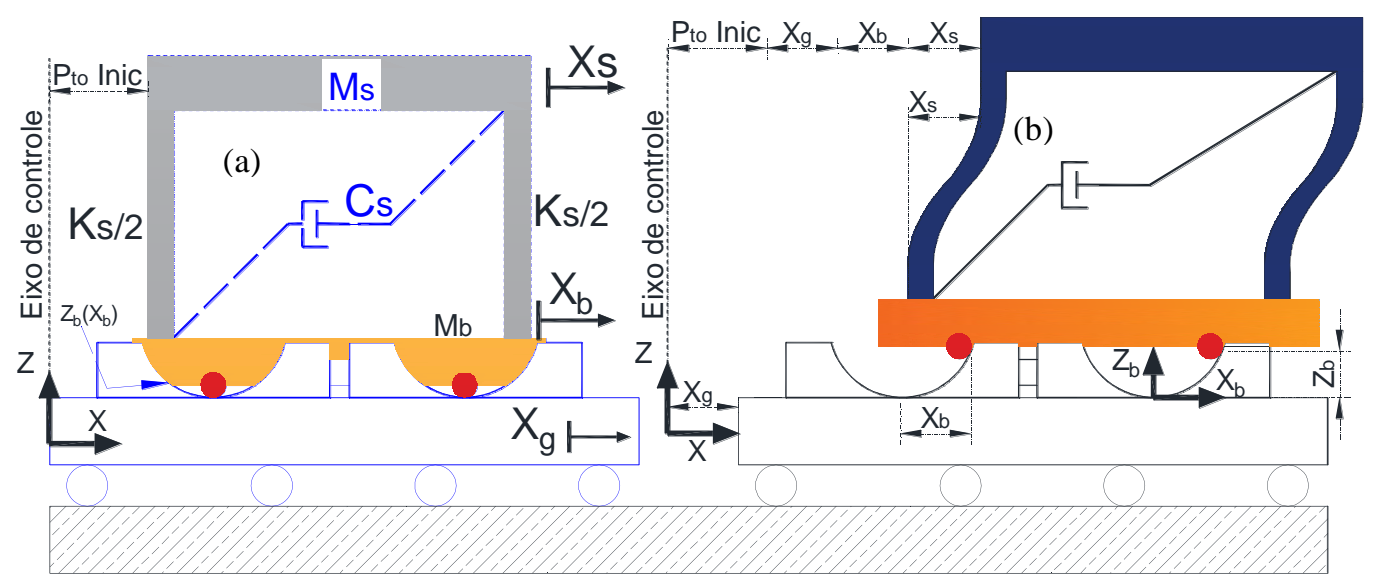

Figura 5-1 (a) Estrutura indeformada com isolador de base pendular (IBP), (b) estrutura deformada com IBP pelo deslocamento de base Xg.

\section{1.}

\section{Formulação matemática do IBP}

Com base na Figura 5-1, a energia cinética da estrutura é dada por:

$$
T_{s}=\frac{1}{2} M_{s}\left(\left(\dot{X}_{g}+\dot{X}_{s}+\dot{X}_{b}\right)^{2}+\dot{Z}_{b}^{2}\right)
$$

onde $\dot{X}_{b}$ e $\dot{Z}_{b}$ são, respectivamente, as componentes horizontal e vertical do vetor velocidade da base.

A energia cinética da base é dada por:

$$
T_{b}=\frac{1}{2} M_{b}\left(\left(\dot{X}_{g}+\dot{X}_{b}\right)^{2}+\dot{Z}_{b}^{2}\right)
$$

A energia interna de deformação da estrutura é dada pela Eq. 4.3, enquanto o potencial gravitacional de cargas externas do sistema é dado pela expressão: 


$$
V_{T}=V_{b}+V_{s}=\left(M_{b}+M_{s}\right) \cdot g \cdot Z_{a}
$$

Neste caso tanto a base quanto a estrutura sofrem deslocamento vertical, aumentando a força de restauração que é, neste caso, proporcional à massa total do sistema.

As equações de Euler-Lagrange, Eq.4.12 e 4.13, são usadas para obter o sistema de equações diferenciais que representa matematicamente o comportamento dinâmico do sistema. Tem-se assim que:

$$
\begin{aligned}
& \left(\ddot{X}_{S}+\ddot{X}_{g}+R_{c} \cos (\theta) \ddot{\theta}-R \sin (\theta)(\dot{\theta})^{2}\right) M_{s}+C_{s} \dot{X}_{S}+K_{S} X_{S}=0 \\
& R_{c}\left(\begin{array}{l}
\left(R \ddot{\theta}+\cos (\theta) \ddot{X}_{g}+g \sin (\theta)\right) M_{b}+M_{S}\left(R_{c} \ddot{\theta}+\cos (\theta)\left(\ddot{X}_{g}+\ddot{X}_{S}\right)\right)+ \\
C_{b} R_{c} \dot{\theta}+M_{S} g \sin (\theta)
\end{array}\right)=0
\end{aligned}
$$

\section{2.}

\section{Equações de movimento na forma adimensional}

As equações de movimento na forma adimensional são expressas novamente em função dos parâmetros adimensionais definidos nos capítulos anteriores $\left(\Delta, \delta, \xi_{s} e \xi_{a}\right)$. Neste caso, redefinimos os parâmetros $\delta$ e $\Gamma$ como:

$$
\delta=\frac{M_{b}}{M_{S}} ; \quad \Gamma=\frac{C_{b}}{C_{S}}=\frac{\xi_{b}}{\xi_{S}}(\delta+1) \Delta
$$

onde $\xi_{b}$ é a taxa de amortecimento do isolador.

Após a substituição dos parâmetros adimensionais, o sistema de equações diferencias 5.4 e 5.5 toma a forma:

$$
\begin{aligned}
& \left(\frac{d^{2} \bar{X}_{S}}{d \tau^{2}}+\frac{d^{2} \bar{X}_{g}}{d \tau^{2}}\right)+\cos (\theta) \frac{d^{2} \theta}{d \tau^{2}}+2 \xi_{s} \frac{d \bar{X}_{s}}{d \tau}-\sin (\theta)\left(\frac{d \theta}{d \tau}\right)^{2}+\bar{X}_{s}=0 \\
& \cos (\theta)\left(\frac{d^{2} \bar{X}_{S}}{d \tau^{2}}+(\delta+1) \frac{d^{2} \bar{X}_{g}}{d \tau^{2}}\right)+(\delta+1) \frac{d^{2} \theta}{d \tau^{2}}+2(\delta+1) \Delta \xi_{b} \frac{d \theta}{d \tau}+ \\
& \Delta^{2}(\delta+1) \sin (\theta)=0
\end{aligned}
$$

Considerando o comportamento não linear da força de amortecimento, a Eq. 5.7 é reescrita como: 


$$
\begin{aligned}
& \cos (\theta)\left(\frac{d^{2} \bar{X}_{S}}{d \tau^{2}}+(\delta+1) \frac{d^{2} \bar{X}_{g}}{d \tau^{2}}\right)+(\delta+1) \frac{d^{2} \theta}{d \tau^{2}}+ \\
& 2(\delta+1) \Delta \xi_{b} R_{c}^{\alpha-1} \omega_{S}^{\alpha-1}\left|\frac{d \theta}{d \tau}\right|^{\alpha} \operatorname{sing}\left(\frac{d \theta}{d \tau}\right)+\Delta^{2}(\delta+1) \sin (\theta)=0
\end{aligned}
$$

\section{3.}

\section{Frequências naturais e modos de vibração do sistema Estrutura - IBP}

As frequências naturais e modos de vibração são obtidos a partir da linearização das Eqs. 5.6 e 5.7, chegando-se ao seguinte problema de autovalor:

$$
\left[\begin{array}{cc}
1-\lambda & -\lambda \\
-\lambda & \Delta^{2}(\delta+1)-\lambda(\delta+1)
\end{array}\right\rfloor\left\{\begin{array}{l}
X_{1} \\
X_{2}
\end{array}\right\}=\left\{\begin{array}{l}
0 \\
0
\end{array}\right\}
$$

As frequências naturais são obtidas através da seguinte expressão

$$
\omega_{i}=\frac{1}{2} \sqrt{2} \sqrt{\frac{\left(\Delta^{2}+1\right)(1+\delta) \pm \sqrt{\Delta^{4}(\delta+1)^{2}-2 \Delta^{2}(\delta-1)+(\delta+1)^{2}}}{\delta}} ; i=1,25.10
$$

A variação das duas frequências naturais com a razão de frequências, $\Delta$, para valores selecionados da razão de massas, $\delta$, é mostrada na Figura 5-2. Quando a curvatura é nula, a primeira frequência fundamental é zero, o que corresponde a um movimento de corpo rígido. A primeira frequência não é influenciada pelo valor de $\delta$, crescendo de forma não linear com $\Delta$, ou seja, com o valor do raio de curvatura $R_{c}$, tendendo assintoticamente a um quando $\Delta$ tende a infinito. A segunda frequência decresce com $\delta$, sendo quase constante para $\delta=20 \%$. O seu valor apresenta um leve crescimento com a razão de frequências, $\Delta$. Verifica-se, finalmente, que a segunda frequência é bem superior à frequência natural da estrutura isolada $(\omega=1)$.

Para estruturas sob uma excitação sísmica, um dos objetivos do sistema de isolamento de base é reduzir a frequência fundamental do sistema, alongando assim o período, e levando a estrutura à região onde o conteúdo de frequências do sismo causa pouco ou nenhum dano à estrutura, como comentado no Capítulo 2 (ver Figura 2-15). Verifica-se através da Figura 5-2 que, usando o IBP, pode-se reduzir facilmente a frequência fundamental da estrutura a um valor adequado, usando-se um valor suficientemente pequeno de $\Delta$. Cabe lembrar que o raio de 
curvatura do sistema pendular é inversamente proporcional a $\Delta^{2}$, o que leva a um raio elevado e consequentemente uma superfície bastante suave para o IBP.

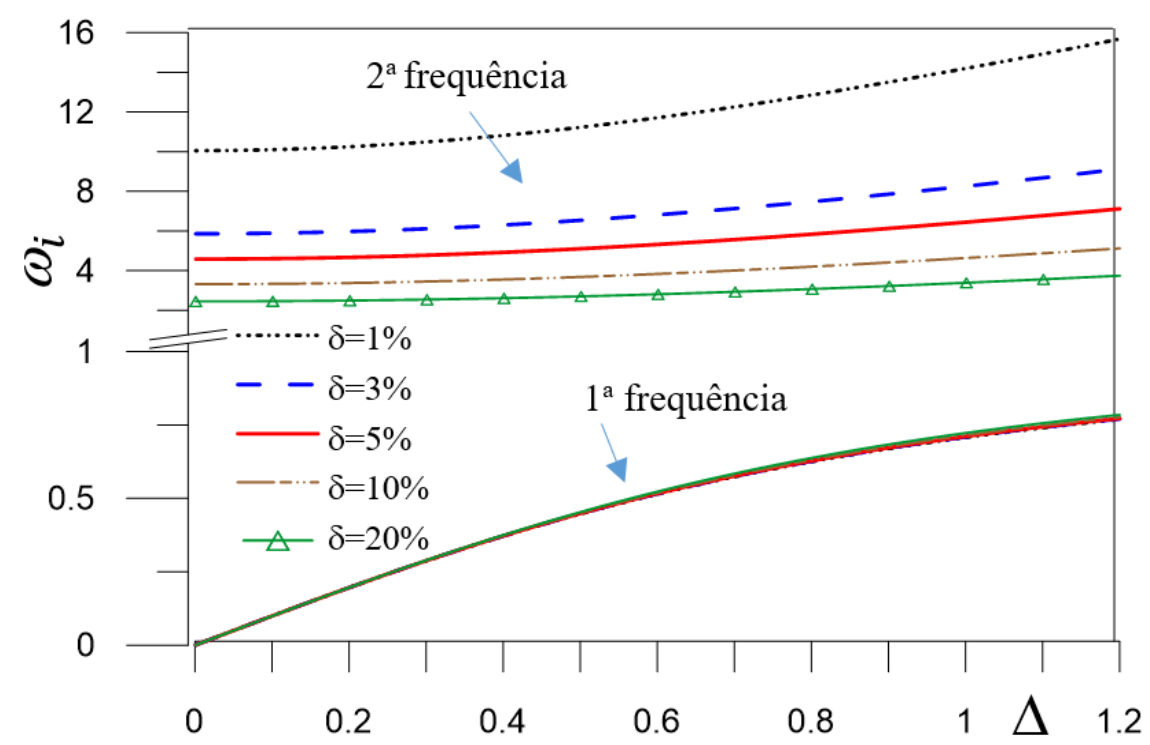

Figura 5-2 Frequências de vibração da estrutura com IBP em função de ( $\Delta$ )

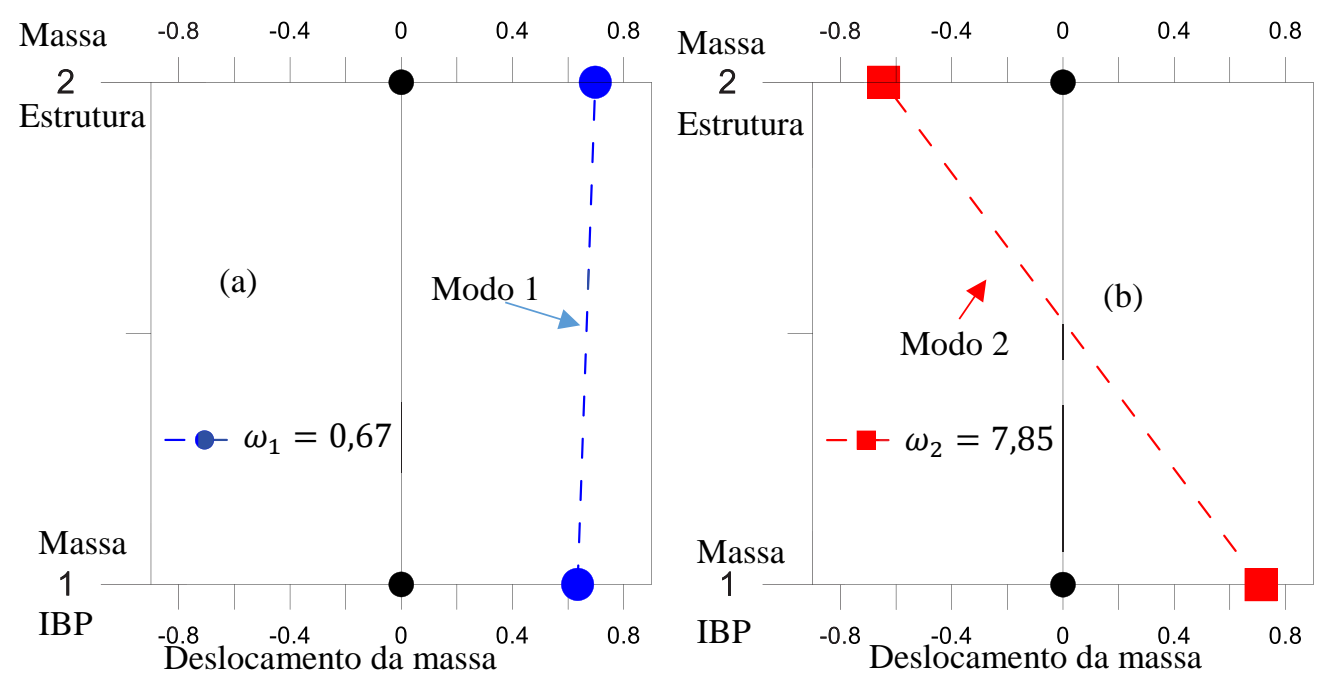

Figura 5-3 Modos de vibração da estrutura com IBP, (a) primeiro e (b) segundo modo

A Figura 5-3 mostra os dois modos de vibração da estrutura com isolador pendular de base considerando $\Delta=0,9 ; \delta=3 \%$. O primeiro modo corresponde a um deslocamento da base (massa 1) e da estrutura (massa 2) no mesmo sentido, sendo o deslocamento relativo entre as massas bem pequeno, demostrando que tem-se um movimento quase de corpo rígido segundo o autovetor 
$X_{2}=\{0,634 \quad 0,697\}^{T}$. No segundo modo de vibração, as duas massas deslocamse em sentidos contrários como mostra o autovetor $X_{2}=\{0,712-0,644\}^{T}$.

\section{4 .}

\section{Análise paramétrica da resposta permanente sob carga harmônica}

Os parâmetros principais de projeto neste tipo de sistema de isolamento de base são os parâmetros $\delta$ e $\Delta$. Na presente análise a razão de massas é definida dentro da faixa de valores $0,01 \leq \delta \leq 0,2$. Em relação à razão de frequências $\Delta$ os valores são definidos na faixa de $0,1 \leq \Delta \leq 1,3$, os outros parâmetros são: $\xi_{S}=0,02$ e $\xi_{a}=0,035$. A força excitadora gerada pelo deslocamento de base é inicialmente do tipo harmônico, definida como $d^{2} \bar{X}_{g} / d \tau^{2}=0,01 \Delta^{2} \beta^{2} \operatorname{sen}(\beta \tau)$. Como referência, na Tabela 5-1 são mostrados os valores das frequências naturais de vibração do sistema estrutura-IBP; para $0,1 \leq \Delta \leq 1,3$, e $0,01 \leq \delta \leq 0,2$.

Tabela 5-1 Frequências naturais de vibração da estrutura com IBP (Adimensional)

\begin{tabular}{|c|c|c|c|c|c|c|c|c|c|}
\hline \multirow{2}{*}{$\delta$} & \multirow{2}{*}{ Frequência } & \multicolumn{8}{|c|}{$\Delta$} \\
\hline & & 0,1 & 0,2 & 0,3 & 0,5 & 0,7 & 0,9 & 1 & 1,1 \\
\hline \multirow{2}{*}{0,01} & 1ra & 0,099 & 0,196 & 0,287 & 0,447 & 0,574 & 0,669 & 0,707 & 0,741 \\
\hline & $2 \mathrm{da}$ & 10,090 & 10,240 & 10,480 & 11,220 & 12,520 & 13,550 & 14,190 & 14,920 \\
\hline \multirow{2}{*}{$\mathbf{0 , 0 3}$} & 1ra & 0,099 & 0,196 & 0,287 & 0,448 & 0,575 & 0,671 & 0,709 & 0,743 \\
\hline & $2 \mathrm{da}$ & 5,880 & 5,970 & 6,110 & 6,530 & 7,120 & 7,850 & 8,260 & 8,670 \\
\hline \multirow{2}{*}{0,05} & 1ra & 0,099 & 0,196 & 0,287 & 0,448 & 0,576 & 0,672 & 0,711 & 0,744 \\
\hline & $2 \mathrm{da}$ & 4,600 & 4,660 & 4,770 & 5,100 & 5,560 & 6,130 & 6,440 & 6,770 \\
\hline \multirow{2}{*}{$\mathbf{0 , 0 7}$} & 1ra & 0,099 & 0,196 & 0,288 & 0,448 & 0,577 & 0,674 & 0,713 & 0,746 \\
\hline & 2da & 3,920 & 3,980 & 4,070 & 4,340 & 4,730 & 5,210 & 5,480 & 5,764 \\
\hline \multirow{2}{*}{0,1} & 1ra & 0,099 & 0,196 & 0,288 & 0,450 & 0,579 & 0,676 & 0,715 & 0,748 \\
\hline & $2 \mathrm{da}$ & 3,330 & 3,370 & 3,450 & 3,680 & 4,000 & 4,410 & 4,630 & 4,870 \\
\hline \multirow{2}{*}{0,15} & 1ra & 0,099 & 0,196 & 0,288 & 0,452 & 0,582 & 0,680 & 0,719 & 0,752 \\
\hline & 2da & 2,780 & 2,810 & 2,870 & 3,060 & 3,320 & 3,660 & 3,849 & 4,046 \\
\hline \multirow{2}{*}{0,2} & 1ra & 0,099 & 0,196 & 0,289 & 0,453 & 0,584 & 0,683 & 0,723 & 0,756 \\
\hline & 2da & 2,450 & 2,490 & 2,540 & 2,700 & 2,930 & 3,220 & 3,387 & 3,560 \\
\hline
\end{tabular}




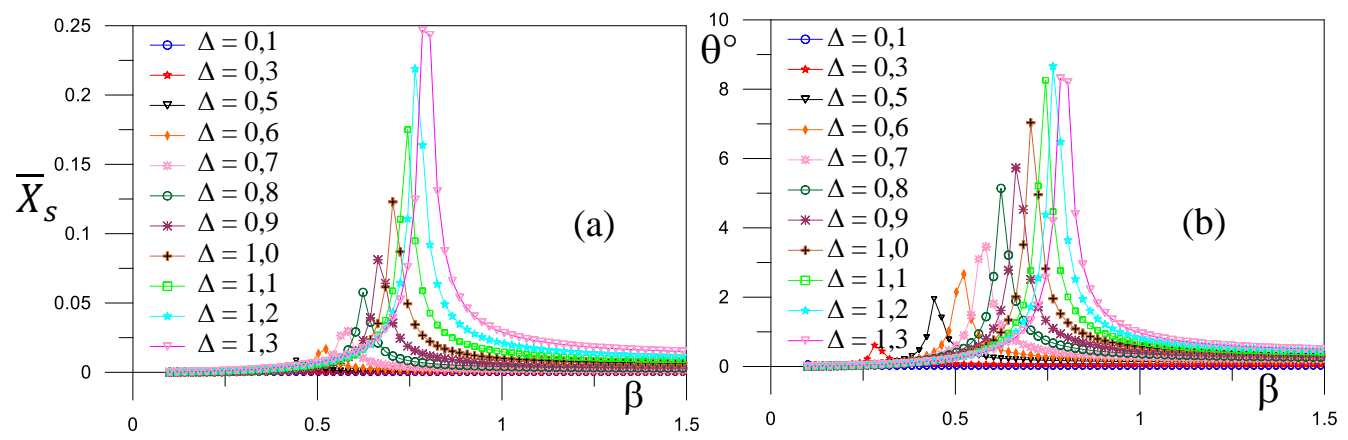

Figura 5-4 (a) Curvas de bifurcação do deslocamento horizontal da estrutura e (b) rotação do IBP. $\delta=0,01$.
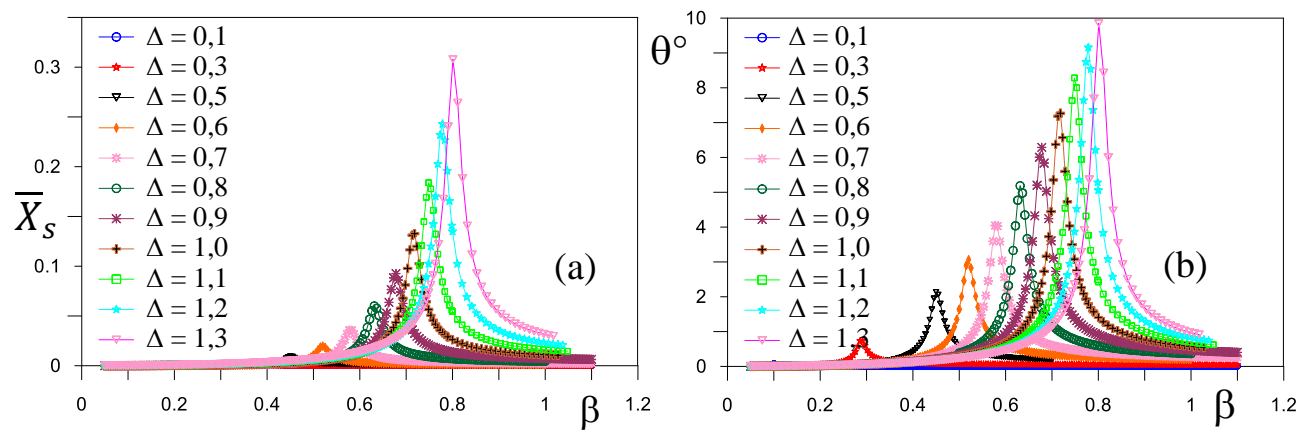

Figura 5-5 (a) Deslocamento horizontal da estrutura e (b) rotação do IBP. $\delta=0,1$

A Figura 5-4 mostra as curvas de ressonância na região da frequência fundamental para valores de $\Delta$ no intervalo $0,1 \leq \Delta \leq 1,3$ e $\delta=0,01$, enquanto na Figura 5-5 mostram-se no intervalo $0,1 \leq \Delta \leq 1,3$ os resultados para $\delta=0,1$. Observa-se que o pico de ressonância de deslocamento da estrutura e da rotação do IBP cresce com $\Delta$. Nas Figuras 5-6 e 5-7 mostra-se a comparação entre os valores máximos de deslocamentos e acelerações da estrutura com IBP e aqueles da estrutura sem isolamento de base. Nota-se que em ambos os casos os valores adimensionais de pico crescem com o aumento do parâmetro $\Delta$. A diferença em valor absoluto entre os valores com e sem controle também cresce com $\Delta$, sendo os valores do sistema estrutura-IBP sempre menores que os deslocamentos e acelerações da estrutura sem controle, mostrando que o IBP é bastante eficiente para todos os valores de $\Delta$ aqui analisados. O valor da rotação máxima do IBP não ultrapassa $10^{0}$, sendo compatível com os critérios de projeto de apoios de grandes estruturas (Lee et al., 2009 e Ramberger, 2002) 

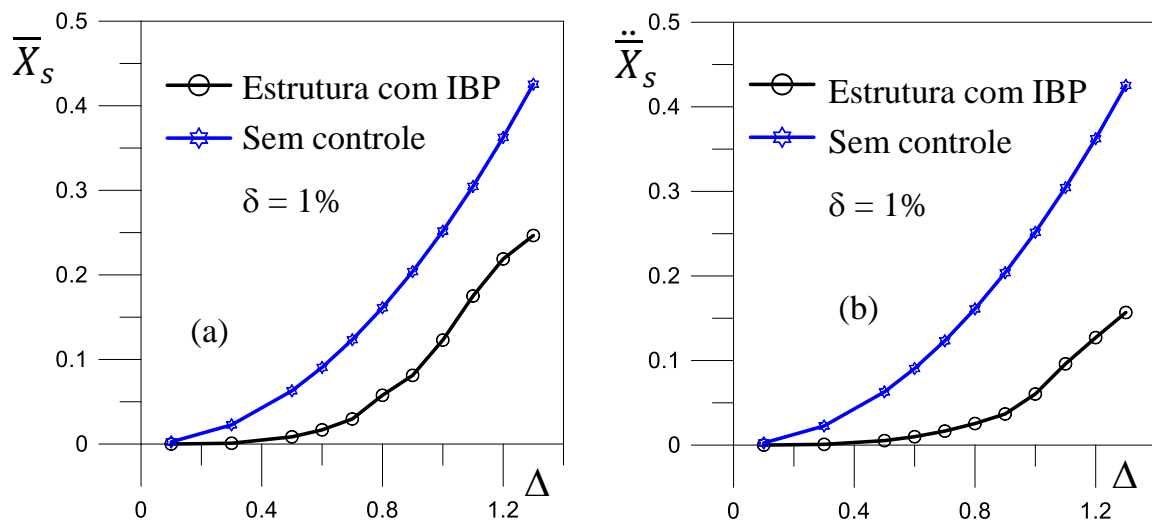

Figura 5-6 (a) Deslocamentos e (b) acelerações máximas da estrutura com IBP em função de $(\Delta)$
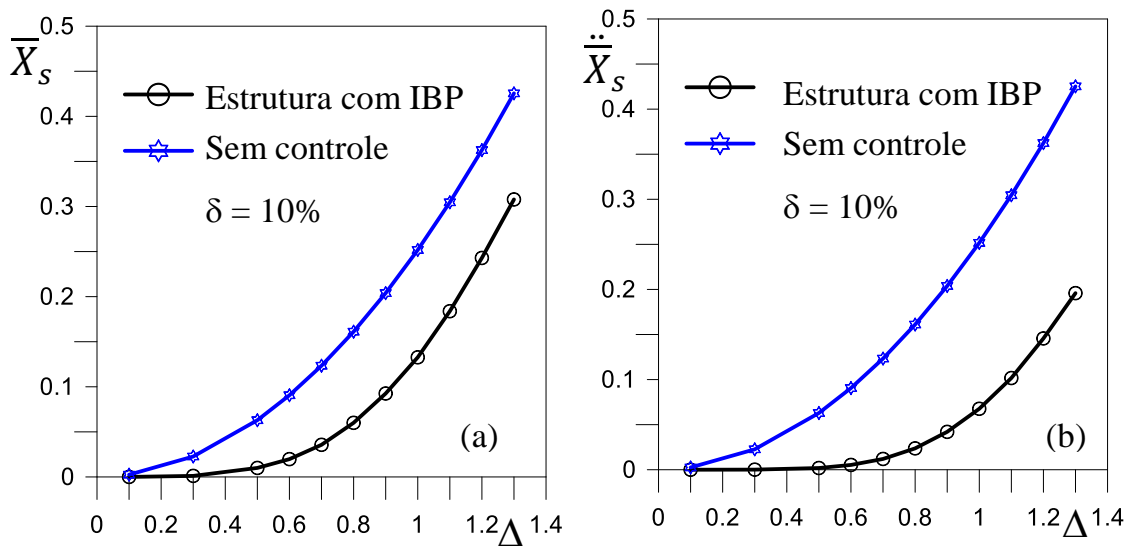

Figura 5-7 Deslocamentos e acelerações máximas da estrutura com IBP em função de ( $\Delta$ )

Tabela 5-2 Eficiência do IBP em função do valor de $\Delta, \quad \delta=0,01$. $d^{2} \bar{X}_{g} / d \tau^{2}=0,01 \Delta^{2} \beta^{2} \operatorname{sen}(\beta \tau)$

\begin{tabular}{|c|c|c|c|c|c|c|c|c|}
\hline \multirow{3}{*}{$\begin{array}{l}\text { TIPO DE } \\
\text { CURVA }\end{array}$} & \multirow{3}{*}{$\begin{array}{c}\text { Razão } \\
\text { de } \\
\text { freq. } \\
\Delta\end{array}$} & \multicolumn{3}{|c|}{ Estrutura com IBP } & \multirow{2}{*}{\multicolumn{2}{|c|}{ Sem controle }} & \multirow{2}{*}{\multicolumn{2}{|c|}{$\begin{array}{c}\text { Eficiência } \\
(\%)\end{array}$}} \\
\hline & & \multicolumn{2}{|c|}{ Estrutura Principal } & \multirow{2}{*}{$\frac{I B P}{\left(\theta^{\circ}\right)}$} & & & & \\
\hline & & $\left(\bar{X}_{s}\right)$ & $\left(\ddot{\bar{X}}_{s}\right)$ & & $\left(\overline{\boldsymbol{X}}_{s}\right)$ & $\left(\ddot{\bar{X}}_{s}\right)$ & $\left(\bar{X}_{s}\right)$ & $\left(\ddot{\bar{X}}_{s}\right)$ \\
\hline \multirow{11}{*}{ Circular } & 0,1 & 0,00001 & 0,00002 & 0,08 & 0,003 & 0,003 & 99,429 & 99,100 \\
\hline & 0,3 & 0,001 & 0,0009 & 0,61 & 0,023 & 0,023 & 95,755 & 96,084 \\
\hline & 0,5 & 0,009 & 0,0053 & 1,94 & 0,063 & 0,063 & 86,483 & 91,572 \\
\hline & 0,6 & 0,017 & 0,010 & 2,67 & 0,091 & 0,091 & 81,500 & 89,050 \\
\hline & 0,7 & 0,030 & 0,017 & 3,45 & 0,123 & 0,123 & 75,994 & 86,551 \\
\hline & 0,8 & 0,058 & 0,026 & 5,14 & 0,161 & 0,161 & 64,202 & 84,164 \\
\hline & 0,9 & 0,081 & 0,037 & 5,73 & 0,204 & 0,204 & 60,175 & 81,932 \\
\hline & 1,0 & 0,123 & 0,060 & 7,03 & 0,252 & 0,252 & 51,175 & 75,991 \\
\hline & 1,1 & 0,175 & 0,096 & 8,26 & 0,305 & 0,304 & 42,537 & 68,443 \\
\hline & 1,2 & 0,219 & 0,127 & 8,66 & 0,363 & 0,362 & 39,628 & 64,924 \\
\hline & 1,3 & 0,247 & 0,157 & 8,31 & 0,425 & 0,425 & 42,046 & 63,127 \\
\hline
\end{tabular}


Tabela 5-3 Eficiência do IBP em função do valor de $\Delta$, $\delta=0,1 . d^{2} \bar{X}_{g} / d \tau^{2}=0,01 \Delta^{2} \beta^{2} \operatorname{sen}(\beta \tau)$

\begin{tabular}{|c|c|c|c|c|c|c|c|c|}
\hline \multirow{3}{*}{$\begin{array}{l}\text { TIPO DE } \\
\text { CURVA }\end{array}$} & \multirow{3}{*}{$\begin{array}{c}\text { Razão } \\
\text { de } \\
\text { freq. } \\
\Delta\end{array}$} & \multicolumn{3}{|c|}{ Estrutura com IBP } & \multirow{2}{*}{\multicolumn{2}{|c|}{ Sem controle }} & \multirow{2}{*}{\multicolumn{2}{|c|}{$\begin{array}{c}\text { Eficiência } \\
(\%)\end{array}$}} \\
\hline & & \multicolumn{2}{|c|}{ Estrutura Principal } & \multirow{2}{*}{$\begin{array}{r}\text { IBP } \\
\left(\theta^{\circ}\right)\end{array}$} & & & & \\
\hline & & $\left(\bar{X}_{s}\right)$ & $\left(\ddot{\bar{X}}_{s}\right)$ & & $\left(\bar{X}_{s}\right)$ & $\left(\bar{X}_{s}\right)$ & $\left(\bar{X}_{s}\right)$ & $\left(\overline{\bar{X}}_{s}\right)$ \\
\hline \multirow{11}{*}{ Circular } & $\overline{0,1}$ & 0,00001 & 0,000002 & 0,08 & 0,003 & 0,003 & 99,43 & 99,93 \\
\hline & 0,3 & 0,001 & 0,0001 & 0,74 & 0,023 & 0,023 & 94,85 & $\mathbf{9 9 , 5 0}$ \\
\hline & 0,5 & 0,010 & 0,0019 & 2,14 & 0,063 & 0,063 & 84,88 & 96,94 \\
\hline & 0,6 & 0,020 & 0,005 & 3,07 & 0,091 & 0,091 & 78,20 & 94,13 \\
\hline & 0,7 & 0,036 & 0,012 & 4,04 & 0,123 & 0,123 & 71,10 & 90,29 \\
\hline & 0,8 & 0,060 & 0,024 & 5,19 & 0,161 & 0,161 & 62,73 & 85,29 \\
\hline & 0,9 & 0,093 & 0,042 & 6,29 & 0,204 & 0,204 & 54,61 & 79,38 \\
\hline & 1,0 & 0,133 & 0,068 & 7,27 & 0,252 & 0,252 & 47,29 & 73,12 \\
\hline & 1,1 & 0,184 & 0,102 & 8,28 & 0,305 & 0,304 & 39,65 & 66,59 \\
\hline & 1,2 & 0,243 & 0,146 & 9,16 & 0,363 & 0,362 & 32,99 & 59,80 \\
\hline & 1,3 & 0,308 & 0,196 & 9,85 & 0,425 & 0,425 & 27,65 & 53,94 \\
\hline
\end{tabular}

Quantitativamente, a eficiência do IBP é ilustrada na Tabela 5-2. Pode-se observar que, quanto menor é o valor de $\Delta$, maior é a eficiência do IBP, chegando a ter uma redução de mais de 99\% nos deslocamento e aceleração máxima para $\Delta=0,1$. Para $\Delta=1,3$ a redução no deslocamento cai para $42 \%$, enquanto a redução na aceleração cai para 63 \%, valores ainda bem satisfatórios em termos de projeto. Cabe ressaltar que na Tabela 5-2 a força de excitação na forma adimensional usadas para gerar o movimento de base, definida no Cap.2.6, Eq.2.30, encontra-se em função do parâmetro $\Delta$. Assim para cada valor de $\Delta$ tem-se uma diferente amplitude da força harmônica de excitação adimensional.

A maior eficiência deste tipo de sistema de controle é baseada na definição clássica do isolador de base Naeim e Kelly (1999), Soong e Dargush (1997); quanto maior é o deslocamento da base da estrutura, menores são os deslocamentos relativos da estrutura, diminuindo consequentemente os esforços adicionais na estrutura gerados pela excitação de base. Para sintonizar as frequências necessita-se determinar o raio de curvatura. Usando como exemplo uma estrutura com frequência fundamental de 3,17 rad/s e tendo-se que o raio de curvatura é inversamente proporcional ao valor de $\Delta$, para $\Delta=0,1$ encontra-se $R_{c}=$ $99,24 m$ e para $\Delta=1,3$ é necessário um $R_{c}=0,58 m$. Verifica-se assim que um valor menor de $\Delta$ permite maiores deslocamentos da base, além de gerar pequenos movimentos verticais e, portanto, pequenos valores de $\theta$, como mostra a Figura 5-4. Cabe destacar que o IBP é eficiente tanto no controle dos deslocamentos 
quanto no controle das acelerações da estrutura principal, contribuindo não só para a segurança da estrutura, como também para o conforto dos usuários.

O valor máximo do ângulo $\theta$ no projeto do IBP é uma variável muito importante, já que dele depende, por exemplo, o valor mínimo do coeficiente $\mu_{s}$ para garantir o rolamento sem deslizamento do cilindro (Lee et al., 2009) e, principalmente, a quantidade de energia a ser absorvida pelo IBP, como mostrado no Cap. 3.

Como mostra a Figura 5-2, tem-se na região estudada uma segunda frequência de vibração relacionada com o deslocamento das duas massas em sentidos opostos, criando grandes deslocamentos relativos. Em estruturas com sistemas de isolamento de base a massa da base acima do sistema de isolamento varia na faixa de $1 \%$ a $20 \%$ da massa da estrutura. Um estudo mais minucioso na vizinhança da primeira frequência de vibração é apresentado nas Figura 5-8 e Figura 5-9, com $\delta$ variando no intervalo $0,01 \leq \delta \leq 0,2$, considerando dois valores de $\Delta(0,1$ e 0,3$)$.

A Figura 5-8, mostra as curvas de ressonância na faixa de frequências que contém as duas frequências naturais do sistema para $\Delta=0,1$. Verifica-se que na vizinhança da segunda frequência natural os valores máximos são apenas um pouco maiores que na região da primeira frequência, mas bem menores que aqueles observados para a estrutura não controlada, não oferecendo, portanto, riscos para a estrutura.

A Figura 5-9, mostra os resultados da análise paramétrica, considerando $\Delta=0,3$. Neste caso os picos de ressonância da segunda frequência são bem menores que aqueles do primeiro pico, mantendo este comportamento para valores mais altos de $\Delta$. 


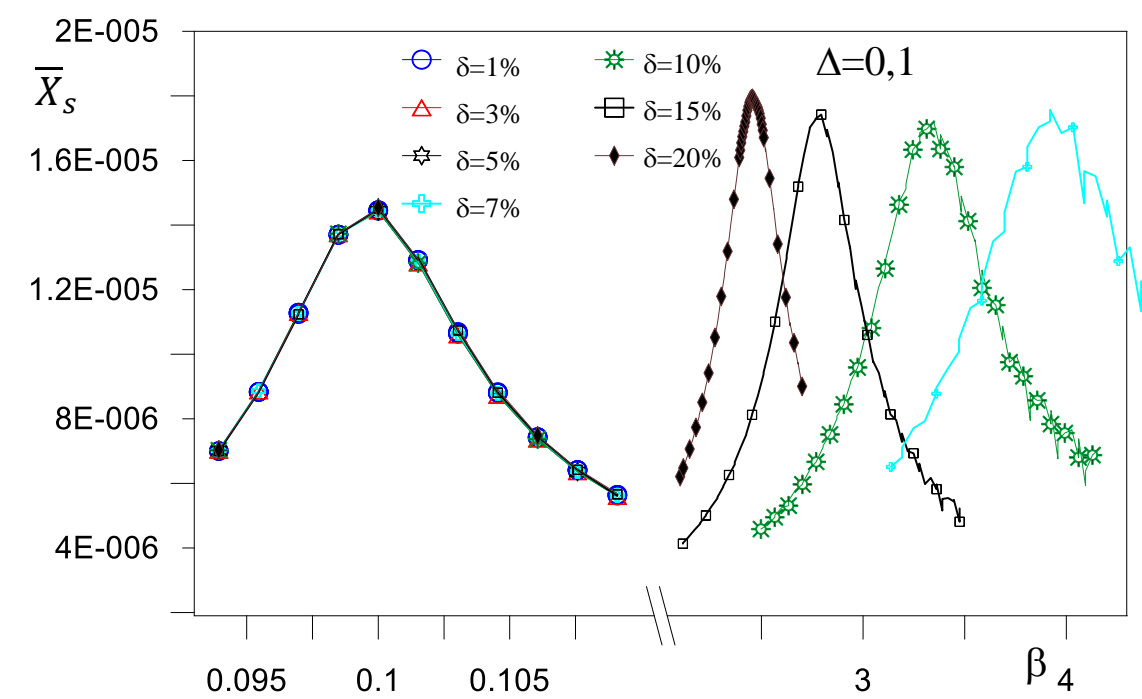

Figura 5-8 Diagrama de bifurcação na vizinhança das frequências de vibração $(\Delta=0,1)$ da estrutura com IBP

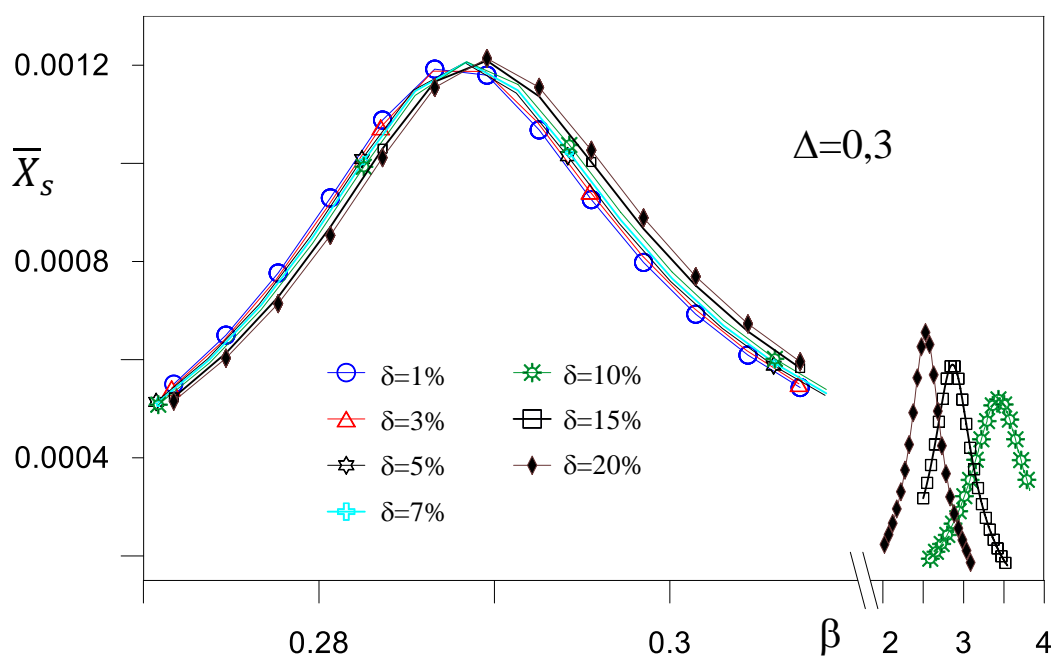

Figura 5-9 Diagrama de bifurcação na vizinhança das frequências de vibração $(\Delta=0,3)$ da estrutura com IBP

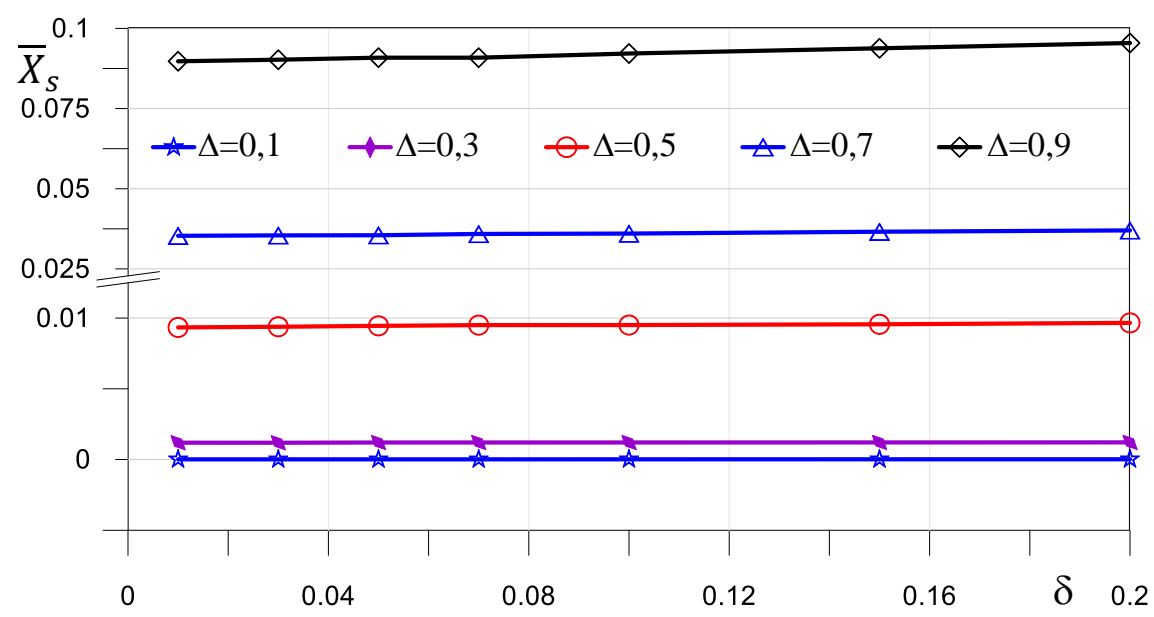

Figura 5-10 Deslocamento máximo da estrutura em função da razão de massas. 
A Figura 5-10 mostra a variação dos deslocamentos máximos para valores selecionados de $\Delta$. Como já observado nos exemplos anteriores, a razão de massas $\delta$ tem pequena influência no deslocamento máximo da estrutura controlada. Temse, portanto, que $\Delta$ é o principal parâmetro de projeto no caso do IBP.

As Tabela 5-4 a Tabela 5-6 demonstram a eficiência do IBP em função da razão de massas para $\delta$ variando no intervalo $0,01 \leq \delta \leq 0,2$, considerando três valores de $\Delta(0,1,0,3$ e 0,9$)$. Verifica-se, como nos estudos anteriores, uma redução considerável nos deslocamentos e acelerações da estrutura, com poucas variações nos valores das reduções. A eficiência diminui lentamente com $\Delta$, mas mesmo para $\Delta=0,9$, ainda se tem valores aceitáveis. Cabe lembrar que valores elevados de $\Delta$ (pequeno raio de curvatura) não são apropriados para o IBP. Em todos os casos verifica-se que as rotações do IBP são muito pequenas, facilmente ajustáveis ao projeto mecânico do isolador de base

Tabela 5-4 Valores máximos dos deslocamentos e acelerações da estrutura e rotações do IBP $\Delta=0,1$

Estrutura com IBP

\begin{tabular}{|c|c|c|c|c|c|}
\hline \multirow{2}{*}{ Controle } & & \multirow{2}{*}{$\begin{array}{c}\text { Razão de } \\
\text { massas } \\
\delta\end{array}$} & \multicolumn{2}{|c|}{ Estrutura Principal } & \multirow{2}{*}{$\begin{array}{c}\text { IBP } \\
\begin{array}{c}\text { Rotação } \\
\left({ }^{\circ}\right)\end{array} \\
\end{array}$} \\
\hline & & & Deslocamento & Aceleração & \\
\hline \multirow{7}{*}{$\begin{array}{c}\text { IBP } \\
\text { Circular }\end{array}$} & $\boldsymbol{A}$ & $1 \%$ & 0,000014 & 0,000001 & 0,082 \\
\hline & $\boldsymbol{B}$ & $3 \%$ & 0,000014 & 0,000001 & 0,082 \\
\hline & $C$ & $5 \%$ & 0,000014 & 0,000001 & 0,082 \\
\hline & $D$ & $7 \%$ & 0,000014 & 0,000001 & 0,082 \\
\hline & $E$ & $10 \%$ & 0,000017 & 0,000000 & 0,082 \\
\hline & $\boldsymbol{F}$ & $15 \%$ & 0,000018 & 0,000134 & 0,082 \\
\hline & $G$ & $20 \%$ & 0,000018 & 0,000108 & 0,010 \\
\hline Sem Controle & $H$ & & 0,003 & 0,003 & \\
\hline \multirow{7}{*}{$\underset{\%}{\text { Redução }}$} & $H-A$ & & 99,43 & 99,96 & \\
\hline & $H-B$ & & 99,43 & 99,96 & \\
\hline & $\mathrm{H}-\mathrm{C}$ & & 99,43 & 99,96 & \\
\hline & $H-D$ & & 99,43 & 99,96 & \\
\hline & $H-E$ & & 99,31 & 99,99 & \\
\hline & $H-F$ & & 99,27 & 94,68 & \\
\hline & $H-G$ & & 99,27 & 95,71 & \\
\hline
\end{tabular}


Tabela 5-5 Valores máximos dos deslocamentos e acelerações da estrutura e rotações do IBP $\Delta=0,3$

Estrutura com IBP

\begin{tabular}{|c|c|c|c|c|c|}
\hline \multirow[b]{2}{*}{ Controle } & & \multirow{2}{*}{$\begin{array}{c}\text { Razão de } \\
\text { massas }\end{array}$} & \multicolumn{2}{|c|}{ Estrutura Principal } & \multirow{2}{*}{$\begin{array}{c}\text { IBP } \\
\text { Rotação } \\
\left({ }^{\circ}\right)\end{array}$} \\
\hline & & & Deslocamento & Aceleração & \\
\hline \multirow{7}{*}{$\begin{array}{c}\text { IBP } \\
\text { Circular }\end{array}$} & $\bar{A}$ & $1 \%$ & 0,001192 & 0,000099 & 0,757 \\
\hline & $\boldsymbol{B}$ & $3 \%$ & 0,001188 & 0,000100 & 0,753 \\
\hline & C & $5 \%$ & 0,001205 & 0,000101 & 0,762 \\
\hline & $D$ & $7 \%$ & 0,001206 & 0,000101 & 0,762 \\
\hline & $\boldsymbol{E}$ & $10 \%$ & 0,001207 & 0,000101 & 0,762 \\
\hline & $\boldsymbol{F}$ & $15 \%$ & 0,001209 & 0,000102 & 0,760 \\
\hline & $G$ & $20 \%$ & 0,001214 & 0,000102 & 0,760 \\
\hline Sem Controle & $\boldsymbol{H}$ & & $\mathbf{0 , 0 2 3}$ & $\mathbf{0 , 0 2 3}$ & \\
\hline \multirow{7}{*}{$\underset{\%}{\text { Redução }}$} & $\boldsymbol{H}-\boldsymbol{A}$ & & 94,74 & 99,56 & \\
\hline & $H-B$ & & 94,76 & 99,56 & \\
\hline & $\mathrm{H}-\mathrm{C}$ & & 94,68 & 99,56 & \\
\hline & $H-D$ & & 94,68 & 99,56 & \\
\hline & $H-E$ & & 94,67 & 99,56 & \\
\hline & $H-F$ & & 94,66 & 99,55 & \\
\hline & $H-G$ & & 94,64 & 99,55 & \\
\hline
\end{tabular}

Tabela 5-6 Valores máximos dos deslocamentos e acelerações da estrutura e rotações do IBP $\Delta=0,9$

Estrutura com IBP

\begin{tabular}{|c|c|c|c|c|c|}
\hline \multirow[b]{2}{*}{ Controle } & & \multirow{2}{*}{$\begin{array}{c}\text { Razão de } \\
\text { massas } \\
\delta\end{array}$} & \multicolumn{2}{|c|}{ Estrutura Principal } & \multirow{2}{*}{$\begin{array}{c}\text { IBP } \\
\text { Rotação } \\
\left({ }^{\circ}\right)\end{array}$} \\
\hline & & & Deslocamento & Aceleração & \\
\hline \multirow{7}{*}{$\begin{array}{c}\text { IBP } \\
\text { Circular }\end{array}$} & $\bar{A}$ & $1 \%$ & 0,0897 & 0,040 & 6,34 \\
\hline & $\boldsymbol{B}$ & $3 \%$ & 0,0902 & 0,040 & 6,32 \\
\hline & C & $5 \%$ & 0,0909 & 0,041 & 6,31 \\
\hline & $D$ & $7 \%$ & 0,0909 & 0,041 & 6,30 \\
\hline & $\boldsymbol{E}$ & $10 \%$ & 0,0922 & 0,042 & 6,26 \\
\hline & $\boldsymbol{F}$ & $15 \%$ & 0,0938 & 0,043 & 6,26 \\
\hline & $G$ & $20 \%$ & 0,0955 & 0,044 & 6,235 \\
\hline Sem Controle & $\boldsymbol{H}$ & & 0,204 & 0,204 & \\
\hline \multirow{7}{*}{$\underset{\%}{\text { Redução }}$} & $H-A$ & & 55,99 & 80,45 & \\
\hline & $H-B$ & & 55,75 & 80,15 & \\
\hline & $\mathrm{H}-\mathrm{C}$ & & 55,44 & 80,04 & \\
\hline & $H-D$ & & 55,44 & 80,04 & \\
\hline & $H-E$ & & 54,80 & 79,42 & \\
\hline & $H-F$ & & 54,00 & 78,86 & \\
\hline & $H-G$ & & 53,20 & 78,30 & \\
\hline
\end{tabular}

\subsection{1.}

\section{Análise paramétrica da não linearidade da força de amortecimento}

A força de amortecimento não linear descrita pela Eq.2.28 é função da variável $\alpha$ cuja faixa de variação usual ocorre no intervalo $0,2 \leq \alpha \leq 2$ 
(Constantinou et al., 1993). A análise paramétrica é realizada para os seguintes parâmetros adimensionais: $\xi_{S}=0,02 ; \xi_{a}=0,035 ; \Delta=0,1$ e $\delta=0,1$.
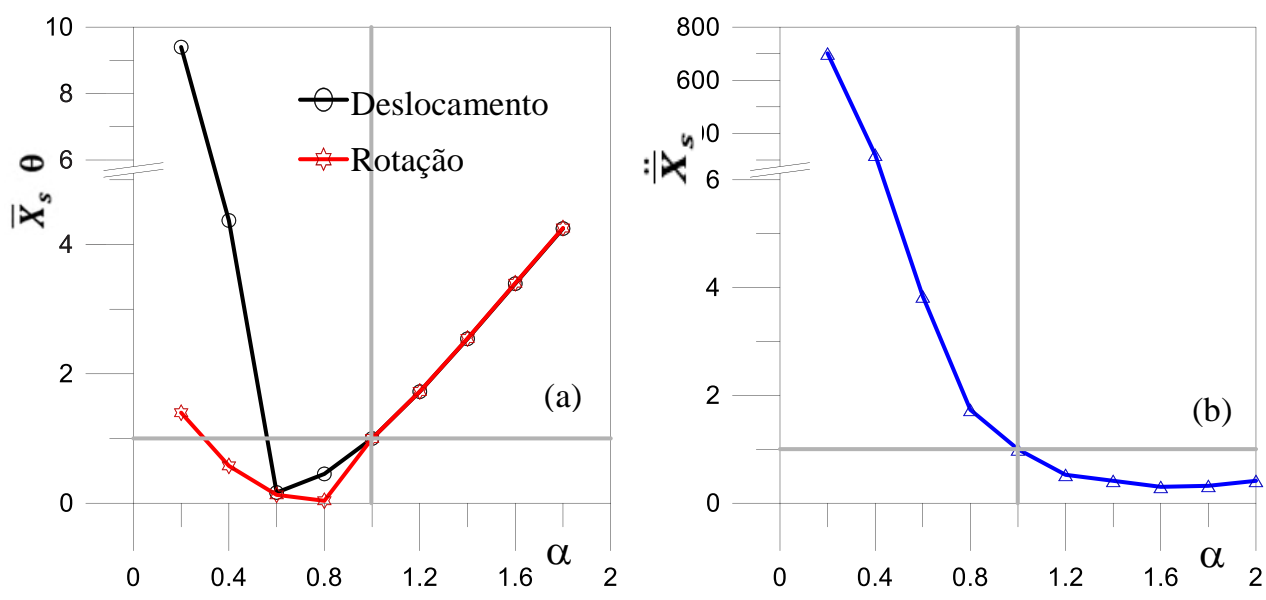

Figura 5-11 (a) Influência no deslocamento da estrutura e rotação do IBP e (b) das acelerações da estrutura da variável $\alpha$. Para $\xi_{s}=0,02 ; \xi_{s}=0,035 ; \Delta=0,1 ; \delta=0,1$

A Figura 5-11-(a) mostra a influência do parâmetro $\alpha$ nos deslocamentos máximos da estrutura e rotações do IBP. O parâmetro provoca uma sensível redução no intervalo $0,4 \leq \alpha<1$. A maior redução em relação ao caso linear de referência $(\alpha=1,0)$ acontece para o valor de $\alpha=0,6$. Entretanto, em termos de acelerações, há um aumento considerável nesta região, como mostra a Figura 5-11-(b). Por outro lado, há uma clara redução da aceleração para $\alpha>1$. As variações com relação ao caso linear são apresentadas na Tabela 5-7.

Tabela 5-7 Influência da variável $(\alpha)$ do amortecimento na resposta do sistema Estrutura IBP-2GL $\xi_{s}=0,02 ; \xi_{s}=0,035 ; \Delta=0,1 ; \delta=0,1$

\begin{tabular}{cccccccc}
\hline \multirow{2}{*}{$\begin{array}{c}\text { TIPO } \\
\text { DE }\end{array}$} & \begin{tabular}{c} 
Parâmetro \\
\cline { 3 - 7 } CURVA
\end{tabular} & $(\boldsymbol{\alpha})$ & \multicolumn{7}{c}{ Estrutura Principal } & \multicolumn{2}{c}{ IBP } \\
\cline { 3 - 8 } & & $\left(\overline{\boldsymbol{X}}_{\boldsymbol{s}}\right)$ & Variação & $\left.\ddot{\overline{\boldsymbol{X}}}_{\boldsymbol{s}}\right)$ & Variação & $\left(\boldsymbol{\theta}^{\circ}\right)$ & Variação \\
\hline & 0,2 & 0,000136 & $\mathbf{9 , 7 6}$ & 0,001606 & $\mathbf{1 3 9 8 , 7 0}$ & 0,12 & $\mathbf{1 , 4 5}$ \\
& 0,4 & 0,000063 & $\mathbf{4 , 5 4}$ & 0,000733 & $\mathbf{6 3 8 , 6 9}$ & 0,05 & $\mathbf{0 , 6 0}$ \\
& 0,6 & 0,000002 & $\mathbf{0 , 1 7}$ & 0,000009 & $\mathbf{7 , 6 6}$ & 0,01 & $\mathbf{0 , 1 3}$ \\
& 0,8 & 0,000007 & $\mathbf{0 , 4 7}$ & 0,000001 & $\mathbf{1 , 1 7}$ & 0,04 & $\mathbf{0 , 4 6}$ \\
Circular & 1,0 & 0,000014 & $\mathbf{1 , 0 0}$ & 0,000001 & $\mathbf{1 , 0 0}$ & 0,08 & $\mathbf{1 , 0 0}$ \\
& 1,2 & 0,000025 & $\mathbf{1 , 7 9}$ & 0,000001 & $\mathbf{1 , 0 5}$ & 0,14 & $\mathbf{1 , 7 9}$ \\
& 1,4 & 0,000037 & $\mathbf{2 , 6 4}$ & 0,000001 & $\mathbf{0 , 8 3}$ & 0,21 & $\mathbf{2 , 6 5}$ \\
& 1,6 & 0,000049 & $\mathbf{3 , 5 3}$ & 0,000001 & $\mathbf{0 , 6 0}$ & 0,28 & $\mathbf{3 , 5 3}$ \\
& 1,8 & 0,000062 & $\mathbf{4 , 4 1}$ & 0,000001 & $\mathbf{0 , 6 4}$ & 0,35 & $\mathbf{4 , 4 2}$ \\
& 2,0 & 0,000074 & $\mathbf{5 , 2 7}$ & 0,000001 & $\mathbf{0 , 8 3}$ & 0,42 & $\mathbf{5 , 2 8}$ \\
\hline
\end{tabular}




\section{5.}

\section{Análise da resposta no tempo com carga harmônica e step load}

\subsection{1.}

\section{Resposta no tempo com carga harmônica}

Nos itens anteriores analisou-se a influência do IBP na resposta permanente da estrutura através da análise das curvas de ressonância não lineares (diagramas de bifurcação). A seguir, estuda-se o efeito do IBP na resposta no tempo, incluindo a fase transiente e a fase permanente da resposta. Inicialmente estuda-se o efeito de um carregamento harmônico.

A resposta do sistema estrutura-IBP e estrutura sem controle, quando é excitada com carregamento harmônico de base $\left(d^{2} \bar{X}_{g} / d \tau^{2}=0,01 \Delta^{2} \beta^{2} \operatorname{sen}(\beta \tau)\right)$ é mostrada na Figura 5-12 e a resposta do IBP é mostrada na Figura 5-13. A estrutura é excitada com a frequência natural de vibração da estrutura sem controle, $\beta=1$. Os parâmetros adotados são $\delta=0,1, \Delta=0,1, \xi_{s}=0,02$ e $\xi_{a}=0,035$.

No caso da estrutura sem controle, o deslocamento máximo é de $\bar{X}_{s}=$ $2,5 E+3$ e para a estrutura com IBP o máximo valor é de $\bar{X}_{S}=1,08 E-5$, ambas na fase permanente. A eficiência do sistema de controle passivo neste caso é de 99,5 \%. A rotação máxima do IBP neste caso é de $0,06^{\circ}$, na fase transiente. Notase que o efeito do IBP se faz sentir logo nos primeiros ciclos do movimento, chegando a estrutura rapidamente a um movimento permanente de pequena amplitude.

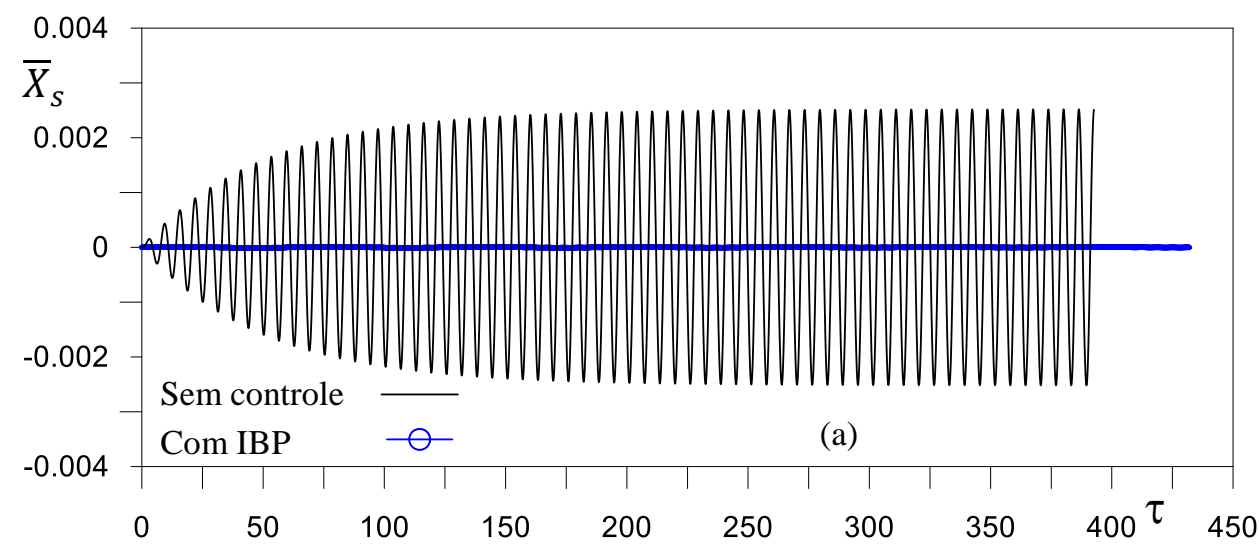




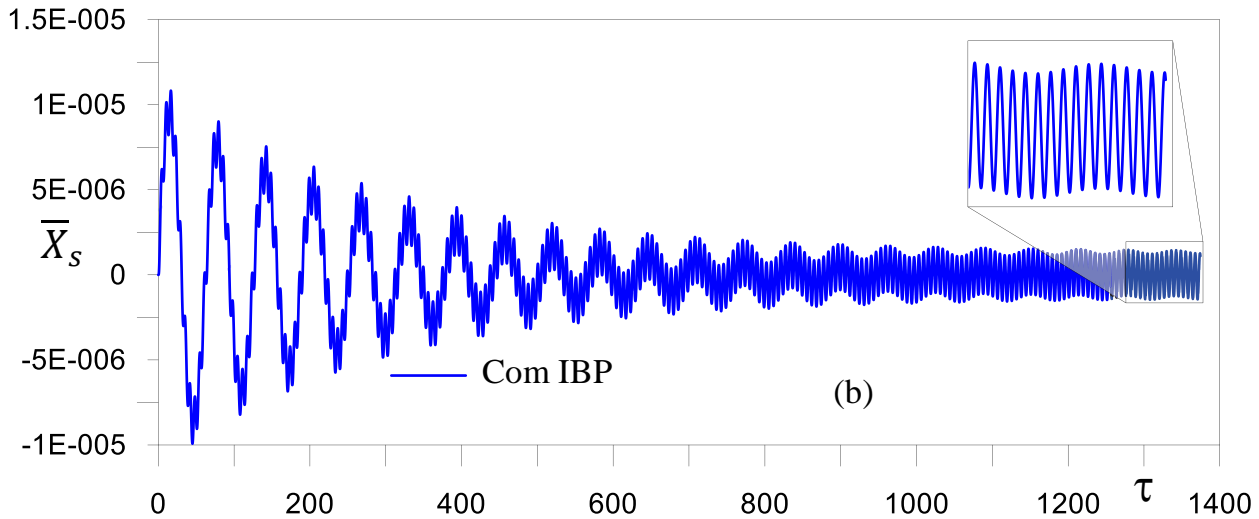

Figura 5-12 Deslocamento da estrutura com e sem controle, (b) estrutura com IBP no tempo para $\beta=1 \delta=0,1 ; \Delta=0,1$

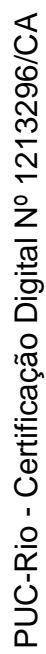

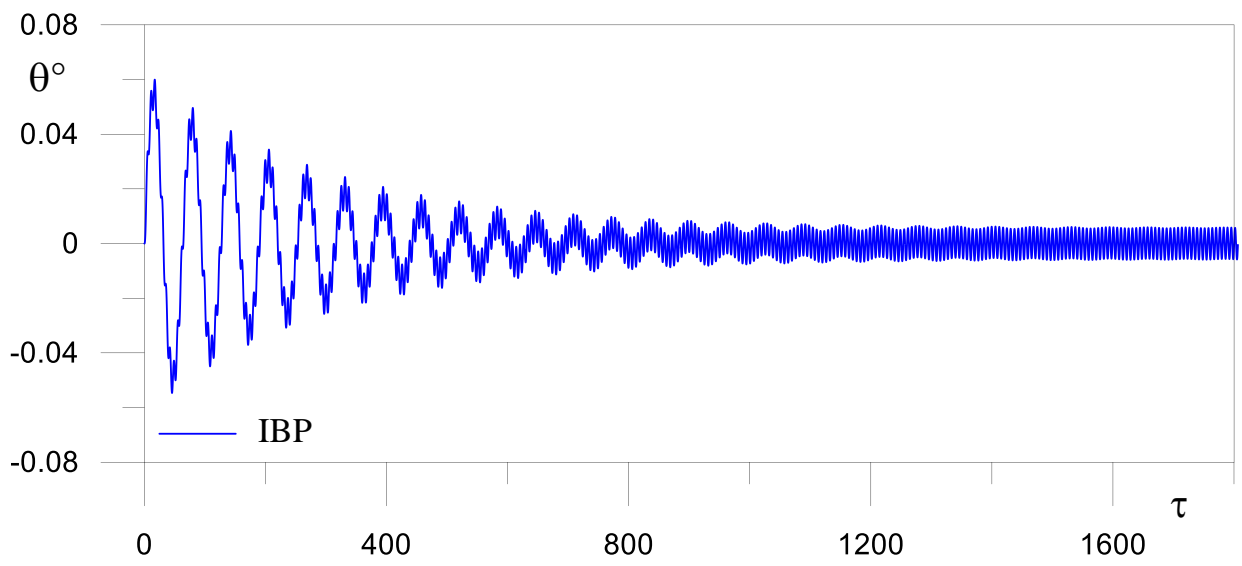

Figura 5-13 Rotações do IBP no tempo $\beta=1 \delta=0,1 ; \Delta=0,1$

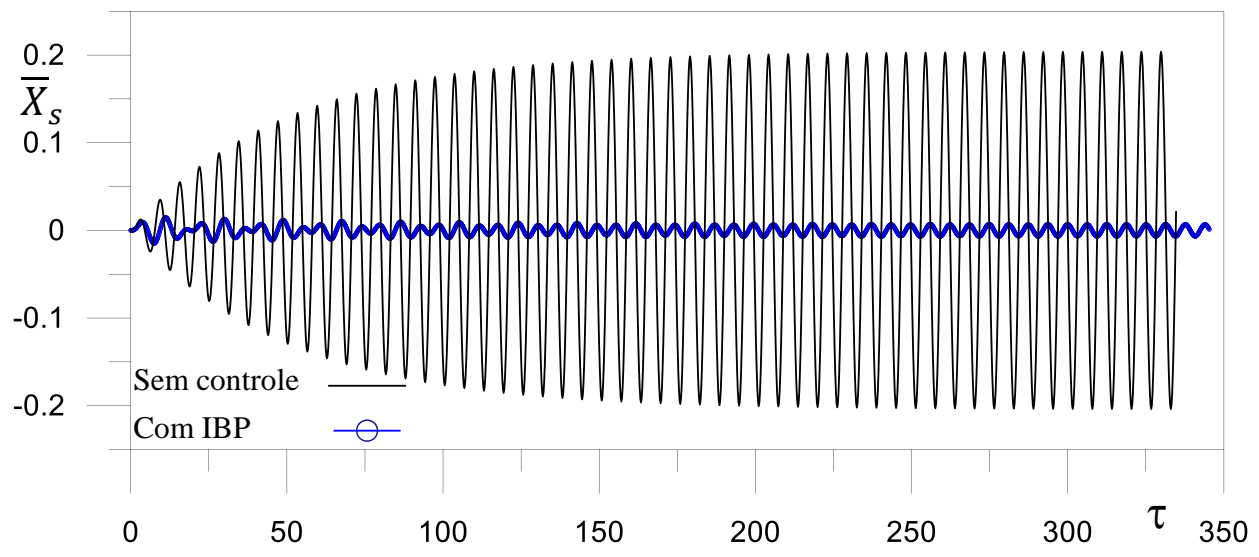




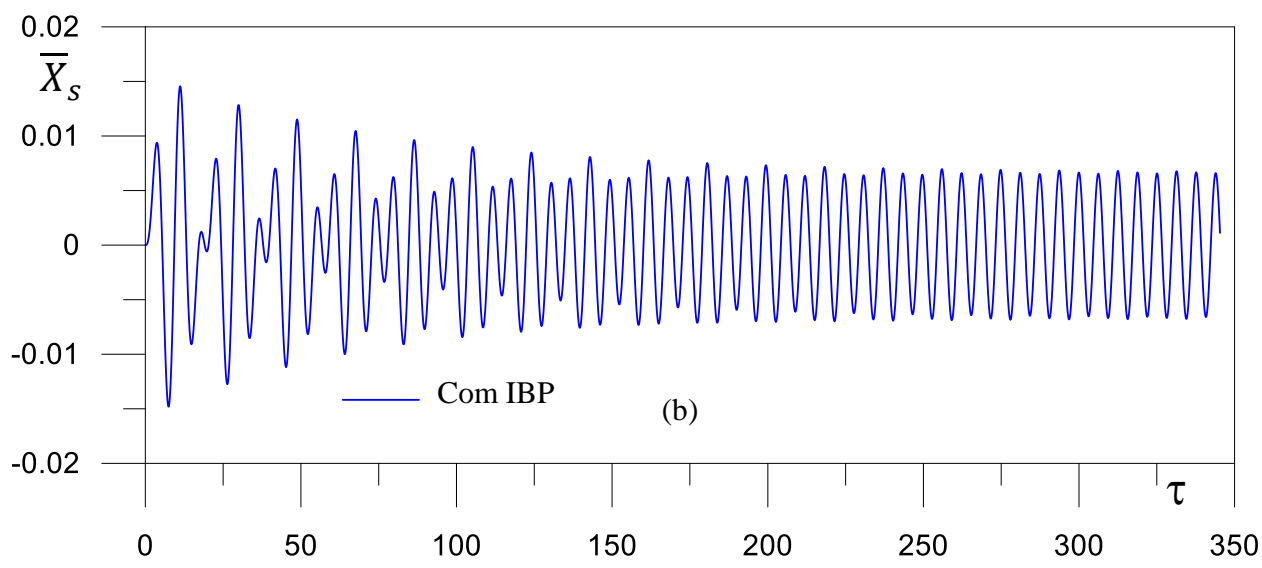

Figura 5-14 (a) Deslocamento da estrutura com e sem controle, (b) estrutura com IBP no tempo para $\beta=1 \delta=0,01 ; \Delta=0,9$

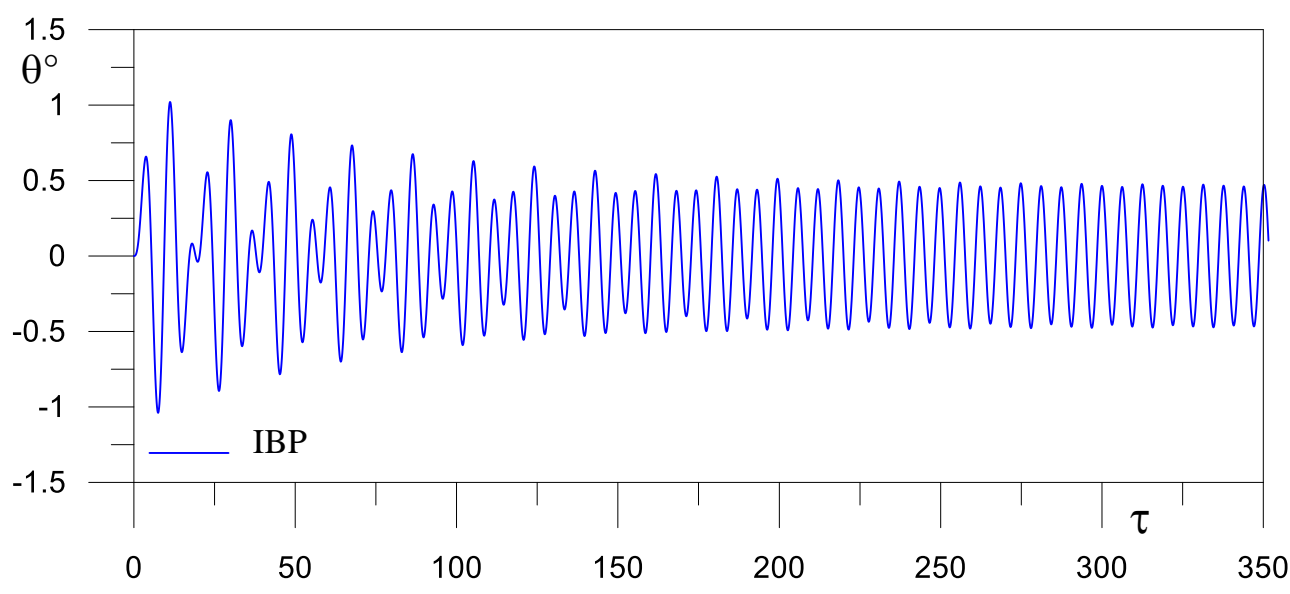

Figura 5-15 Rotações do IBP no tempo $\beta=1 \delta=0,01 ; \Delta=0,9$

A Figura 5-14 e a Figura 5-15, mostram a resposta da estrutura no tempo para $\delta=0,01$ e $\Delta=0,9$. Nota-se novamente a grande eficiência do IBP na redução dos deslocamentos.

\subsection{2.}

\section{Resposta a um deslocamento inicial}

As estruturas podem estar sujeitas a certos distúrbios momentâneos que podem ser modelados como condições iniciais da vibração livre amortecida. Uma análise da estrutura é conduzida impondo-se um deslocamento inicial à estrutura $\bar{X}_{S}(0)=0,1$. Os parâmetros adotados são $\delta=0,1, \Delta=0,1, \xi_{S}=0,02$ e $\xi_{a}=0,035$. A Figura 5-16, mostra o comportamento da estrutura com e sem controle ao longo do tempo. Pode-se observar que a estrutura com IBP, ao se deslocar no sentido 
oposto, já apresenta uma redução de deslocamento antes de atingir o primeiro pico negativo e volta rapidamente à posição de repouso, enquanto as rotações do IBP decrescem suavemente. É interessante observar a diferença de período das três soluções, com a estrutura controlada apresentando uma sensível redução de período comparada à solução sem controle e o IBP apresentando um período bastante longo.

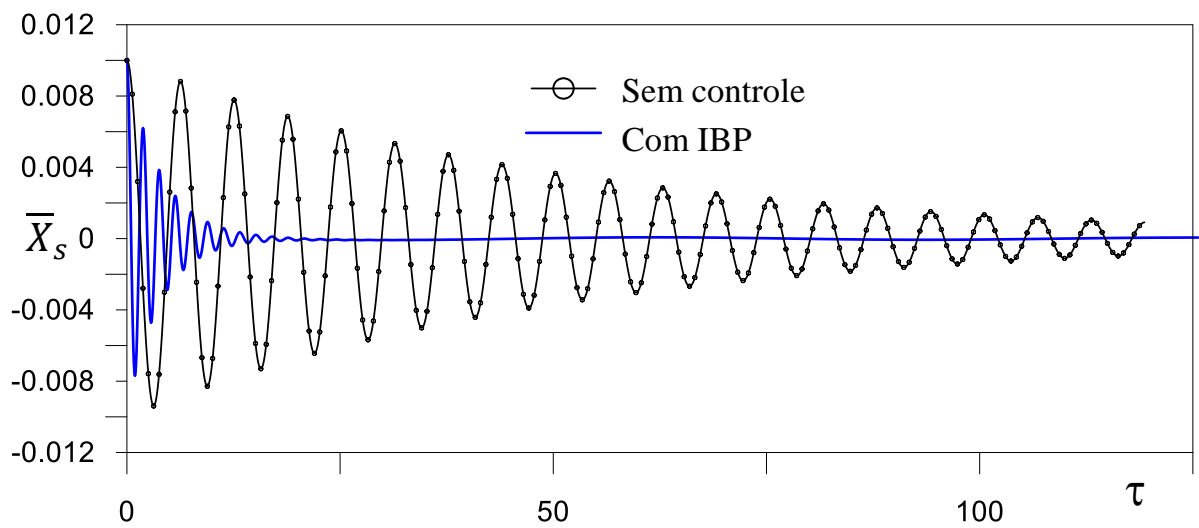

Figura 5-16 Deslocamento da estrutura com IBP e sem controle no tempo $\delta=0,1 ; \Delta=0,1$

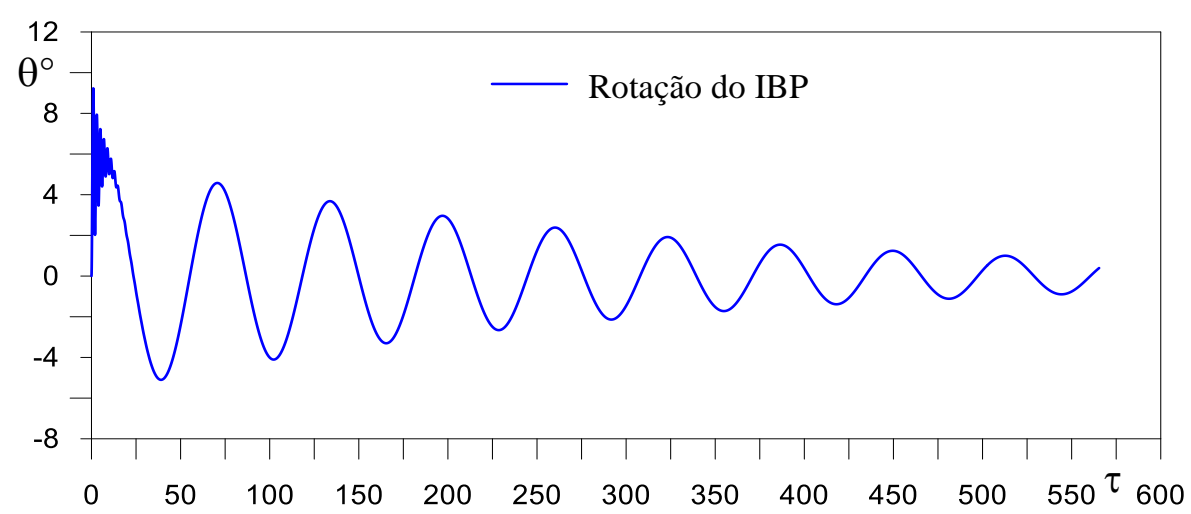

Figura 5-17 Variação da rotação do IBP no tempo em vibração livre $\delta=0,1 ; \Delta=0,1$

\section{6.}

\section{Análise da resposta no tempo com carga sísmica}

Os sistemas de isolamento de base têm como uma de suas caraterísticas principais a diminuição sensível da primeira frequência natural da estrutura, em particular para valores pequenos de $\Delta$, como mostra a Tabela 5-1, afastando-a do conteúdo de frequências perigosas da maioria dos sismos. Com a finalidade de avaliar a eficiência do IBP na presença de eventos sísmicos, analisa-se a seguir a estrutura com e sem isolamento de base submetida aos seguintes acelerogramas: 
componentes EW e NS do terremoto El-Centro e a componente EW do terremoto Loma Prieta. Os três sinais têm diferentes conteúdos de frequências e níveis de aceleração do solo, como visto nos capítulos anteriores, permitindo uma análise abrangente da eficiência do IBP. Inicialmente considera-se um sistema estruturaIBP $\operatorname{com} \delta=0,1, \Delta=0,1, \xi_{s}=0,02$ e $\xi_{a}=0,035$. A Figura 5-18 à Figura 5-23 ilustram as respostas em termos de deslocamentos e acelerações da estrutura e rotação do IBP para os três acelerogramas. Considera-se para o El-Centro EW uma magnitude de $\ddot{\bar{X}}_{g}=0,21 g$, para o El-Centro NS uma magnitude de $\ddot{\bar{X}}_{g}=$ $0,35 g$ e para o Loma-Prieta uma magnitude de $\ddot{\bar{X}}_{g}=0,15 g$. Em todos os casos observa-se uma redução considerável nos deslocamentos e acelerações da estrutura com o IBP apresentando pequenas rotações. Ao contrário do APMS, verifica-se que a eficiência do IBP é pouco influenciada pelo conteúdo de frequência do sismo e por sua magnitude.
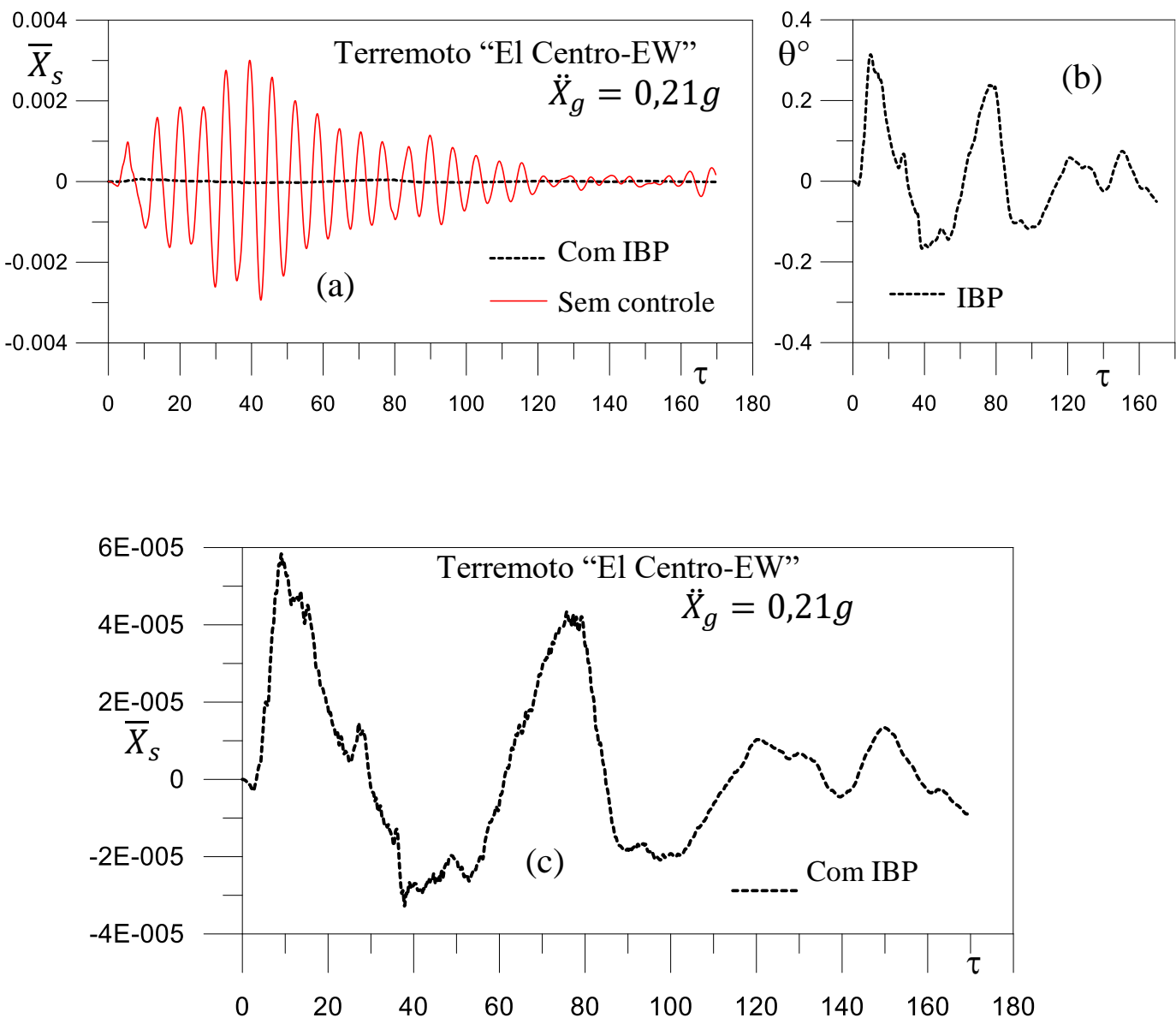

Figura 5-18 (a) Comparação dos deslocamentos da estrutura com e sem controle, (b) rotação do IBP e (c) deslocamento da estrutura com IBP, com carga sísmica $\xi_{s}=$ 0,$02 ; \xi_{s}=0,035 ; \Delta=0,1 ; \delta=0,1$ 


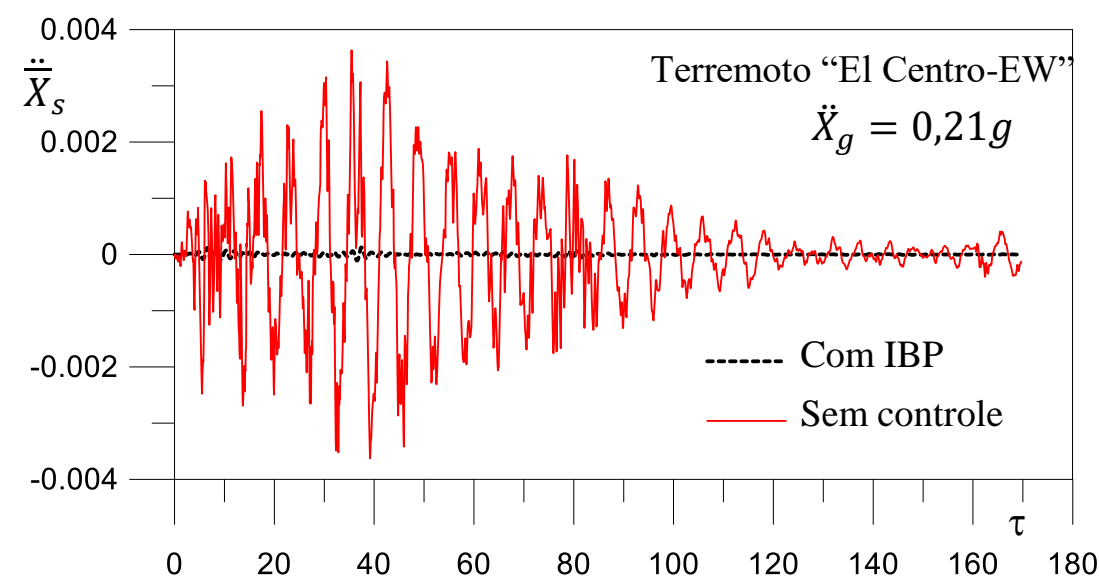

Figura 5-19 Acelerações da estrutura com carga sísmica $\left(\xi_{s}=0,02 ; \xi_{s}=0,035 ; \Delta=\right.$ 0,$1 ; \delta=0,1$

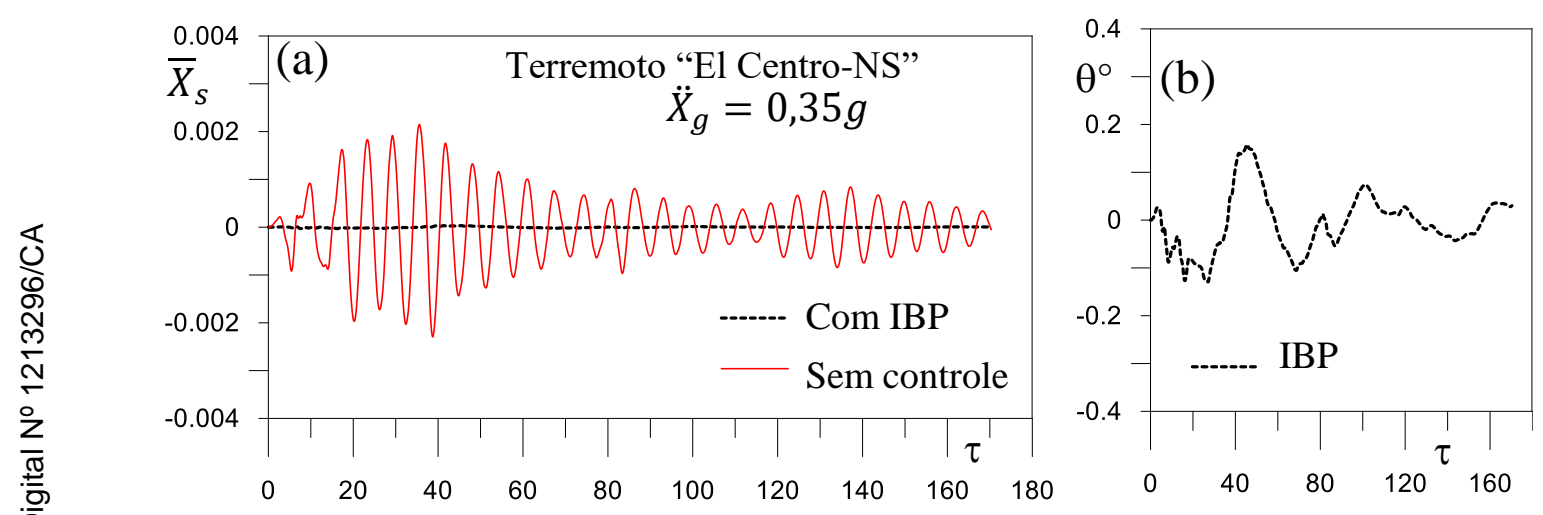

Figura 5-20 Deslocamentos da estrutura (a) e rotação do IBP (b) com carga sísmica ( $\xi_{s}=$ 0,$\left.02 ; \xi_{s}=0,035 ; \Delta=0,1 ; \delta=0,1\right)$

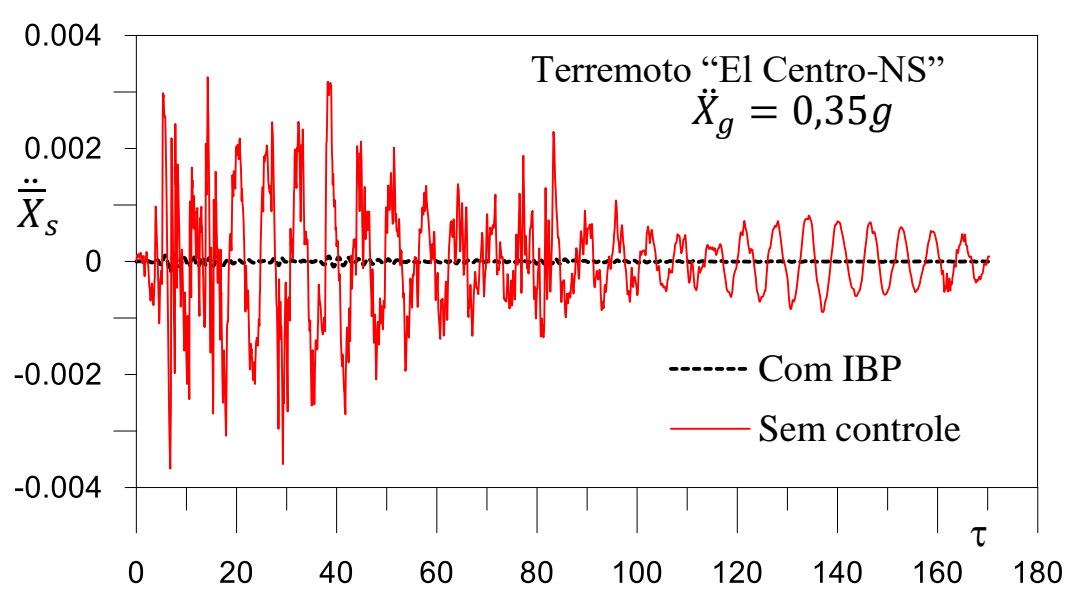

Figura 5-21 Acelerações da estrutura com carga sísmica $\left(\xi_{s}=0,02 ; \xi_{s}=0,035 ; \Delta=\right.$ $0,1 ; \delta=0,1)$ 

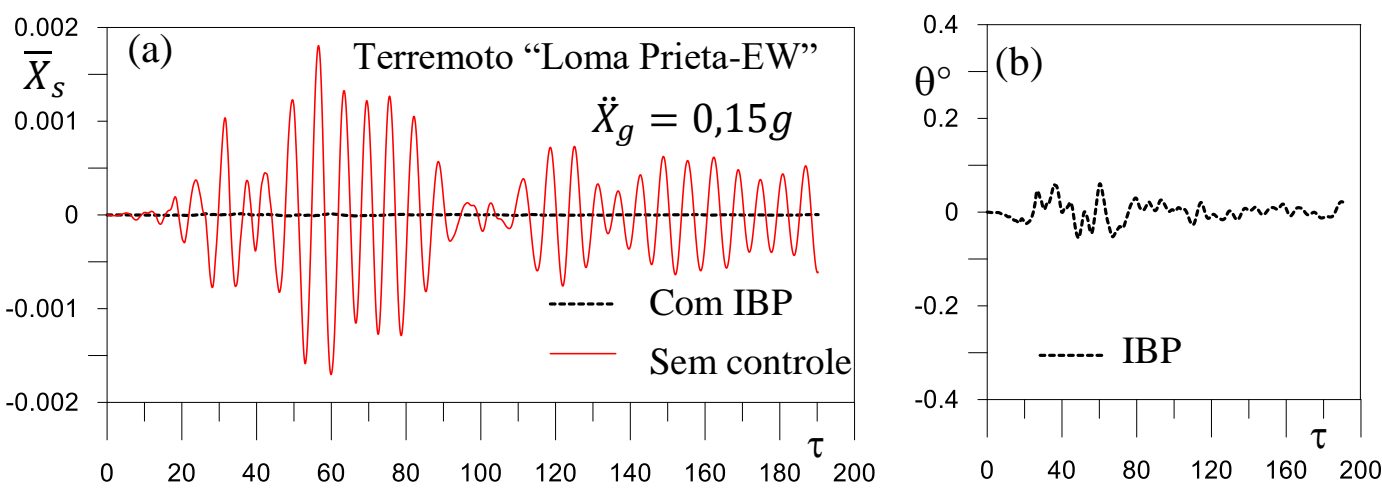

Figura 5-22 (a) Deslocamentos da estrutura e (b) rotação do IBP com carga sísmica $\xi_{s}=$ 0,$02 ; \xi_{s}=0,035 ; \Delta=0,1 ; \delta=0,1$

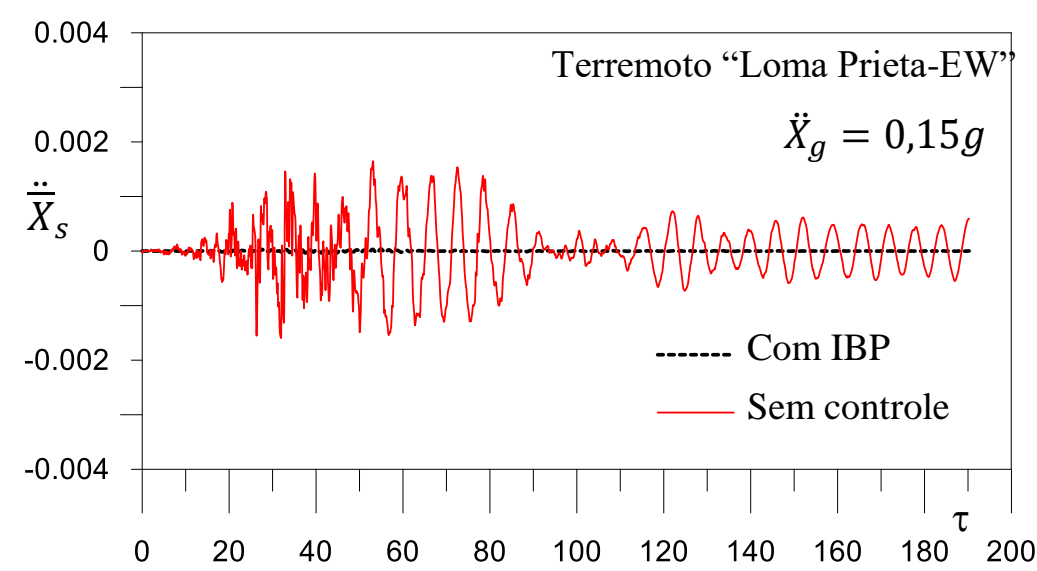

Figura 5-23 Acelerações da estrutura com carga sísmica $\xi_{s}=0,02 ; \xi_{s}=0,035 ; \Delta=$ 0,$1 ; \delta=0,1$

A Figura 5-24 à Figura 5-32 ilustram as respostas em termos de deslocamentos e acelerações da estrutura e rotação do IBP para o acelerograma do terremoto El Centro-EW, considerando diferentes valores de $\Delta$ e $\delta=0,01$. Em todos os exemplos comprova-se a eficiência do IBP.

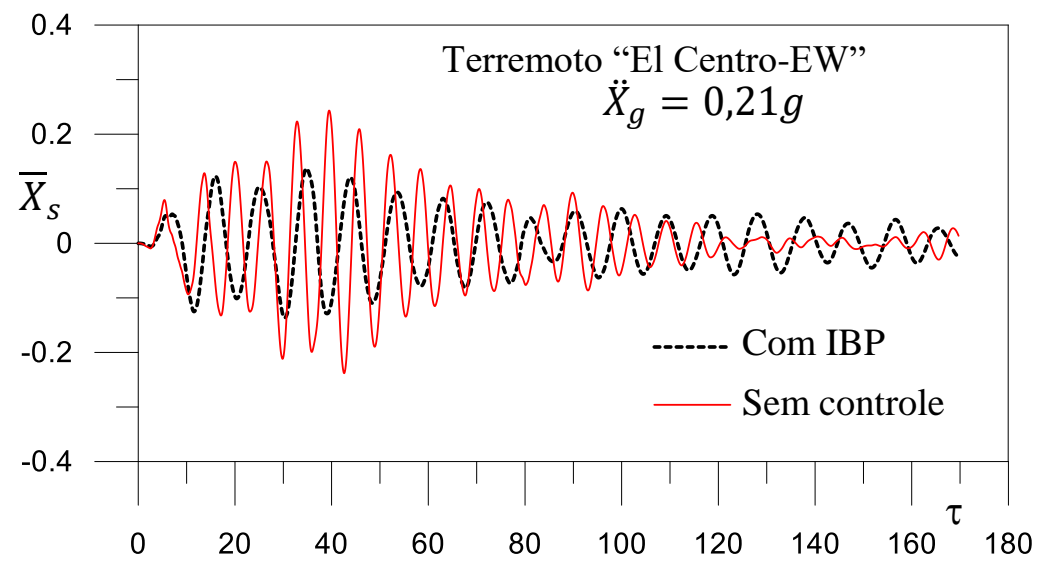

Figura 5-24 Deslocamentos da estrutura com carga sísmica $\xi_{s}=0,02 ; \xi_{s}=0,035 ; \Delta=$ 0,$9 ; \delta=0,01$ 


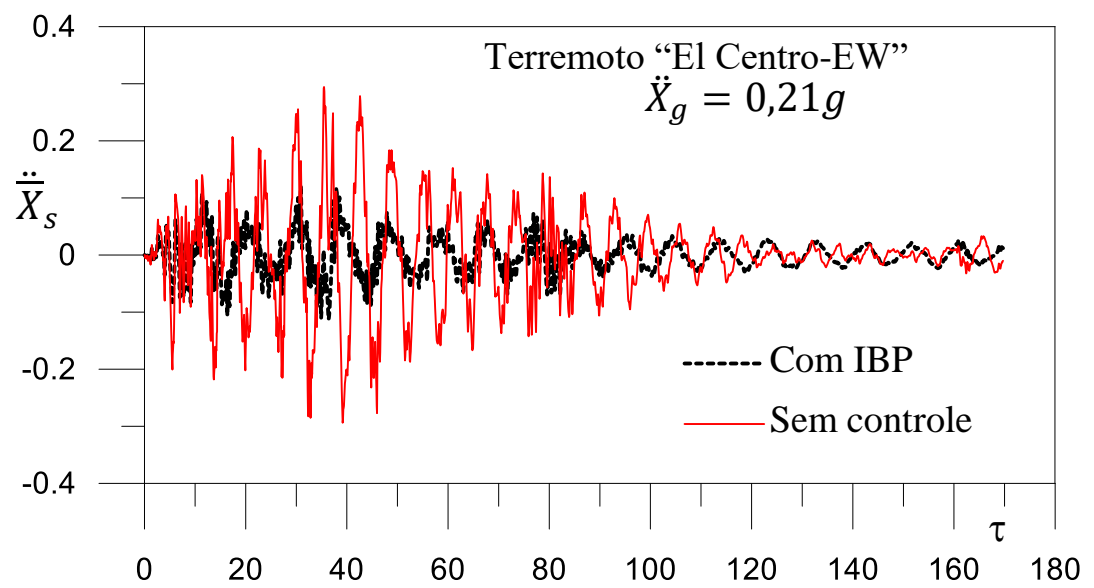

Figura 5-25 Acelerações da estrutura com carga sísmica $\xi_{s}=0,02 ; \xi_{s}=0,035 ; \Delta=$ 0,$9 ; \delta=0,01$

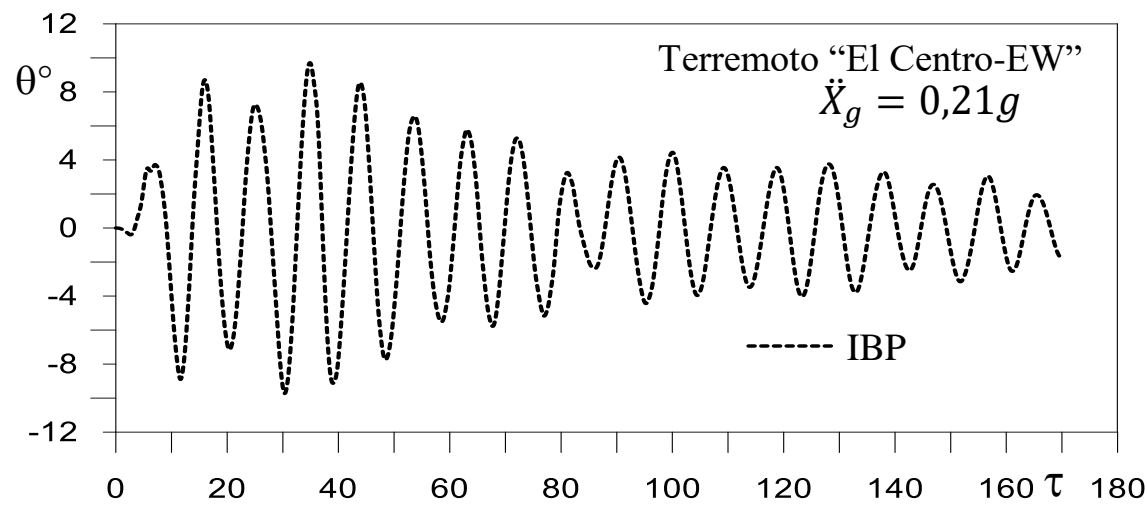

Figura 5-26 Rotações do IBP sob carga sísmica $\xi_{s}=0,02 ; \xi_{s}=0,035 ; \Delta=0,9 ; \delta=0,01$

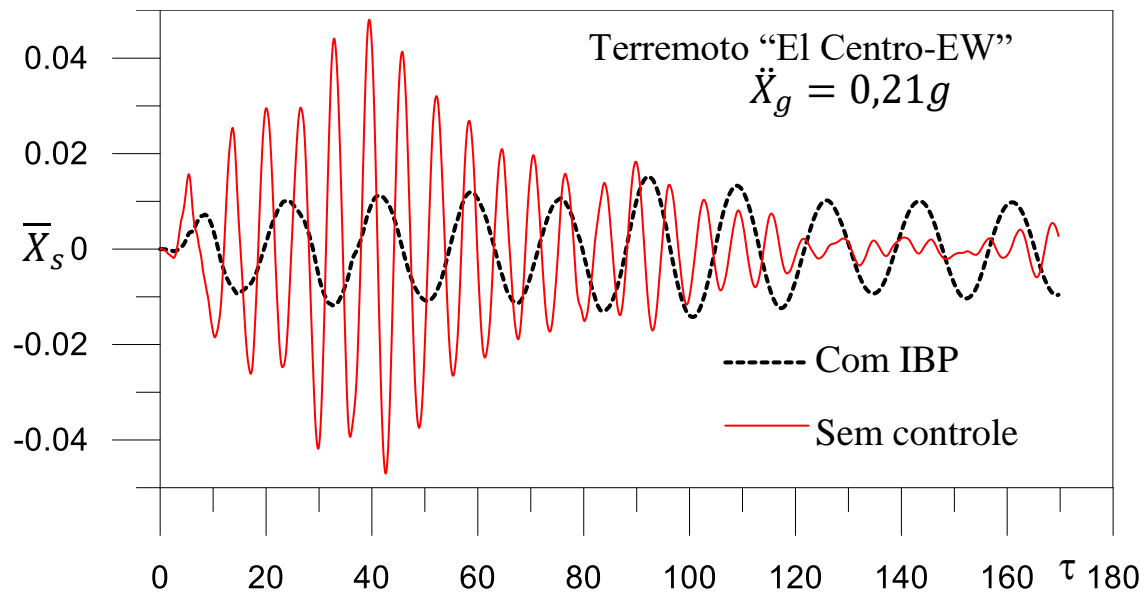

Figura 5-27 Deslocamentos da estrutura com carga sísmica $\xi_{s}=0,02 ; \xi_{s}=0,035 ; \Delta=$ 0,$4 ; \delta=0,01$ 


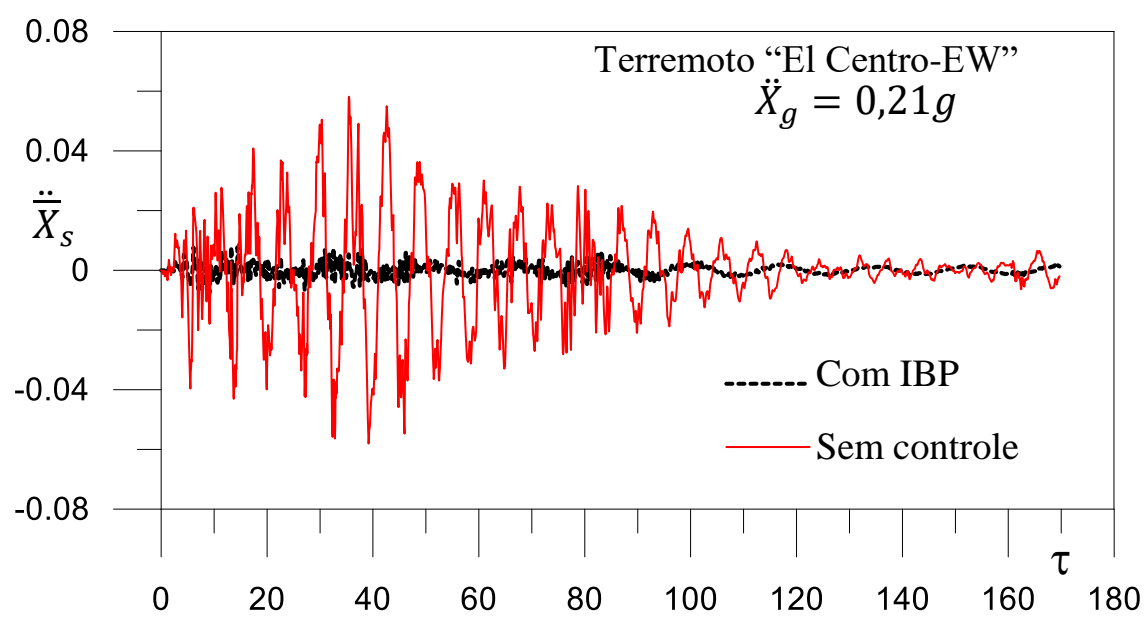

Figura 5-28 Acelerações da estrutura com carga sísmica $\xi_{s}=0,02 ; \xi_{s}=0,035 ; \Delta=$ 0,$4 ; \delta=0,01$

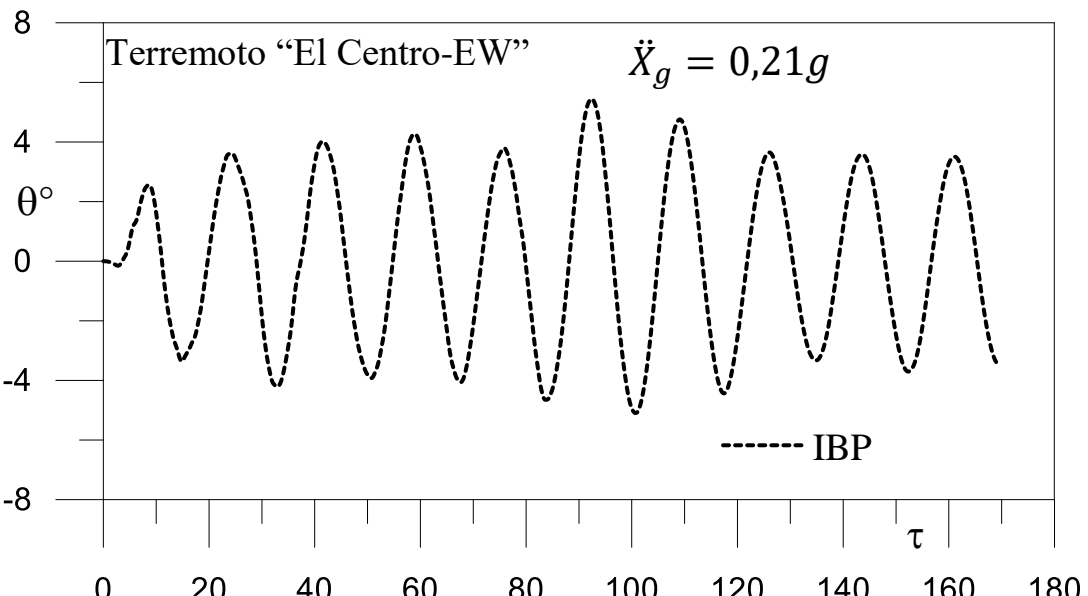

Figura 5-29 Rotações do IBP sob carga sísmica $\xi_{s}=0,02 ; \xi_{s}=0,035 ; \Delta=0,4 ; \delta=0,01$

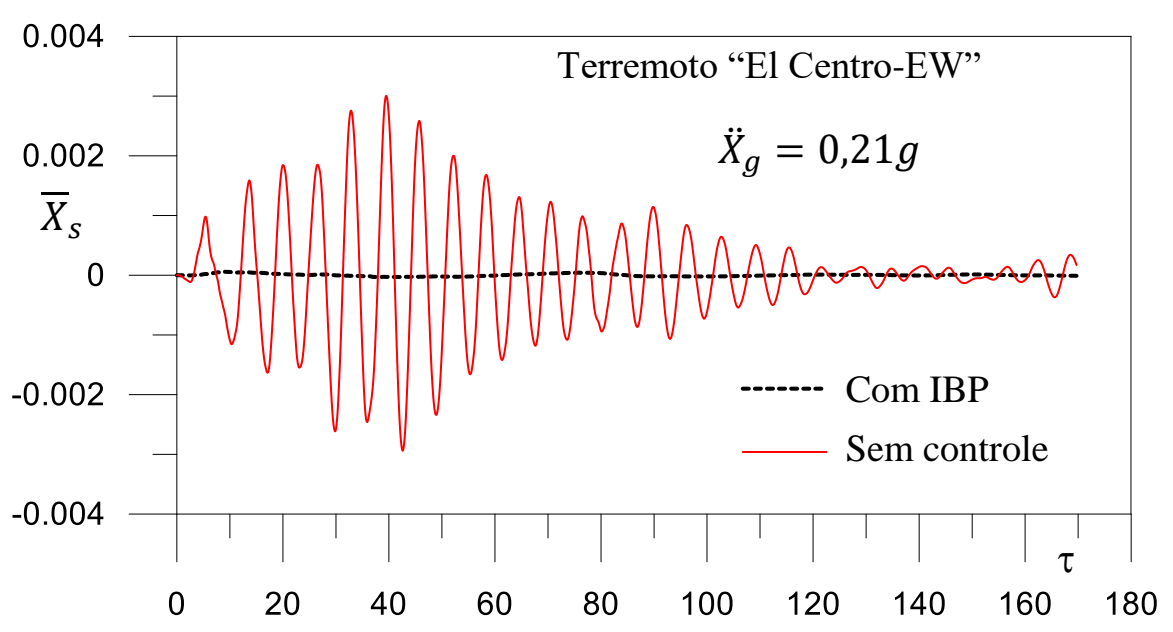

Figura 5-30 Deslocamentos da estrutura com carga sísmica $\xi_{s}=0,02 ; \xi_{s}=0,035 ; \Delta=$ 0,$1 ; \delta=0,01$ 


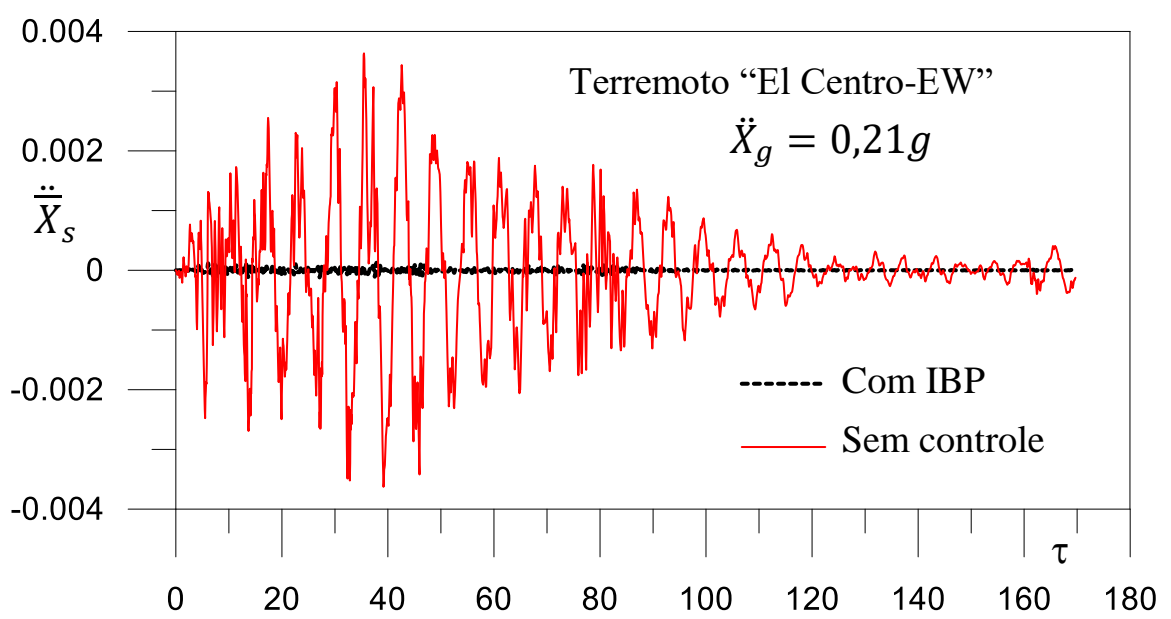

Figura 5-31 Acelerações da estrutura com carga sísmica $\xi_{s}=0,02 ; \xi_{s}=0,035 ; \Delta=$ 0,$1 ; \delta=0,01$

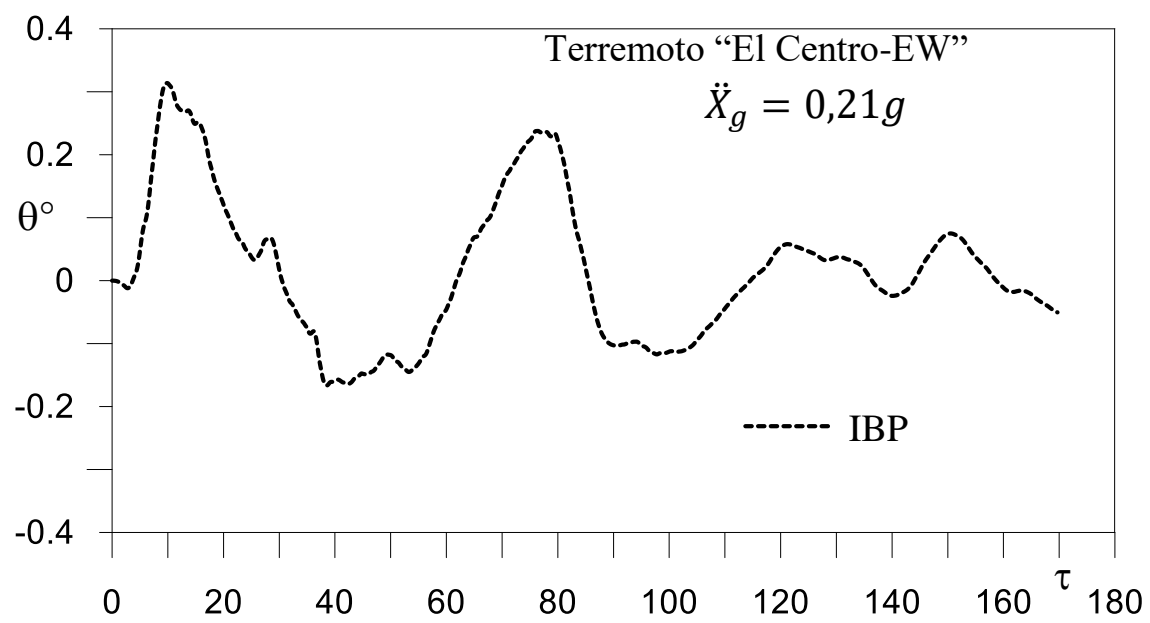

Figura 5-32 Rotações do IBP sob carga sísmica $\xi_{s}=0,02 ; \xi_{s}=0,035 ; \Delta=0,1 ; \delta=0,01$

As Figura 5-33 à Figura 5-38 ilustram as respostas em termos de deslocamentos e acelerações da estrutura e rotação do IBP para os três acelerogramas, considerando $\Delta=0,1 ; \delta=0,01 ; \xi_{S}=2 \%$ e $\xi_{a}=3,5 \%$. Considerase para a componente EW do El-Centro uma magnitude de $\ddot{\bar{X}}_{g}=0,21 g$, para a componente NS do o El-Centro NS uma magnitude de $\ddot{\bar{X}}_{g}=0,35 \mathrm{~g}$ e para LomaPrieta, $\ddot{\bar{X}}_{g}=0,15 g$. 


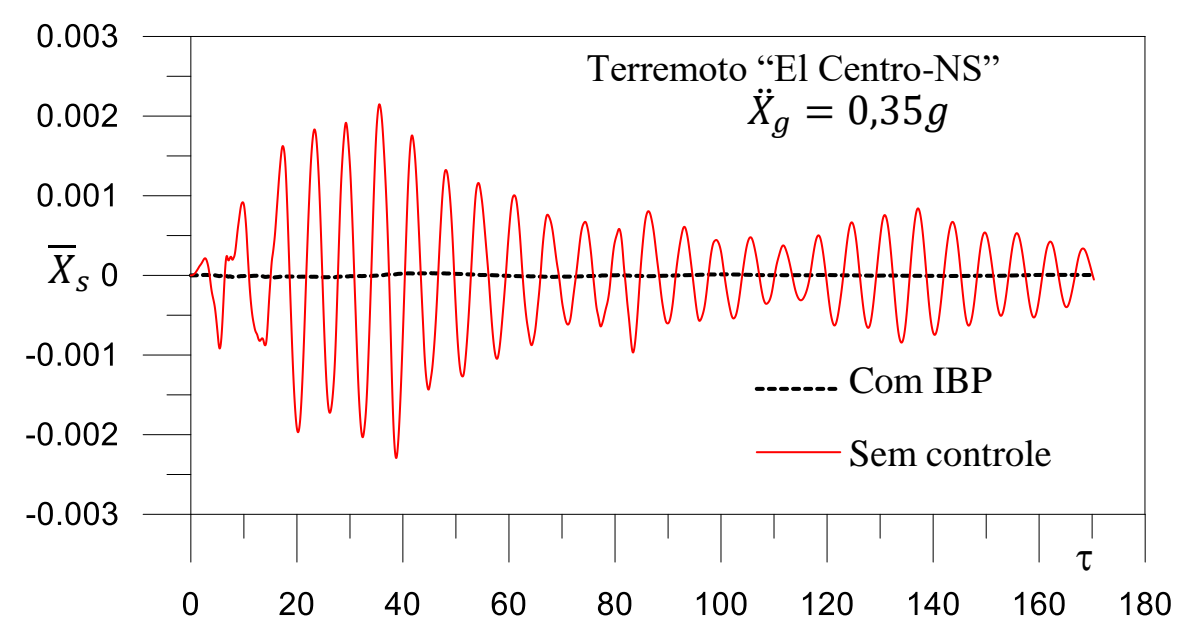

Figura 5-33 Deslocamentos da estrutura com carga sísmica $\xi_{s}=0,02 ; \xi_{s}=0,035 ; \Delta=$ 0,$1 ; \delta=0,01$

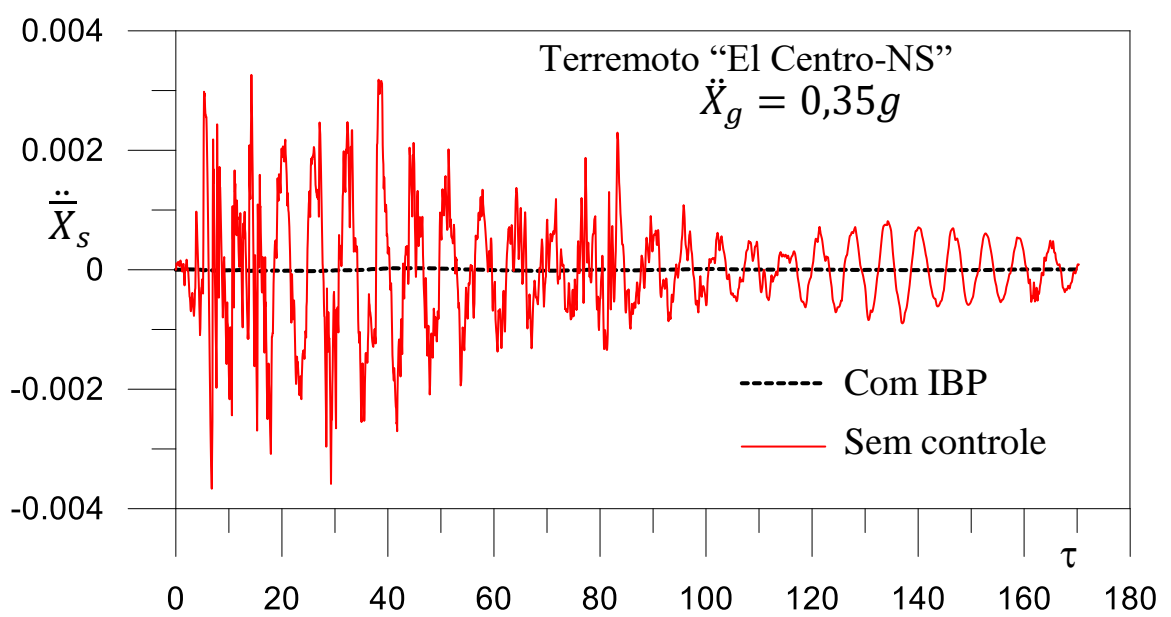

Figura 5-34 Acelerações da estrutura com carga sísmica $\xi_{s}=0,02 ; \xi_{s}=0,035 ; \Delta=$ 0,$1 ; \delta=0,01$

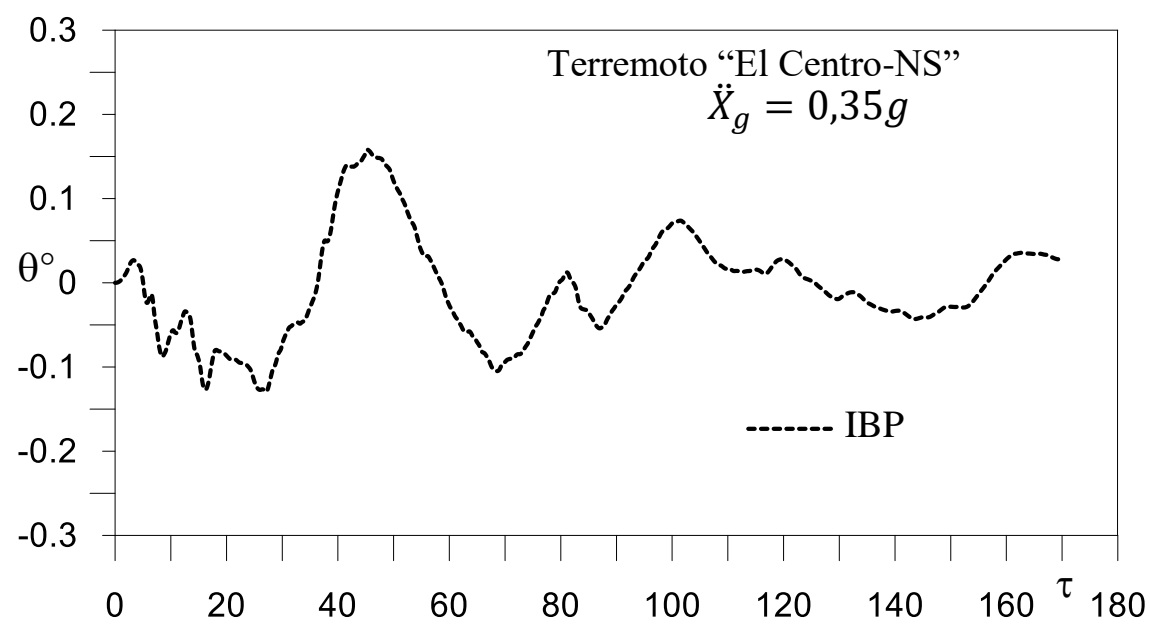

Figura 5-35 Rotações do IBP sob carga sísmica $\xi_{s}=0,02 ; \xi_{s}=0,035 ; \Delta=0,1 ; \delta=0,01$ 


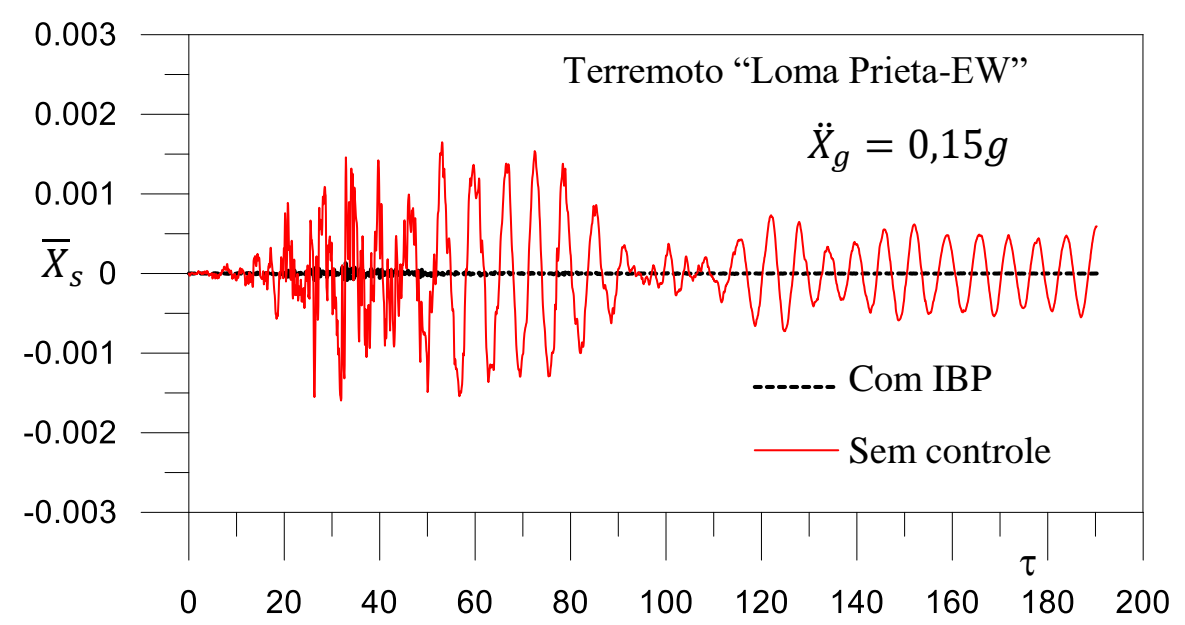

Figura 5-36 Deslocamentos da estrutura com carga sísmica $\xi_{s}=0,02 ; \xi_{s}=0,035 ; \Delta=$ 0,$1 ; \delta=0,01$

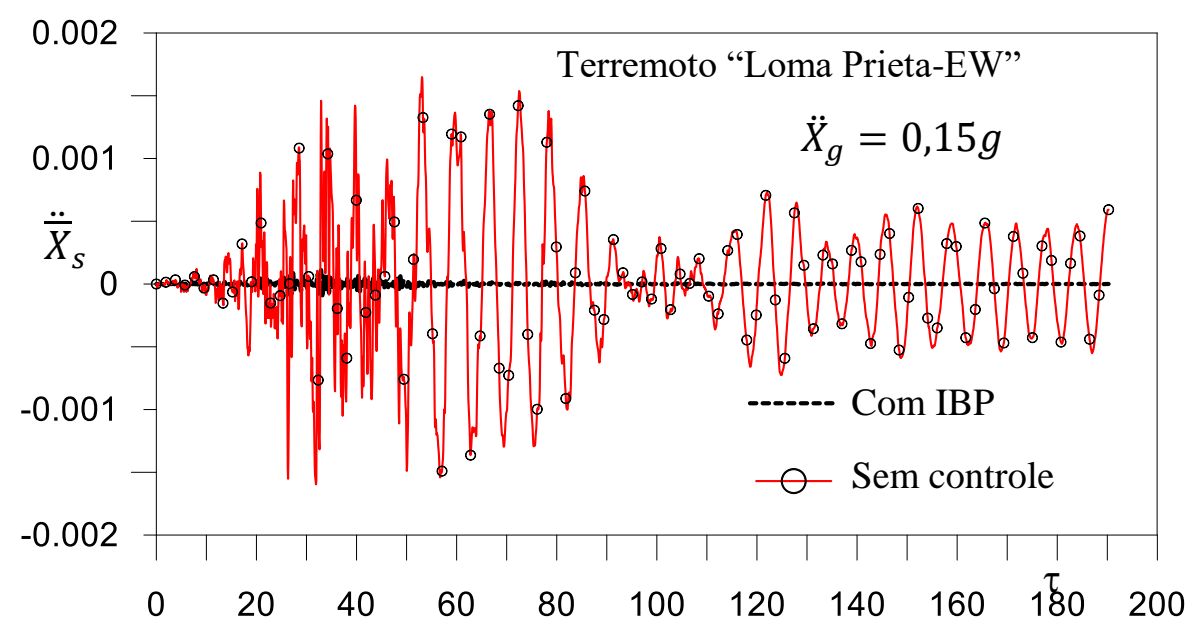

Figura 5-37 Acelerações da estrutura com carga sísmica $\xi_{s}=0,02 ; \xi_{s}=0,035 ; \Delta=$ 0,$1 ; \delta=0,01$

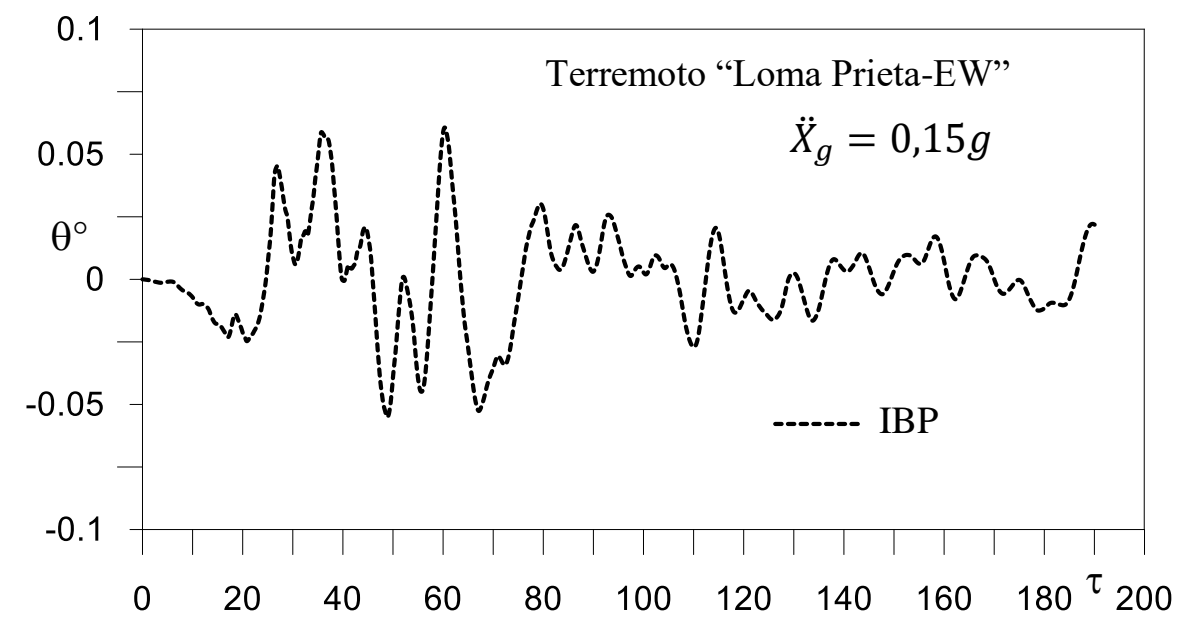

Figura 5-38 Rotações do IBP sob carga sísmica $\xi_{s}=0,02 ; \xi_{s}=0,035 ; \Delta=0,1 ; \delta=0,01$ 
A eficiência do IBP é ilustrada quantitativamente em termos de reduções de deslocamentos e acelerações e rotação do IBP nas Tabela 5-8 à Tabela 5-10. A eficiência do IBP é medida em função da resposta da estrutura sem controle; para o caso do terremoto El Centro componente EW, o melhor comportamento ocorre para $\Delta=0,1$. Para valores maiores da razão de frequências, a estrutura experimenta menores reduções de deslocamentos e acelerações, mas com reduções razoáveis. Para os outros sinais de terremoto o comportamento é similar.

Tabela 5-8 Eficiência do IBP no controle de vibrações sob carga sísmica El centro-EW $\delta=0,01$

\begin{tabular}{|c|c|c|c|c|c|c|c|}
\hline \multirow{3}{*}{$\begin{array}{c}\text { Razão } \\
\text { de } \\
\text { freq. } \\
\Delta\end{array}$} & \multicolumn{3}{|c|}{ El Centro-EW $(0,21 \mathrm{~g})$} & \multirow{2}{*}{\multicolumn{2}{|c|}{ Sem controle }} & \multirow{2}{*}{\multicolumn{2}{|c|}{$\begin{array}{c}\text { Eficiência } \\
(\%)\end{array}$}} \\
\hline & \multicolumn{2}{|c|}{ Estrutura Principal } & \multirow{2}{*}{$\begin{aligned} \text { IBP } \\
\left(\theta^{\circ}\right)\end{aligned}$} & & & & \\
\hline & $\left(\bar{X}_{s}\right)$ & $\left(\ddot{\bar{X}}_{s}\right)$ & & $\left(\bar{X}_{s}\right)$ & $\left(\ddot{\bar{X}}_{s}\right)$ & $\left(\bar{X}_{s}\right)$ & $\left(\ddot{\bar{X}}_{s}\right)$ \\
\hline 0,1 & 0,0001 & 0,0001 & 0,314 & 0,003 & 0,004 & 98,06 & 96,53 \\
\hline 0,2 & 0001 & 0,001 & 1,374 & 0,012 & 0,015 & 91,99 & 93,28 \\
\hline 0,3 & 0,005 & 0,004 & 3,022 & 0,027 & 0,033 & 82,42 & 89,29 \\
\hline 0,4 & 0,015 & 0,008 & 5,446 & 0,048 & 0,058 & 68,33 & 86,43 \\
\hline 0,5 & 0,018 & 0,023 & 4,233 & 0,075 & 0,091 & 75,40 & 74,63 \\
\hline 0,7 & 0,051 & 0,062 & 6,021 & 0,147 & 0,178 & 65,14 & 64,94 \\
\hline 0,9 & 0,137 & 0,121 & 9,713 & 0,243 & 0,294 & 43,59 & 58,96 \\
\hline 1,0 & 0,209 & 0,220 & 11,942 & 0,300 & 0,363 & 30,55 & 39,41 \\
\hline 1,1 & 0,228 & 0,245 & 10,847 & 0,364 & 0,440 & 37,22 & 44,26 \\
\hline 1,2 & 0,258 & 0,227 & 10,175 & 0,433 & 0,523 & 40,42 & 56,60 \\
\hline 1,3 & 0,314 & 0,284 & 10,633 & 0,508 & 0,614 & 38,07 & 53,81 \\
\hline
\end{tabular}

Tabela 5-9 Eficiência do IBP no controle de vibrações sob carga sísmica El centro-NS $\delta=0,01$

\begin{tabular}{|c|c|c|c|c|c|c|c|}
\hline \multirow{3}{*}{$\begin{array}{c}\text { Razão } \\
\text { de } \\
\text { freq. } \\
\Delta\end{array}$} & \multicolumn{3}{|c|}{ El Centro- $N S(0,35 g)$} & \multirow{2}{*}{\multicolumn{2}{|c|}{ Sem controle }} & \multirow{2}{*}{\multicolumn{2}{|c|}{$\begin{array}{c}\text { Eficiência } \\
(\%)\end{array}$}} \\
\hline & \multicolumn{2}{|c|}{ Estrutura Principal } & \multirow{2}{*}{$\frac{\text { IBP }}{\left(\theta^{\circ}\right)}$} & & & & \\
\hline & $\left(\bar{X}_{s}\right)$ & $\left(\ddot{\bar{X}}_{s}\right)$ & & $\left(\bar{X}_{s}\right)$ & $\left(\ddot{\bar{X}}_{s}\right)$ & $\left(\bar{X}_{s}\right)$ & $\left(\ddot{\bar{X}}_{s}\right)$ \\
\hline 0,1 & 0,00003 & 0,00027 & 0,158 & 0,002 & 0,003 & 98,61 & 91,76 \\
\hline 0,2 & 0,001 & 0,002 & 0,814 & 0,009 & 0,013 & 93,36 & 84,18 \\
\hline 0,3 & 0,002 & 0,007 & 0,988 & 0,019 & 0,029 & 91,91 & 77,15 \\
\hline 0,4 & 0,005 & 0,015 & 1,604 & 0,034 & 0,052 & 86,87 & 70,49 \\
\hline 0,5 & 0,009 & 0,029 & 2,058 & 0,054 & 0,082 & 83,03 & 64,19 \\
\hline 0,7 & 0,031 & 0,075 & 3,590 & 0,105 & 0,160 & 70,71 & 52,95 \\
\hline 0,9 & 0,130 & 0,151 & 9,301 & 0,174 & 0,264 & 25,27 & 42,93 \\
\hline 1,0 & 0,196 & 0,202 & 11,308 & 0,215 & 0,326 & 8,73 & 38,07 \\
\hline 1,1 & 0,213 & 0,264 & 10,050 & 0,260 & 0,395 & 17,90 & 33,20 \\
\hline 1,2 & 0,277 & 0,344 & 11,020 & 0,309 & 0,470 & 10,48 & 26,81 \\
\hline 1,3 & 0,347 & 0,430 & 11,809 & 0,363 & 0,551 & 4,38 & 22,01 \\
\hline
\end{tabular}


Tabela 5-10 Eficiência do IBP no controle de vibrações sob carga sísmica Loma Prieta-EW $\delta=0,01$

\begin{tabular}{|c|c|c|c|c|c|c|c|}
\hline \multirow{3}{*}{$\begin{array}{c}\text { Razão } \\
\text { de } \\
\text { freq. } \\
\Delta\end{array}$} & \multicolumn{3}{|c|}{ Loma Prieta-EW-0,15g } & \multirow{2}{*}{\multicolumn{2}{|c|}{ Sem controle }} & \multirow{2}{*}{\multicolumn{2}{|c|}{$\begin{array}{c}\text { Eficiência } \\
(\%)\end{array}$}} \\
\hline & \multicolumn{2}{|c|}{ Estrutura Principal } & \multirow{2}{*}{$\frac{\text { IBP }}{\left(\theta^{\circ}\right)}$} & & & & \\
\hline & $\left(\bar{X}_{s}\right)$ & $\left(\ddot{\bar{X}}_{s}\right)$ & & $\left(\bar{X}_{s}\right)$ & $\left(\ddot{\bar{X}}_{s}\right)$ & $\left(\bar{X}_{s}\right)$ & $\left(\ddot{\bar{X}}_{s}\right)$ \\
\hline 0,1 & 0,00001 & 0,00013 & 0,061 & 0,002 & 0,002 & 99,33 & 92,08 \\
\hline 0,2 & 0,00039 & 0,00103 & 0,547 & 0,007 & 0,007 & 94,62 & 84,37 \\
\hline $\mathbf{0 , 3}$ & 0,002 & 0,004 & 1,082 & 0,016 & 0,015 & 89,50 & 76,35 \\
\hline 0,4 & 0,005 & 0,008 & 1,852 & 0,029 & 0,026 & 82,07 & 68,66 \\
\hline 0,5 & 0,010 & 0,016 & 2,307 & 0,045 & 0,041 & 77,61 & 61,49 \\
\hline $\mathbf{0 , 7}$ & 0,038 & 0,039 & 4,385 & 0,089 & 0,081 & 57,51 & 51,41 \\
\hline 0,9 & 0,125 & 0,074 & 8,898 & 0,146 & 0,134 & 14,44 & 44,41 \\
\hline 1,0 & 0,237 & 0,133 & 13,652 & 0,181 & 0,165 & $-31,31$ & 19,41 \\
\hline 1,1 & 0,352 & 0,205 & 16,689 & 0,219 & 0,200 & $-60,97$ & $-2,70$ \\
\hline 1,2 & 0,446 & 0,281 & 17,768 & 0,260 & 0,237 & $-71,54$ & $-18,43$ \\
\hline 1,3 & 0,515 & 0,346 & 17,422 & 0,305 & 0,279 & $-68,59$ & $-24,07$ \\
\hline
\end{tabular}

As Figura 5-39 à Figura 5-41 ilustram as respostas em termos de deslocamentos e acelerações da estrutura e rotação do IBP para os três acelerogramas, em função do parâmetro $\Delta$ para $\delta=0,1$. Nota-se que, para valores de $\Delta$ menores que 0,5 , os deslocamentos e acelerações da estrutura são bastante similares para os três sinais. A Tabela 5-11 à Tabela 5-13 ilustram a influência de $\Delta$ na eficiência do IBP no controle de vibrações sob carga sísmica usando os três acelerogramas, para $\delta=0,1$. Como já mostrado nos exemplos anteriores, a eficiência decresce com $\Delta$, enfatizando a importância de se adotar um pequeno valor de $\Delta$ no projeto do IBP. A Figura 5-42 ilustra a influência de $\delta$ no comportamento dinâmico do sistema, comparando-se os valores máximos para $\delta=0,1$ e $\delta=0,01$ com os valores máximos da estrutura sem controle. A Figura 5-43 e Figura 5-44 apresentam a mesma análise para, respectivamente, as componentes EW e NS do El Centro. Observa-se a pequena influência de $\delta$ nos valores máximos. 


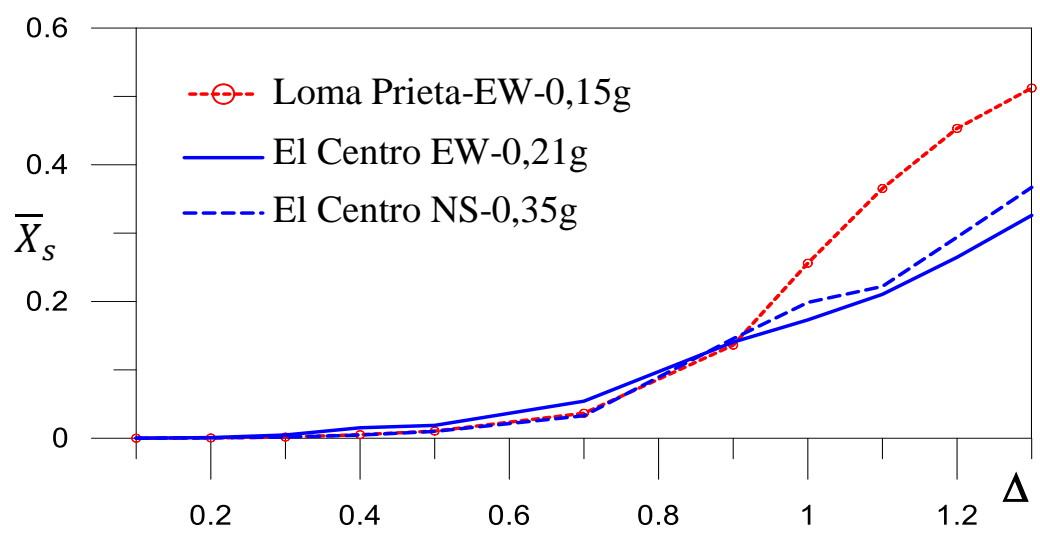

Figura 5-39 Deslocamentos máximos da estrutura em função de $\Delta$ para $\delta=0,1$

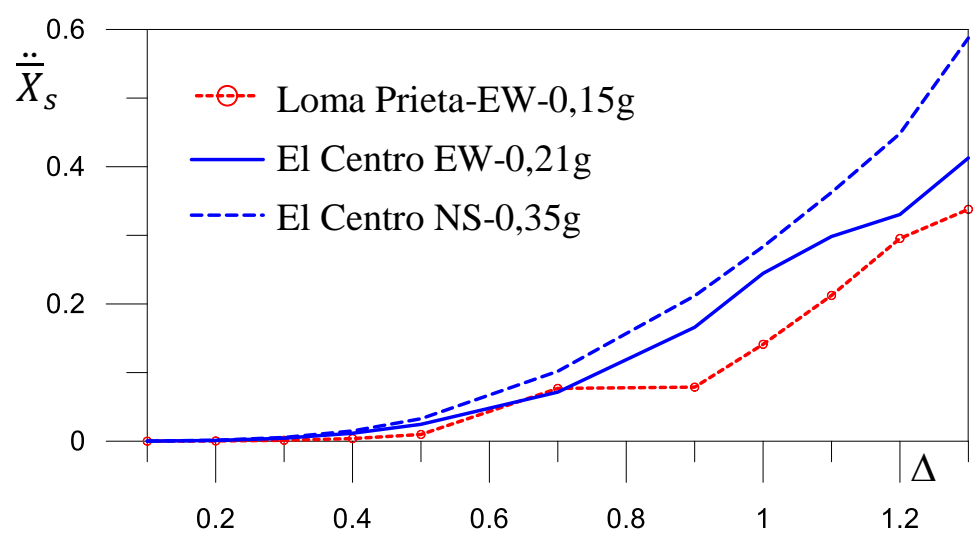

Figura 5-40 Acelerações máximas da estrutura em função de $\Delta$ para $\delta=0,1$

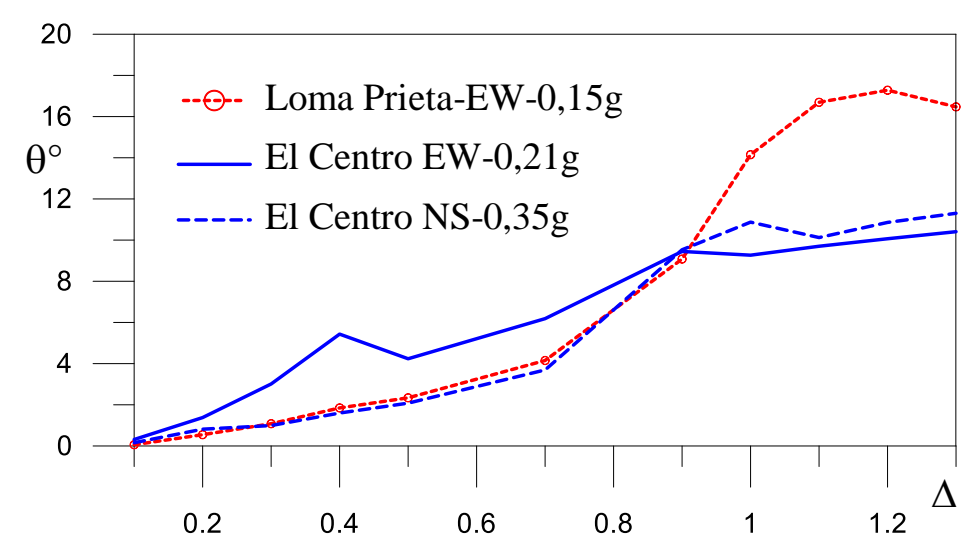

Figura 5-41 Rotações máximas do IBP em função de $\Delta$ para $\delta=0,1$ 
Tabela 5-11 Eficiência do IBP no controle de vibrações sob carga sísmica "Loma PrietaEW" $\delta=0,1$

\begin{tabular}{|c|c|c|c|c|c|c|c|}
\hline \multirow{3}{*}{$\begin{array}{c}\text { Razão } \\
\text { de } \\
\text { freq. } \\
\Delta\end{array}$} & \multicolumn{3}{|c|}{ Loma Prieta-EW-0,15g } & \multirow{2}{*}{\multicolumn{2}{|c|}{ Sem controle }} & \multirow{2}{*}{\multicolumn{2}{|c|}{$\begin{array}{c}\text { Eficiência } \\
(\%)\end{array}$}} \\
\hline & \multicolumn{2}{|c|}{ Estrutura Principal } & \multirow{2}{*}{$\frac{\text { IBP }}{\left(\theta^{\circ}\right)}$} & & & & \\
\hline & $\left(\bar{X}_{s}\right)$ & $\left(\ddot{\bar{X}}_{s}\right)$ & & $\left(\bar{X}_{s}\right)$ & $\left(\ddot{\bar{X}}_{s}\right)$ & $\left(\bar{X}_{s}\right)$ & $\left(\ddot{\bar{X}}_{s}\right)$ \\
\hline 0,1 & 0,00001 & 0,00004 & 0,061 & 0,002 & 0,002 & 99,24 & 97,67 \\
\hline 0,2 & 0,00040 & 0,00035 & 0,547 & 0,007 & 0,007 & 94,40 & 94,74 \\
\hline 0,3 & 0,002 & 0,001 & 1,081 & 0,016 & 0,015 & 89,42 & 90,94 \\
\hline 0,4 & 0,005 & 0,004 & 1,848 & 0,029 & 0,026 & 82,06 & 85,52 \\
\hline 0,5 & 0,011 & 0,010 & 2,339 & 0,045 & 0,041 & 76,73 & 76,19 \\
\hline 0,7 & 0,037 & 0,077 & 4,152 & 0,089 & 0,081 & 58,71 & 4,80 \\
\hline 0,9 & 0,136 & 0,079 & 9,079 & 0,146 & 0,134 & 6,91 & 41,00 \\
\hline 1,0 & 0,256 & 0,141 & 14,148 & 0,181 & 0,165 & $-41,75$ & 14,38 \\
\hline 1,1 & 0,365 & 0,212 & 16,694 & 0,219 & 0,200 & $-67,15$ & $-6,46$ \\
\hline 1,2 & 0,453 & 0,295 & 17,282 & 0,260 & 0,237 & $-74,23$ & $-24,42$ \\
\hline 1,3 & 0,512 & 0,338 & 16,472 & 0,305 & 0,279 & $-67,81$ & $-21,26$ \\
\hline
\end{tabular}

Tabela 5-12 Eficiência do IBP no controle de vibrações sob carga sísmica "El centro-EW" $\delta=0,1$

\begin{tabular}{|c|c|c|c|c|c|c|c|}
\hline \multirow{3}{*}{$\begin{array}{c}\text { Razão } \\
\text { de } \\
\text { freq. } \\
\Delta\end{array}$} & \multicolumn{3}{|c|}{ El Centro-EW $(0,21 \mathrm{~g})$} & \multirow{2}{*}{\multicolumn{2}{|c|}{ Sem controle }} & \multirow{2}{*}{\multicolumn{2}{|c|}{$\begin{array}{c}\text { Eficiência } \\
(\%)\end{array}$}} \\
\hline & \multicolumn{2}{|c|}{ Estrutura Principal } & \multirow{2}{*}{$\frac{\text { IBP }}{\left(\theta^{\circ}\right)}$} & & & & \\
\hline & $\left(\overline{\boldsymbol{X}}_{s}\right)$ & $\left(\ddot{\bar{X}}_{s}\right)$ & & $\left(\bar{X}_{s}\right)$ & $\left(\ddot{\bar{X}}_{s}\right)$ & $\left(\bar{X}_{s}\right)$ & $\left(\ddot{\bar{X}}_{s}\right)$ \\
\hline 0,1 & 0,0001 & 0,0001 & 0,314 & 0,003 & 0,004 & $\mathbf{9 7 , 8 4}$ & 96,50 \\
\hline 0,2 & 0,001 & 0,001 & 1,380 & 0,012 & 0,015 & 91,92 & 92,38 \\
\hline $\mathbf{0 , 3}$ & 0,005 & 0,004 & 3,011 & 0,027 & 0,033 & 82,36 & 86,69 \\
\hline 0,4 & 0,015 & 0,012 & 5,433 & 0,048 & 0,058 & 68,17 & 80,06 \\
\hline 0,5 & 0,019 & 0,025 & 4,236 & 0,075 & 0,091 & 74,97 & 72,91 \\
\hline 0,7 & 0,054 & 0,072 & 6,185 & 0,147 & 0,178 & 63,17 & $\mathbf{5 9 , 8 0}$ \\
\hline 0,9 & 0,141 & 0,166 & 9,449 & 0,243 & 0,294 & 42,24 & 43,59 \\
\hline 1,0 & 0,173 & 0,245 & 9,268 & 0,300 & 0,363 & 42,38 & 32,68 \\
\hline 1,1 & 0,211 & 0,298 & 9,702 & 0,364 & 0,440 & 42,09 & 32,14 \\
\hline 1,2 & 0,265 & 0,330 & 10,066 & 0,433 & 0,523 & 38,81 & 36,85 \\
\hline 1,3 & 0,326 & 0,413 & 10,408 & 0,508 & 0,614 & 35,79 & 32,77 \\
\hline
\end{tabular}

Tabela 5-13 Eficiência do IBP no controle de vibrações sob carga sísmica "El centro-NS" $\delta=0,1$

\begin{tabular}{|c|c|c|c|c|c|c|c|}
\hline \multirow{3}{*}{ 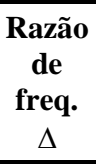 } & \multicolumn{3}{|c|}{ El Centro-NS $(0,35 g)$} & \multirow{2}{*}{\multicolumn{2}{|c|}{ Sem controle }} & \multirow{2}{*}{\multicolumn{2}{|c|}{$\begin{array}{c}\text { Eficiência } \\
(\%)\end{array}$}} \\
\hline & \multicolumn{2}{|c|}{ Estrutura Principal } & \multirow{2}{*}{$\frac{\text { IBP }}{\left(\theta^{\circ}\right)}$} & & & & \\
\hline & $\left(\bar{X}_{s}\right)$ & $\left(\ddot{\bar{X}}_{s}\right)$ & & $\left(\bar{X}_{s}\right)$ & $\left(\ddot{\bar{X}}_{s}\right)$ & $\left(\bar{X}_{s}\right)$ & $\left(\ddot{\bar{X}}_{s}\right)$ \\
\hline $\mathbf{0 , 1}$ & 0,00003 & 0,00016 & 0,158 & 0,002 & 0,003 & 98,48 & 94,97 \\
\hline 0,2 & 0,001 & 0,001 & 0,816 & 0,009 & 0,013 & 93,16 & 89,20 \\
\hline $\mathbf{0 , 3}$ & 0,002 & 0,005 & 0,992 & 0,019 & 0,029 & 91,75 & 81,37 \\
\hline $\mathbf{0 , 4}$ & 0,005 & 0,015 & 1,600 & 0,034 & 0,052 & 86,48 & 71,33 \\
\hline 0,5 & 0,010 & 0,033 & 2,080 & 0,054 & 0,082 & 81,47 & 59,84 \\
\hline $\mathbf{0 , 7}$ & 0,033 & 0,102 & 3,693 & 0,105 & 0,160 & 68,77 & 36,25 \\
\hline 0,9 & 0,146 & 0,212 & 9,531 & 0,174 & 0,264 & 16,30 & 19,83 \\
\hline 1,0 & 0,199 & 0,283 & 10,872 & 0,215 & 0,326 & 7,52 & 13,11 \\
\hline 1,1 & 0,222 & 0,363 & 10,123 & 0,260 & 0,395 & 14,56 & 8,16 \\
\hline 1,2 & 0,294 & 0,448 & 10,858 & 0,309 & 0,470 & 4,91 & 4,57 \\
\hline 1,3 & 0,367 & 0,588 & 11,302 & 0,363 & 0,551 & $-1,09$ & $-6,57$ \\
\hline
\end{tabular}



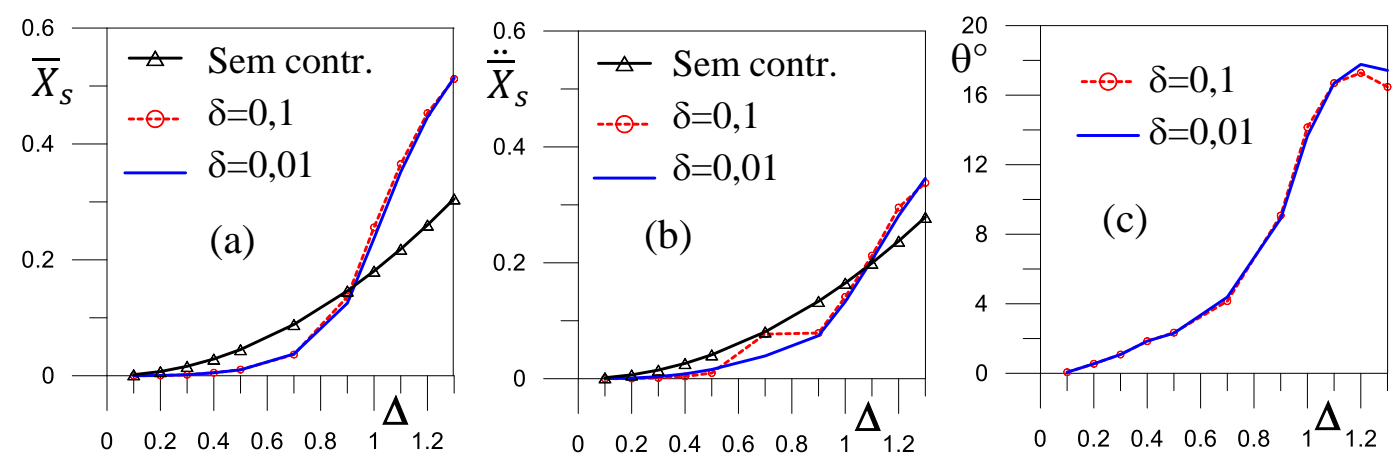

Figura 5-42 Deslocamentos (a) e Acelerações máximas (b) da estrutura; rotações máximas do IBP (c) gerados pelo terremoto "Loma Prieta-EW-0,15g"
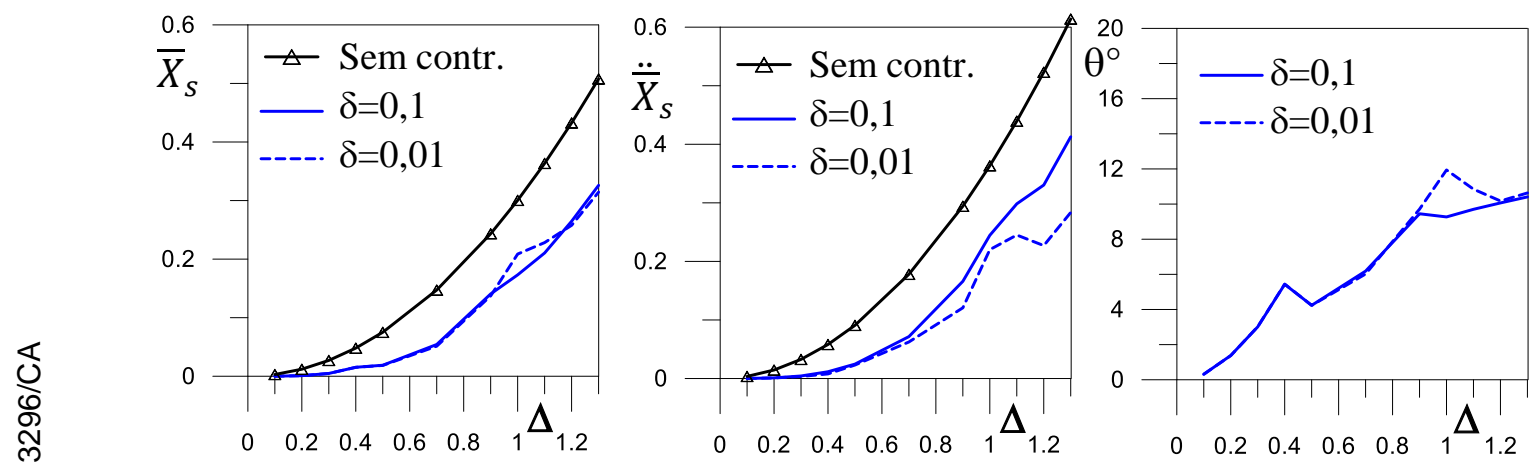

Figura 5-43 Deslocamentos (a) e Acelerações máximas (b) da estrutura; rotações máximas do IBP (c) gerados pelo terremoto "El Centro-EW-0,21g"

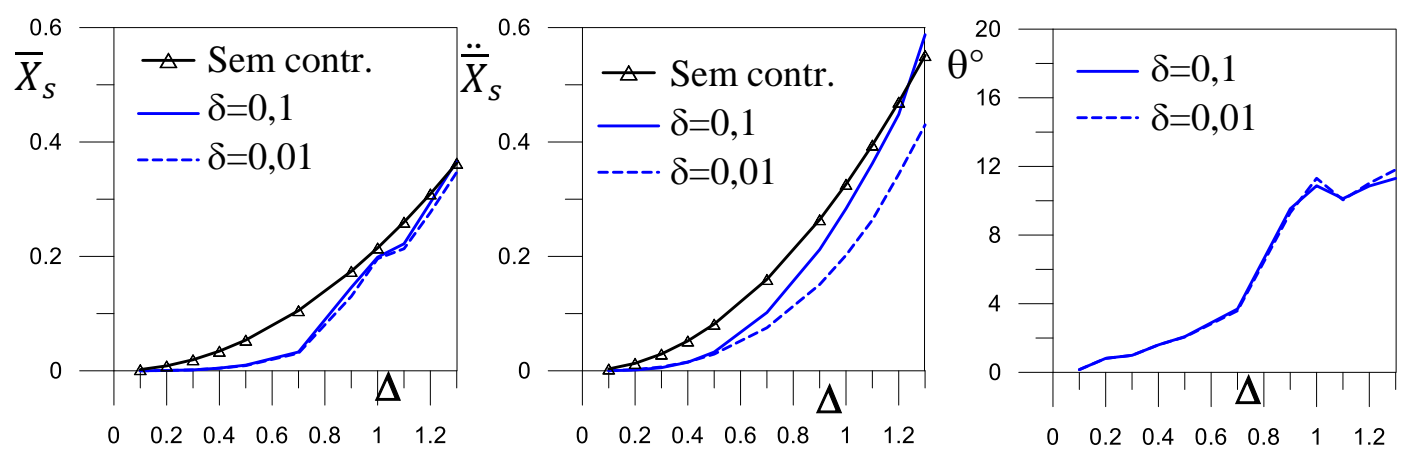

Figura 5-44 Deslocamentos (a) e Acelerações máximas (b) da estrutura; rotações máximas gerados pelo terremoto "El Centro-NS-0,35g" 


\section{6}

\section{Variação da curvatura}

Vários pesquisadores têm estudado a influência da equação que descreve uma superfície no movimento de uma massa que rola sobre a mesma (Shaw e Haddow, 1992; Gottwald et al., 1992; Gottlieb, 1997; Matta e De Stefano, 2009; Legeza, 2013). O pêndulo virtual clássico é formado por uma superfície curva circular que tem a característica de que seu raio de curvatura $R_{C}$ é constante ao longo da superfície. Neste capítulo é estudado o efeito da variação do raio de curvatura nos dois mecanismos de controle; APMS e IBP. Consideram-se cinco tipos diferentes de superfície curva com raio de curvatura variável ao longo da superfície.

\section{1.}

\section{Variação do raio de curvatura}

A frequência natural do pendulo Eq.3.12 é definida em função da aceleração da gravidade e do raio de curvatura da superfície. Um raio de curvatura variável faz com que a frequência instantânea do pêndulo e a razão de frequências tornemse variáveis ao longo da superfície curva. O efeito da variação da geometria da superfície curva na resposta da estrutura é estudado nesta seção.

O raio de curvatura de uma superfície curva descrita por uma função qualquer $Z_{a}\left(X_{a}\right)$ é dado por

$$
R_{c}=\frac{\left(1+\left(\frac{d Z_{a}}{d X_{a}}\right)^{2}\right)^{\frac{3}{2}}}{\frac{d^{2} Z_{a}}{d X_{a}^{2}}}
$$

Para o estudo da influência do raio de curvatura variável são usados três diferentes tipos de superfícies definidas a seguir.

A superfície curva quadrática: 


$$
Z_{a}=\frac{X_{a}^{2}}{4 f}
$$

onde $f$ é a distância focal

O raio de curvatura para a Eq. 6.2 é igual a

$$
R_{c}=2 f\left(\frac{X_{a}^{2}}{4 f}+1\right)^{\frac{3}{2}}
$$

A segunda curva a ser usada é a curva quadrática modificada por uma parcela com exponente $2 \phi$ da seguinte forma

$$
\begin{aligned}
& Z_{a}=\frac{1}{4 f} X_{a}^{2}-b X_{a}^{2 \phi} \\
& b:=\frac{\left(-4 m f^{2}+R_{c}^{2}\right)}{4 f R_{c}^{2 \phi}}
\end{aligned}
$$

onde $m e \phi$ são parâmetros geométricos que definem a curva. Este termo adicional permite um aumento do raio de curvatura longe da origem, diminuindo os deslocamentos do pêndulo para grandes amplitudes de vibração.

O raio de curvatura neste caso tem a forma

$$
R_{c}=\frac{\left(\left(\frac{X_{a}}{2 f}-2 b X_{a}^{2 \phi-1} \phi\right)^{2}+1\right)^{\frac{3}{2}}}{\frac{1}{2 f}-4 b \phi^{2} X_{a}^{2 \phi-1}+2 b \phi X_{a}^{2 \phi-1}}
$$

Com a finalidade de normalizar o raio de curvatura das Eq.6.3 e 6.6, calculam-se seus valores na origem $\left(X_{a}=0\right)$, onde o raio de curvatura para as duas curvas é dado por:

$$
\left.R_{c}\right|_{X_{a}=0}=2 f
$$

Geometricamente as duas curvas são ilustradas Figura 6-1.

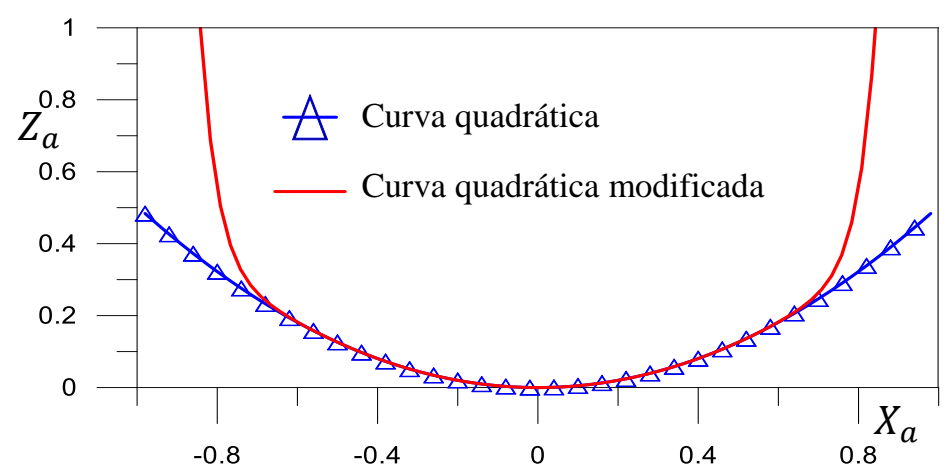

Figura 6-1 Superfícies curvas quadráticas usadas para o pêndulo de raio variável. 
A terceira superfície curva a ser analisada é descrita pelo seguinte polinômio de quarta ordem

$$
Z_{a}=\frac{a}{2} X_{a}^{2}-\frac{b}{4} X_{a}^{4}
$$

A superfície descrita pela Eq. 6.8 é mostrada na Figura 6-2

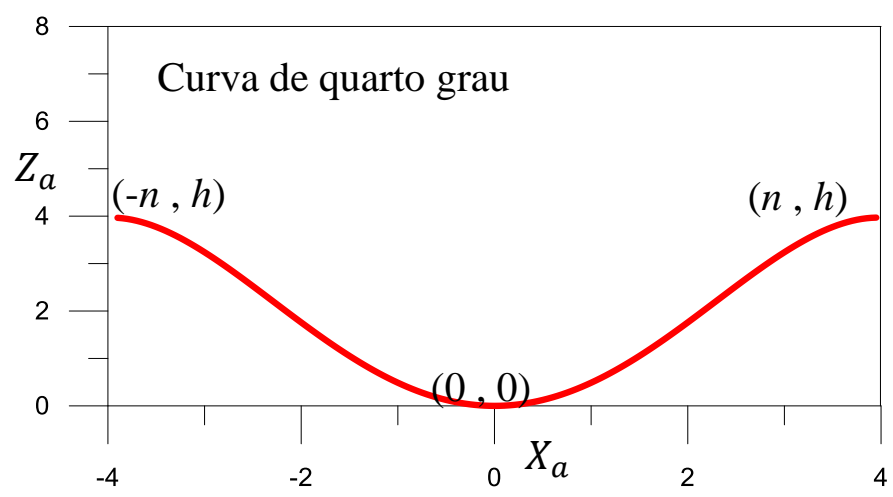

Figura 6-2 Superfície de quarto grau usada para gerar o pêndulo

A Eq.6.8 deve obedecer às seguintes restrições

$$
\begin{aligned}
& \left.\frac{d}{d X_{a}} Z\left(X_{a}\right)\right|_{X_{a= \pm n}} ^{X_{a}=0}=0 \\
& Z(n)=h
\end{aligned}
$$

onde $n$ e $h$ são parâmetros geométricos que definem a curva.

Após impor as condições Eq.6.9, obtém-se a equação do quarto grau em termos dos parâmetros $n$ e $h$

$$
\begin{aligned}
& Z_{a}=\frac{2 \mathrm{H}}{n} X_{a}^{2}-\frac{\mathrm{H}}{n^{3}} X_{a}^{4} \\
& \mathrm{H}=\frac{h}{n}
\end{aligned}
$$

O raio de curvatura para a Eq. 6.10 é na origem dado por:

$$
\left.R_{c}\right|_{X_{a}=0}=\frac{n}{4 \mathrm{H}}=\frac{n^{2}}{4 h}
$$

Essas superfícies são descritas em termos das coordenadas $\left(X_{a}, Z_{a}\right)$. Para efeitos de comparação com a curva circular, sua equação é reescrita em termos de $X_{a}$ e $Z_{a}$, sendo dada por:

$$
Z_{a}=R_{c}-\sqrt{R_{c}^{2}-X_{a}^{2}}
$$




\section{2.}

\section{Equações de movimento}

\subsection{1.}

\section{Formulação matemática da estrutura com APMS com superfície curva polinomial}

A energia cinética do sistema é dada por

$$
T_{S}=\frac{1}{2} M_{s}\left(\dot{X}_{g}+\dot{X}_{s}\right)^{2}+\frac{1}{2} M_{a}\left(\left(\dot{X}_{g}+\dot{X}_{s}+\dot{X}_{a}\right)^{2}+\left(\frac{d Z_{a}}{X_{a}}\right)^{2}\left(\dot{X}_{a}\right)^{2}\right)
$$

A energia potencial total do sistema é

$$
\Pi=\frac{1}{2} K_{s} X_{s}^{2}+M_{a} \cdot g \cdot Z_{a}
$$

A função de Rayleigh tem a forma.

$$
R=\frac{1}{2} C_{a}\left(\left(\frac{d X_{a}}{d \theta} \dot{\theta}\right)^{2}+\left(\frac{d Z_{a}}{d \theta} \dot{\theta}\right)^{2}\right)+\frac{1}{2} C_{s}\left(\dot{X}_{s}\right)^{2}
$$

A equação de Euler-Lagrange em função do grau de liberdade da estrutura principal $X_{S}$ é dada pela Eq.4.12. A equação relativa ao grau de liberdade do pêndulo virtual $X_{a}$ é dada por

$$
\frac{d}{d t}\left(\frac{\partial T}{\partial \dot{X}_{a}}\right)-\frac{\partial T}{\partial X_{a}}+\frac{\partial \pi}{\partial X_{a}}+\frac{\partial R}{\partial \dot{X}_{a}}=0
$$

Substituindo cada uma das derivadas na Eq.4.12 e Eq.6.16, obtém-se o sistema de equações diferenciais que descreve o comportamento dinâmico do sistema estrutura-APMS com superfície curva polinomial, a saber:

$$
\begin{gathered}
\left(\ddot{X}_{g}+\ddot{X}_{s}\right) M_{s}+\left(\ddot{X}_{g}+\ddot{X}_{s}+\ddot{X}_{a}\right) M_{a}+C_{s} \dot{X}_{s}+K_{s} X_{s}=0 \\
M_{a}\left(\ddot{X}_{s}+\ddot{X}_{g}\right)+M_{a}\left(\left(\frac{d Z_{a}}{d X_{a}}\right)^{2}+1\right) \ddot{X}_{a}+M_{a}\left(\frac{d Z_{a}}{d X_{a}}\right)\left(\dot{X}_{a}\right)^{2} \frac{d^{2} Z_{a}}{d X_{a}^{2}}+ \\
M_{a} g \frac{d Z_{a}}{d X_{a}}+C_{a} \dot{X}_{a}\left(1+\left(\frac{d Z_{a}}{d X_{a}}\right)^{2}\right)=0
\end{gathered}
$$

As equações explícitas para cada tipo de curva são apresentadas no Apêndice A. Verifica-se na Eq.6.18 que podem surgir não linearidades inerciais (segundo e terceiro termo da equação) bem como forças de amortecimento não lineares (último termo da equação) para todas as funções polinomiais. Para a 
curva de quarto grau também surge um termo não linear cúbico no quarto termo da equação diferencial associado ao potencial gravitacional do pêndulo.

\subsection{2.}

\section{Isolador de base pendular}

A formulação matemática para a geração das equações de movimento da estrutura com IBP foi apresentada no Cap-5.1. Neste item são apresentadas as equações diferenciais de movimento para uma superfície polinomial. Tem-se neste caso

$$
\begin{gathered}
\left(\ddot{X}_{g}+\ddot{X}_{s}+\ddot{X}_{b}\right) M_{s}+C_{s} \dot{X}+K_{s} X=0 \\
\left(\ddot{X}_{g}+g \frac{d Z_{a}}{d X_{a}}+\left(\left(\frac{d Z_{a}}{d X_{a}}\right)^{2}+1\right) \ddot{X}_{b}+\frac{d Z_{a}}{d X_{a}} \frac{d^{2} Z_{a}}{d X_{a}^{2}} \dot{X}_{b}^{2}\right)\left(M_{S}+M_{b}\right)+ \\
\ddot{X}_{s} M_{s}+\left(\left(\frac{d Z_{a}}{d X_{a}}\right)^{2}+1\right) C_{b} \dot{X}_{b}=0
\end{gathered}
$$

Novamente verifica-se na Eq.6.20 o aparecimento de diversos termos não lineares.

\section{3. \\ Análise paramétrica em função do tipo de curva}

\subsection{1.}

\section{Estrutura com APMS}

A análise paramétrica do APMS em função do tipo de superfície é feita fixando-se $\delta=0,01$ e variando o valor da razão de frequência $(\Delta=0,9 ; 1,0$ e 1,1$)$. As taxas de amortecimento da estrutura e do APMS são $\xi_{s}=0,02$ e $\xi_{a}=0,035$, respectivamente. A força geradora de movimento de base na estrutura com APMS é do tipo harmônico e tem a seguinte forma $d^{2} \bar{X}_{g} / d \tau^{2}=0,01 \Delta^{2} \beta^{2} \operatorname{sen}(\beta \tau)$. A geometria dos diferentes tipos de curva é mostrada na Figura 6-4. Com a finalidade de comparar os resultados, todas as curvas têm o mesmo raio de curvatura no ponto $X_{a}=0$ e $Z_{a}=0$ (origem do sistema de referência), sendo este, para efeito de comparação, igual ao raio de curvatura da superfície circular. 
Para a curva quadrática modificada, Eq.6.4, consideram-se três valores de $\phi$ e $m=$ 800, como ilustra a Figura 6-3.

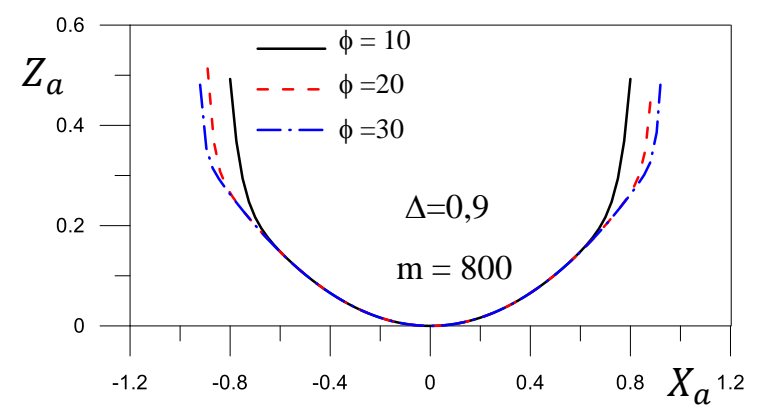

Figura 6-3 Curvas quadráticas modificadas em função da variável $(\phi)$
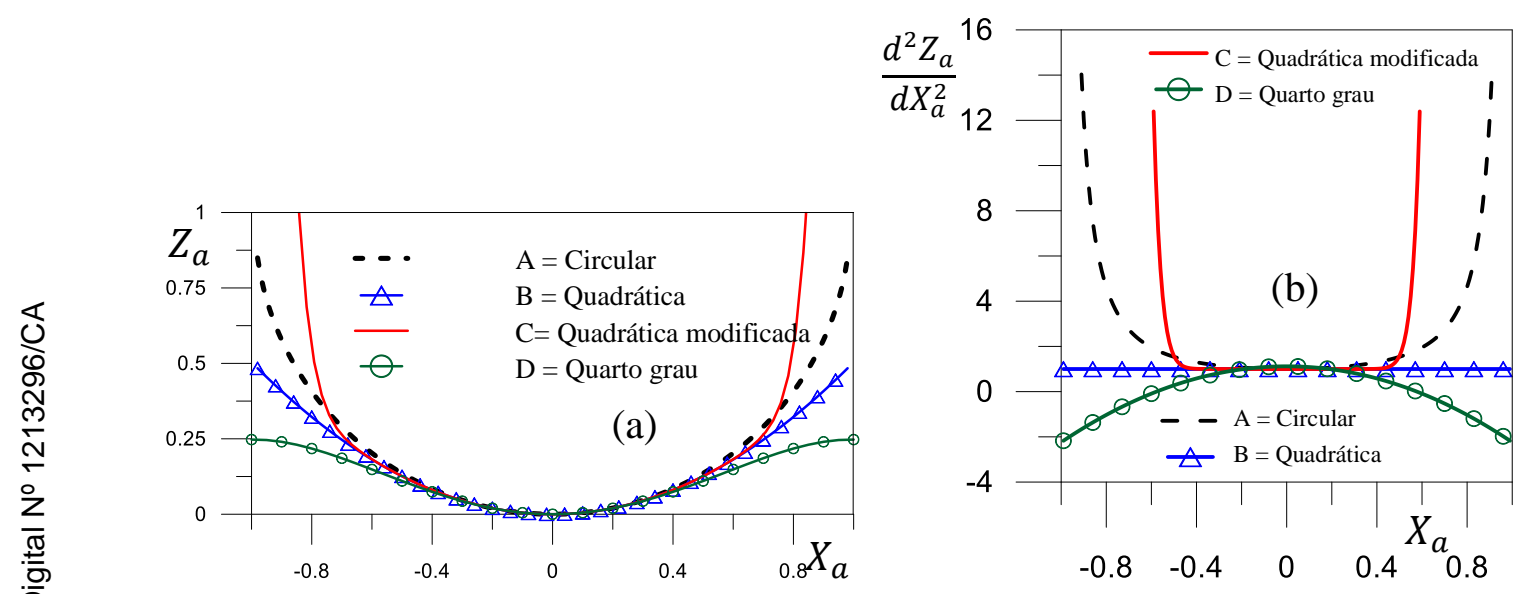

Figura 6-4 Funções que descrevem o pêndulo virtual (a), rigidez efetiva $\left(d^{2} Z_{a} / d X_{a}^{2}\right)$ para os tipos de curva (b), para $R_{c}=1 ; \varnothing=10 ; H=0,25 ; n=1 ; m=800$

As diversas curvas são comparadas na Figura 6-4 (a) e na Figura 6-4 (b) mostra-se a variação da segunda derivada que é proporcional à rigidez efetiva do pêndulo virtual. Verifica-se que as curvas de segundo grau levam a um aumento de rigidez, que é associada ao aumento da curvatura, enquanto a curva de quarto grau leva a um decréscimo da rigidez.

Na Figura 6-5 é mostrado o comportamento da estrutura e do APMS em função da frequência de excitação adimensional $\beta$ para $\Delta=0,9$. Neste caso, os resultados mostram um comportamento similar da estrutura para todas as curvas, com poucas diferenças nos valores máximos que, neste caso, ocorrem na vizinhança da segunda frequência natural da estrutura. No caso dos deslocamentos do APMS, os maiores valores acontecem para a superfície circular e os menores valores para a superfície de quarto grau. A pequena influência da superfície curva nas oscilações da estrutura é devido ao fato dos deslocamentos máximos serem 
pequenos e ocorrerem na região onde todas as curvas praticamente coincidem (ver Figura 6-4-(a)).
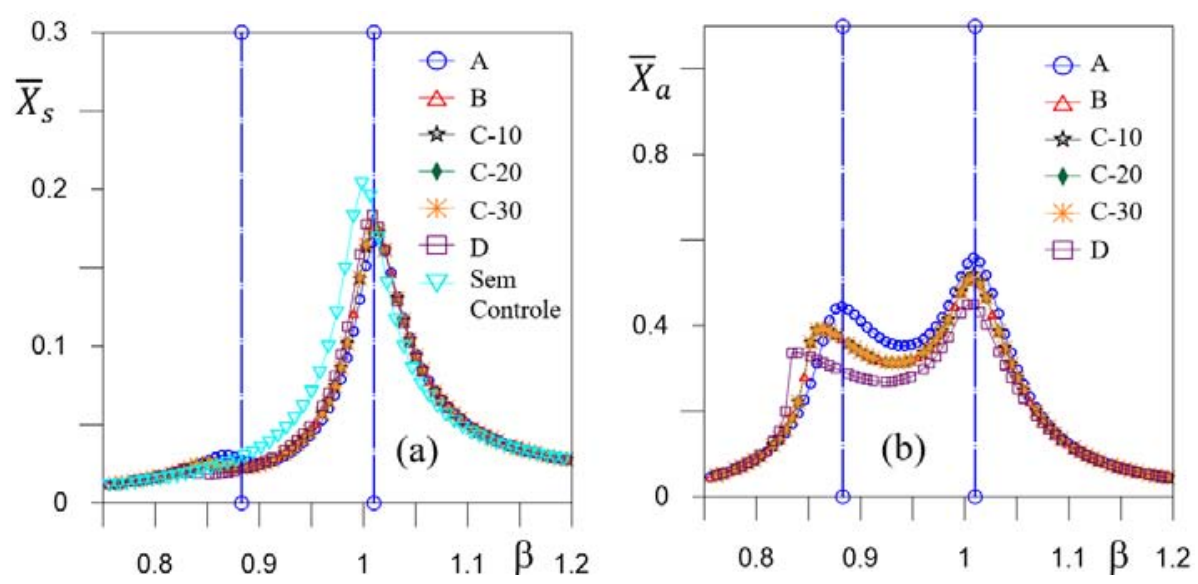

Figura 6-5 Diagramas de bifurcação da estrutura (a) e do APMS (b) para os diferentes tipos de curvas $(\Delta=0,9)$.

Tabela 6-1 Deslocamentos e acelerações máximas para cada tipo de curva $(\delta=0,01 ; \Delta=0,9)$

\begin{tabular}{|c|c|c|c|c|}
\hline \multirow{2}{*}{$\begin{array}{l}\text { TIPO } \\
\text { CURVA }\end{array}$} & & \multicolumn{2}{|c|}{ Estrutura Principal } & \multirow{2}{*}{$\begin{array}{l}\text { APMS } \\
\text { Deslocamento }\end{array}$} \\
\hline & & Deslocamento & Aceleração & \\
\hline Sem Controle & $\boldsymbol{A}$ & 0,204 & 0,204 & \\
\hline Circular & $\boldsymbol{B}$ & 0,169 & 0,173 & 0,559 \\
\hline Quadrática & $C$ & 0,176 & 0,178 & 0,512 \\
\hline Quadrática-M- $\phi=10$ & $D$ & 0,174 & 0,178 & 0,521 \\
\hline Quadrática-M- $\phi=20$ & $E$ & 0,176 & 0,178 & 0,512 \\
\hline Quadrática-M- $\phi=30$ & $\boldsymbol{F}$ & 0,176 & 0,178 & 0,512 \\
\hline $4^{\circ}$ grau & $G$ & 0,184 & 0,186 & 0,450 \\
\hline \multirow{6}{*}{ Redução (\%) } & $A-B$ & 17,32 & 15,15 & \\
\hline & $A-C$ & 13,76 & 12,45 & \\
\hline & $A-D$ & 14,50 & 12,76 & \\
\hline & $A-E$ & 13,76 & 12,45 & \\
\hline & $A-F$ & 13,76 & 12,45 & \\
\hline & $A-G$ & 9,97 & $\mathbf{8 , 5 7}$ & \\
\hline
\end{tabular}

Na Tabela 6-1 é ilustrada a eficiência do APMS em comparação com a estrutura sem controle para cada tipo de curva. Neste caso a maior eficiência (17,3 \%) é para a curva circular e a menor (10\%) é para a curva de quarto grau. O mesmo se observa para a aceleração máxima. Compatível com as reduções na resposta da estrutura, a massa do APMS teve maior deslocamento para a curva circular e menor deslocamento para a curva de quarto grau.

Para $\Delta=1,0$ Figura 6-6, verifica-se que a estrutura e o AMPS experimentam comportamentos diferentes para cada tipo de superfície curva. A curva de quarto 
grau e a quadrática modificada com $\phi=10$ levam aos maiores picos dos deslocamentos, mas para diferentes frequências de excitação. Os menores deslocamentos ocorrem para a curva circular, que, como esperado, leva aos maiores deslocamentos do APMS. As diferenças devem-se ao fato dos deslocamentos máximos já ocorrem na região onde as diversas curvas divergem e onde as diferentes não linearidades passam a influenciar a resposta da estrutura e do APMS. Verifica-se que para a curva quadrática modificada com $\phi=10$ a presenças de diversos saltos nos deslocamentos na vizinhança da segunda frequência. Esta é a curva, como mostra a Figura 6-6, que tem a mudança mais abrupta de curvatura, gerando uma forte não linearidade. À esquerda da primeira frequência observa-se que os deslocamentos do APMS sofrem uma variação brusca, apresentado inclusive um salto no caso da curva de quarto grau. Isto se deve à não linearidade do pêndulo que é do tipo softening, como mostrado no capítulo 3. No caso da curva de quarto grau esta não linearidade aumenta em virtude da não linearidade cúbica negativa proveniente do termo de quarto grau.
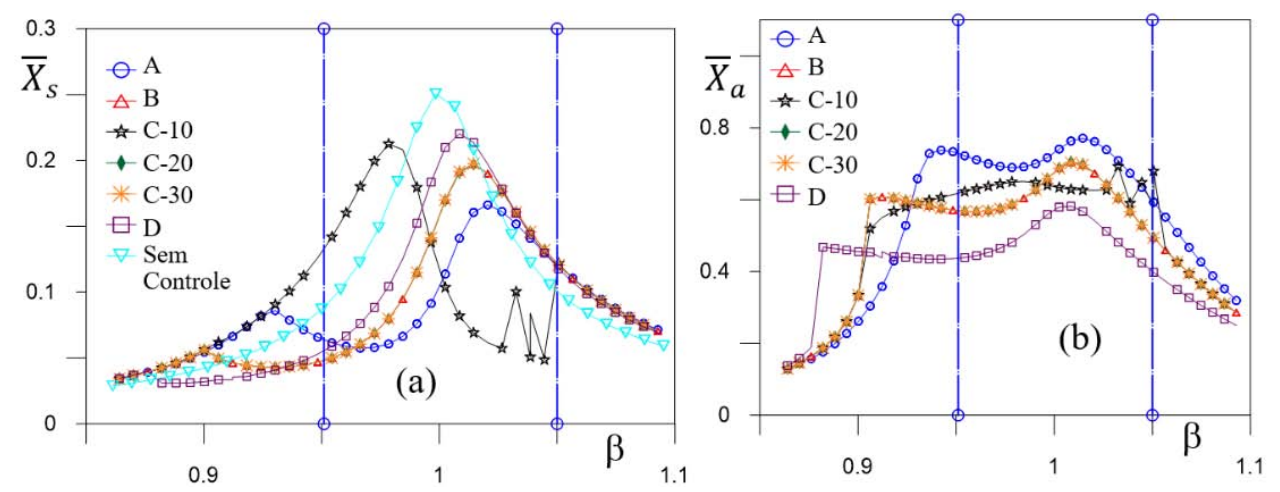

Figura 6-6 Diagramas de bifurcação da estrutura (a) e do APMS (b) para os diferentes tipos de curvas $(\Delta=1,0)$. 
Tabela 6-2 Deslocamentos e acelerações máximas para cada tipo de curva $(\delta=0,01 ; \Delta=1,0)$

\begin{tabular}{|c|c|c|c|c|}
\hline \multirow{2}{*}{$\begin{array}{l}\text { TIPO DE } \\
\text { CURVA }\end{array}$} & & \multicolumn{2}{|c|}{ Estrutura Principal } & \multirow{2}{*}{$\frac{\text { APMS }}{\text { Deslocamento }}$} \\
\hline & & Deslocamento & Aceleração & \\
\hline Sem Controle & $\bar{A}$ & 0,252 & 0,252 & \\
\hline Circular & $B$ & 0,166 & 0,173 & 0,771 \\
\hline Quadrática & $C$ & 0,197 & 0,203 & 0,703 \\
\hline Quadrática-M- $\phi=10$ & $D$ & 0,212 & 0,206 & 0,692 \\
\hline Quadrática-M- $\phi=20$ & $E$ & 0,197 & 0,202 & 0,705 \\
\hline Quadrática-M- $\phi=30$ & $F$ & 0,197 & 0,203 & 0,703 \\
\hline $4^{\circ}$ grau & $G$ & 0,220 & 0,223 & 0,582 \\
\hline \multirow{6}{*}{ Redução (\%) } & $A-B$ & 33,96 & 31,40 & \\
\hline & $A-C$ & 21,56 & 19,51 & \\
\hline & $A-D$ & 15,62 & 18,21 & \\
\hline & $A-E$ & 21,73 & 19,68 & \\
\hline & $A-F$ & 21,56 & 19,51 & \\
\hline & $A-G$ & 12,51 & 11,22 & \\
\hline
\end{tabular}

Os deslocamentos e acelerações máximas da estrutura e o deslocamento máximo do APMS são mostrados na Tabela 6-2. O APMS com curva circular tem uma eficiência de 33,9 \% na redução dos deslocamentos e 31,4 \% nas acelerações. O APMS com menor eficiência neste caso é aquele descrito pela curva de quarto grau com uma eficiência de 12,5 \% na redução dos deslocamentos e 11,2 \% das acelerações.
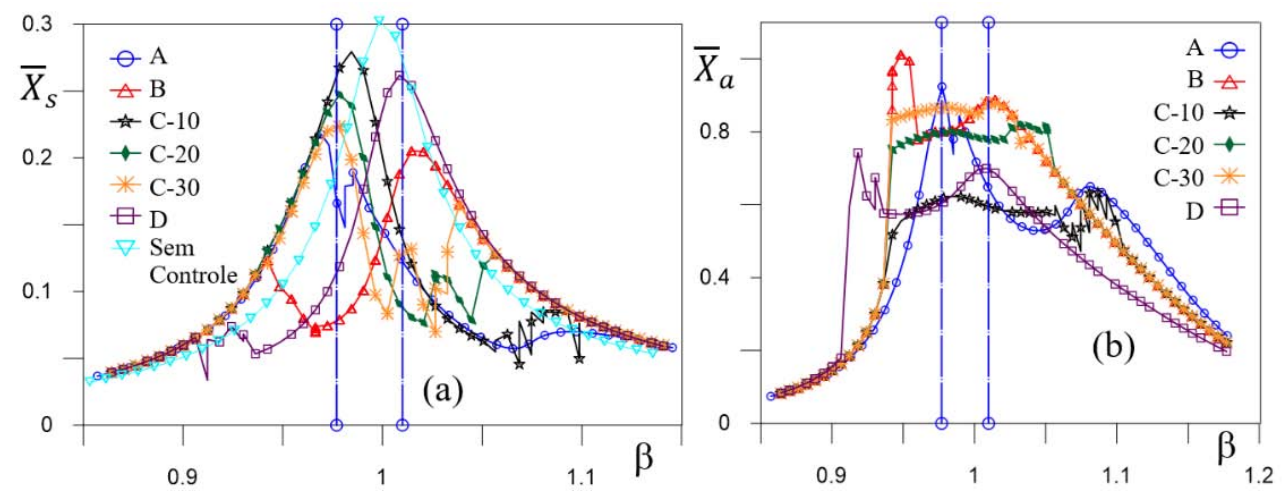

Figura 6-7 Diagramas de bifurcação da estrutura (a) e do APMS (b) para os diferentes tipos de curvas $(\Delta=1,1)$.

Finalmente, para $\Delta=1,1$ a Figura $6-7$, observa-se resultados semelhantes aos resultados anteriores. Numericamente, o comportamento da estrutura com diferentes tipos de curva para $\Delta=1,1$ é resumido na Tabela 6-3. Neste caso a estrutura experimenta deslocamentos maiores, aumentando os efeitos não lineares na resposta e as diferenças no comportamento da estrutura e do APMS para cada tipo de curva. Neste caso, a curva de quarto grau é a que leva à maior eficiência 
com redução de 42,2 \% e 41,3 \% para, respectivamente, os deslocamentos e acelerações.

Observa-se que, à medida que $\Delta$ cresce, aumentam os deslocamentos do APMS, aumentando os efeitos da não linearidade geométrica e a resposta do APMS passa a apresentar várias descontinuidades em virtude de saltos dinâmicos entre soluções coexistentes. Os saltos ocorrem à esquerda da frequência natural, indicando uma não linearidade com perda de rigidez.

Como já observado no Capítulo 4, o APMS reduz as vibrações da estrutura, mas o grau de redução depende muito da sintonização e, como mostrado neste capítulo, da forma da curva.

Tabela 6-3 Deslocamentos e acelerações máximas para cada tipo de curva $(\delta=0,01 ; \Delta=1,1)$

\begin{tabular}{ccccc}
\hline \multirow{2}{*}{$\begin{array}{c}\text { TIPO DE } \\
\text { CURVA }\end{array}$} & & \multicolumn{2}{c}{ Estrutura Principal } & APMS \\
\cline { 2 - 5 } & & Deslocamento & Aceleração & Deslocamento \\
\hline Sem Controle & $\boldsymbol{A}$ & 0,305 & 0,304 & \\
\hline Circular & $\boldsymbol{B}$ & 0,218 & 0,206 & 0,9238 \\
\hline Quadrática & $\boldsymbol{C}$ & 0,205 & 0,213 & 1,012 \\
\hline Quadrática-M- $\phi=\mathbf{1 0}$ & $\boldsymbol{D}$ & 0,279 & 0,271 & 0,634 \\
\hline Quadrática-M- $\phi=\mathbf{2 0}$ & $\boldsymbol{E}$ & 0,247 & 0,238 & 0,820 \\
\hline Quadrática-M- $\phi=\mathbf{3 0}$ & $\boldsymbol{F}$ & 0,224 & 0,216 & 0,879 \\
\hline \multirow{4}{*}{$\mathbf{4}^{\mathbf{0}}$ grau } & $\boldsymbol{G}$ & 0,176 & 0,178 & 0,512 \\
\hline \multirow{3}{*}{ Redução $(\boldsymbol{\%})$} & $\boldsymbol{A}-\boldsymbol{B}$ & $\mathbf{2 8 , 5 2}$ & $\mathbf{3 2 , 2 8}$ & \\
\cline { 2 - 5 } & $\boldsymbol{A}-\boldsymbol{C}$ & $\mathbf{3 2 , 6 4}$ & $\mathbf{3 0 , 2 0}$ & \\
\cline { 2 - 5 } & $\boldsymbol{A}-\boldsymbol{D}$ & $\mathbf{8 , 2 6}$ & $\mathbf{1 0 , 9 2}$ & \\
\cline { 2 - 5 } & $\boldsymbol{A}-\boldsymbol{E}$ & $\mathbf{1 8 , 8 0}$ & $\mathbf{2 1 , 6 9}$ & \\
\cline { 2 - 5 } & $\boldsymbol{A}-\boldsymbol{F}$ & $\mathbf{2 6 , 6 2}$ & $\mathbf{2 8 , 9 3}$ & \\
\cline { 2 - 5 } & $\boldsymbol{A}-\boldsymbol{G}$ & $\mathbf{4 2 , 2 7}$ & $\mathbf{4 1 , 3 9}$ & \\
\hline
\end{tabular}

\subsection{2.}

\section{Estrutura com IBP}

A análise da influência da variação de curvatura da curva do IBP na resposta da estrutura é feita considerando $\delta=0,1, \Delta=0,1 \quad \xi_{s}=3,5 \%$ e $\xi_{s}=2 \%$. A aceleração de base é dada por $d^{2} \bar{X}_{g} / d \tau^{2}=0,3 \Delta^{2} \beta^{2} \operatorname{sen}(\beta \tau)$. 

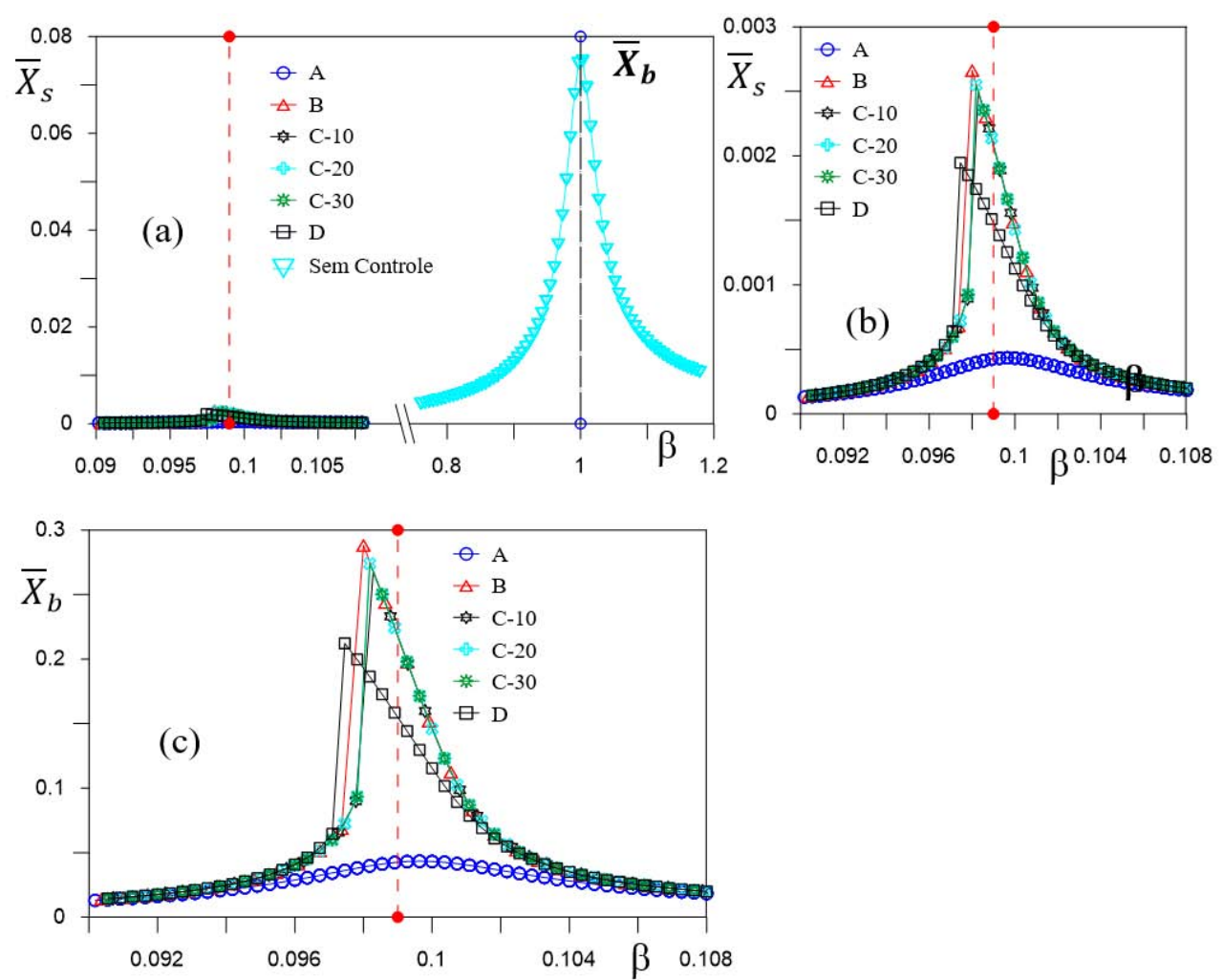

Figura 6-8 (a) Diagramas de bifurcação da estrutura com IBP e sem controle, (b) e da estrutura com IBP, (c) deslocamento horizontal do IBP; em função da variação da curva, $\delta=0,1 ; \Delta=0,1$

Na Figura 6-8 é mostrada a influência da variação da curvatura nos deslocamentos da estrutura principal e do IBP para os seis tipos de curva. Pode-se ver que a resposta para um IBP com base circular (Curva-A) é distintamente diferente dos outros casos, apresentando maior eficiência, com um comportamento praticamente linear. Em todos os outros casos observa-se uma forte não linearidade com a curva de ressonância dobrando para a esquerda em virtude da não linearidade com perda de rigidez, o que leva a saltos dinâmicos para frequências de excitação menores que a da estrutura. Entre as curvas polinomiais, a curva D ( $4^{\circ}$ grau) leva ao melhor desempenho. Em relação ao valor de pico dos deslocamentos ela acontece para frequências menores que a frequência natural de vibração linear na forma adimensional $(0,099)$.

A resposta da estrutura para a curva circular é $83 \%$ menor que a resposta para as curvas quadráticas e 78 \% menor que para a curva de quarto grau. Comparando com a estrutura sem controle, a curva circular leva a uma redução de 99,4 \% nos deslocamentos, sendo esta de 96,6 \% para as curvas quadráticas na média e de 97,4 \% para a curva de quarto grau, como mostra a Tabela 6-4. Notase em todos os casos uma grande eficiência no controle das acelerações, sendo as 
reduções superiores a 99 \%. Mais uma vez se demonstra a eficiência do IBP no controle de vibrações de estruturas sob excitação de base.

Tabela 6-4 Valores máximos de deslocamentos e acelerações da estrutura e deslocamentos do IBP

\begin{tabular}{|c|c|c|c|c|}
\hline \multicolumn{5}{|c|}{ Estrutura com isolador pendular } \\
\hline \multirow{2}{*}{$\begin{array}{l}\text { TIPO DE } \\
\text { CURVA }\end{array}$} & & \multicolumn{2}{|c|}{ Estrutura } & \multirow{2}{*}{$\begin{array}{c}\text { IBP } \\
\text { Deslocamento }\end{array}$} \\
\hline & & Deslocamento & Acelerações & \\
\hline Sem Controle & $A$ & 0,075 & 0,075 & \\
\hline Circular & $B$ & 0,00043 & 0,000005 & 0,043 \\
\hline Quadrática & $C$ & 0,00266 & 0,000026 & 0,288 \\
\hline Quadrática-M- $\phi=10$ & $D$ & 0,00250 & 0,000024 & 0,268 \\
\hline Quadrática-M- $\phi=20$ & $E$ & 0,00255 & 0,000024 & 0,274 \\
\hline Quadrática-M- $\phi=30$ & $F$ & 0,00255 & 0,000024 & 0,274 \\
\hline $4^{\circ}$ grau & $G$ & 0,00195 & 0,000018 & 0,212 \\
\hline \multirow{6}{*}{$\underset{\%}{\text { Redução }}$} & $A-B$ & 99,42 & 99,99 & \\
\hline & $A-C$ & 96,45 & 99,97 & \\
\hline & $A-D$ & 96,66 & 99,97 & \\
\hline & $A-E$ & 96,60 & 99,97 & \\
\hline & $A-F$ & 96,60 & 99,97 & \\
\hline & $A-G$ & 97,40 & 99,98 & \\
\hline
\end{tabular}




\section{7 Impacto como mecanismo auxiliar de dissipação de energia}

Vários trabalhos recentes têm investigado o uso de mecanismos de impacto no controle de vibrações em estruturas, de forma a limitar os deslocamentos máximos do AMS e dissipar energia durante o impacto (Spencer e Michael, 1997, Nucera et al., 2007 e Ekwaro-Osire e Desen, 2001). Neste trabalho apresenta-se um estudo da influência do impacto da massa do APMS contra uma superfície flexível ou rígida na redução de deslocamentos e acelerações. O controle de vibrações por impacto é obtido restringindo o deslocamento máximo da massa do APMS ou da massa da base, no caso do IBP.

\section{1. \\ Forças de impacto e métodos de análise}

As forças de impacto são produzidas por um corpo em movimento de massa $M_{a}$ que, ao se chocar com um anteparo flexível ou rígido, gera uma mudança brusca na rigidez e amortecimento, no caso de ser uma barreira flexível, e uma variação brusca da magnitude e sentido da velocidade, no caso de um anteparo rígido.

\subsection{1.}

Impacto sobre superfícies flexíveis

Os anteparos flexíveis são compostos por um ou vários amortecedores com coeficiente de amortecimento $C_{c}$ e molas de rigidez $K_{c}$, como ilustra a Figura 7-1. A influência do anteparo flexível na resposta da estrutura inicia-se no instante em que a estrutura atinge o anteparo com velocidade diferente de zero. O deslocamento que experimenta a estrutura flexível durante o impacto é chamado de penetração e, nesse intervalo, a rigidez e coeficiente de amortecimento do sistema são modificados pela rigidez e coeficiente de amortecimento do anteparo. 


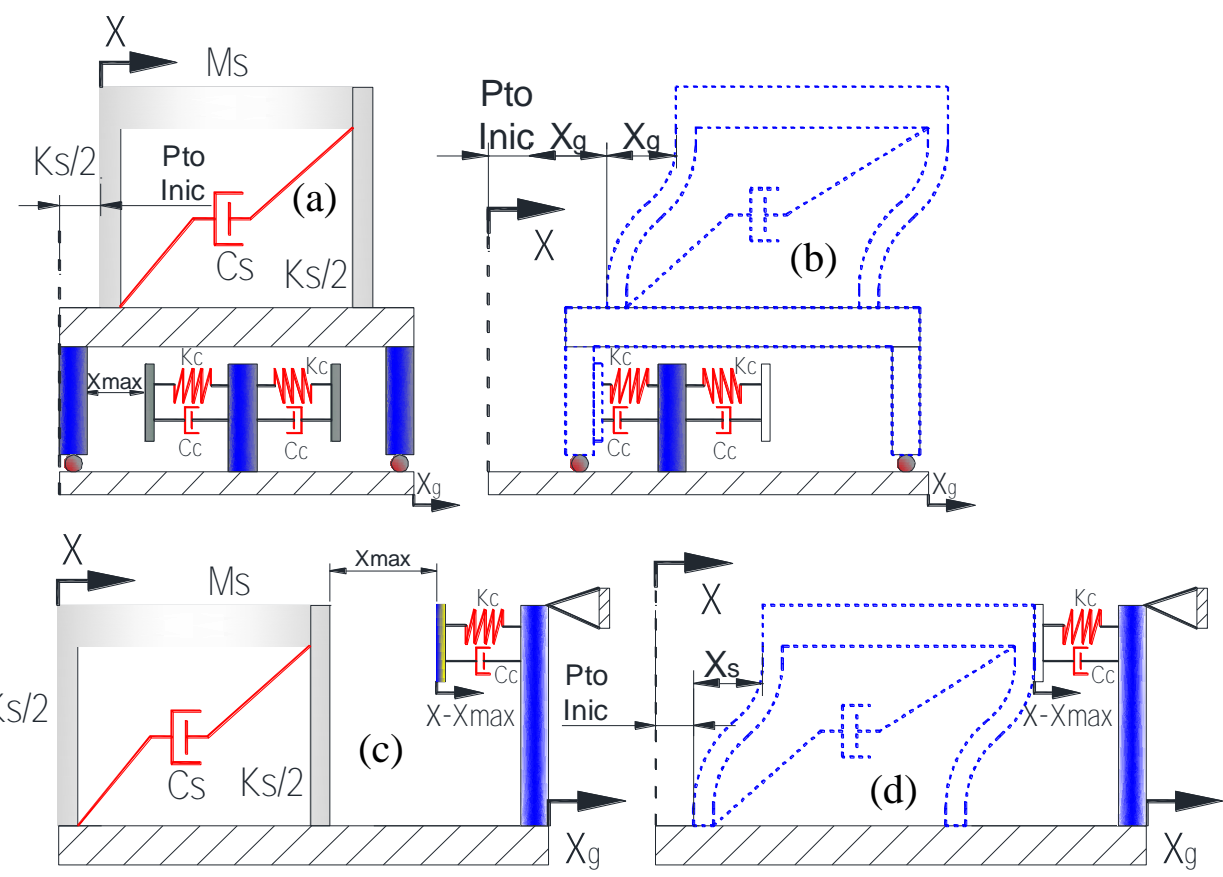

Figura 7-1 (a) e (b)-Impacto de uma estrutura sobre uma superfície flexível como isolador de base, (c) e (d)- amortecedor de massa sintonizado

Com a finalidade de estudar o fenômeno de impacto de um corpo sobre uma superfície flexível, usa-se inicialmente a estrutura da Figura 7-1-(b), cuja equação de movimento é dada por:

$$
\begin{aligned}
& M_{a} \frac{d^{2} x}{d t^{2}}+C_{a} \frac{d x}{d t}+K_{a} x+\frac{d^{2} x_{g}}{d t^{2}}+F_{I M P}=0 \\
& F_{I M P}=\left\{\begin{array}{c}
\max (0, F S), x>X_{\text {max }} \\
0, x \leq X_{\max }
\end{array}\right\}
\end{aligned}
$$

$\mathrm{Na}$ análise numérica apresentada a seguir os seguintes parâmetros são utilizados: massa $M_{a}=98,3 \mathrm{Kg}$, amortecimento $C_{a}=43,444 \mathrm{~N} * \mathrm{~m} / \mathrm{s}$ e rigidez $K_{a}=12000 \mathrm{~N} / \mathrm{m}$ (Pezo, 2012). O anteparo tem rigidez $K_{c}=240000 \mathrm{~N} / \mathrm{m}$ e amortecimento variável $C_{c}=F\left(C_{m a}\right)$, função da penetração, como ilustrado na Figura 7-2, onde $C_{m a}=347,5500541 \mathrm{~N} * \mathrm{~m} / \mathrm{s}$ é o amortecimento máximo do anteparo. Assim a Eq.7.1 toma a seguinte forma:

$$
\begin{aligned}
& 98.3 \frac{d^{2} x}{d t^{2}}+43.44375676 \frac{d x}{d t}+12000 x-9.915 \omega^{2} \sin (\omega t)+F_{I M P}=0 \\
& F_{I M P}=\left\{\begin{array}{c}
\max \left(0, \mathrm{~K}_{c}(x-0.1)^{2}-\left(34755.00541(x-0.1)^{2}(3-20(x-0.1))\right)\right), x>0.05 \\
0, x \leq 0.05
\end{array}\right\}
\end{aligned}
$$




$$
\begin{aligned}
& F S=K_{c}(x-0.1)^{2}-C_{c} \frac{d x}{d t} \\
& C_{c}=\frac{(x-X \max )^{2} C_{m a}\left(3-\frac{2(x-X \max )}{X \max }\right)}{X \max ^{2}} \\
& C_{c}=34755.00541(x-0.1)^{2}(3-20(x-0.1))
\end{aligned}
$$

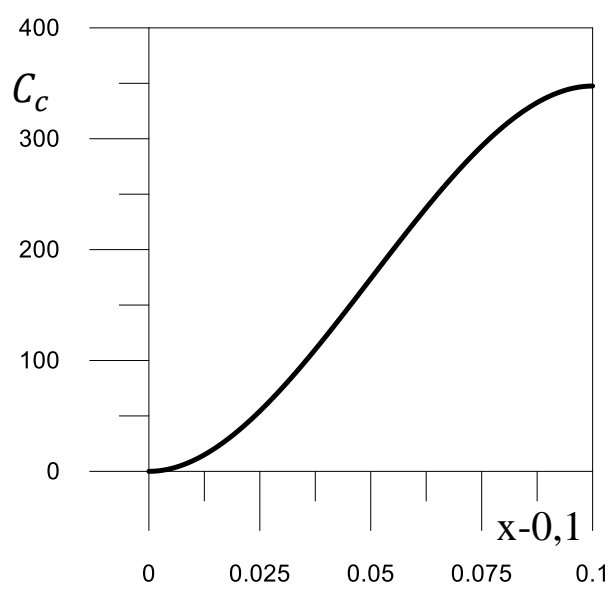

Figura 7-2 Variação do amortecimento Cc em função da penetração.

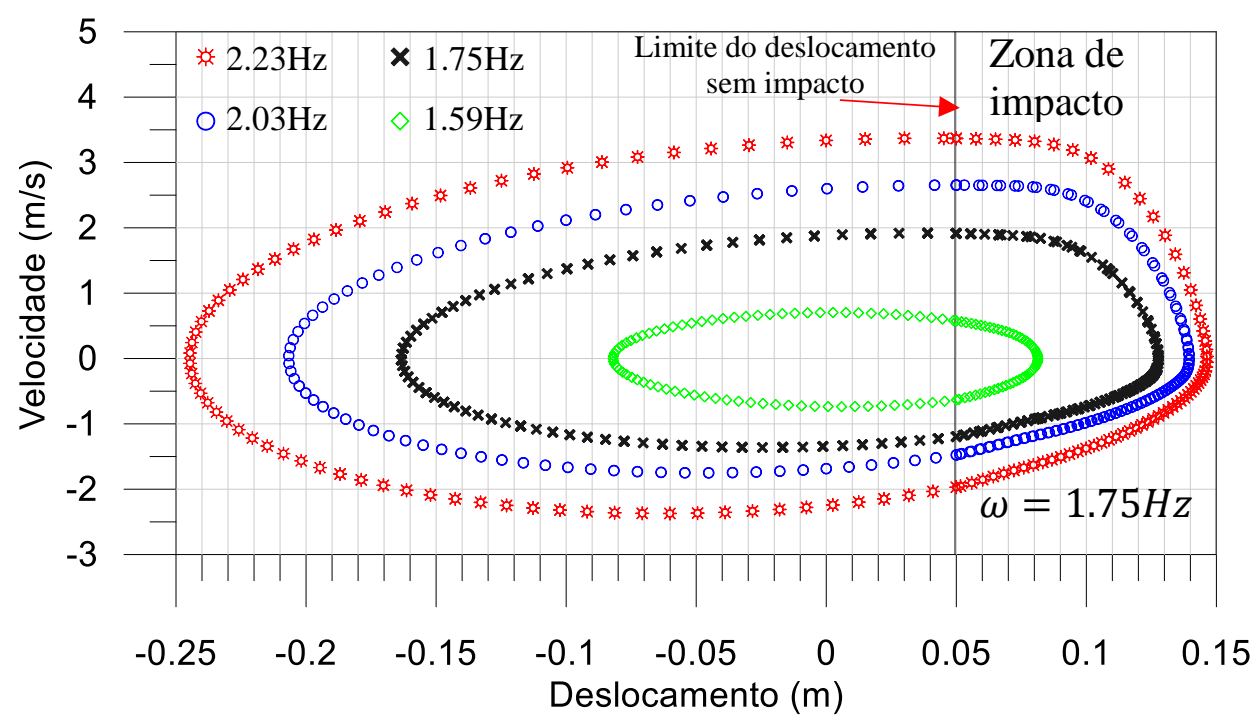

Figura 7-3 Plano fase da estrutura com impacto sobre superfície flexível

Na Figura 7-3 é mostrada a resposta permanente da estrutura no plano de fase para diferentes frequências de excitação. Na figura pode-se diferenciar duas regiões separadas pelo limite dos deslocamentos sem impacto. Após este limite a rigidez e o coeficiente de amortecimento do sistema aumentam, decrescendo, 
consequentemente, os deslocamentos durante o tempo de penetração e saída desta zona.

\subsection{2.}

\section{Impacto sobre superfícies rígidas}

O impacto de um corpo sobre uma superfície rígida (barreira de rigidez infinita), ou de dois corpos rígidos com velocidade finita é considerado como impacto instantâneo. A velocidade de retorno depois do evento instantâneo é obtida de acordo com as leis de Newton. No caso de barreiras que têm rigidez finita tem-se que o problema torna-se um problema não linear de vibração randômica segundo Dimentberg e Iourtchenko (2004).

Para o impacto envolvendo corpos rígidos, as equações da dinâmica não são suficientes para determinar as mudanças de velocidade. Uma relação adicional é necessária. Normalmente esta relação é fornecida pelo coeficiente de restituição que é uma relação empírica para a componente normal da velocidade relativa no momento do contato e separação dos corpos. Isto tem sido satisfatório para impactos entre corpos lisos, mas para impactos entre superfícies ásperas, onde o atrito opõe-se ao deslizamento durante o impacto, o coeficiente de restituição tem uma deficiência grave como é mostrado por Stronge, (2004).

\subsubsection{1.}

\section{Coeficiente de restituição e energia cinética absorvida no impacto}

Stronge (2004) afirma que, a menos que a velocidade de impacto seja extremamente pequena, há uma certa dissipação de energia na colisão. Isto pode ocorrer por deformação plástica, vibração elástica ou visco plasticidade, dentre outros fatores. 


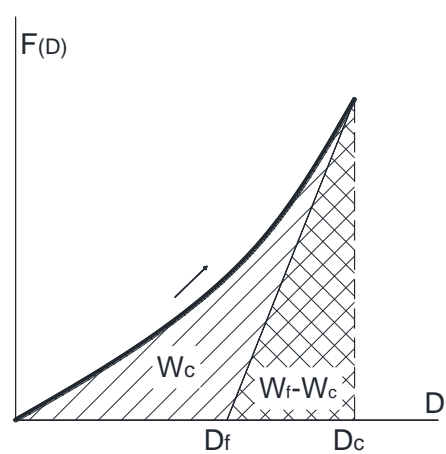

(a)

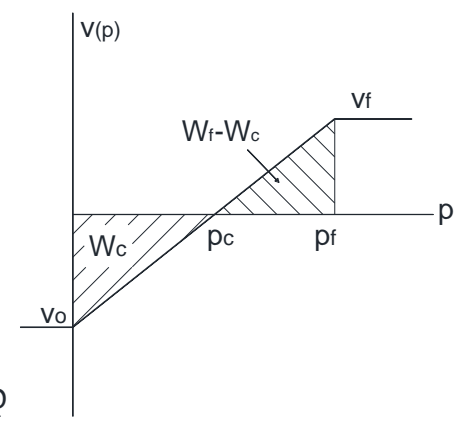

(b)

Figura 7-4 Trabalho $W_{c}$ feito pela força normal de contato $\mathrm{F}$ entre os corpos durante o período de compressão, e o trabalho $W_{f}-W_{c}$ recuperado durante a restituição, como função do deslocamento normal relativo D no ponto de contato. (b) Trabalho da força normal de contato relacionado com alterações na velocidade relativa normal durante o período de compressão ( $p<$ $p_{c}$ ) e restituição $p_{c}<p<p_{f}$.

Por definição, o quadrado do coeficiente de restituição é a razão entre a variação da energia de deformação elástica liberada durante a restituição e a energia interna de deformação absorvida durante a compressão, ou seja

$$
\begin{aligned}
& e^{2}=\frac{W\left(p_{f}\right)-W\left(p_{c}\right)}{W\left(p_{c}\right)} ; \\
& 0 \leq e \leq 1
\end{aligned}
$$

O valor 0, implica em uma colisão perfeitamente plástica (isto é, sem separação final, de modo que nenhuma parte da energia cinética inicial do movimento é recuperada), enquanto que 1 indica uma colisão perfeitamente elástica (isto é, sem perda de energia).

As velocidades final e inicial estão relacionadas com o coeficiente de restituição da forma

$$
e=-\frac{v_{f}}{v_{o}}=-\frac{V_{f}-V_{f}^{\prime}}{V_{0}-V_{0}^{\prime}}=\frac{P_{f}-P_{c}}{P_{c}}
$$

\subsubsection{2.}

\section{Vibração de uma massa com impacto rígido}

O segundo estudo da influência da forca de impacto no controle de vibrações em estruturas é conduzido usando a Eq.7.1, mas é eliminada a parcela da força de impacto flexível $\left(F_{I M P}=0\right)$. 


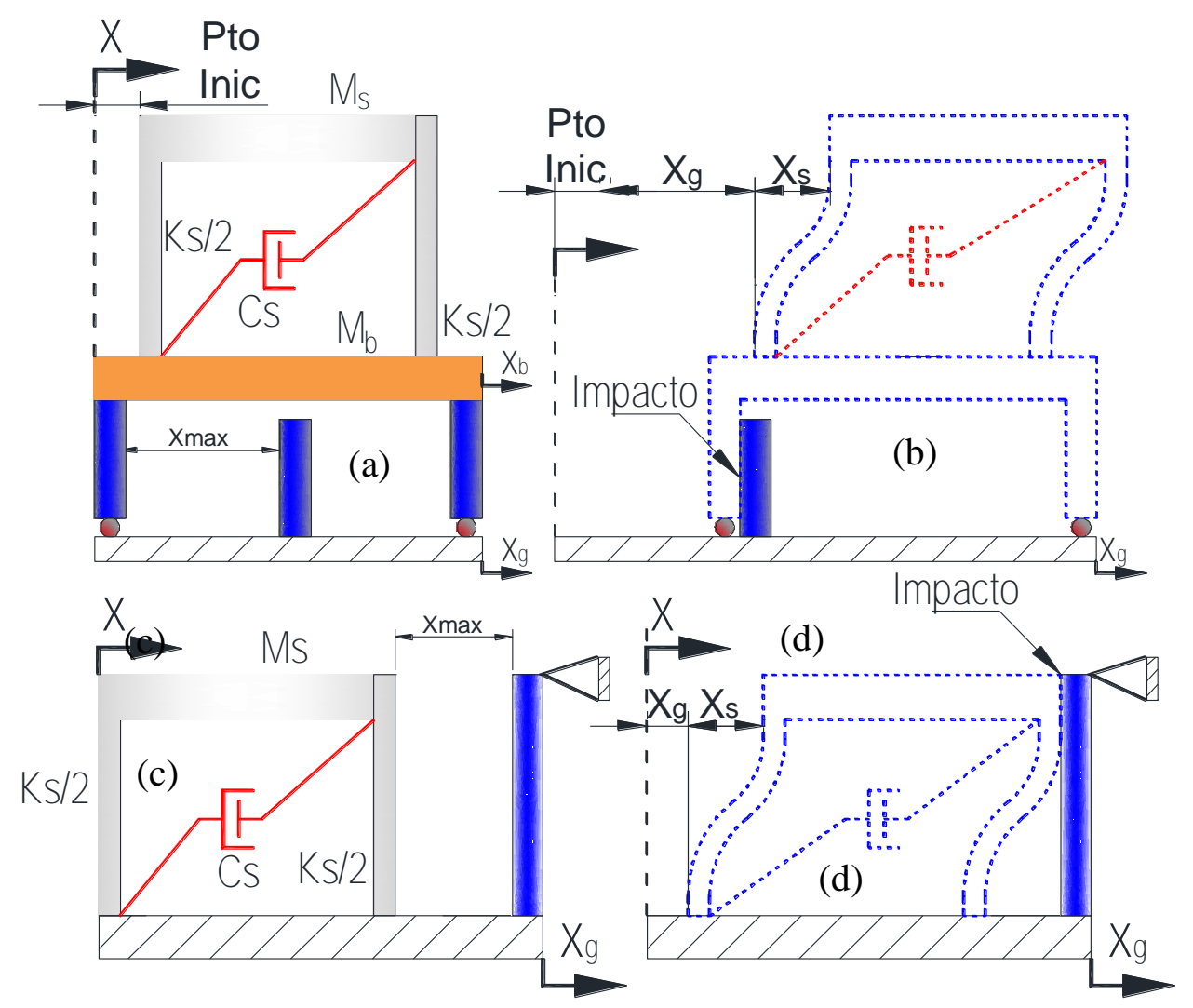

Figura 7-5 (a) e (b)-Estrutura com controle de vibrações com IB, (c) e (d)- estrutura impacto rígido

A estrutura mostrada na Figura 7-5-(b) é representada matematicamente pela equação

$$
98,3 \frac{d^{2} x}{d t^{2}}+43,44375676 \frac{d x}{d t}+12000 x-9,915 \Omega^{2} \sin (\Omega t)=0
$$

Na integração numérica da Eq.7.6, quando a estrutura atinge o deslocamento limite $\left(X_{\text {máx }}=0,05\right)$ em um instante do tempo $t$, calcula-se, após o impacto, a velocidade pela Eq.7.5 que deve ter sinal oposto e ser igual ou menor que a velocidade em um tempo infinitesimal antes do impacto segundo Mitić (1997). O fator de redução da velocidade é dado pelo coeficiente de restituição $0 \leq e \leq 1$. 


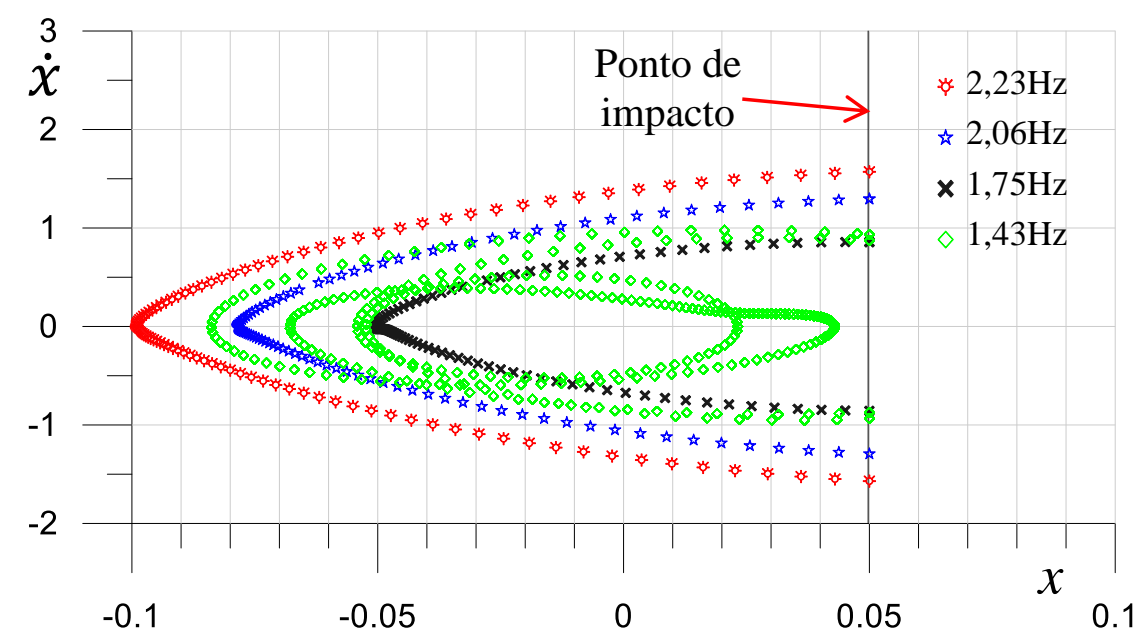

Figura 7-6 Plano face da estrutura com impacto rígido $(e=1)$

A Figura 7-6 mostra o comportamento da estrutura no plano de fase (deslocamento versus velocidade) imediatamente antes e depois do impacto para diferentes valores de frequência de excitação. O deslocamento é constante durante o impacto, mas a velocidade tem uma mudança brusca de magnitude e sentido que depende do valor do coeficiente de restituição. Na Figura 7-6 considera-se $e=1$ (impacto perfeitamente elástico).

\section{2.}

Impacto entre duas massas em movimento

Para entender a influência do impacto nas vibrações não lineares, um sistema mecânico composto por uma massa $\mathrm{m}_{1}$ e um sistema acoplado elasticamente com massa $m_{2}$ foi estudado por Blazejczyk e Kapitaniak (1996). Este sistema é ilustrado na Figura 7-7. Neste tipo de sistemas, o impacto acontece entre as duas massas em movimento e é necessário, além do coeficiente de restituição, calcular as velocidades depois do impacto através da expressão

$$
m_{A} V_{A}+m_{B} V_{B}=m_{B} V_{B}^{\prime}+m_{B} V_{B}^{\prime}
$$

Com a finalidade de entender os efeitos do impacto no controle de vibrações, são usadas as equações de movimento Eq.7.9 que representam o comportamento dinâmico do sistema da Figura 7-7.

Os seguintes parâmetros adimensionais são definidos. 


$$
\begin{aligned}
& \omega_{1}=\sqrt{\frac{k_{1}}{m_{1}}} ; \quad \omega_{2}=\sqrt{\frac{k_{2}}{m_{2}}} ; \quad \xi_{1}=\frac{c_{1}}{2 \sqrt{k_{1} m_{1}}} ; \quad \xi_{2}=\frac{c_{2}}{2 \sqrt{k_{2} m_{2}}} \\
& \tau=\omega_{1} t ; \beta=\frac{\Omega}{\omega_{1}} ; \Delta=\frac{\omega_{2}}{\omega_{1}} ; \delta=\frac{m_{2}}{m_{1}} ; \varepsilon=\frac{e}{x_{s t}} ; x_{s t}=\frac{F_{o}}{k_{1}} ; x_{s t}=\frac{F_{o}}{k_{1}} \quad 7.8 \\
& \frac{d^{2} x_{1}}{d \tau^{2}}+2 \xi_{1} \frac{d x_{1}}{d \tau}+x_{1}+2 \xi_{2} \delta \Delta\left(\frac{d x_{1}}{d \tau}-\frac{d x_{2}}{d \tau}\right)+\delta \Delta\left(x_{1}-x_{2}\right)-\cos (\beta \tau)=0 \\
& \frac{d^{2} x_{2}}{d \tau^{2}}-2 \xi_{2} \Delta\left(\frac{d x_{1}}{d \tau}-\frac{d x_{2}}{d \tau}\right)-\Delta^{2}\left(x_{1}-x_{2}\right)=0 \\
& \text { }
\end{aligned}
$$

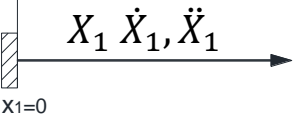

Figura 7-7 Modelo proposto por Blazejczyk e Kapitaniak, (1996)

Os diagramas de bifurcação do sistema, para diferentes valores dos parâmetros adimensionais foram obtidos, usando o método de força bruta, para identificar as possíveis bifurcações geradas pelo impacto. Os resultados são apresentados nas Figura 7-8 à Figura 7-11. Na Figura 7-8 a resposta do sistema linear sem impacto é ilustrada, onde se observam os dois picos referentes às duas frequências naturais do sistema. Nas figuras seguintes observam-se os diagramas do sistema com impacto. Observa-se a presença de saltos dinâmicos e várias sequências de bifurcações, em particular na vizinhança da segunda frequência natural de vibração, mostrando um comportamento altamente não linear. Cabe ressaltar que a única fonte de não linearidade provem do impacto. Observa-se também a influência do coeficiente de restituição nas amplitudes de vibração e sequências de bifurcações. Este exemplo foi usado para ilustrar a não linearidade gerada pelo impacto e para verificar a qualidade dos algoritmos aqui implementados, já que a solução é bastante sensível à definição precisa do instante 
que o impacto ocorre durante o processo de integração numérica, exigindo um processo iterativo para determinar com exatidão o incremento de tempo que coincide com o instante do impacto.

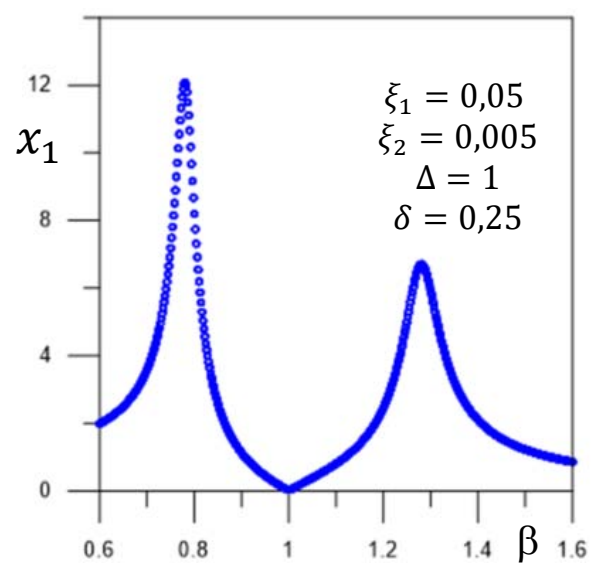

Figura 7-8 Curva de bifurcação do sistema de 2GL sem impacto
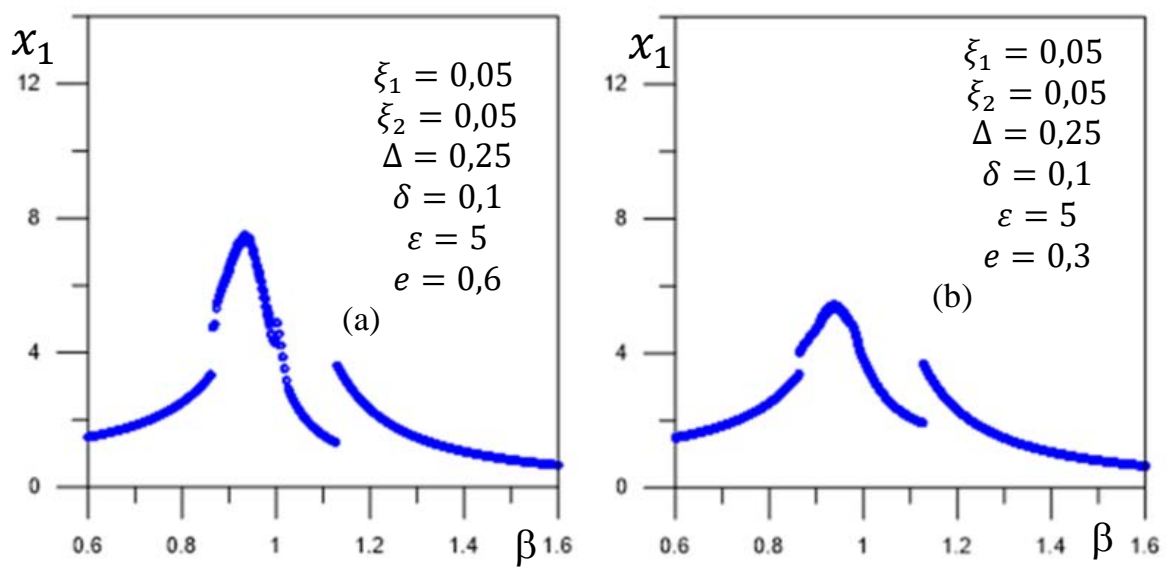

Figura 7-9 Diagrama de bifurcação do oscilador principal com impacto e $\delta=0,1$
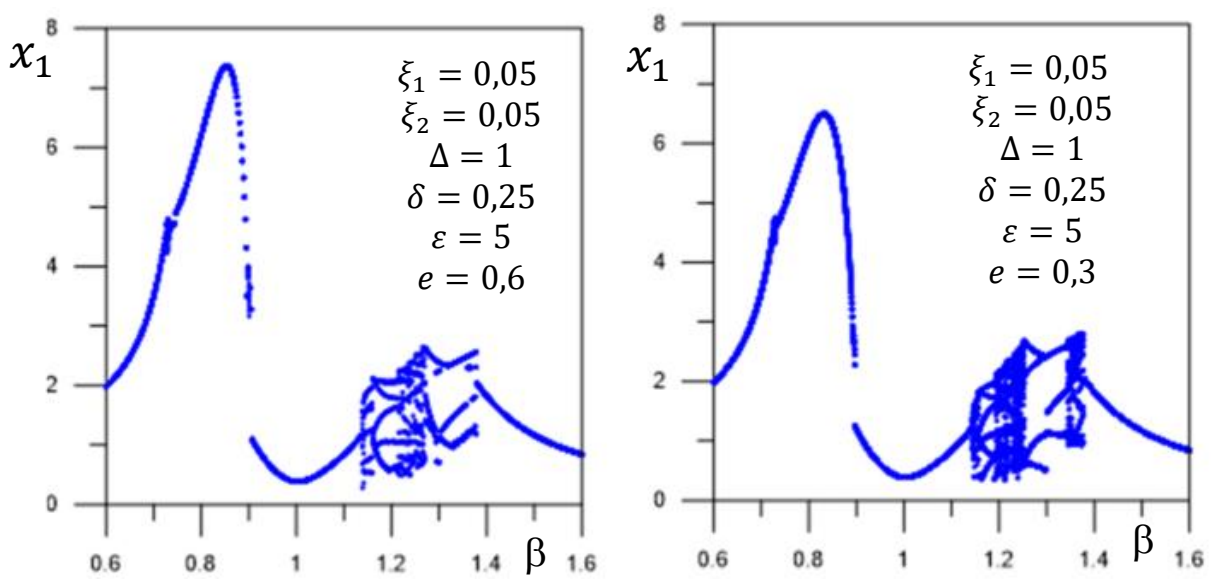

Figura 7-10 Diagrama de bifurcação do oscilador principal com impacto e $\delta=0,25$ 


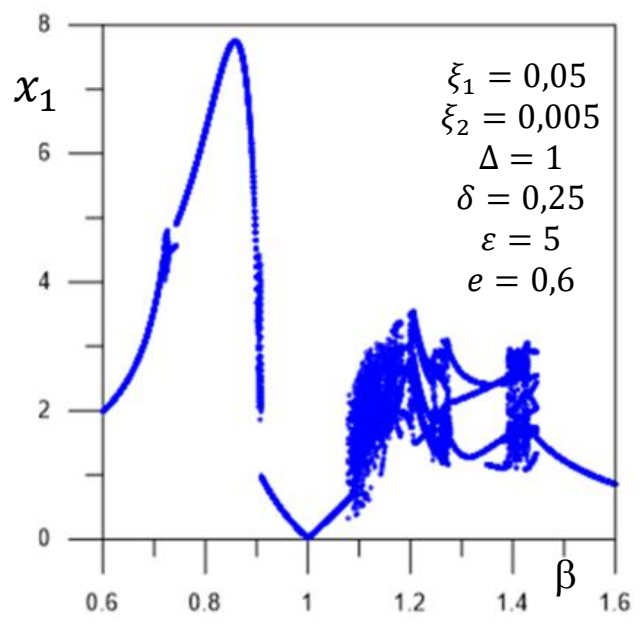

Figura 7-11 Diagrama de bifurcação do oscilador principal com impacto

\section{3.}

\section{Efeito do impacto sobre as oscilações do APMS e do IBP}

\subsection{1.}

\section{Estrutura com APMS com rotação restrita}

A influência do impacto da massa do APMS nos deslocamentos e acelerações da estrutura principal é estudada neste item. Para o estudo do impacto são usadas as Eqs.4.16 e 4.17, e os valores dos parâmetros adimensionais são aqueles usados no item 4.3 para se obter a Tabela 4.2. O impacto acontece quando limitamos o ângulo de rotação do APMS com barreiras fixas de rigidez infinita. Neste caso a rotação máxima do APMS é fixada em $\theta_{\text {lim }}=10^{\circ} ; 15^{\circ}$ e $30^{\circ}$, respectivamente, e adota-se o coeficiente de restituição $e=0,6$ (Mitić, 1997).

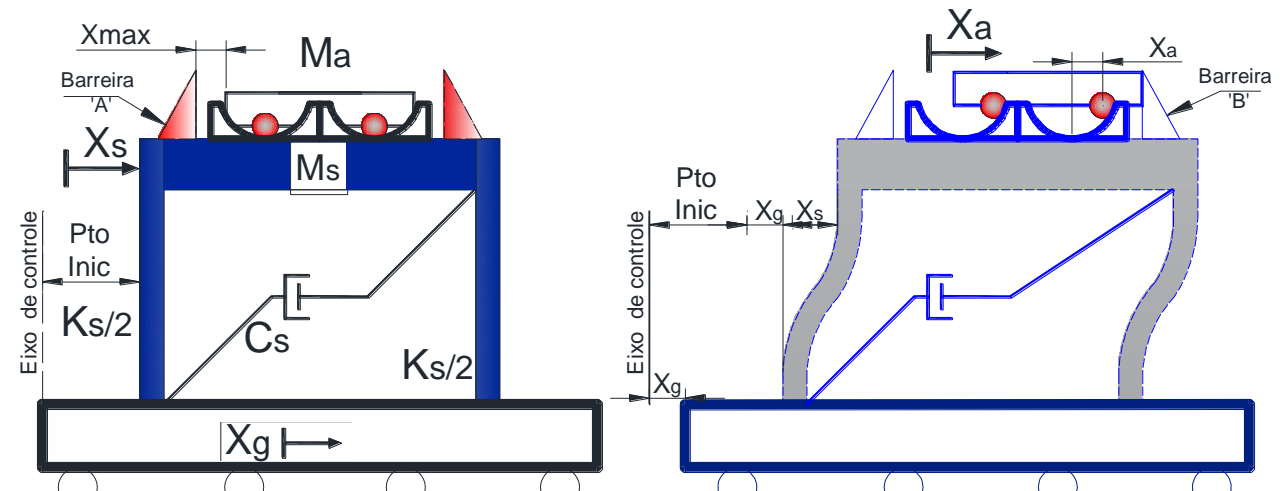

Figura 7-12 Estrutura com APMS com rotação restrita sem deformar e deformada pelo deslocamento de base $\mathrm{Xg}$ 
A rotação máxima permitida do APMS é controlada por duas barreiras localizadas a uma distância $\pm X_{\text {máx }}$ do centro da superfície circular, como mostra a Figura 7-12. Defina-se assim o deslocamento horizontal máximo da massa adicional como

$$
X_{\text {máx }}=R_{c} \operatorname{sen}\left(\theta_{\text {limite }}\right)
$$

Na forma adimensional o deslocamento horizontal é definido como

$$
\bar{X}_{\text {máx }}=\operatorname{sen}\left(\theta_{\text {limite }}\right)
$$

O maior deslocamento horizontal da massa adicional é de 1 para $\theta_{\text {lim }}=$ $90^{\circ}$. Embora $90^{\circ}$ seja o limite máximo de rotação do APMS, não é aconselhável que o APMS apresente rotações de grande magnitude, pois isto pode ocasionar deslizamento sem rotação e até mesmo perda de contato com a superfície curva. Assim deve-se impor $\theta_{\text {lim }}<90^{\circ}$
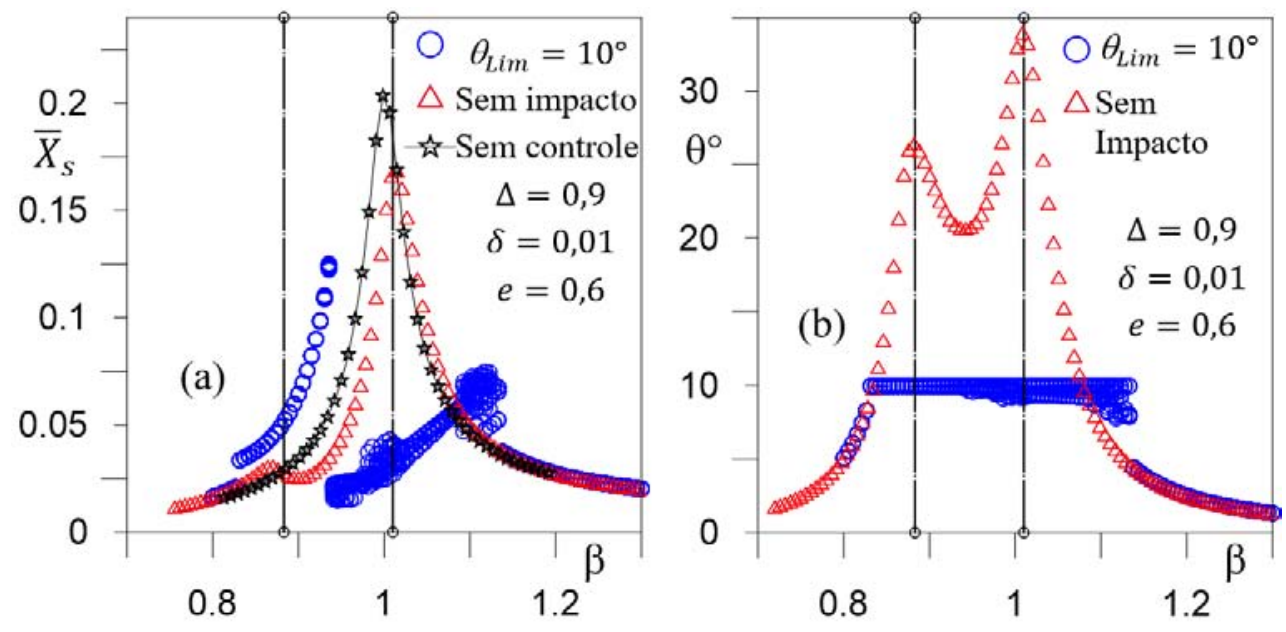

Figura 7-13 Diagramas de bifurcação da estrutura (a) e do APMS (b) com $\theta_{\lim }=10^{\circ}$

A Figura 7-13-b mostra o comportamento do APMS sem e com impacto para $\theta_{\text {lim }}=10^{\circ}$. O impacto acontece para a faixa de $0,83 \leq \beta \leq 1,2$. Quanto aos deslocamentos da estrutura, Figura 7-13-(a), verifica-se que o impacto do APMS causa um aumento dos deslocamentos máximos da resposta permanente na vizinhança da primeira frequência natural de vibração $(\beta=0,883)$ e causa três descontinuidades no diagrama de bifurcação. Por outro lado, o segundo pico na vizinhança da segunda frequência natural de vibração e da frequência natural da estrutura não controlada $(\beta=1)$, onde estrutura experimenta os maiores deslocamentos, há uma redução drástica nos deslocamentos. Nesta região observa- 
se a presença de respostas não periódicas. Verifica-se que o impacto leva a menores deslocamentos da estrutura devido à perda de energia no instante do impacto. Tanto a estrutura quanto o APMS apresentam respostas com período igual ao da força (um ponto na seção de Poincaré).

Os planos de fase da resposta permanente da estrutura com e sem impacto para uma frequência de excitação $\beta=0,833$ são mostrados na Figura 7-14-(a) e do APMS na Figura 7-14-(b). As seções de Poincaré da estrutura principal com e sem impacto são mostradas na Figura 7-14-(c). A resposta no tempo da estrutura é mostrada na Figura 7-16 e do APMS na Figura 7-17. Verifica-se neste caso que, ao limitar os deslocamentos do APMS, há uma redução em sua eficiência, ou seja, a energia dissipada originalmente pelo APMS não é compensada pela energia dissipada durante o impacto, mesmo considerando um coeficiente de restituição $e=0,6$.
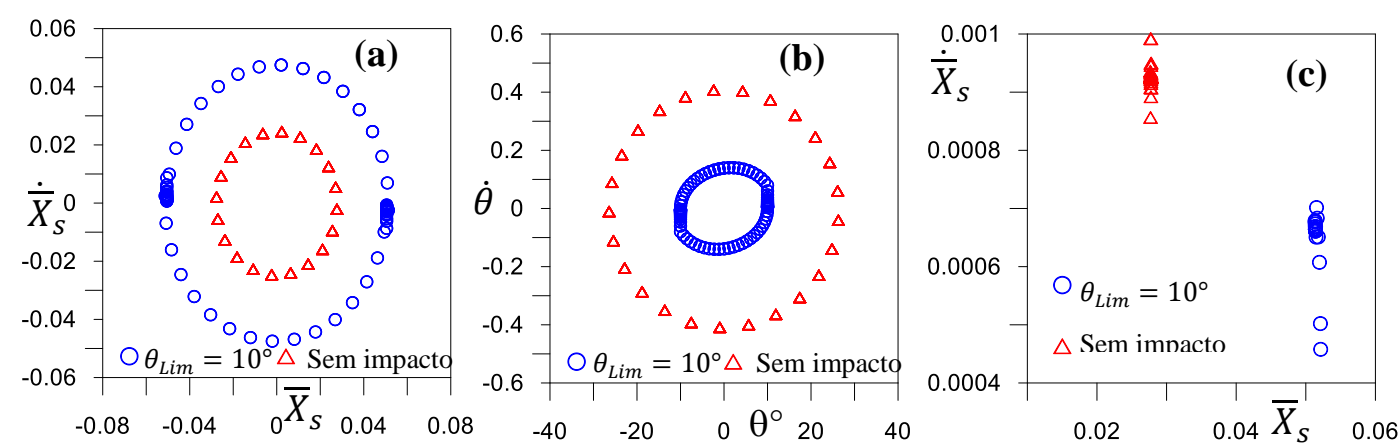

Figura 7-14 Plano de fase da estrutura como e sem impacto. (a), APMS (b) com limite de $\theta=10^{\circ}$ e a seção de Poincaré (c) para $\delta=0,01 ; \Delta=0,9 ; e=0,6$ e $\beta=0,883$
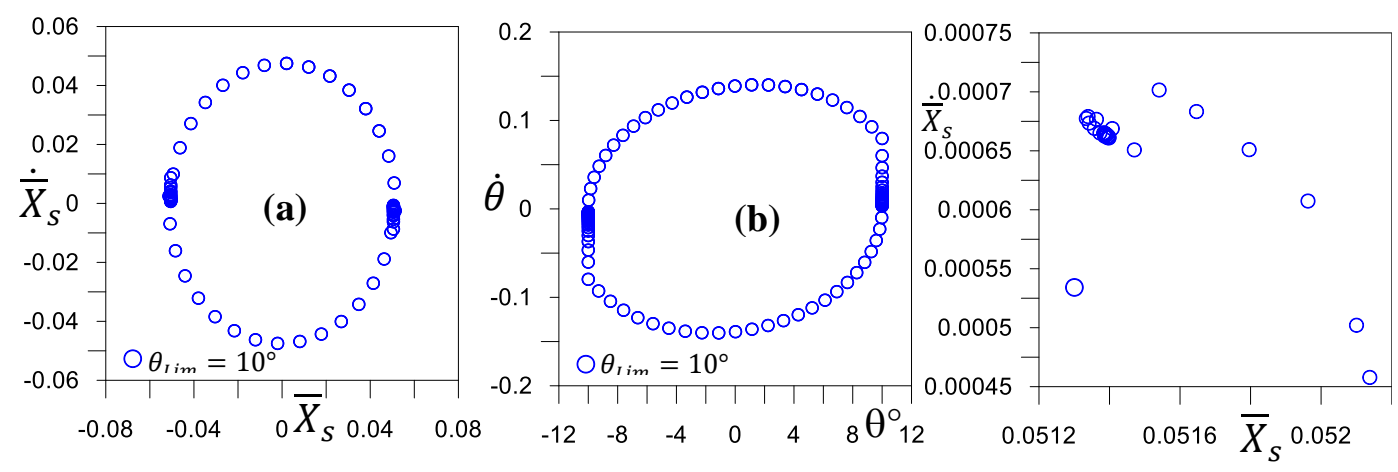

Figura 7-15 Plano de fase da estrutura (a) e do APMS (b) com limite de $\theta=10^{\circ}$ para $\delta=$ 0,$01 ; \Delta=0,9 ; e=0,6$ e $\beta=0,883$ 


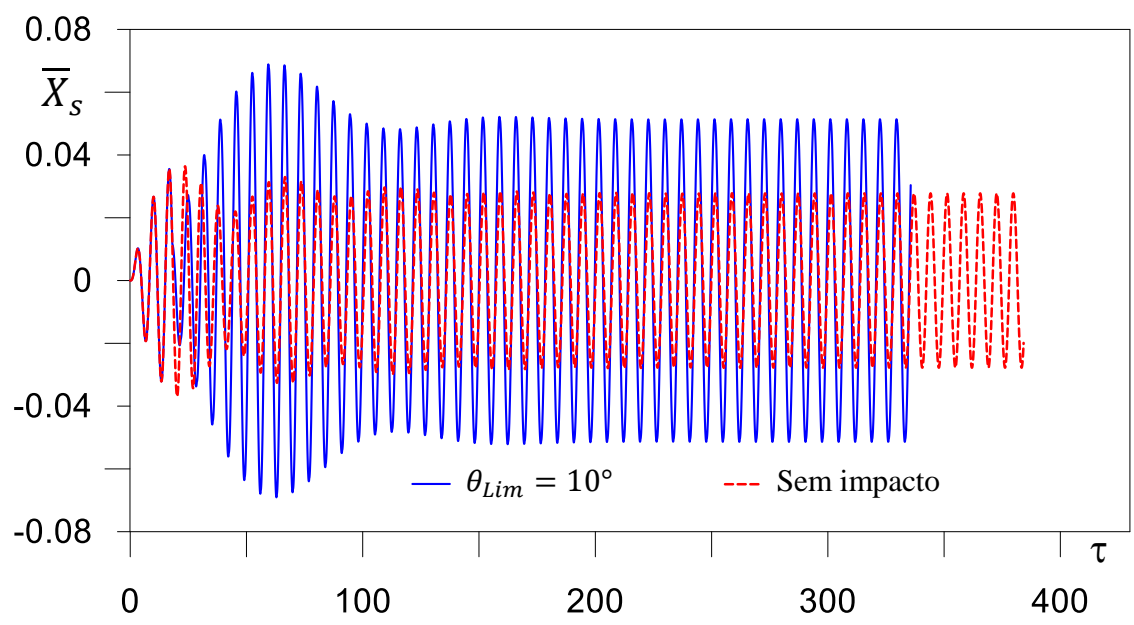

Figura 7-16 Deslocamentos da estrutura com e sem impacto para $e=0,6 ; \delta=0,01 ; \Delta=0,9$ e $\beta=0,883$

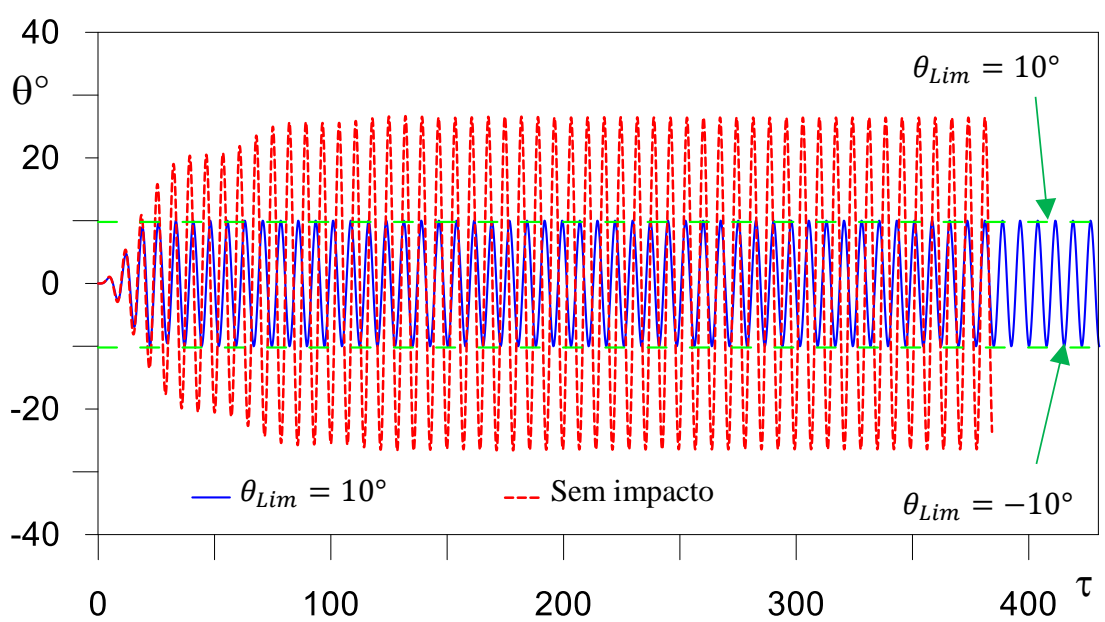

Figura 7-17 Deslocamentos da estrutura com e sem impacto para $e=0,6 ; \delta=0,01 ; \Delta=0,9$ e $\beta=0,883$

Os planos de fase da resposta permanente da estrutura com e sem impacto para uma frequência de excitação $\beta=1$ são mostrados na Figura 7-18-(a) e do APMS na Figura 7-18-(b). As seções de Poincaré da estrutura principal com e sem impacto são mostradas na Figura 7-18-(c). Detalhes da resposta com impacto são apresentados na Figura 7-19. Nota-se que o impacto do APMS gera mudanças bruscas na velocidade da estrutura. A Figura 7-20 e a Figura 7-21 mostram, respectivamente, a variação do deslocamento da estrutura com e sem impacto e rotações do APMS ao longo do tempo. Observa-se que a estrutura apresenta uma resposta aperiódica sem um regime permanente definido. Verifica-se também que o impacto não ocorre em todos os ciclos de vibração. Neste caso verifica-se que o impacto melhora bastante a eficiência do APMS. Por outro lado, a não linearidade 
do impacto leva a uma resposta aperiódica da estrutura (nuvem de pontos na seção de Poincaré).
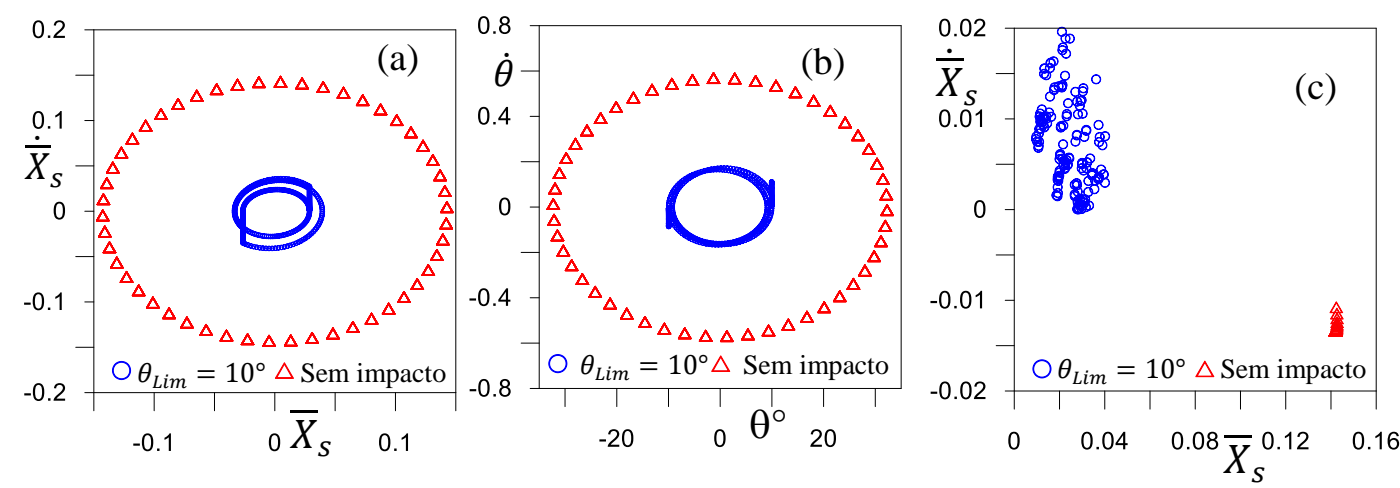

Figura 7-18 Plano de fase da estrutura com e sem impacto. (a), APMS (b) com limite de $\theta=10^{\circ}$ e a seção de Poincaré (c) para $\delta=0,01 ; \Delta=0,9 ; e=0,6$ e $\beta=1$

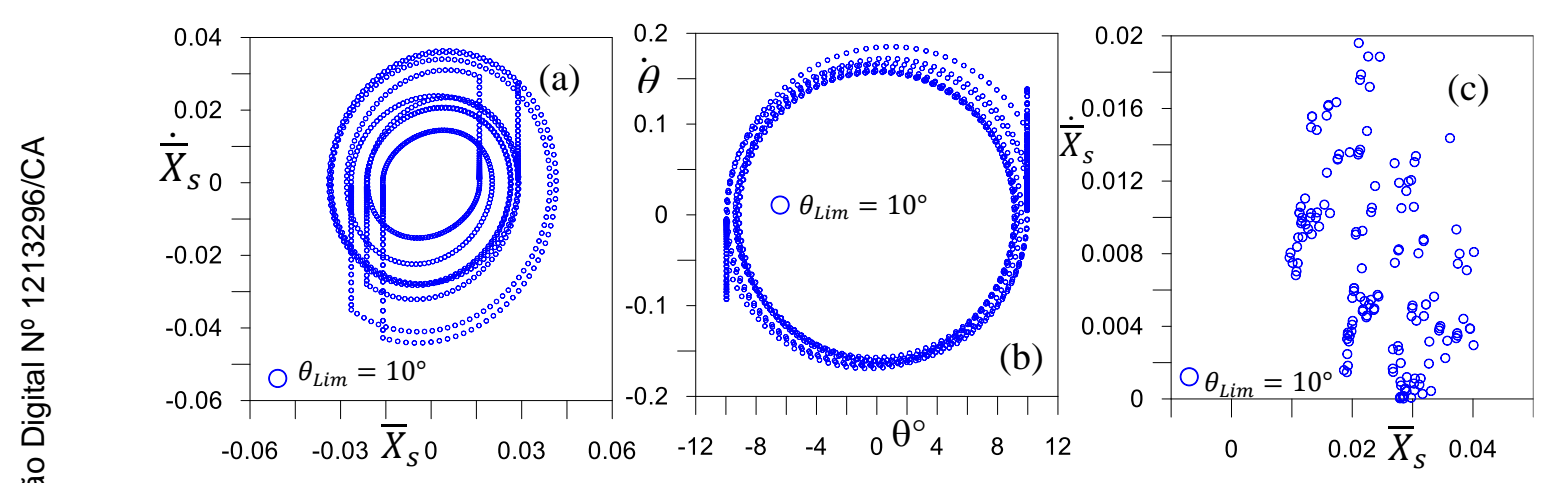

Figura 7-19 Plano de fase da estrutura (a) e do APMS (b) com limite de $\theta_{\lim }=10^{\circ}$ para $\delta=$ 0,$01 ; \Delta=0,9 ; e=0,6$ e $\beta=1$

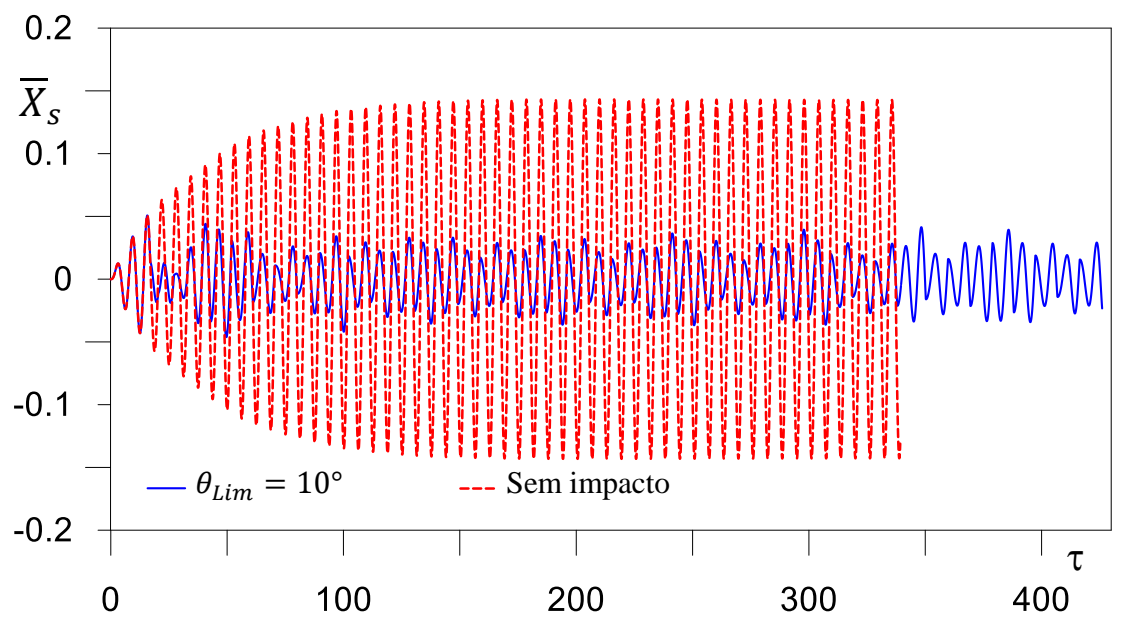

Figura 7-20 Deslocamentos da estrutura com e sem impacto $\operatorname{com} \theta_{\lim }=10$, para $e=0,6 ; \delta=$ 0,$01 ; \Delta=0,9$ e $\beta=1,0$ 


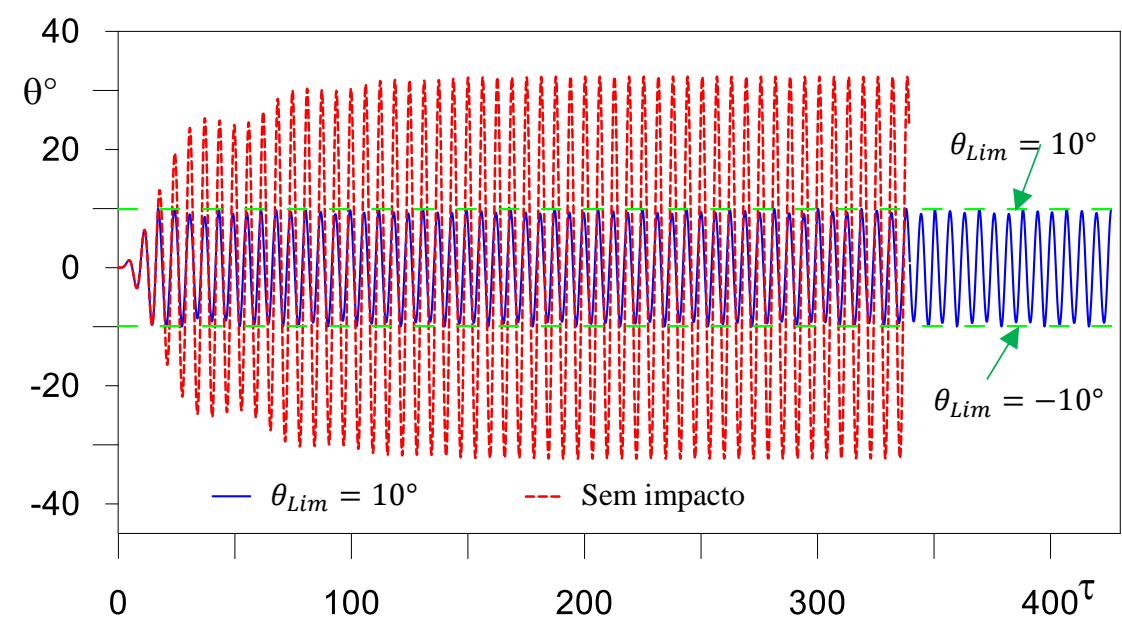

Figura 7-21 Rotações do APMS com e sem impacto para $e=0,6 ; \delta=0,01 ; \Delta=0,9$ e $\beta=$ 1,0
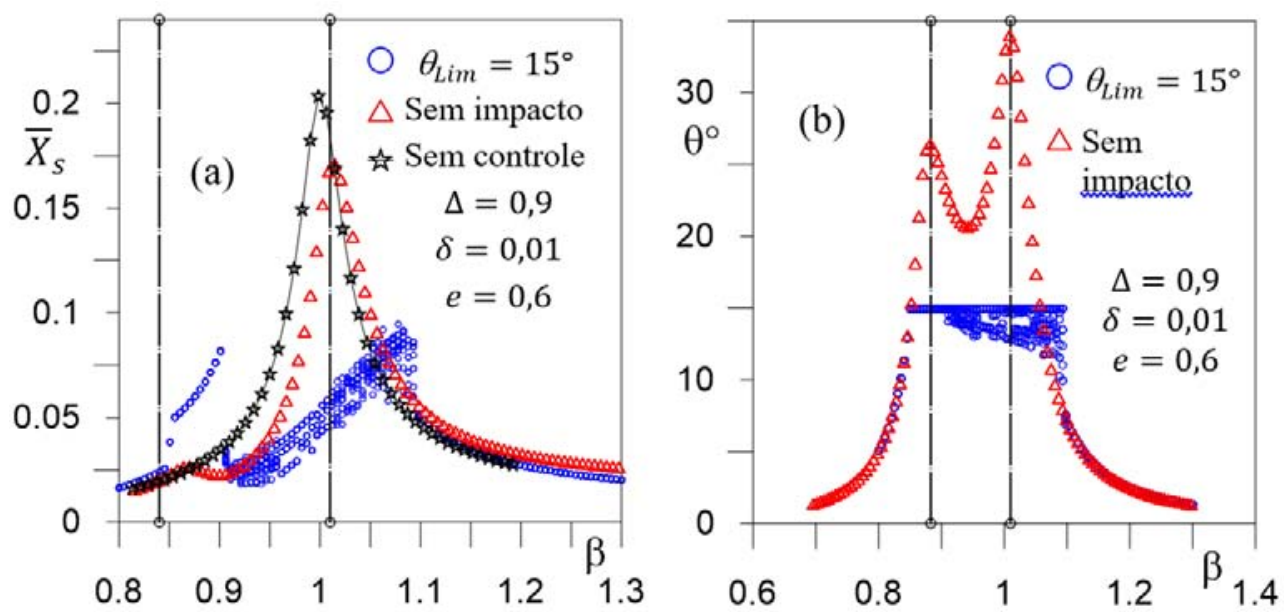

Figura 7-22 Diagramas de bifurcação da estrutura (a) e do APMS (b) com limite de $\theta=15^{\circ}$

Aumenta-se agora o valor limite da rotação do APMS para $\theta_{\text {Lím }}=15^{\circ}$. Neste caso o impacto do APMS na fase permanente acontece na faixa de 0,85 $\leq$ $\beta \leq 1.09$, como mostra a Figura 7-22-(b). A Figura 7-22-(a) mostra a influência do impacto sobre a resposta permanente da estrutura. Como no caso anterior, o impacto gera saltos na resposta permanente da estrutura e soluções não periódicas. Apesar da resposta sem impacto ter menores amplitudes na região da primeira frequência em virtude de saltos gerados pela não linearidade do impacto, globalmente as respostas da estrutura com impacto são mais eficientes que aquelas da estrutura sem impacto, particularmente na segunda região de ressonância, onde se encontra a frequência da estrutura não controlada. Os planos de fase da resposta permanente da estrutura com e sem impacto para uma frequência de excitação $\beta$ =0,883 são mostrados na Figura 7-23-(a) e do APMS na Figura 7-23-(b). As 
seções de Poincaré da estrutura principal com e sem impacto são mostradas na Figura 7-23-(c). Ambas as respostas têm período um.

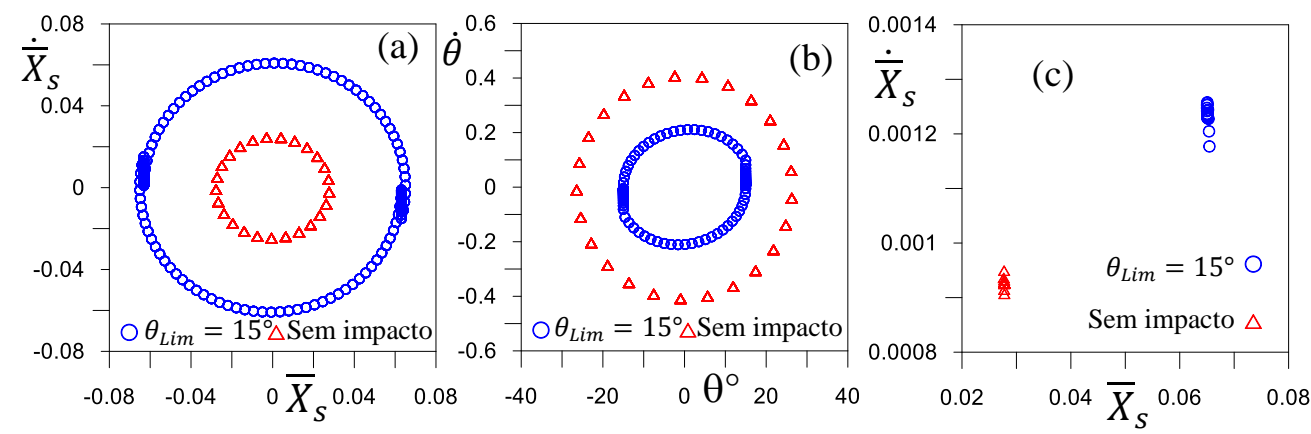

Figura 7-23 Plano de fase da estrutura como e sem impacto. (a), APMS (b) com limite de $\theta=15^{\circ}$ e a seção de Poincaré (c) para $\delta=0,01 ; \Delta=0,9 ; e=0,6$ e $\beta=0,883$

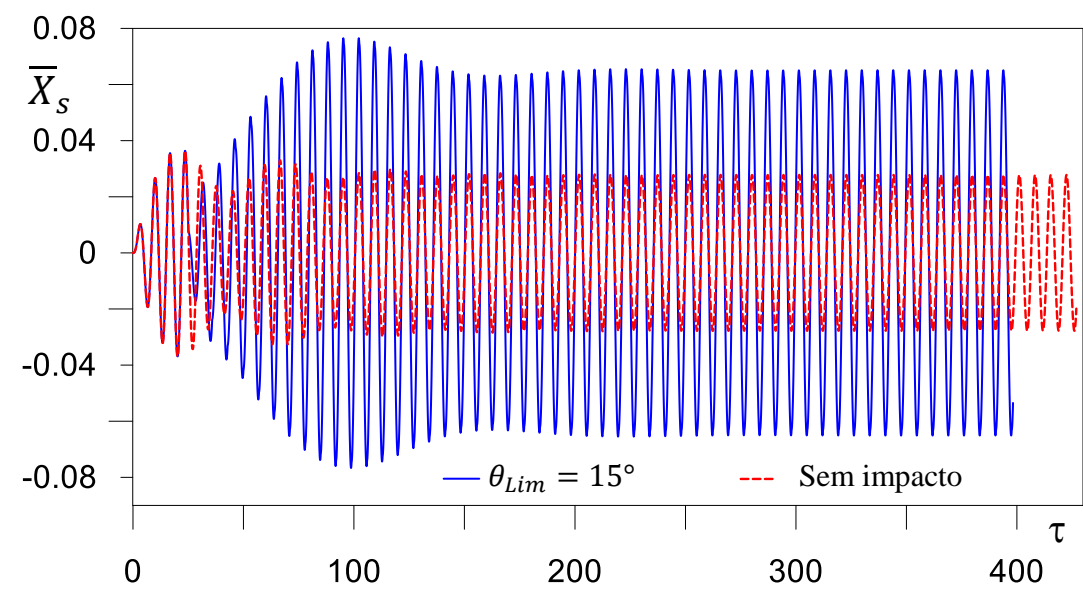

Figura 7-24 Deslocamentos da estrutura com e sem impacto para $e=0,6 ; \delta=0,01 ; \Delta=0,9$ e $\beta=0,883$

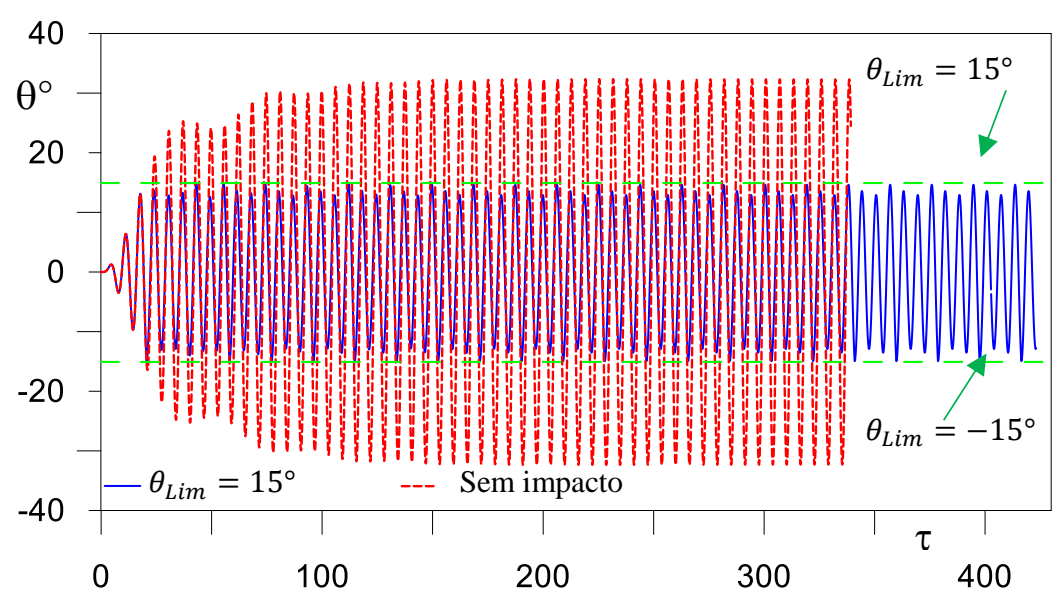

Figura 7-25 Rotações do APMS com e sem impacto, para $e=0,6 ; \delta=0,01 ; \Delta=0,9$ e $\beta=$ 0,883 


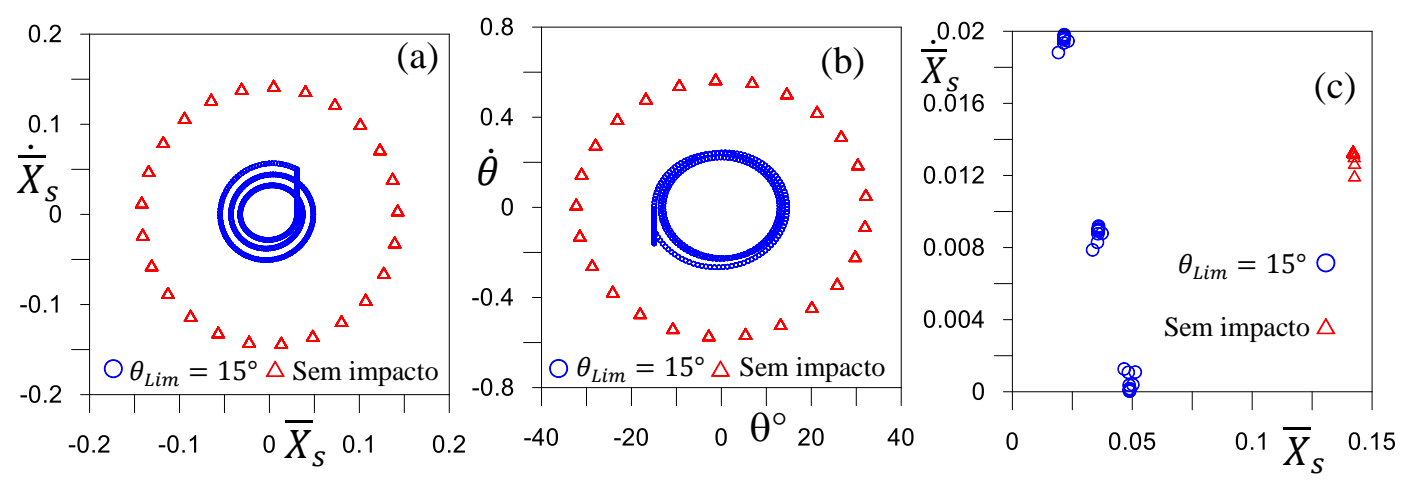

Figura 7-26 Plano de fase da estrutura como e sem impacto. (a), APMS (b) com limite de $\theta=15^{\circ}$ e a seção de Poincaré (c) para $\delta=0,01 ; \Delta=0,9 ; e=0,6$ e $\beta=1,0$
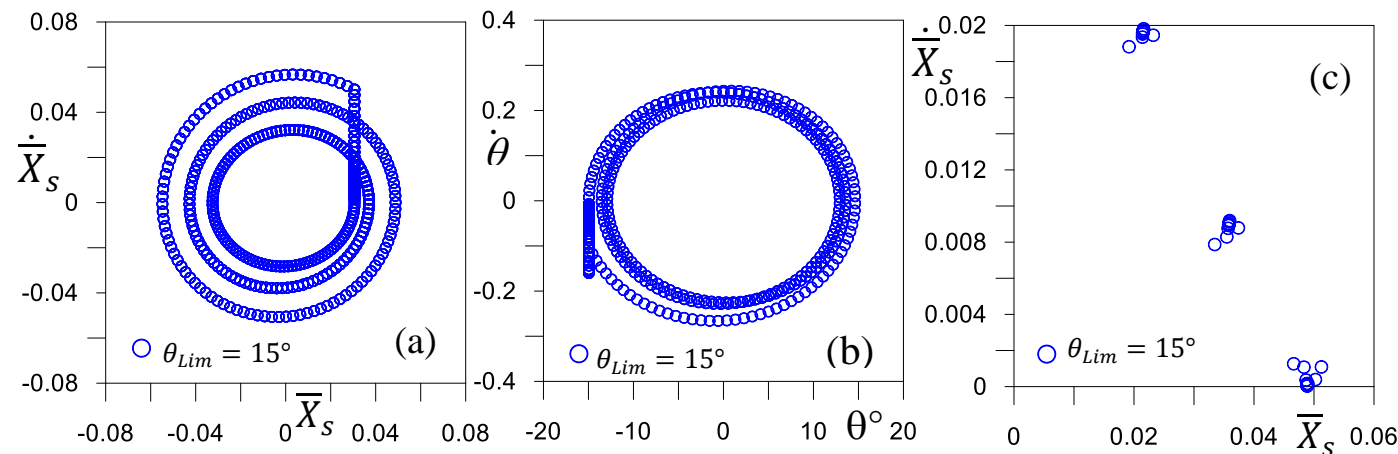

Figura 7-27 Plano de fase da estrutura (a), do APMS (b) com limite de $\theta=15^{\circ}$ e a seção de Poincaré (c)

A Figura 7-26 mostra os planos de fase da estrutura com e sem impacto na vizinhança da segunda frequência natural de vibração do sistema estrutura-APMS, $\beta=1,0$. A seção de Poincaré, Figura 7-27-(c), mostra que a resposta da estrutura com impacto apresenta um período igual a três vezes o período da força. A Figura 7-27-(a), mostra a variação brusca de velocidade da estrutura principal durante o impacto do APMS. Simultaneamente nota-se na Figura 7-27-(b) a variação da velocidade do APMS quando o mesmo se desloca no sentido oposto ao da estrutura. As respectivas respostas no tempo são apresentadas nas Figura 7-28 e Figura 7-29. Neste caso o impacto reduz bastante as amplitudes de vibração da estrutura controlada, aumentando a eficiência do APMS. 


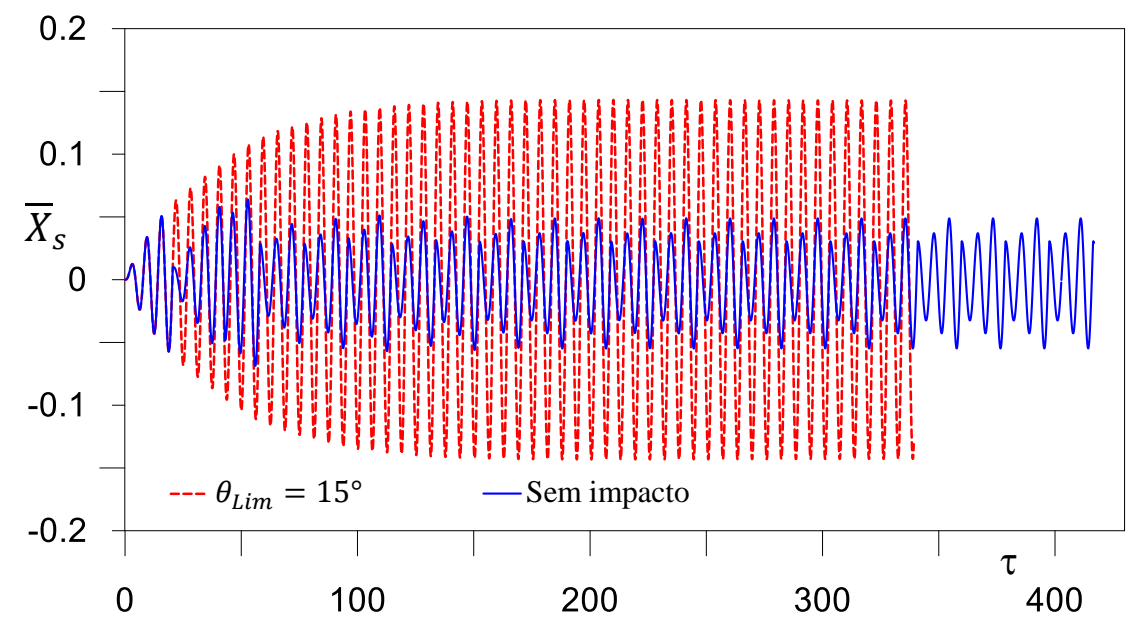

Figura 7-28 Deslocamentos da estrutura com e sem impacto para $e=0,6 ; \delta=0,01 ; \Delta=0,9$ e $\beta=1,0$

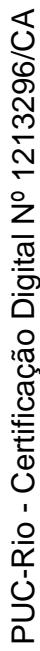

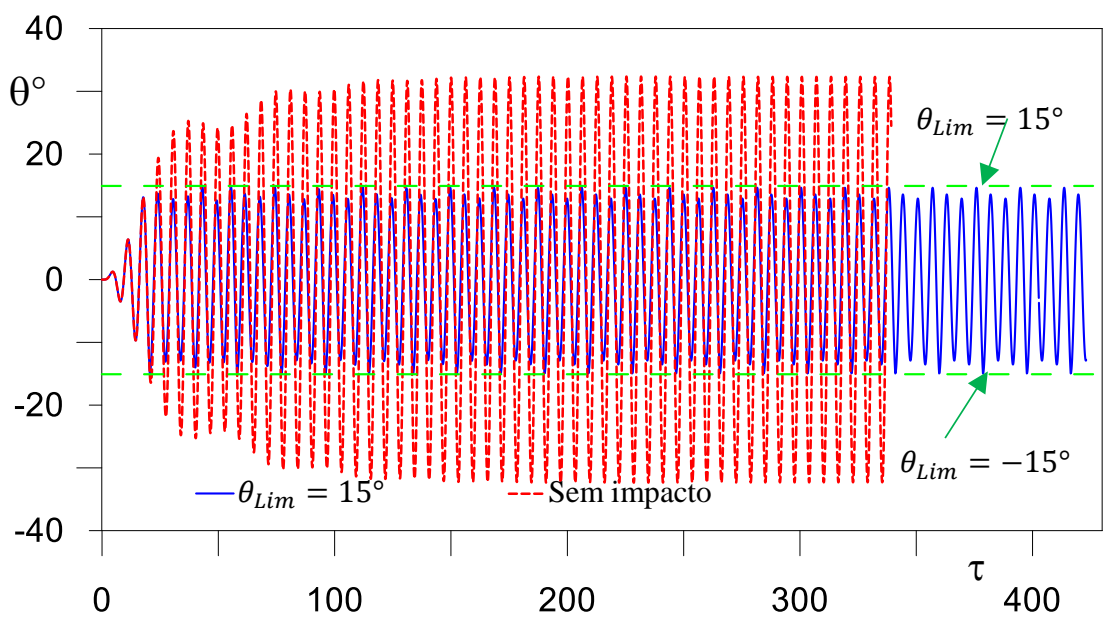

Figura 7-29 Rotações do APMS com e sem impacto para e $=0,6 ; \delta=0,01 \Delta=0,9$ e $\beta=1,0$
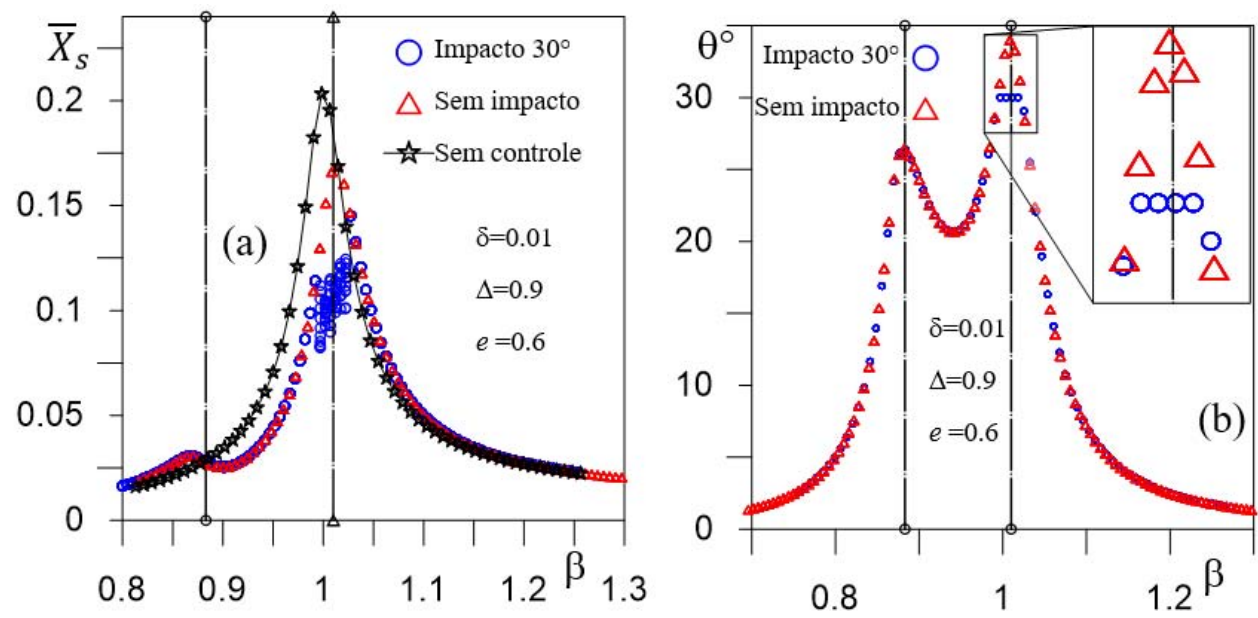

Figura 7-30 Diagramas de bifurcação da estrutura (a) e do APMS (b) com limite de $\theta=30^{\circ}$ 
Finalmente, a Figura 7-30 mostra os diagramas de bifurcação para $\theta_{\text {lim }}=$ $30^{\circ}$. O impacto do APMS acontece para um faixa bem menor de frequências de excitação na fase permanente $(0,99 \leq \beta \leq 1,02)$. Neste caso o impacto influencia a resposta apenas na vizinhança da segunda frequência natural de vibração, causando uma redução nos deslocamentos da estrutura. A Figura 7-31 mostra os planos de fase da resposta permanente com impacto enquanto a Figura 7-32 e a Figura 7-33 mostram a resposta no tempo. Neste caso tanto o APMS quanto a estrutura apresentam uma resposta aperiódica em virtude da não linearidade do impacto.

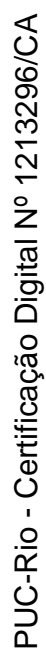
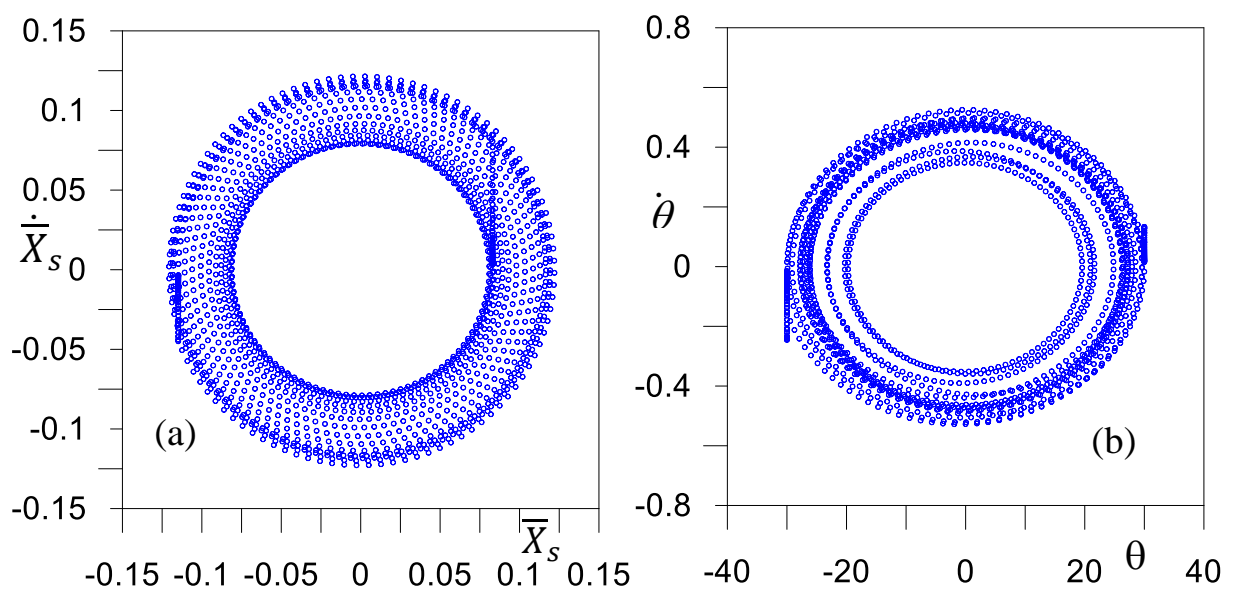

Figura 7-31 Plano de fase da estrutura (a) e do APMS (b) com $\theta_{\lim }=30^{\circ}$, para $\delta=0,01$; $\Delta$ $=0,9 ; e=0,6$ e $\beta=1$

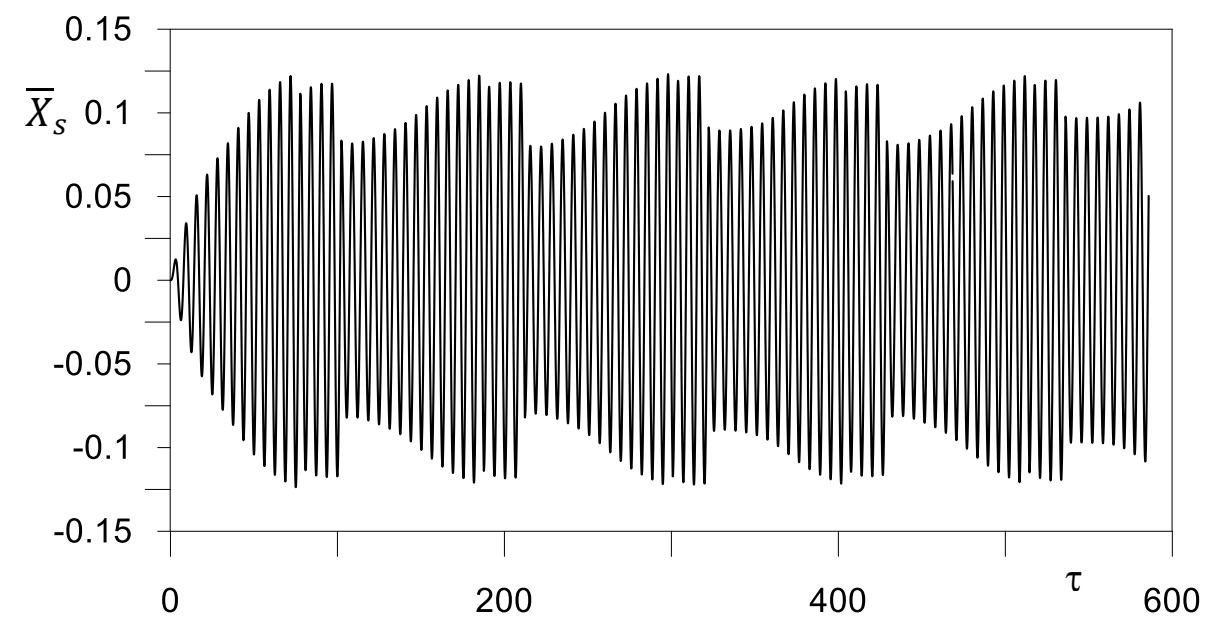

Figura 7-32 Deslocamento no tempo da estrutura $\operatorname{com} \theta_{\lim }=30^{\circ}$, para $\delta=0,01 ; \Delta=0,9 ; e$ $=0,6$ e $\beta=1$ 


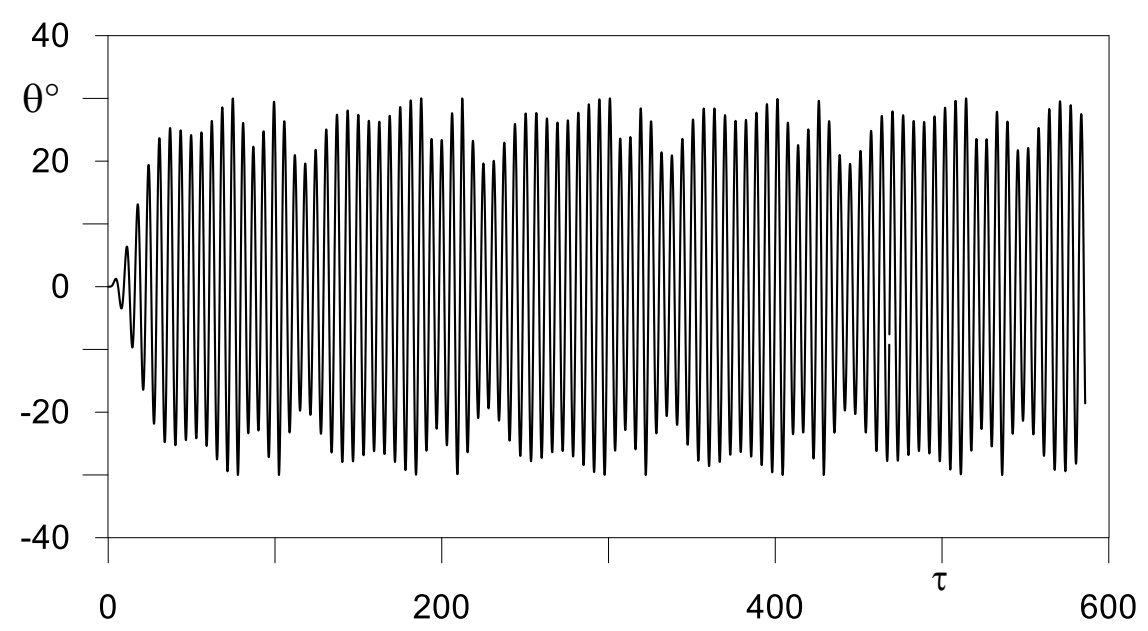

Figura 7-33 Rotações do pêndulo no tempo com limite de $\theta_{\lim }=30^{0}$, para $\delta=0,01 ; \Delta=0,9$; $e=0,6$ e $\beta=1$

A eficiência do impacto na redução da resposta da estrutura principal é ilustrada na Tabela 7-1 onde se comparam os deslocamentos e acelerações máximas da estrutura com e sem impacto do APMS para os três valores de $\theta_{\text {limm }}$ Verifica-se que na faixa da frequência de excitação que engloba as duas frequências naturais o impacto reduz tanto os deslocamentos quanto as acelerações da estrutura, levando a um aumento de segurança e conforto. Por exemplo, para a estrutura sem controle tem-se um deslocamento de 0,204, este valor cai para 0,169 quando se usa o APMS e para 0,123 quando se usa o APMS com impacto e $\theta_{\lim }=10^{\circ}$, ou seja, a redução passa de $27,22 \%$ para $39,82 \%$ um ganho de $12,6 \%$.

Tabela 7-1 Deslocamentos e acelerações máximas com e sem impacto do APMS $\delta=0,01$; $\Delta=0,9$

Estrutura-APMS

\begin{tabular}{|c|c|c|c|c|c|}
\hline \multirow{2}{*}{$\begin{array}{l}\text { TIPO DE } \\
\text { CURVA }\end{array}$} & & \multirow{2}{*}{$\begin{array}{c}\theta \\
\text { Limite }\end{array}$} & \multicolumn{2}{|c|}{ Estrutura Principal } & \multirow{2}{*}{$\begin{array}{c}\text { APMS } \\
\text { Rotação } \\
\left(\theta_{\text {Máx }}^{\circ}\right) \\
\end{array}$} \\
\hline & & & Deslocamento & Aceleração & \\
\hline & $\mathbf{A}$ & Sem controle & 0,204 & 0,204 & \\
\hline \multirow{4}{*}{ Circular } & $\boldsymbol{B}$ & Sem impacto & 0,169 & 0,173 & 34,00 \\
\hline & $C$ & $30^{\circ}$ & 0,145 & 0,153 & 30,0 \\
\hline & $D$ & $15^{\circ}$ & 0,095 & 0,099 & 15,0 \\
\hline & $E$ & $10^{\circ}$ & 0,123 & 0,121 & 10,0 \\
\hline \multirow{3}{*}{$\begin{array}{c}\text { Diferença } \\
\text { Sem e com } \\
\text { impacto } \\
\%\end{array}$} & $B-C$ & & 13,93 & 11,66 & 11,77 \\
\hline & $B-D$ & & 43,92 & 42,71 & 56,03 \\
\hline & $B-E$ & & 27,22 & 30,07 & 70,70 \\
\hline \multirow{4}{*}{$\begin{array}{l}\text { Diferença } \\
\text { sem e com } \\
\text { controle } \\
\%\end{array}$} & $A-B$ & & 17,32 & 15,15 & \\
\hline & $A-C$ & & 28,84 & 25,05 & \\
\hline & $A-D$ & & 53,64 & 51,39 & \\
\hline & $A-E$ & & 39,82 & 40,66 & \\
\hline
\end{tabular}




\subsection{2.}

\section{Isolamento pendular de base com rotação restrita}

Verificou-se no Capítulo 6 que o IBP, ao contrário do APMS, sofre rotações muitos pequenos na presença de excitações de base de mesma magnitude, não necessitando de qualquer mecanismo para limitar as rotações nos exemplos até aqui analisados.

Entretanto deseja-se verificar neste item qual a influência do impacto no controle de vibrações. Neste caso tem-se o impacto da massa do IBP em movimento contra uma barreira de rigidez infinita, localizada a uma distância horizontal $X_{\max }$, como mostra a Figura 7-34.

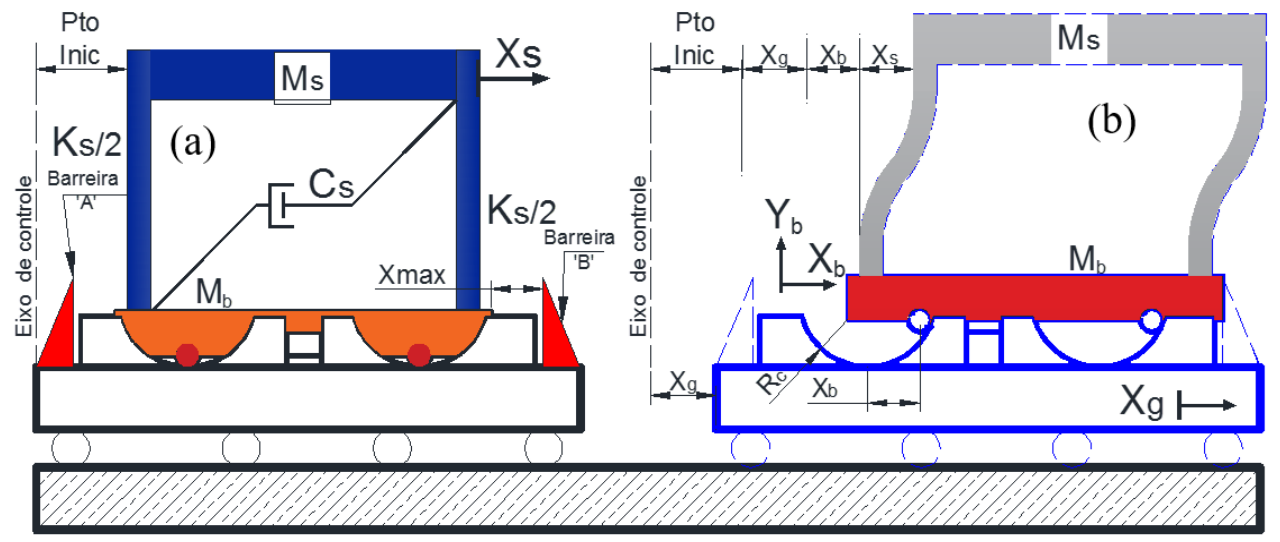

Figura 7-34 Estrutura com IBP com deslocamento restrito, (a) na posição inicial e (b) após o deslocamento de base Xg
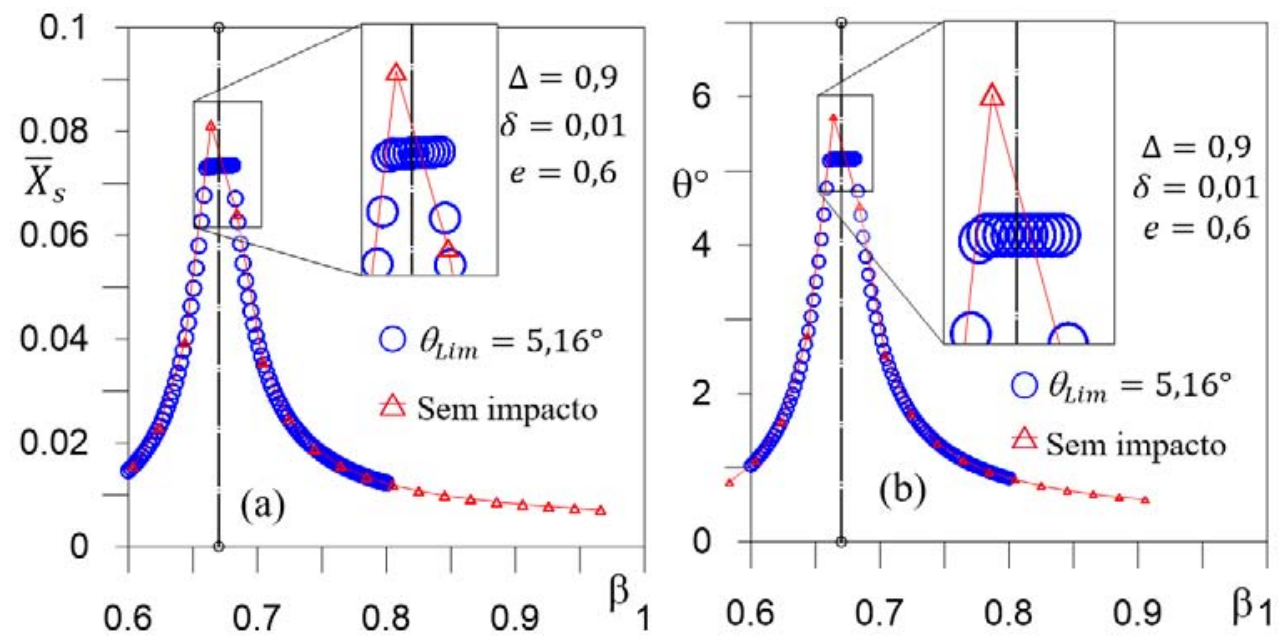

Figura 7-35 Diagramas de bifurcação da estrutura (a) e do IBP (b) com e sem impacto a $\theta_{\text {Lim }}=5,16^{\circ}$ 
Na Figura 7-35 é mostrada a resposta da estrutura e do IBP com e sem impacto. A rotação máxima sem impacto atinge o valor de $5,72^{\circ}$, já para um valor limite da rotação do IBP de $\theta_{\text {lim }}=5,16^{\circ}$, a estrutura passa a ser influenciada pelo impacto do IBP com a barreira rígida. A restrição das rotações leva a uma redução de 9,51\% nos deslocamentos máximos da estrutura.

No Capítulo 5, Tabela 5-2, observa-se que a rotação máxima para uma razão de frequências $\Delta=0,1$ é de $0,08^{\circ}$ para uma aceleração de $d^{2} \bar{X}_{g} / d \tau^{2}=0,01 \Delta^{2} \beta^{2} \operatorname{sen}(\beta \tau)$. Com o objetivo de analisar a influência do impacto, aumenta-se a magnitude da aceleração da base para $d^{2} \bar{X}_{g} / d \tau^{2}=0,3 \Delta^{2} \beta^{2} \operatorname{sen}(\beta \tau)$. Na Figura 7-36 é mostrada a resposta da estrutura e do IBP para a nova aceleração, onde a maior rotação do IBP é de 2,48 . Para avaliar a influência do impacto na estrutura, a rotação do IBP é limitada a $\theta_{\text {lim }}=$ $1^{\circ}$. Na Figura 7-36 são mostrados os diagramas de bifurcação da estrutura em termos de deslocamentos e das rotações do IBP para os dois casos. Observa-se uma redução nos deslocamentos da estrutura de 58,48 \%. No caso de restringir a rotação do IBP a $\theta_{\text {lim }}=0,5^{\circ}$, Figura 7-38-(a), verifica-se que na vizinhança da primeira frequência natural de vibração da estrutura isolada a redução dos deslocamentos da estrutura principal foi de 81,19\%.
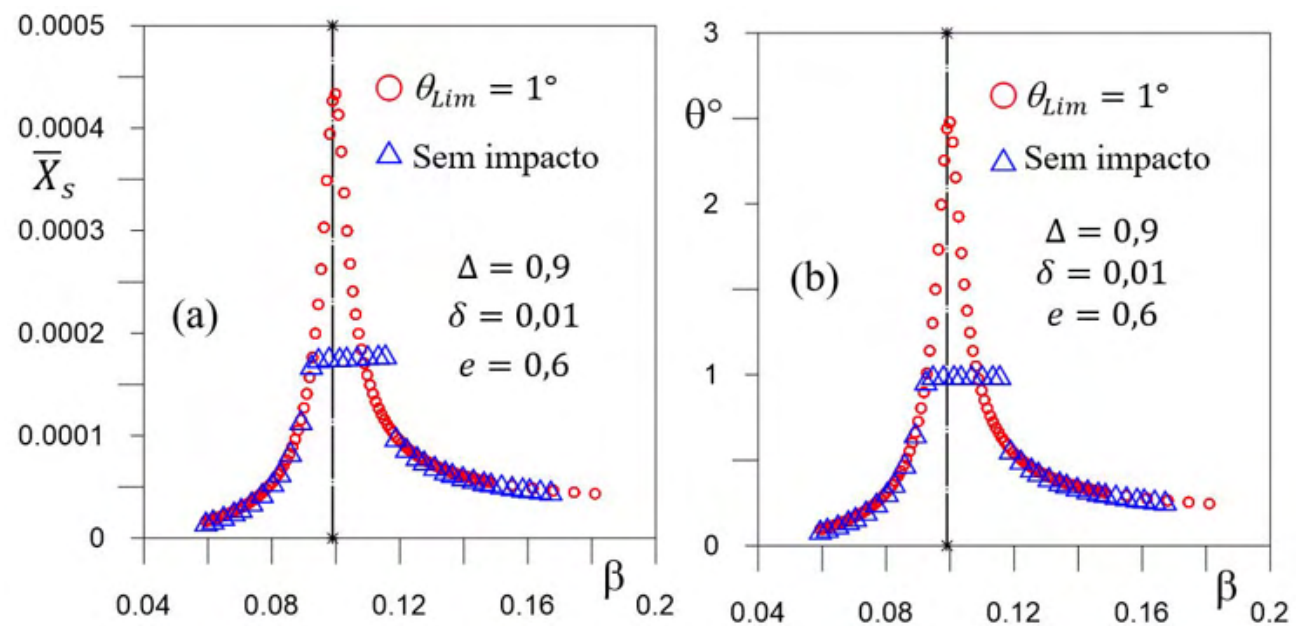

Figura 7-36 Diagramas de bifurcação da estrutura (a) e do IBP (b) sem e com impacto de $\theta_{\text {Lím }}=1^{\circ}$, para e $=0,6 ; \delta=0,1$ e $\Delta=0,1$

Entretanto, o impacto tem uma influência negativa nas acelerações, como ilustra a Figura 7-37. Elas aumentam na faixa onde acontece o impacto. Embora 
as acelerações sejam maiores, elas ainda são pequenas, dentro de limites aceitáveis de projeto.

As variações nos valores máximos de deslocamentos e acelerações são mostradas na Tabela 7-2 para a estrutura na vizinhança da primeira frequência natural com diferentes limites de $\theta$.

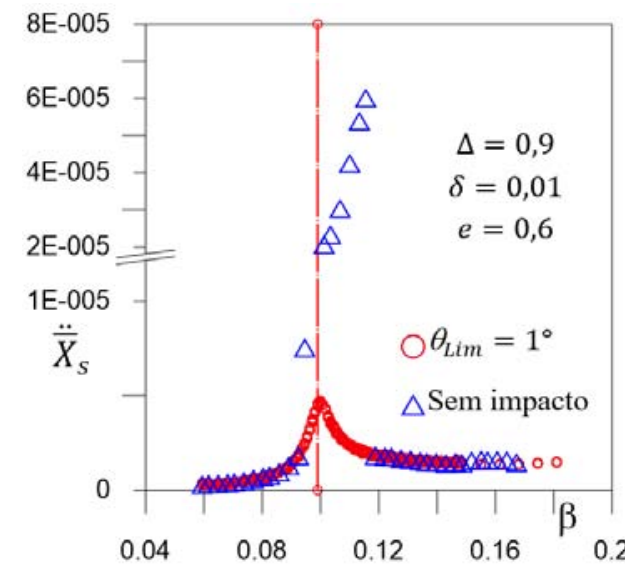

Figura 7-37 Diagrama de ressonância das acelerações da estrutura com e sem impacto para $\theta_{\text {Lím }}=1^{\circ}$ para e $=0,6 ; \delta=0,1$ e $\Delta=0,1$

Tabela 7-2 Deslocamentos e acelerações máximas da estrutura na vizinhança da primeira frequência com diferentes limites de $\theta$, para $e=0,6 ; \delta=0,1$ e $\Delta=0,1$

Estrutura-IBP

\begin{tabular}{cccccc}
\hline \multirow{2}{*}{$\begin{array}{c}\text { TIPO DE } \\
\text { CURVA }\end{array}$} & & $\begin{array}{c}\boldsymbol{\theta} \\
\text { Limite. }\end{array}$ & Deslocamento & Aceleração & $\begin{array}{c}\text { Rotação } \\
\left(\boldsymbol{\theta}_{M a ́ x}^{\circ}\right)\end{array}$ \\
\cline { 2 - 6 } Circular & $\boldsymbol{A}$ & Sem impacto & 0,000433 & 0,000005 & 2,48 \\
\cline { 2 - 6 } & $\boldsymbol{B}$ & $1^{\circ}$ & 0,00018 & 0,00006 & 1,00 \\
\cline { 2 - 6 } & $\boldsymbol{C}$ & $0,5^{\circ}$ & 0,00009 & 0,00010 & 0,500 \\
\hline Diferença & $\boldsymbol{A}-\boldsymbol{B}$ & & $\mathbf{5 8 , 4 8}$ & $\mathbf{- 1 2 3 0 , 3 9}$ & \\
$\%$ & $\boldsymbol{B}-\boldsymbol{C}$ & & $\mathbf{7 8 , 3 5}$ & $\mathbf{- 1 9 9 4 , 5 6}$ & \\
\hline
\end{tabular}
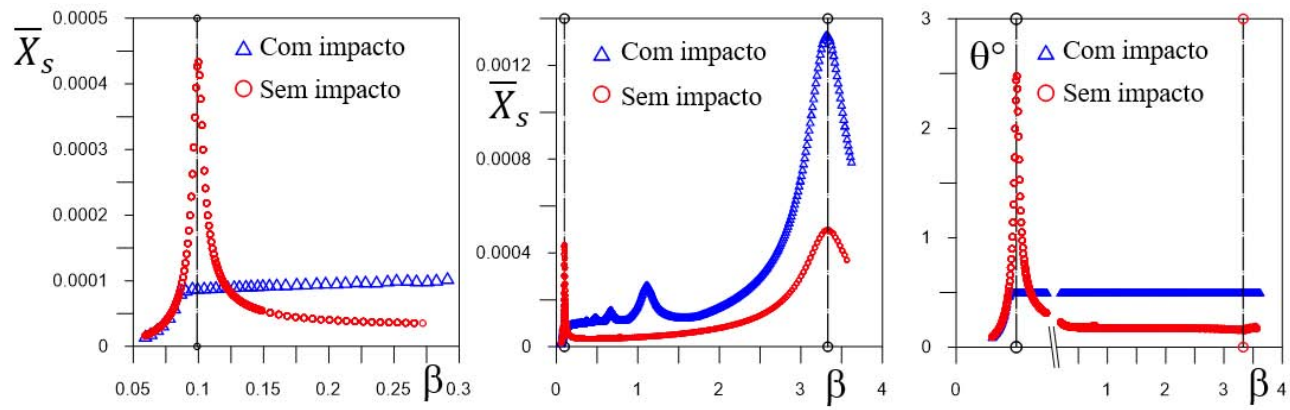

Figura 7-38 Diagramas de bifurcação da estrutura (a) e (b), e do IBP (c) sem e com impacto para $\theta_{\text {Lim }}=0,5^{\circ} ; e=0,6 ; \delta=0,1$ e $\Delta=0,1$ 
Na Figura 7-38 são mostrados os diagramas de bifurcação da estrutura e do IBP, neste caso para $\theta_{\text {Lim }}=0,5^{\circ}$, considerando $e=0,6, \delta=0,1$ e $\Delta=0,1$. Na Figura 7-38 (a) mostra-se o comportamento na primeira região de ressonância enquanto Figura 7-38 (b) mostra-se toda a faixa de frequências que inclui as duas frequências naturais do sistema. A Figura 7-38 (c) mostra a resposta do IBP. Na vizinhança da primeira frequência de vibração os deslocamentos são reduzidos em 79 \% e na vizinhança da segunda frequência de vibração da estrutura isolada, o deslocamento da estrutura principal cresce em 207,62 \% em relação à estrutura sem restrição de rotação do IBP. A eficiência do IBP com restrição da rotação do IBP na vizinhança da primeira frequência natural de vibração do sistema estrutura-IBP, em relação a estrutura sem controle, o deslocamento da estrutura principal foi de 99,87 \% e da aceleração de 99,86 \%, Já na vizinhança da segunda frequência a eficiência do deslocamento da estrutura principal foi de 98,22 \% e da aceleração de 79,85 \%.

O incremento dos deslocamentos da estrutura principal na vizinhança da segunda frequência de vibração é devido a que, na fase transiente, as rotações do IBP sem restrição chegam a 5,58 ${ }^{\circ}$ (Figura 7-43) absorvendo grande parte da energia transmitida pelo movimento de base. No caso de restringir as rotações, sendo $\theta_{\text {Lim }}$ um valor muito pequeno, a energia dissipada pelo movimento do IBP e pelo impacto é pequena, sendo o restante da energia transmitida para a estrutura principal, gerando assim maiores deslocamentos. Cabe ressaltar que este valor de $\theta_{\text {Lim }}$ é extremamente pequeno e não seria usando em um projeto. Aqui é usado apenas para mostrar o efeito da não linearidade do sistema com impacto nas oscilações não lineares e bifurcações. As Figura 7-39 à Figura 7-41, comparam os planos de fase da estrutura e do IBP com e sem impacto para, respectivamente, $\beta=0,099, \beta=1,3$ e $\beta=3,3$. Observa-se que o impacto aumenta a não linearidade da resposta. As Figura 7-42 à Figura 7-45 mostram a resposta da estrutura e do IBP no tempo para $\beta=3,33$, onde a resposta permanente da estrutura com impacto apresenta o maior pico. Observa-se que a resposta da estrutura sem impacto tem um longo e complexo transiente, atingindo a fase permanente após um longo período de excitação. Para estrutura com impacto, a fase transiente é bastante curta. Observa-se que, apesar da resposta permanente da estrutura com impacto apresentar uma maior amplitude de oscilação na fase permanente que a estrutura 
sem impacto, os maiores deslocamentos são observados para a estrutura sem impacto e ocorrem na fase transiente (Figura 7-42). O IBP apresenta uma resposta transiente com a participação de duas frequências distintas. As velocidades e acelerações máximas com e sem impacto são aproximadamente iguais.
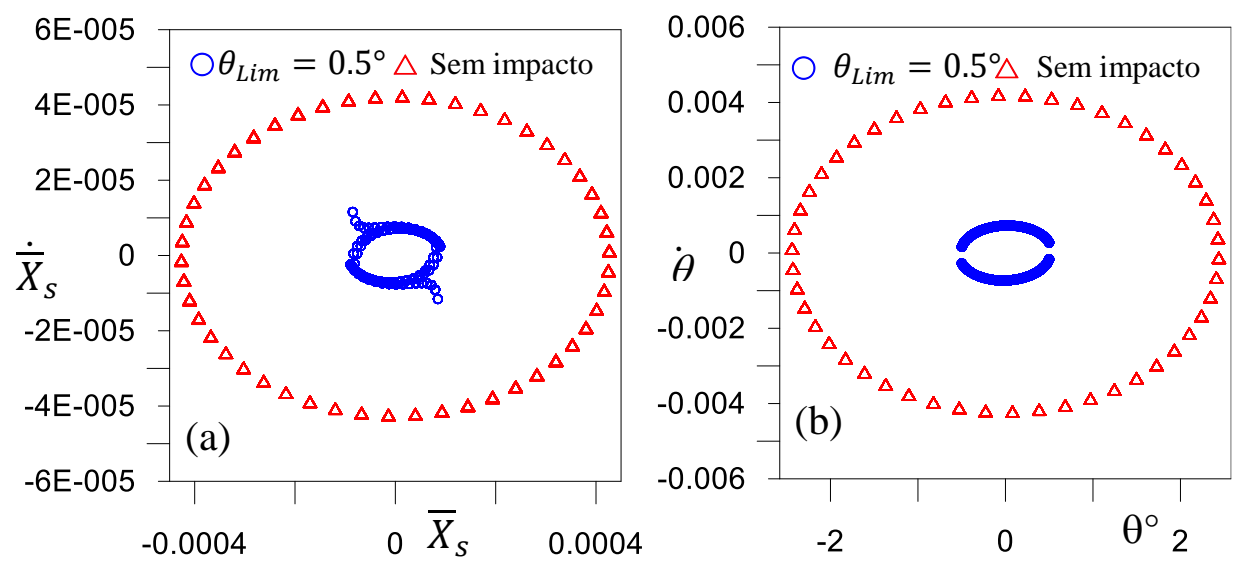

Figura 7-39 Plano fase da estrutura (a) e do IBP (b) para $\beta=0,099 ; e=0,6$; $\delta=0,1$ e $\Delta=0,1$
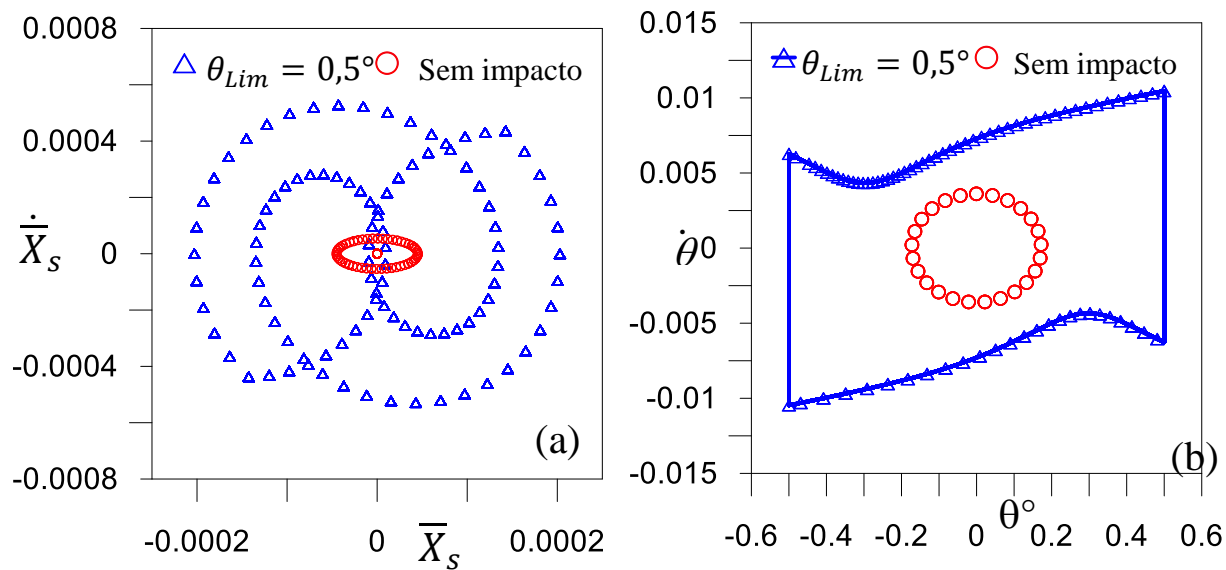

Figura 7-40 Plano de fase da estrutura (a) e do IBP (b) para $\beta=1,2 ; e=0,6 ; \delta=0,1$ e $\Delta=0,1$
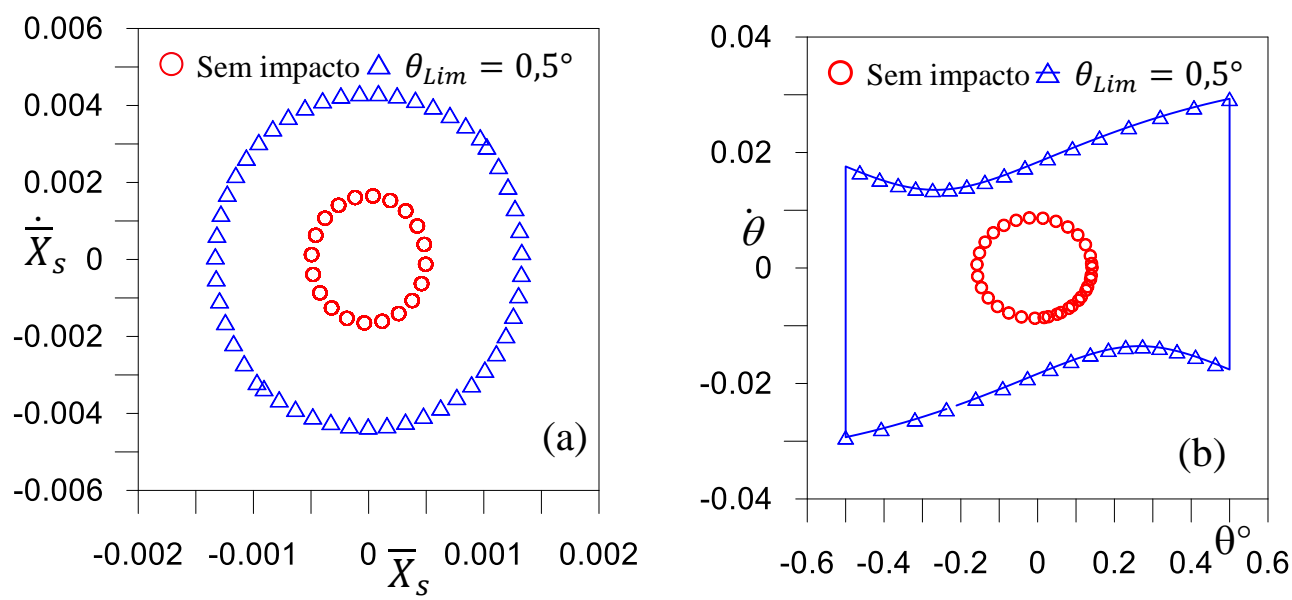

Figura 7-41 Plano de fase da estrutura (a) e do IBP (b) para $\beta=3,33 ; e=0,6 ; \delta=0,1$ e $\Delta=$ 0,1 


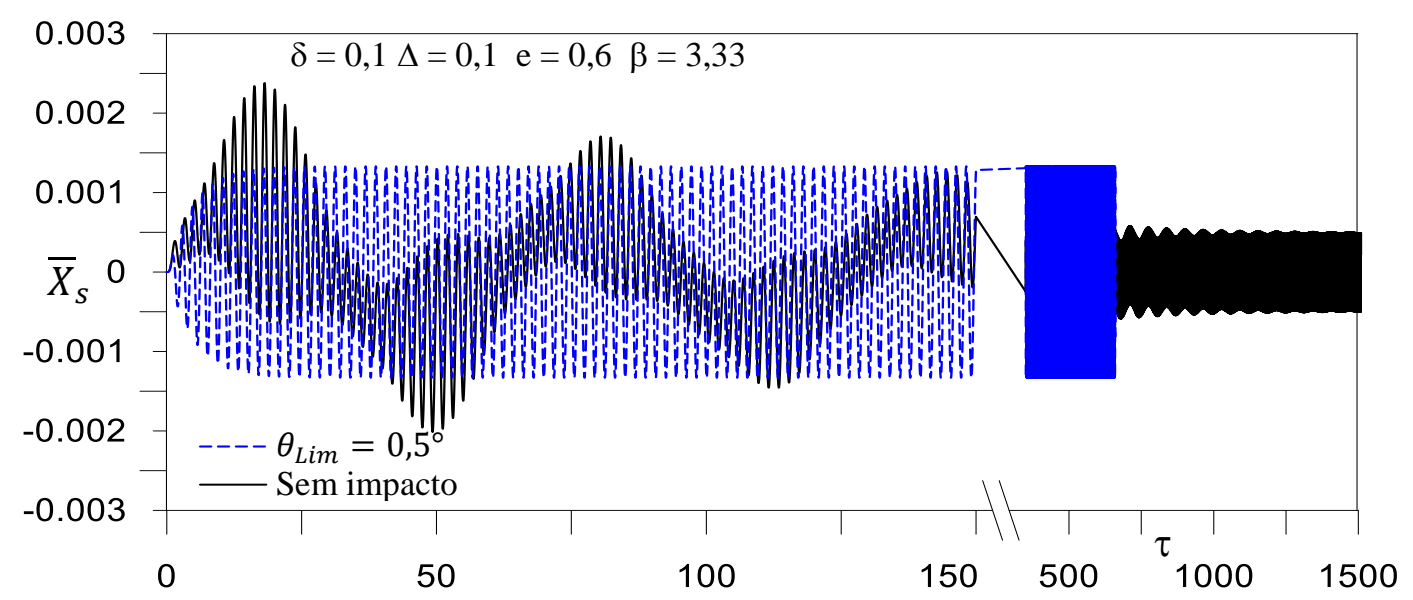

Figura 7-42 Deslocamento da estrutura no tempo para IBP com e sem impacto $\theta_{\text {Lim }}=0,5^{\circ}$

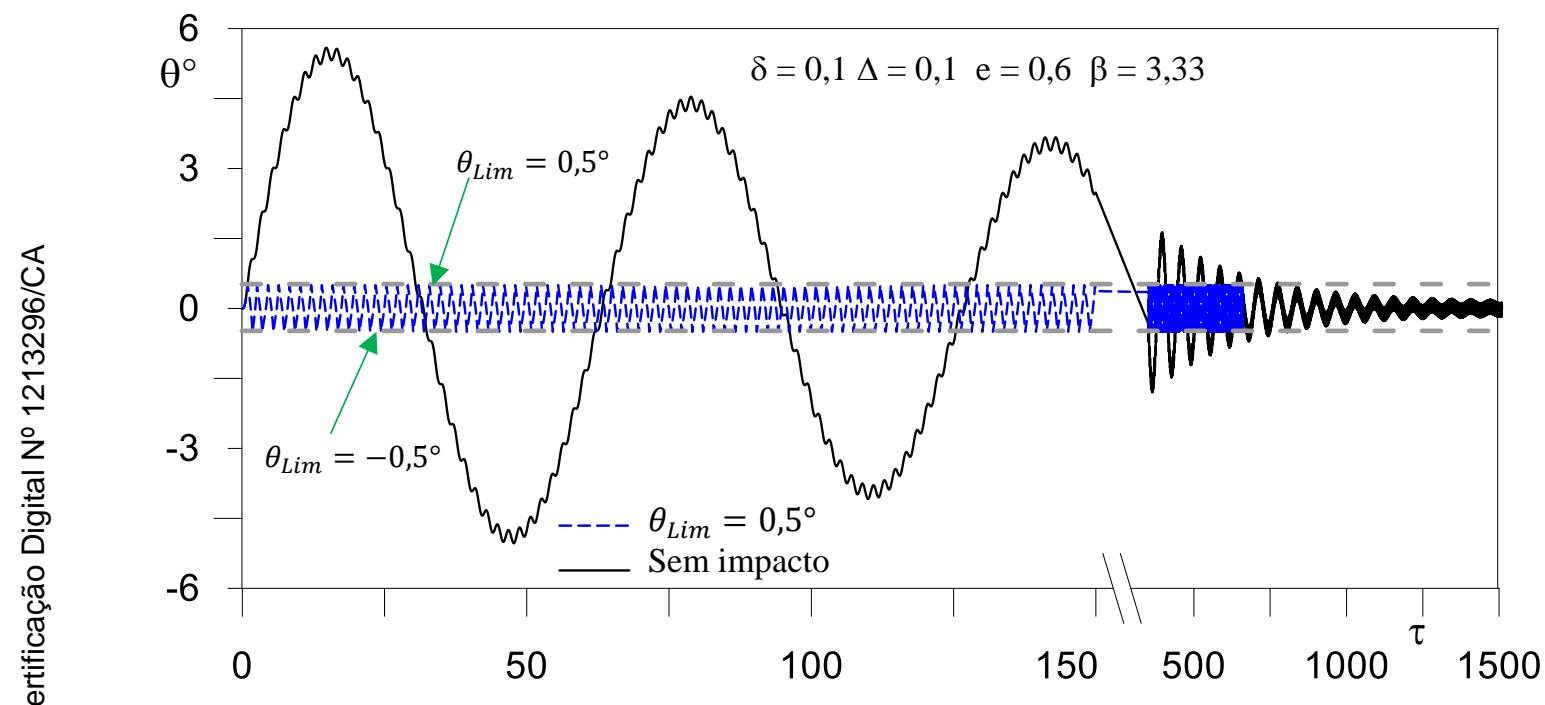

Figura 7-43 Rotação do IBP no tempo para IBP com e sem impacto $\theta_{\text {Lím }}=0,5^{\circ}$

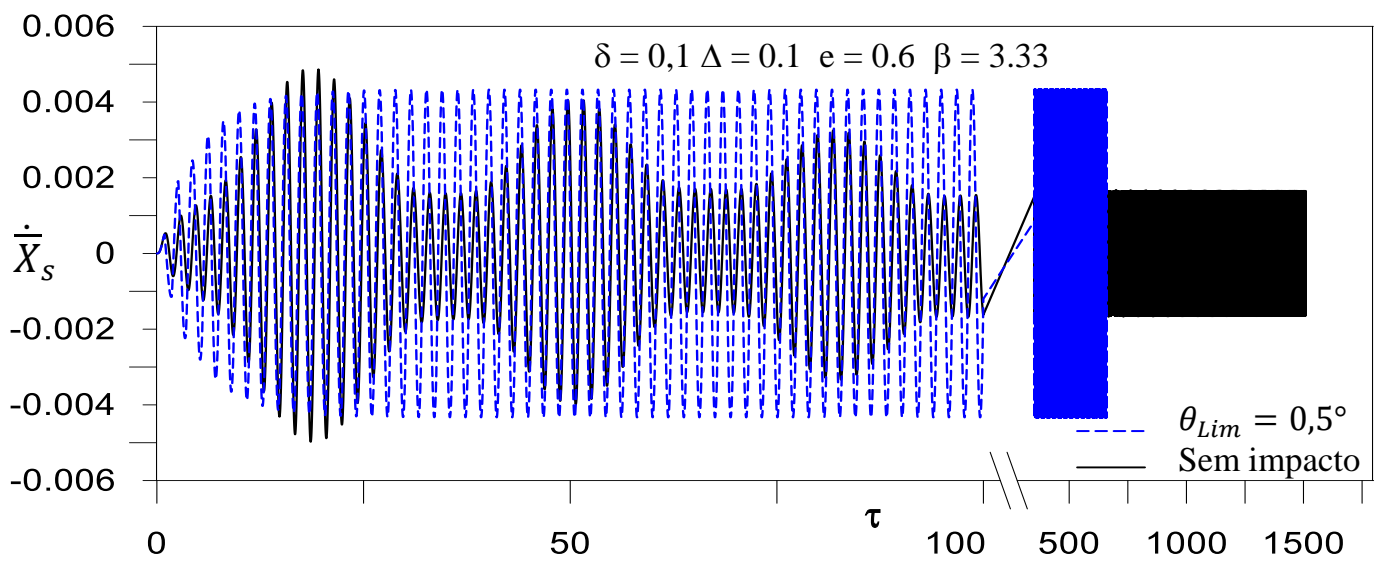

Figura 7-44 Velocidades da estrutura no tempo para IBP com e sem impacto $\theta_{\text {Lím }}=0,5^{\circ}$ 


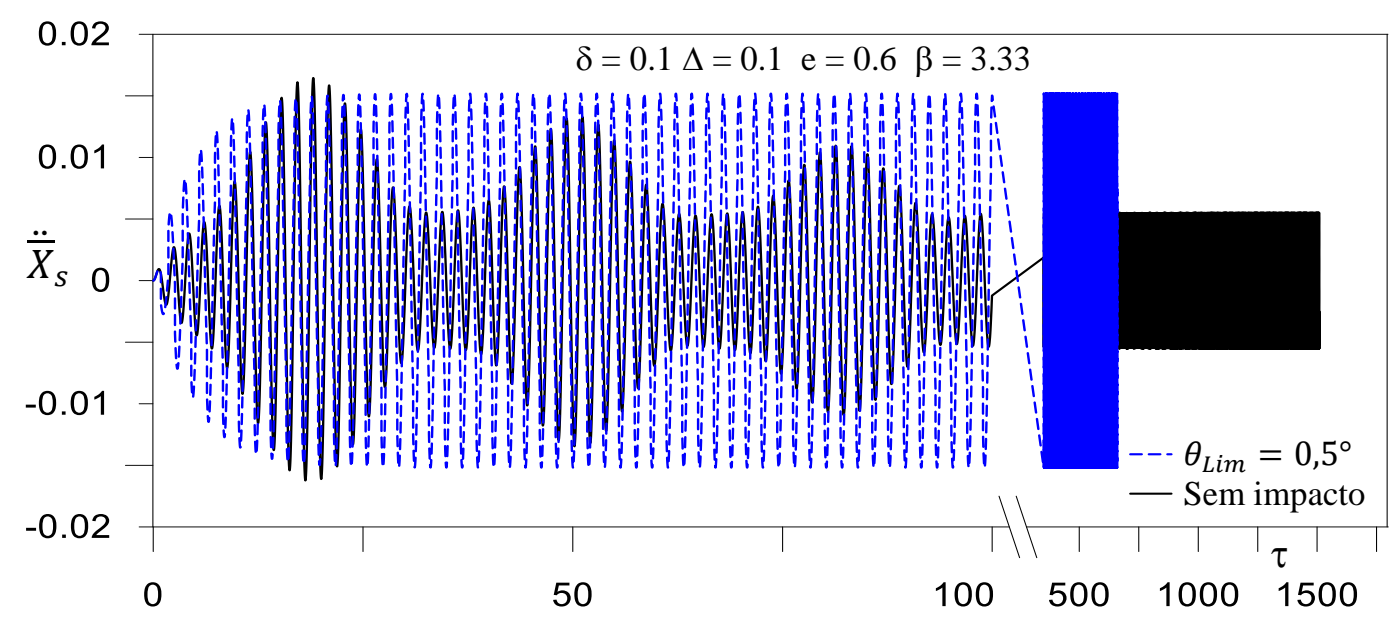

Figura 7-45 Acelerações da estrutura no tempo para IBP com e sem impacto $\theta_{\text {L'm }}=0,5^{\circ}$

A Figura 7-46 apresenta os diagramas de bifurcação para três valores do coeficiente de impacto e, a saber, 1,0, 0,6 e 0,2, comparando os mesmos com o diagrama da estrutura sem impacto para $\theta_{\text {Lim }}=10^{\circ}$. A Figura 7-47 apresenta a

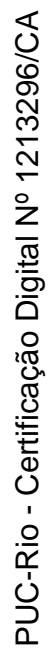
resposta da estrutura no tempo para os três coeficientes de restituição e $\beta=1,1$.

Observa-se que para e=1,0 a influência na redução do deslocamento máximo é pequena, mas a estrutura apresenta um comportamento não linear complexo com soluções não periódicas. Para os dois outros valores de e a resposta é semelhante e o efeito da não linearidade diminui.
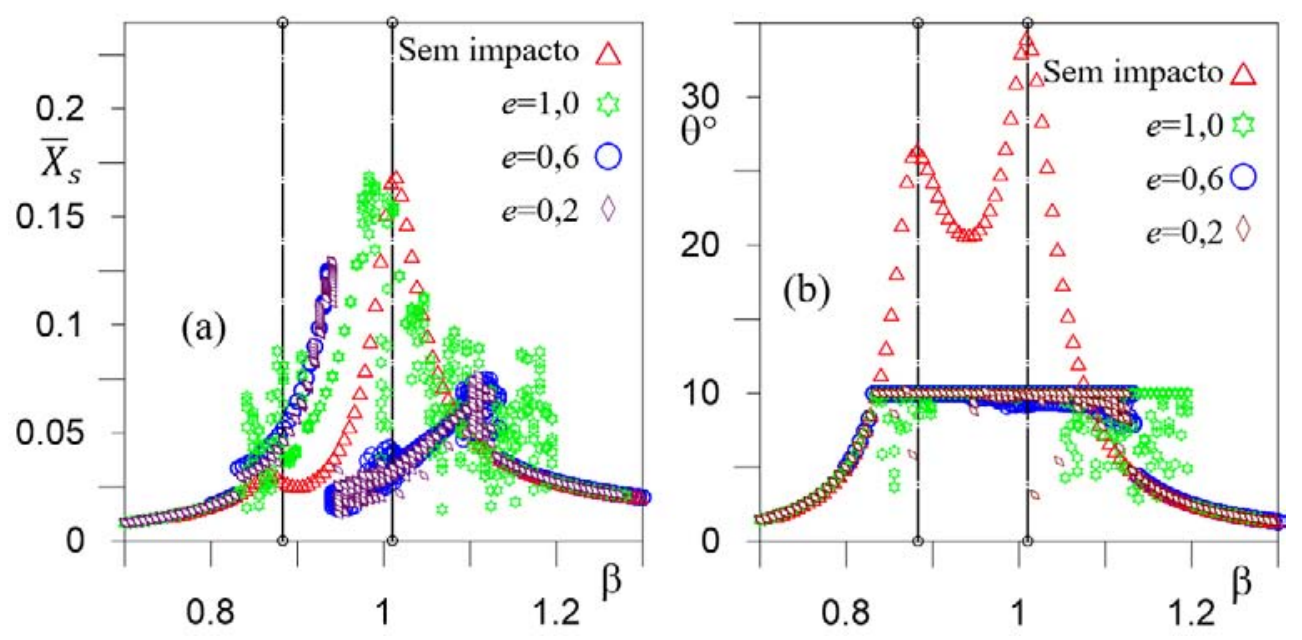

Figura 7-46 Curvas de ressonância em função do coeficiente de restituição (e) $\Delta=0,9$; $\delta=0,01 \theta_{\text {Lím }}=10^{\circ}$ 


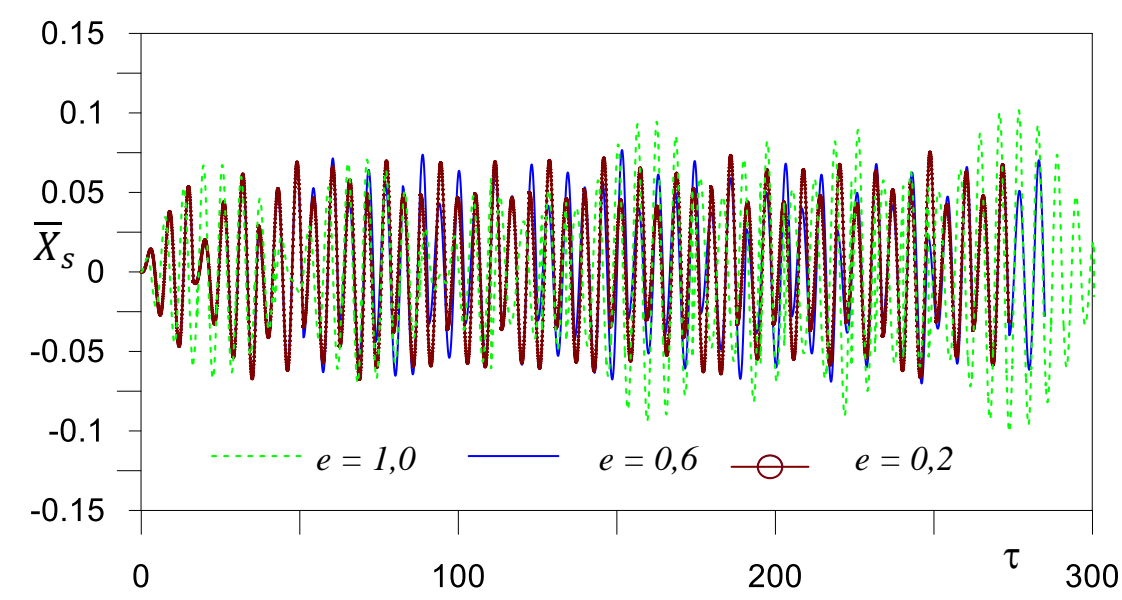

Figura 7-47 Deslocamento da estrutura no tempo em função do coeficiente de restituição (e), para $\theta_{\text {Lim }}=10^{\circ}$ e $\beta=1,1$

\section{4.}

\section{Impacto no controle sísmico}

A influência do impacto no controle de vibrações em estruturas sob excitação sísmica é estudada usando o sinal do terremoto El Centro EW e $\delta=0,1$; $\Delta=0,9 ; \xi_{S}=2 \%$ e $\xi_{a}=3,5 \%$. Na Figura 7-48 são mostrados os deslocamentos da estrutura ao longo do tempo com e sem restrição das rotações do IBP. A rotação máxima do IBP sem impacto é de $9,45^{\circ}$. Para estudar o efeito do impacto, adota-se $\theta_{\text {Lim }}=5^{\circ}$. O impacto gera uma redução de $41,7 \%$ nos deslocamentos da estrutura, além disso, após o impacto, os deslocamentos são sempre menores ao longo do tempo. Observa-se que rapidamente se faz sentir a influência do impacto na resposta da estrutura. Na Figura 7-49 é mostrada a variação da aceleração ao longo do tempo. Verifica-se que o impacto aumenta em 50,4 \% a aceleração máxima da estrutura. O máximo ocorre logo no início da resposta no tempo. Entretanto, logo as acelerações da estrutura com impacto se tornam menores que aquelas do IBP sem impacto. A Tabela 7-3 mostra os valores máximos dos deslocamentos e acelerações da estrutura com e sem impacto.

Em todos os exemplos deste capítulo verifica-se que o valor de $\theta_{\text {Lim }}$ tem uma grande influência na resposta transiente e permanente. Um valor de $\theta_{\text {Lim }}$ muito pequeno leva a uma perda de eficiência do IBP já que ele não consegue dissipar energia suficiente durante o movimento e, com o decréscimo da velocidade, também ocorre uma diminuição da dissipação de energia durante o impacto. Assim o valor de $\theta_{\text {Lim }}$ deve ser grande o suficiente para dissipar grande 
parte da energia gerada pelo movimento de base, mantendo, por outro lado, dentro de limites aceitáveis as rotações do IBP.

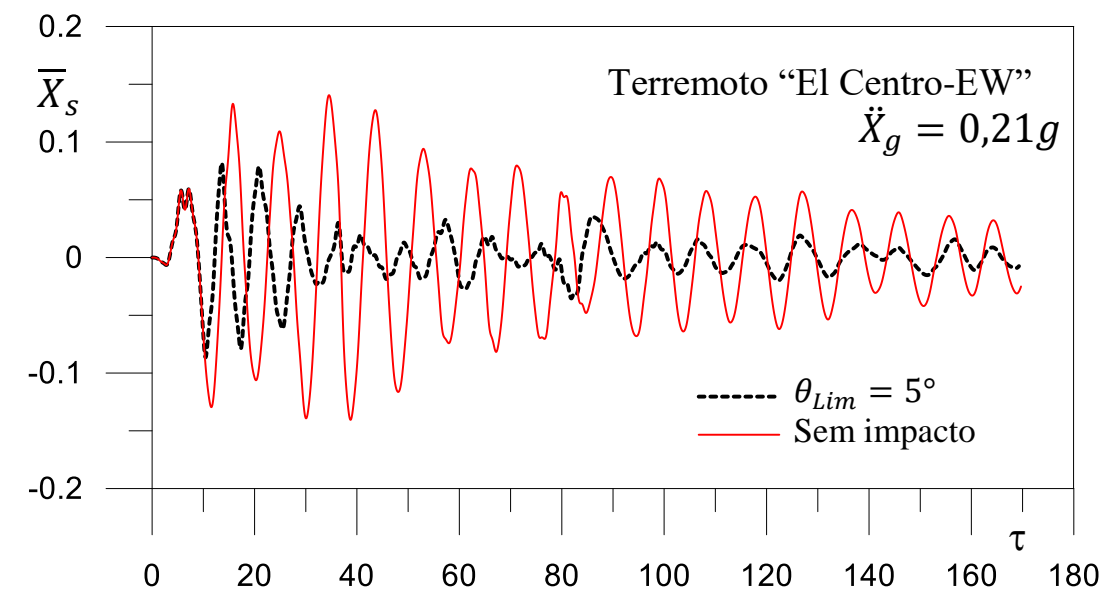

Figura 7-48 Deslocamentos no tempo da estrutura com IBP, sob carregamento sísmico

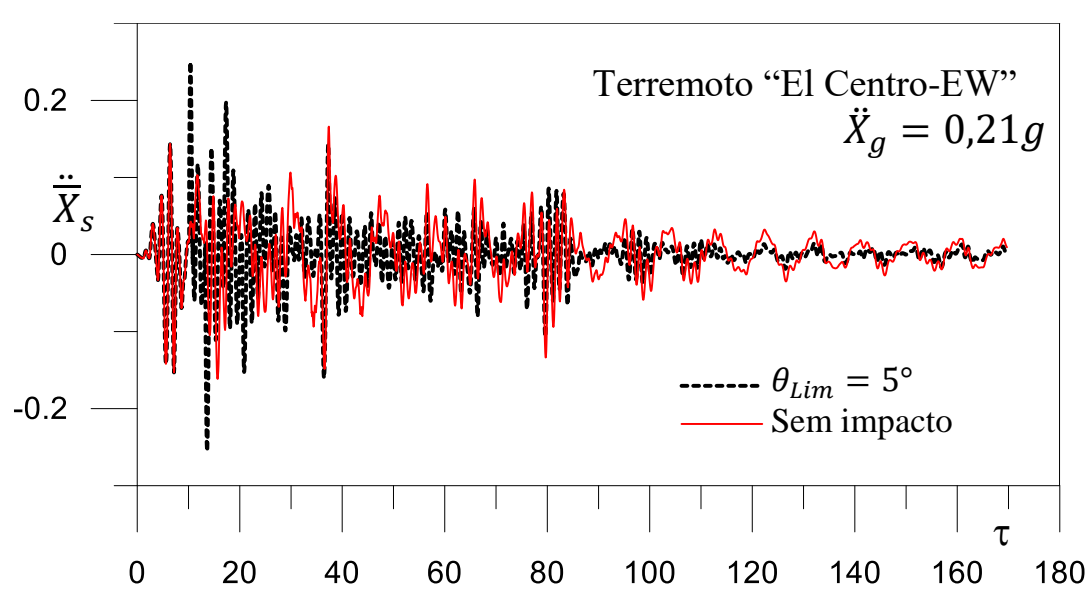

Figura 7-49 Acelerações no tempo da estrutura com IBP, sob carregamento sísmico

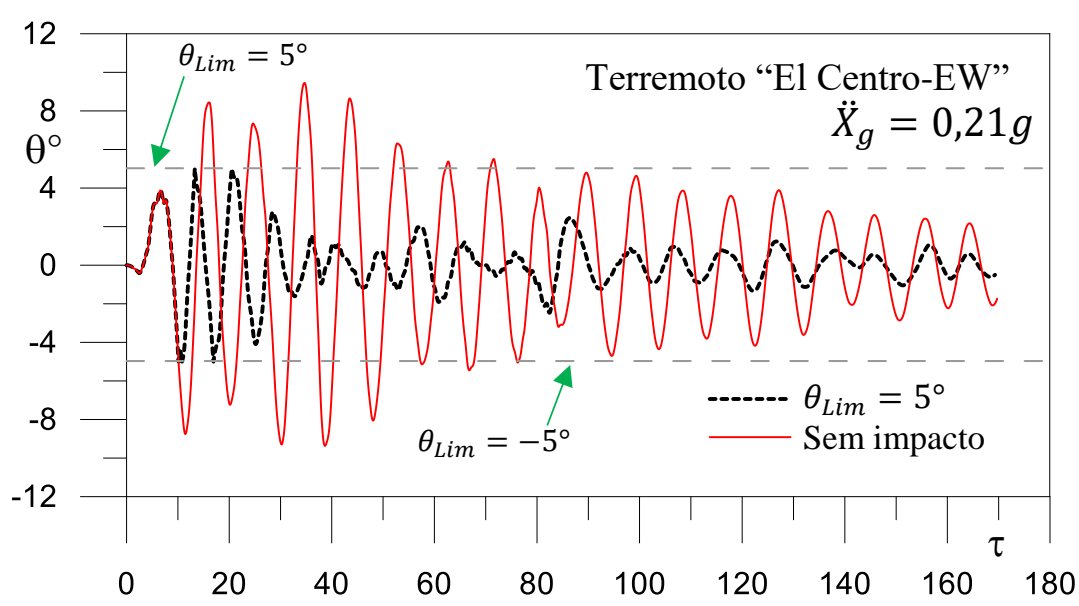

Figura 7-50 Rotaç̃̃es no tempo do IBP com carregamento sísmico 
Tabela 7-3 Deslocamentos e acelerações máximas da estrutura e rotações máximas do IBP com e sem impacto

Estrutura-IBP-Terremoto El Centro-EW

\begin{tabular}{|c|c|c|c|c|c|}
\hline \multirow{2}{*}{$\begin{array}{l}\text { TIPO DE } \\
\text { CURVA }\end{array}$} & & \multirow{2}{*}{$\begin{array}{c}\theta \\
\text { Limite }\end{array}$} & \multicolumn{2}{|c|}{ Estrutura Principal } & \multirow{2}{*}{$\begin{array}{c}\text { IBP } \\
\text { Rotação } \\
\left(\theta_{M a ́ x}^{\circ}\right)\end{array}$} \\
\hline & & & Deslocamento & Aceleração & \\
\hline \multirow[t]{2}{*}{ Circular } & $A$ & $\begin{array}{c}\text { Sem } \\
\text { impacto }\end{array}$ & 0,140558 & 0,166001 & 9,45 \\
\hline & $\boldsymbol{B}$ & $5^{\circ}$ & 0,08185 & 0,24970 & 5,0 \\
\hline $\begin{array}{c}\text { Diferença } \\
\%\end{array}$ & $A-B$ & & 41,77 & $-50,42$ & \\
\hline
\end{tabular}




\section{8 \\ Conclusões e sugestões do trabalho}

\section{1. Conclusões}

Este trabalho propôs o uso de um sistema pendular como controlador passivo de vibrações em estruturas e equipamentos, principalmente em edificações para minorar as vibrações de estruturas submetidas a um movimento de base, sendo este incorporado à estrutura principal como amortecedor de massa sintonizado ou como isolador de base. Foi estudada detalhadamente nesta tese a eficiência do sistema de controle sob carregamentos de base harmônicos e sísmicos. A forma da curva que descreve o absorsor pendular foi também analisada bem como a influência de forças de impacto no controle de vibrações.

Após uma detalhada análise paramétrica em termos dos parâmetros adimensionais característicos do sistema, em particular a razão de massas e a razão de frequências, chega-se às seguintes conclusões sobre o uso do sistema pendular passivo como amortecedor pendular de massa sintonizado (APMS) para o controle de vibrações:

1. Em relação ao parâmetro da razão de massas, $\delta$, a eficiência do APMS cresce com o valor de $\delta$, estando o seu valor máximo condicionado apenas às restrições de sobrecarga na estrutura principal e localização. Por exemplo, o incremento de $\delta=0,01$ para $\delta=0,05$ aumentou a eficiência do APMS de $17.32 \%$ para $41.61 \%$, para uma razão de frequências $\Delta=0,09$, sob um carregamento harmônico.

2. Em relação ao parâmetro que sintoniza as frequências naturais do pêndulo e da estrutura a controlar, pode se concluir que o APMS é mais eficiente entre os valores de $\Delta=0,9$ e $\Delta=1$, chegando a ter uma eficiência máxima de 33.95\% em relação à estrutura sem controle, para $\delta=0.01$, considerando um carregamento harmônico. 
3. Verifica-se que o APMS exibe uma boa eficiência não só no controle dos deslocamentos, como também no controle das acelerações, aumentando a segurança da estrutura e o conforto dos usuários.

4. Quanto a não linearidade do amortecimento do APMS (parâmetro $\alpha$ ), verifica-se que esta influencia a resposta da estrutura em termos de deslocamentos e acelerações. Para valores de $1,0<\alpha \leq 2,0$ os deslocamentos foram reduzidos em 0,89 vezes em relação ao valor do deslocamento considerando $\alpha=1,0$ (caso linear), e de 0,90 vezes o valor da aceleração máxima para $\Delta=0,9$ e $\delta=0.01$, considerando um carregamento harmônico.

5. Em relação à eficiência do APMS no controle de vibrações sob carregamento sísmico (resposta transiente), especificamente para sinais no tempo dos terremotos Loma Prieta-EW e El Centro (EW e NS), foi observada uma grande variabilidade na redução dos deslocamentos e acelerações devido aos diferentes conteúdos de frequências e magnitudes dos sismos, demostrando uma menor eficiência do APMS na presença de carga aleatórias. A eficiência máxima neste caso foi de $47,49 \%$ e $27,26 \%$ em termos de deslocamentos e acelerações, respectivamente.

6. Não se observou para o APMS sob excitação harmônica ou sísmica de base bifurcações ou saltos dinâmicos que pudessem comprometer a eficiência do mesmo. Verifica-se que o absorsor aqui proposto apresenta eficiência no controle de deslocamentos e acelerações, pode ser facilmente construído, entra rapidamente em movimento em virtude da resistência rolamento ser muito pequena aparecendo seu efeito benéfico logo no início da resposta transiente, volta normalmente à posição inicial de equilíbrio estático em virtude da força de restauração advinda do potencial gravitacional de sua massa e, para valores usuais de frequência fundamental leva a valores de raio de curvatura que conduzem a uma superfície suave.

7. O comportamento não linear do APMS em virtude de grandes rotações na presença de cargas de valor elevado tem influência na frequência natural, reduzindo as frequências naturais 
(comportamento com perda de rigidez). Embora as grandes rotações absorvam mais energia gerada pelo movimento de base, reduzindo ainda mais os deslocamentos da estrutura principal, as grandes rotações requerem de coeficiente de atrito maior para garantir o rolamento sem deslizamento.

8. Em relação à variação da função que descreve a superfície curva, verifica-se que a variação da curvatura, no caso das funções polinomiais, aumenta de forma acentuada a não linearidade do sistema dando origem a não linearidades inerciais e geométricas (no caso da superfície potencial de quarto grau) não existentes do caso circular. Os resultados mostram que estas não linearidades podem causar, principalmente quando há regiões com grande variação de curvatura, bifurcações, soluções não periódicas e saltos dinâmicos. Em geral a superfície curva circular leva aos melhores resultados.

9. A limitação das rotações do APMS através de barreiras rígidas gera forças de impacto, absorvendo parte da energia gerada pelo movimento de base através de impactos, sendo esta dissipação função do coeficiente de restituição. A limitação da rotação pode gerar reduções adicionais nos deslocamentos e acelerações da estrutura principal. Em alguns casos reduções de mais de $40 \%$ foram observadas. Embora o impacto gere redução de energia, ele também aumenta a não linearidade que é função da descontinuidade da velocidade. Isto pode levar, como no caso de variação de curvatura, a bifurcações, soluções não periódicas e saltos dinâmicos. Entretanto, com base nos resultados, é preferível o uso de barreiras para limitar as rotações que aumentar a curvatura.

Com base nas análises paramétricas do sistema pendular usado como IBP no controle de vibrações em estruturas de edificações sob excitação de base harmônica e sísmica, chega-se às seguintes conclusões:

1. A eficiência do isolamento de base cresce à medida que o parâmetro de sintonização de frequências diminui, ou seja, a medida que o raio de curvatura da superfície aumenta. Por exemplo, para $\Delta=0,1$ e $\delta=$ 
0.1, observa-se uma redução de 99,43\% nos deslocamentos e de 99.93\% nas acelerações. Isto se deve ao fato da frequência fundamental decrescer com $\Delta$, e ser o modo de vibração associado a este frequência próximo de um deslocamento de corpo rígido. Com isto há uma diminuição sensível nos deslocamentos relativos entre os andares do edifício e, consequentemente, nos esforços adicionais provenientes da excitação de base, principal fonte de dano em estruturas sob cargas sísmicas. Também, à medida que $\Delta$ decresce, aumenta a diferença entre a frequência fundamental e a segunda frequência de vibração. Este comportamento está de acordo com a filosofia de projeto de sistemas de isolamento de base que prescreve um aumento do período fundamental de modo a afastar a estrutura da região de maior conteúdo de frequências do evento sísmico.

2. A influência da razão de massas ( $\delta$ ) na redução da resposta da estrutura mostrou ser pequena, demostrando que o parâmetro de sintonização de frequências $(\Delta)$ é o parâmetro mais relevante no projeto dos sistema de controle pendular passivo.

3. Em todos os casos a eficiência do IPB é bem superior à eficiência do APMS, o que é esperado par estruturas sob excitação de base. Tendo em vista que o potencial gravitacional do IPB é função da massa total da estrutura, a força de restauração é bem maior, o que explica também os ganhos mais elevados.

4. Estas forças de restauração, típicas das superfícies curvas, fazem com que a estrutura volte naturalmente à sua posição original de equilíbrio, não havendo deslocamentos residuais, o que é uma característica positiva do sistema aqui proposto.

5. Como no caso do APMS, o efeito do IPB se faz sentir logo no início da resposta no tempo, o que é uma vantagem na presença de cargas de curta duração.

6. Em todos os exemplos analisados as rotações do IBP foram bastante pequenas, mesmo nos exemplos considerando carreamentos sísmicos de magnitude elevada. Esta é uma vantagem do IPB, comparado com o APMS. 
7. A não linearidade da força de amortecimento na reposta da estrutura usando IBP, reduziu os deslocamentos para uma faixa de valores 0,3 $\leq \alpha \leq 1,0$, até um máximo de 0,47 vezes o deslocamento para $\alpha=$ 1,0. Entretanto os ganhos não justificam um investimento neste tipo de mecanismo de dissipação.

8. O IBP, quando se considera carregamentos sísmicos, apresenta um comportamento grande eficiência com pequenas variações de ganho em função do valor de sintonização das frequências e das características dinâmicas dos sismos. Por exemplo, para $\Delta=0,1$ e $\delta$ $=0,1$, tem-se uma redução de até $99.24 \%$ nos deslocamentos para o sinal do terremoto Loma Prieta, de $97.84 \%$ para o sinal do terremoto El Centro-EW e de $98.48 \%$ para os sinal do terremoto El CentroNS.

9. A limitação da rotação do IBP, embora não necessária, gera forças de impacto que absorvem energia, diminuindo os deslocamentos da estrutura principal, mas, em muitos casos, observa-se um aumento nas acelerações.

\section{2. \\ Sugestões de trabalhos futuros}

O presente trabalho apresentou dois sistemas de controle das vibrações de estruturas bastante eficientes e com características que o indicam para diversas aplicações em engenharia. Para complementar a pesquisa, sugere-se os trabalhos seguintes:

1. Analisar experimentalmente a eficiência do sistema pendular como amortecedor de massa sintonizada e como isolador de base com a finalidade de refinar a modelagem e investigar a implementação de tais sistemas em estruturas reais.

2. O sistema pendular apresenta deslocamento horizontal e vertical, na formulação apresentada não foi levado em conta a aceleração vertical do sismo, sugere-se sua incorporação para avaliar a sua influência no deslocamento da massa do sistema pendular, assim como no controle das vibrações da estrutura principal. 
3. Derivar o modelo matemático considerando o sistema pendular em duas direções ortogonais para análise do controle das vibrações não planares de estruturas sob excitação de base.

4. Estudar a eficiência dos sistemas de controle aqui apresentados, considerando modelos discretos de edifícios com vários graus de liberdade a fim de estudar a influência dos modos mais altos nas vibrações e forças internas da estrutura.

5. Implementar este mecanismo pendular de controle em programas de elementos finitos, permitindo assim um aprofundamento da análise dinâmica de estruturas de forma arbitrária, inclusive estruturas com assimetrias. 
9

\section{Referências bibliográficas}

AASHTO. Guide Specifications for Seismic Isolation Design, American Association of State Highway and Transportation Officials, Washington, DC, 2000;

ASSOCIAÇÃO BRASILEIRA DE NORMAS TÉCNICAS. NBR 6123: Forças devidas ao vento em edificações. Rio de Janeiro, 1988.

ANDREAUS, U.; CASINI, P. Dynamics of SDOF Oscillators with Hysteretic Motion-Limiting Stop. Nonlinear Dynamics, v. 22, n. 2, p. 145-164, 2000// 2000. ISSN 1573-269X. Disponível em: < http://dx.doi.org/10.1023/A:1008354220584 >.

ARNOLD, C. Earthquake effects on building. NEHRP Recommended Provisions for Seismic Regulations for New Buildings and Other Structures, FEMA 450, 2003, Washington, DC.

AVILA, S. M. Controle Híbrido para Atenuação de Vibrações em Edifícios, 2002. Tese de Doutorado. Tese de Doutorado-Pontifícia Universidade Católica do Rio de Janeiro, Rio de Janeiro.

BLAZEJCZYK-OKOLEWSKA, B. Analysis of an impact damper of vibrations. Chaos, Solitons \& Fractals, v. 12, n. 11, p. 1983-1988, 9// 2001. ISSN 0960-0779. Disponível em: < http://www.sciencedirect.com/science/article/pii/S0960077900001466 >.

BRATOSIN, D. Non-linear effects in seismic base isolation. Proceedings of the Romanian Academy, v. 5, n. 3, p. 297-309, 2004.

BROCK, J., E. A note on the damped vibration absorber. Trans. ASME, J. Appl. Mech., v. 13, n. 4, p. A-284, 1946

CANO, N.A.O., 2013, Avaliação De Sistemas De Isolamento Para O Controle De Vibrações De Edifícios Submetidos A Excitação De Base., Tese De Doutorado, COPPE, UNIVERSIDADE FEDERAL DO RIO DE JANEIRO- BRASIL.

CHATTERJEE, S.; MALLIK, A. K.; GHOSH, A. On impact dampers for non-linear vibrating systems. Journal of Sound and Vibration, v. 187, n. 3, p. 403-420, 1999 
CHEN, J.; GEORGAKIS, C. T. Tuned rolling-ball dampers for vibration control in wind turbines. Journal of Sound and Vibration, v. 332, n. 21, p. 5271-5282, 10/14/ 2013. ISSN 0022-460X. Disponível em: < http://www.sciencedirect.com/science/article/pii/S0022460X13004471 >.

CONTENTO, A; DI EGIDIO, A. Seismic protection of monolithic objects of art using a constrained oscillating base. INTECH Open Access Publisher, 2012.

CONSTANTINOU, M. C., SYMANS, M. D., TSOPELAS, P., \& TAYLOR, D. $P$. Fluid viscous dampers in applications of seismic energy dissipation and seismic isolation. In: Proc., ATC 17-1 Seminar on Seismic Isolation, Passive Energy Dissipation, and Active Control. 1993. p. 581-592.

CONNER, J.J., Introduction to Structural Motion Control, MIT Web Book, July 2001

DEN HARTOG, J.P. Mechanical Vibrations, New York: McGraw-Hill, 1956.

DIMENTBERG, M. F.; IOURTCHENKO, D. V. Random Vibrations with Impacts: A Review. Nonlinear Dynamics, v. 36, n. 2, p. 229-254, 2004// 2004. ISSN 1573-269X. Disponível em: < http://dx.doi.org/10.1023/B:NODY.0000045510.93602.ca >.

EKWARO-OSIRE, S.; DESEN, I. C. Experimental study on an impact vibration absorber. Journal of Vibration and Control, v. 7, n. 4, p. 475493, 2001.

FAN, F. G; AHMADI, G; TADJBAKHSH, I. G. Multi-story base-isolated buildings under a harmonic ground motion-Part II: Sensitivity analysis. Nuclear Engineering and Design, v. 123, n. 1, p. 17-26, 1990.

GARRIDO, H.; CURADELLI, O.; AMBROSINI, D. Improvement of tuned mass damper by using rotational inertia through tuned viscous mass damper. Engineering Structures, v. 56, p. 2149-2153, 11// 2013. ISSN 0141-0296.

Disponível em: http://www.sciencedirect.com/science/article/pii/S0141029613004112 >.

GOTTLIEB, H. P. W. Isodynamical Tracks And Potentials. Journal of Sound and Vibration, v. 199, n. 4, p. 667-678, 1/30/ 1997. ISSN 0022460X. Disponível em: http://www.sciencedirect.com/science/article/pii/S0022460X96906598 >.

GOTTWALD, J. A.; VIRGIN, L. N.; DOWELL, E. H. Experimental mimicry of Duffing's equation. Journal of Sound and Vibration, v. 158, n. 3, p. 447-467, 1992/11/08 1992. ISSN 0022-460X. Disponível em: < http://www.sciencedirect.com/science/article/pii/0022460X9290419X >. 
HOANG, N.; FUJINO, Y.; WARNITCHAI, P. Optimal tuned mass damper for seismic applications and practical design formulas. Engineering Structures, v. 30, n. 3, p. 707-715, 3// 2008. ISSN 0141-0296. Disponível em: http://www.sciencedirect.com/science/article/pii/S0141029607001927 >.

HOGAN, F. R; FORBES, J. R; WALSH, A. Dynamic Modeling of a Rolling Flexible Sphere. In: ASME 2015 International Design Engineering Technical Conferences and Computers and Information in Engineering Conference. American Society of Mechanical Engineers, 2015. p. V008T13A086-V008T13A086.

IBRAHIM, R. A. Recent advances in nonlinear passive vibration isolators. Journal of Sound and Vibration, v. 314, n. 3-5, p. 371-452, 7/22/ 2008. ISSN 0022-460X. Disponível em: < http://www.sciencedirect.com/science/article/pii/S0022460X08000436 >.

JANGID, R.; LONDHE, Y. Effectiveness of Elliptical Rolling Rods for Base Isolation. Journal of Structural Engineering, v. 124, n. 4, p. 469-472, 1998/04/01 1998. ISSN 0733-9445. Disponível em: < http://dx.doi.org/10.1061/(ASCE)0733-9445(1998)124:4(469) >. Acesso em: 2016/06/20.

JANGID, R. S. Stochastic seismic response of structures isolated by rolling rods. Engineering Structures, v. 22, n. 8, p. 937-946, 6// 2000. ISSN 0141-0296. Disponível em: < http://www.sciencedirect.com/science/article/pii/S0141029699000413 >.

KANAI, K. Semi-empirical formula for the seismic characteristics of the ground. 1957.

KELLY, J. M. Earthquake-resistant design with rubber. 1993.

KELLY, J. M.; KONSTANTINIDIS, D. Mechanics of rubber bearings for seismic and vibration isolation. John Wiley \& Sons, 2011.

LEE, G. C., OU, Y. C., NIU, T., SONG, J., \& LIANG, Z. Characterization of a Roller Seismic Isolation Bearing with Supplemental Energy Dissipation for Highway Bridges. Journal of Structural Engineering, v. 136, n. 5, p. 502-510, 2010/05/01 2009. ISSN 0733-9445. Disponível em: < http://dx.doi.org/10.1061/(ASCE)ST.1943-541X.0000136 >. Acesso em: 2016/06/22.

LEGEZA, V. P. Efficiency of a vibroprotection system with an isochronous roller damper. Mechanics of Solids, v. 48, n. 2, p. 168-177, 2013// 2013. ISSN 1934-7936. Disponível em: < http://dx.doi.org/10.3103/S0025654413020088 >.

LI, Q. S., ZHI, L. H., TUAN, A. Y., KAO, C. S., SU, S. C., \& WU, C. F. Dynamic behavior of Taipei 101 tower: field measurement and numerical 
analysis. Journal of Structural Engineering, v. 137, n. 1, p. 143-155, 2010.

LIN, T. W; CHERN, C. C; HONE, C. C. Experimental study of base isolation by free rolling rods. Earthquake engineering \& structural dynamics, v. 24, n. 12, p. 1645-1650, 1995.

MARIAN, L.; GIARALIS, A. Optimal design of a novel tuned massdamper-inerter (TMDI) passive vibration control configuration for stochastically support-excited structural systems. Probabilistic Engineering Mechanics, v. 38, p. 156-164, 10// 2014. ISSN 0266-8920. Disponível em:

http://www.sciencedirect.com/science/article/pii/S0266892014000216 >.

MATTA, E.; DE STEFANO, A. Robust design of mass-uncertain rollingpendulum TMDs for the seismic protection of buildings. Mechanical Systems and Signal Processing, v. 23, n. 1, p. 127-147, 1// 2009a. ISSN 0888-3270.

http://www.sciencedirect.com/science/article/pii/S0888327007001604 >.

MATTA, E; DE STEFANO, A; SPENCER, B. F. A new passive rollingpendulum vibration absorber using a non-axial-symmetrical guide to achieve bidirectional tuning. Earthquake Engineering \& Structural Dynamics, v. 38, n. 15, p. 1729-1750, 2009b.

MINDA, A. A., GILLICH, G. R., IAVORNIC, C. M., \& MINDA, P. F. Analytical and finite element study for friction pendulum with parameterized sliding surfaces. In: Proceedings of the World Congress on Engineering. 2012. p. 4-6.

MITIĆ, E. Dynamics of the duffing oscillator with impacts. The scientific journal FACTA INIVERSITATIS; Working and Living Environmental Protection , v. 1, n. 2, p. 65-72, 1997.

MOKHA, A., CONSTANTINOU, M. C., REINHORN, A. M., \& ZAYAS, V. A. et al. Experimental Study of Friction-Pendulum Isolation System. Journal of Structural Engineering, v. 117, n. 4, p. 1201-1217, 1991/04/01 1991. ISSN 0733-9445. Disponível em: < http://dx.doi.org/10.1061/(ASCE)07339445(1991)117:4(1201) >. Acesso em: 2016/06/20.

NAEIM, F; KELLY, J. M. Design of seismic isolated structures: from theory to practice. John Wiley \& Sons, 1999.

NAGARAJAIAH, S.; REINHORN, A.; CONSTANTINOU, M. Nonlinear Dynamic Analysis of 3-D-Base-Isolated Structures. Journal of Structural Engineering, v. 117, n. 7, p. 2035-2054, 1991/07/01 1991. ISSN 07339445. Disponível em: < http://dx.doi.org/10.1061/(ASCE)07339445(1991)117:7(2035) >. Acesso em: 2016/05/21. 
NARKHEDE, D. I.; SINHA, R. Shock vibration control of structures using fluid viscous dampers. In: Proceedings of 15th World Conference on Earthquake Engineering.

NESTORIDES, E.J., BICERA: A Handbook on Torsional Vibration, University Press, 1958;

NUCERA, F., VAKAKIS, A. F., MCFARLAND, D. M., BERGMAN, L. A., \& KERSCHEN, G. "Targeted energy transfers in vibro-impact oscillators for seismic mitigation." Nonlinear Dynamics 50.3 (2007): 651-677

NUCERA, F., IACONO, F. L., MCFARLAND, D. M., BERGMAN, L. A., \& VAKAKIS, A. F. . Application of broadband nonlinear targeted energy transfers for seismic mitigation of a shear frame: Experimental results. Journal of Sound and Vibration, v. 313, n. 1-2, p. 57-76, 6/3/ 2008. ISSN 0022-460X. Disponível em: < http://www.sciencedirect.com/science/article/pii/S0022460X07008978 >.

ORLANDO, D; GONCALVES, P. B. Hybrid nonlinear control of a tall tower with a pendulum absorber. Structural Engineering and Mechanics, v. 46, n. 2, p. 153-177, 2013.

PARKER, T. S.; CHUA, L. Practical numerical algorithms for chaotic systems. Springer Science \& Business Media, 2012.

PASQUETTI, E. Métodos Aproximados de Solução de Sistemas Dinâmicos Não-Lineares. 2008. Tese de Doutorado. PUC-Rio.

PAULLO, M. L. F. Análise Dinâmica Não Linear de Pórticos com Base Elasto-plática sob Ação Sísmica, 2015. Tese de Doutorado. Tese de Doutorado-Pontifícia Universidade Católica do Rio de Janeiro, Rio de Janeiro.

PEZO, Z. E. Influência de um Amortecedor Magnetoreológico no Isolamento de Base de Edifícios sob Ação Sísmica. 2012. Dissertação de Mestrado. PUC-Rio.

PINTO, O. C.Controle Ativo Das Vibrações Não-Lineares De Estruturas Flexíveis, 1999. Tese de Doutorado-Pontifícia Universidade Católica do Rio de Janeiro, Rio de Janeiro.

PINHEIRO, M. A. Absorsor pendular não-linear para redução de vibrações em torres esbeltas. Absorsor pendular não-linear para redução de vibrações em torres esbeltas, 1997.

PIRNER, M. Actual behaviour of a ball vibration absorber. Journal of Wind Engineering and Industrial Aerodynamics, v. 90, n. 8, p. 9871005, 8// 2002. ISSN 0167-6105. Disponível em: < http://www.sciencedirect.com/science/article/pii/S0167610502002155 >. 
RAMBERGER, G. Structural bearings and expansion joints for bridges. Vol. 6., labse, 2002

RIVIN, E. I.; RIVIN, Eugene I. Passive vibration isolation. New York: Asme press, 2003.

SHAMES, I. H. (1996), Engineering Mechanics: Dynamics, 4th edition, Eaglewood Cliffs, NJ: Prentice-Hall Inc.

SHAW, S. W.; HADDOW, A. G. On 'roller-coaster' experiments for nonlinear oscillators. Nonlinear Dynamics, v. 3, n. 5, p. 375-384, 1992// 1992. ISSN 1573-269X. Disponível em: < http://dx.doi.org/10.1007/BF00045073 >.

SHUSTOV, V. Base isolation: Fresh insight. In: Proceedings of the 10th World Conference on arthquake Engineering. Balkema, Rotterdam. 1992. p. 1983-1986.

SOONG, T. T.; DARGUSH, G. F. Passive energy dissipation systems in structural engineering. Wiley, 1997.

SOONG, TSU T.; COSTANTINOU, Michalakis C. (Ed.). Passive and active structural vibration control in civil engineering. Springer, 2014.

SPENCER, B. F., and MICHAEL K. SAIN. "Controlling buildings: a new frontier in feedback." IEEE Control Systems 17.6 (1997): 19-35;

TANIGUCHI, T.; DER KIUREGHIAN, A.; MELKUMYAN, M. Effect of tuned mass damper on displacement demand of base-isolated structures. Engineering Structures, v. 30, n. 12, p. 3478-3488, 12// 2008. ISSN 0141-0296. Disponível em: < http://www.sciencedirect.com/science/article/pii/S0141029608002149 >.

TAJIMI, H. Statistical method of determining the maximum response of building structure during an earthquake. Proc. of the 2 nd WCEE, v. 2, p. 781-798, 1960.

TAYLOR, D.P. Buildings: design for damping. Taylor Devices Inc, North Tonawanda, EUA, $1999 . \quad$ Disponível em: http://taylordevices.com/literature.html. Acesso em: 01 agosto. 2016.

TSAI, M. H; CHANG, K. C; WU, S. Y. Seismic isolation of a scaled bridge model using rolling-type bearings. In: 4th International Conference on Earthquake Engineering, Taipei, Taiwan. 2006.

UEDA, S; ENOMOTO, T; FUJITA, T. Experiments and analysis of roller type isolation device. In: 13th world conference on earthquake engineering, Vancouver, Canada, Paper. 2004. p. 130Yim. 
WARBURTON, G. B.; AYORINDE, E. O. Optimum absorber parameters for simple systems. Earthquake Engineering \& Structural Dynamics, v. 8, n. 3, p. 197-217, 1980.

WU, S. Y., LEE, S. N., TSAI, M. H., and CHANG, K. C., Seismic Isolation Tests of A Bridge Model Using Rolling Type Seismic Isolation Bearings, Proceeding of the 17th KKCNN Symposium on Civil Engineering, Dec. 13 15, Ayutthya, Thailand, 2004.

YANG, J.; KIM, J.; AGRAWAL, A. Resetting Semiactive Stiffness Damper for Seismic Response Control. Journal of Structural Engineering, v. 126, n. 12, p. 1427-1433, 2000/12/01 2000. ISSN 0733-9445. Disponível em: < http://dx.doi.org/10.1061/(ASCE)0733-9445(2000)126:12(1427) >. Acesso em: 2016/06/24.

http://www.tribology-abc.com/abc/cof.htm, Acesso em: 2016/06/25. https://en.wikipedia.org/wiki/Rolling resistance, Acesso em: 2016/06/25. http://www.vibromech.com/customer/presentation/VESLFull\%20Scope\%20Supplier\%2020-Nov-06.pdf. Acesso em: 2016/06/25. https://en.wikipedia.org/wiki/Peak ground acceleration, Acesso em: 2016/06/25. 


\section{Apêndice A}

\section{1.}

\section{Equações de movimento do sistema pendular de massa sintonizada com curvas não circulares}

No Cap-6 temos definido o sistema de equações diferenciais na forma geral para curvas polinomiais (Eqs.6.17 e 6.18), na Eq. 6.18 pode-se substituir a primeira e segunda derivada da equação polinomial da superfície curva a usar para se obter o sistema pendular. A primeira superfície curva não circular usada para formar o sistema pendular é definida pela Eq.6.2 (curva quadrática). Após fazer a substituição das derivadas da função quadrática é obtida a equação de movimento particular do sistema pendular que tem a seguinte expressão

$$
\begin{gathered}
\left(\ddot{X}_{g}+\ddot{X}_{s}\right) M_{s}+\left(\ddot{X}_{g}+\ddot{X}_{s}+\ddot{X}_{a}\right) M_{a}+C_{s} \dot{X}_{s}+K_{s} X_{s}=0 \\
M_{a}\left(\ddot{X}_{s}+\ddot{X}_{g}\right)+M_{a}\left(\left(\frac{1}{2 f} X_{a}\right)^{2}+1\right) \ddot{X}_{a}+\frac{1}{4 f^{2}} M_{a} X_{a}\left(\dot{X}_{a}\right)^{2}+ \\
2 X_{a} M_{a} g+C_{a} \dot{X}_{a}\left(1+\left(2 X_{a}\right)^{2}\right)=0
\end{gathered}
$$

O sistema de equações de movimento Eq.10.1 e 10.2, reescrito em função dos parâmetros adimensionais definidas no Cap-2 e do raio de curvatura definida pela Eq. 6.7, tem a forma seguinte

$$
\begin{gathered}
\frac{d^{2} \bar{X}_{s}}{d \tau^{2}}+\frac{d^{2} \bar{X}_{g}}{d \tau^{2}}+\frac{d^{2} \bar{X}_{a}}{d \tau^{2}}+2 \xi_{s} \frac{d \bar{X}_{s}}{d \tau}+\bar{X}_{s}=0 \\
\delta\left(\frac{d^{2} \bar{X}_{g}}{d \tau^{2}}+\frac{d^{2} \bar{X}_{s}}{d \tau^{2}}\right)+\delta\left(\left(\bar{X}_{a}\right)^{2}+1\right) \frac{d^{2} \bar{X}_{a}}{d \tau^{2}}+2 \xi_{a} \delta \Delta \frac{d \bar{X}_{a}}{d \tau}\left(\left(\bar{X}_{a}\right)^{2}+1\right)+ \\
\delta \bar{X}_{a}\left(\frac{d \bar{X}_{a}}{d \tau}\right)^{2}+\delta \bar{X}_{a} \Delta^{2}=0
\end{gathered}
$$

A segunda superfície curva usada para formar o sistema pendular é obtida acrescentando uma parcela de grau $2 \phi$ à Eq. 6.2 (curva quadrática), gerando a Eq. 6.4. Graficamente a diferença da curva quadrática e modificada é mostrada na Figura 10-1. 


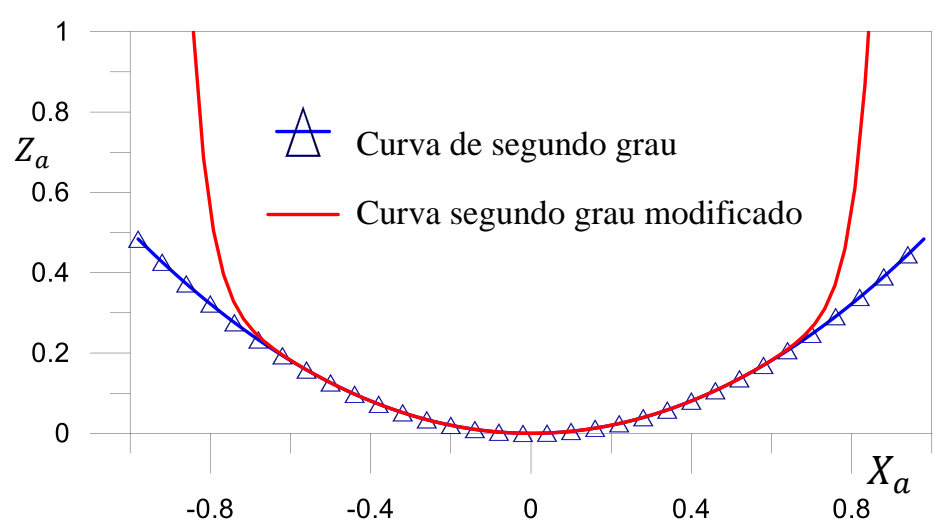

Figura 10-1 Diferença geométrica da curva quadrática e da modificada

Após substituir a primeira e segunda derivada da Eq.6.4 em função do grau de liberdade $\left(X_{a}\right)$ na equação 6.25 , chega-se à seguinte expressão.

$$
\left(\ddot{X}_{g}+\ddot{X}_{s}\right) M_{s}+\left(\ddot{X}_{g}+\ddot{X}_{s}+\ddot{X}_{a}\right) M_{a}+C_{s} \dot{X}_{s}+K_{s} X_{s}=0
$$

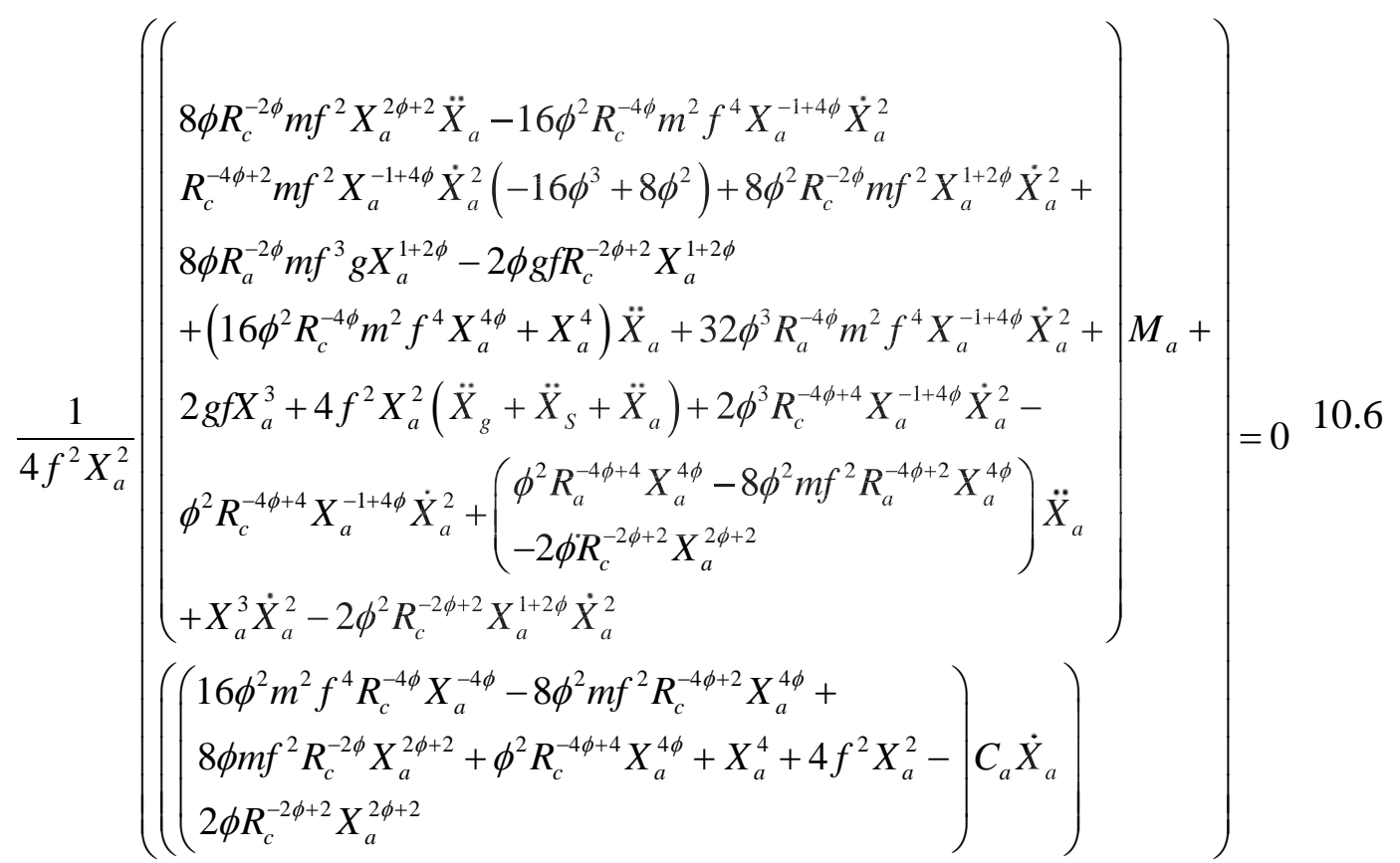

O sistema de equações de movimento na forma adimensional é obtido rescrevendo as Eqs.10.5 e 10.6 em função dos parâmetros adimensionais, chegando às seguintes expressões

$$
(\delta+1)\left(\frac{d^{2} \bar{X}_{s}}{d \tau^{2}}+\frac{d^{2} \bar{X}_{g}}{d \tau^{2}}\right)+\delta \frac{d^{2} \bar{X}_{a}}{d \tau^{2}}+2 \xi_{s} \frac{d \bar{X}_{s}}{d \tau}+\bar{X}_{s}=0
$$




$$
\begin{aligned}
& \delta\left(\frac{d^{2} \bar{X}_{s}}{d \tau^{2}}+\frac{d^{2} \bar{X}_{g}}{d \tau^{2}}\right)+\left(\begin{array}{l}
\phi^{2} \delta\left(\bar{X}_{a}\right)^{4 \phi-2}\left(m^{2}-2 m+1\right)+ \\
2 \phi \delta\left(\bar{X}_{a}\right)^{2 \phi}(m-1)+\delta\left(\bar{X}_{a}^{2}+1\right)
\end{array}\right) \frac{d^{2} \bar{X}_{a}}{d \tau^{2}}+ \\
& \left(\begin{array}{l}
\phi^{2} m \delta\left(\bar{X}_{a}\right)^{4 \phi+1}(2 m \phi-4 \phi-m+2)+ \\
\phi^{2} \delta\left(\bar{X}_{a}\right)^{4 \phi+1}(\phi-1)+2 \phi^{2} \delta\left(\bar{X}_{a}\right)^{2 \phi+1}(m-1)
\end{array}\right)\left(\frac{d \bar{X}_{a}}{d \tau}\right)^{2}+ \\
& \left(\begin{array}{l}
\phi^{2} \bar{X}_{a}^{4 \phi}\left(m^{2}-2 m+1\right)+2 \phi \bar{X}_{a}^{2 \phi}(m-1)+ \\
\bar{X}_{a}^{2}+1 \\
\phi \delta \Delta^{2}\left(\bar{X}_{a}\right)^{2 \phi-1}(m-1)+\delta \Delta^{2} \bar{X}_{a}=0
\end{array}\right) 2 \delta \xi_{a} \frac{d \bar{X}_{a}}{d \tau}+
\end{aligned}
$$

Por último, é usada uma superfície curva não circular descrita por um polinômio de quarto grau, mostrada na Figura 10-2.

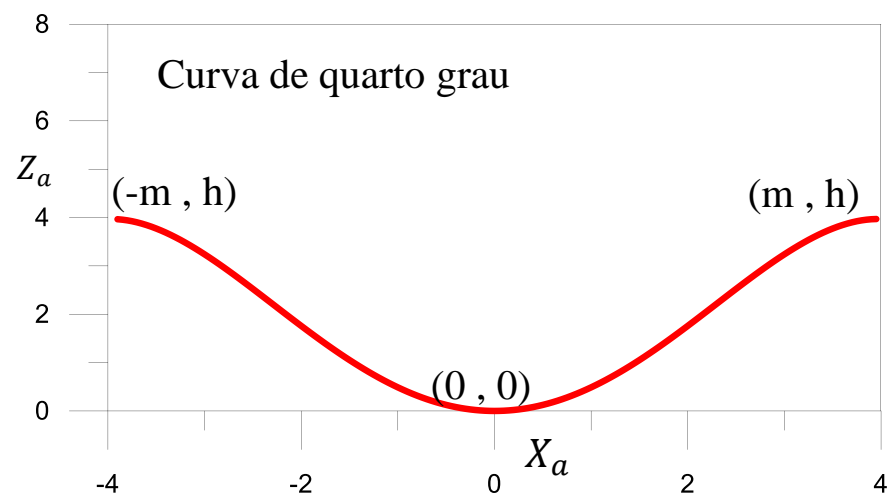

Figura 10-2 Curva de quarto grau para gerar o pêndulo

As equações de movimento da estrutura com APMS em função da superfície curva de quarto grau são dadas por

$$
\begin{gathered}
\left(\ddot{X}_{g}+\ddot{X}_{s}\right) M_{s}+\left(\ddot{X}_{g}+\ddot{X}_{s}+\ddot{X}_{a}\right) M_{a}+C_{s} \dot{X}_{s}+K_{s} X_{s}=0 \\
M_{a}\left(\ddot{X}_{s}+\ddot{X}_{g}\right)+M_{a}\left(\frac{16 \mathrm{H}^{2}\left(X_{a}^{3}-X_{a} m^{2}\right)^{2}+m^{6}}{m^{6}}\right) \ddot{X}_{a}+ \\
16 \mathrm{H}^{2}\left(3 X_{a}^{5}-4 X_{a}^{3} m^{2}+X_{a} m^{4}\right) M_{a}\left(\dot{X}_{a}\right)^{2}+ \\
\left(\frac{-X_{a}^{3} m^{3}+X_{a} m^{5}}{m^{6}}\right) 4 \mathrm{H}_{a} g+C_{a} \dot{X}_{u}\left(\frac{m^{6}+16 \mathrm{H}^{2} X_{a}^{2}\left(X_{a}^{2}-m^{2}\right)^{2}}{m^{6}}\right)=0
\end{gathered}
$$

Rescrevendo as Eqs. 10.9 e 10.10 na forma adimensional em função dos parâmetros adimensionais e do raio de curvatura Eq.6.11 têm-se as seguintes expressões 


$$
\begin{gathered}
(\delta+1)\left(\frac{d^{2} \bar{X}_{s}}{d \tau^{2}}+\frac{d^{2} \bar{X}_{g}}{d \tau^{2}}\right)+\delta \frac{d^{2} \bar{X}_{a}}{d \tau^{2}}+2 \xi \frac{d \bar{X}_{s}}{d \tau}+\bar{X}_{s}=0 \\
\delta\left(\frac{d^{2} \bar{X}_{g}}{d \tau^{2}}+\frac{d^{2} \bar{X}_{s}}{d \tau^{2}}\right)+\delta\left(\frac{\left(4 \bar{X}_{a} \mathrm{H}^{2}-\bar{X}_{a}^{3}\right)^{2}+16 \mathrm{H}^{4}}{16 \mathrm{H}^{4}}\right) \frac{d^{2} \bar{X}_{a}}{d \tau^{2}}+ \\
\delta \Delta \xi_{a}\left(\frac{\left(16 \bar{X}_{a} \mathrm{H}^{2}-\bar{X}_{a}^{3}\right)^{2}+256 \mathrm{H}^{4}}{126 \mathrm{H}^{4}}\right) \frac{d \bar{X}_{a}}{d \tau}+ \\
\delta\left(\frac{256 \bar{X}_{a} \mathrm{H}^{4}-64 \bar{X}_{a}^{3} \mathrm{H}^{2}+3 \bar{X}_{a}^{5}}{256 \mathrm{H}^{4}}\right)\left(\frac{d \bar{X}_{a}}{d \tau}\right)^{2}+\delta \bar{X}_{a} \Delta^{2}\left(\frac{16 \mathrm{H}^{2}+1}{16 \mathrm{H}^{2}}\right)=0
\end{gathered}
$$

10.2.

\section{Equações de movimento do isolador de base pendular para curvas não circulares}

As superfícies curvas usadas anteriormente para obter as diferentes equações da estrutura com APMS são usadas desta vez na geração das equações de movimento do sistema pendular como IBP. A primeira superfície curva a ser usada é a quadrática (Figura 10-1). Para obter as equações de movimento é usada a Eq.6.20, onde são substituídas a primeira e segunda derivada da Eq.6.2 em função do deslocamento horizontal, para logo obter a seguinte equação

$$
\begin{gathered}
\left(\ddot{X}_{s}+\ddot{X}_{a}+\ddot{X}_{g}\right) M_{s}+C_{s} \dot{X}_{s}+K_{s} X_{s}=0 \\
\left(\frac{X_{a}}{4 f^{2}} \dot{X}_{a}^{2}+\frac{X_{a}^{2}}{4 f^{2}} \ddot{X}_{a}^{2}+\frac{X_{a} g}{2 F}+\ddot{X}_{g}+\ddot{X}_{a}\right)\left(M_{s}+M_{a}\right)+\ddot{X}_{s} M_{s}+ \\
\left(\frac{X_{a}^{2}}{4 f^{2}}+1\right) \dot{X}_{a}=0
\end{gathered}
$$

Rescrita a Eq.10.13 e 10.14 em função dos parâmetros adimensionais, obtém-se a seguinte expressão

$$
\begin{gathered}
\frac{d^{2} \bar{X}_{s}}{d \tau^{2}}+\frac{d^{2} \bar{X}_{g}}{d \tau^{2}}+\frac{d^{2} \bar{X}_{a}}{d \tau^{2}}+2 \xi_{s} \frac{d \bar{X}_{s}}{d \tau}+\bar{X}_{s}+=0 \\
\left(\delta \bar{X}_{a}^{2}+\bar{X}_{a}^{2}+\delta+1\right) \frac{d^{2} \bar{X}_{a}}{d \tau^{2}}+\frac{d^{2} \bar{X}_{s}}{d \tau^{2}}+(\delta+1) \frac{d^{2} \bar{X}_{g}}{d \tau^{2}}+ \\
(\delta+1) \bar{X}_{a}\left(\frac{d \bar{X}_{a}}{d \tau}\right)^{2}+2 \delta \xi_{a}\left(\bar{X}_{a}^{2}+1\right) \Delta \frac{d \bar{X}_{a}}{d \tau}+(\delta+1) \bar{X}_{a} \Delta^{2}=0
\end{gathered}
$$

Na Figura 10-1 é mostrada a modificação feita na superfície curva quadrática (Eq.6.4) que é usada para gerar a equação de movimento da estrutura com IBP. A 
obtenção da equação de movimento é obtida também substituindo a primeira e segunda derivada da Eq.6.20 para obter as seguintes equações

$$
\begin{aligned}
& \left(\ddot{X}_{s}+\ddot{X}_{a}+\ddot{X}_{g}\right) M_{s}+C_{s} \dot{X}_{s}+K_{s} X_{s}=0 \\
& \frac{1}{4 f^{2} X_{a}^{2}}\left(\begin{array}{l}
\phi^{2} X_{a}^{4 \phi} R_{c}^{-4 \phi}\left(\begin{array}{l}
16 M_{a} m^{2} f^{4}+16 M_{s} m^{2} f^{4}-8 M_{a} R_{c}^{2} m f^{2} \\
-8 M_{s} R_{c}^{2} m f^{2}
\end{array}\right)+ \\
X_{a}^{4 \phi} R_{c}^{-4 \phi+4} \phi^{2}\left(M_{a}+M_{s}\right)+8 m X_{a}^{2 \phi+2} R_{c}^{-2 \phi} \phi f^{2}\left(M_{a}+M_{s}\right) \\
+X_{a}^{4}\left(M_{a}+M_{s}\right)- \\
2 \phi R_{c}^{-2 \phi+2} X_{a}^{2 \phi+2}\left(M_{a}+M_{s}\right)+4 X_{a}^{2} f^{2}\left(M_{a}+M_{s}\right)
\end{array}\right) \ddot{X}_{a}+ \\
& M_{s} \ddot{X}_{s}+
\end{aligned}
$$

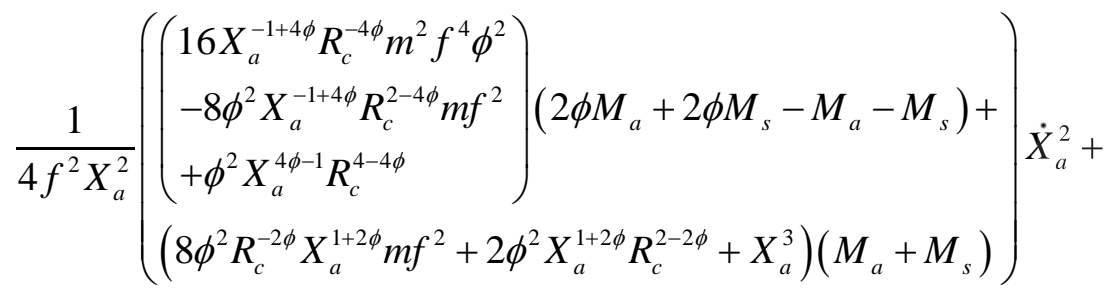

$$
\begin{aligned}
& \frac{1}{4 f^{2} X_{a}^{2}}\left(\begin{array}{l}
16 \phi^{2} X_{a}^{4 \phi} R_{c}^{-4 \phi} m^{2} f^{4}-8 \phi^{2} X_{a}^{4 \phi} R_{c}^{2-4 \phi} m f^{2}+ \\
2 \phi R_{c}^{-2 \phi} X_{a}^{2 \phi+2}\left(4 m f^{2}-R_{c}^{2}\right)+\phi^{2} X_{a}^{4 \phi} R_{c}^{4-4 \phi}+X_{a}^{4}+4 f^{2} X_{a}^{2}
\end{array}\right) C_{a} \dot{X}_{a} \\
& +\left(M_{a}+M_{s}\right) \ddot{X}_{g}+\frac{\left(\begin{array}{l}
2 \phi R_{a}^{-2 \phi} X_{a}^{1+2 \phi} g f\left(\begin{array}{l}
4 M_{a} m f^{2}+4 M_{s} m f^{2}-M_{a} R_{a}^{2} \\
-M_{s} R_{c}^{2}
\end{array}\right)+ \\
\left.2 X^{3} g M_{a}+M_{s}\right)
\end{array}\right)}{4 f^{2} X_{a}^{2}}=0
\end{aligned}
$$

Rescrevendo a Eq.10.17 e 10.18 em função dos parâmetros adimensionais é obtido o sistema de equações de movimento da estrutura com IBP na forma adimensional

$$
\begin{gathered}
\frac{d^{2} \bar{X}_{s}}{d \tau^{2}}+\frac{d^{2} \bar{X}_{g}}{d \tau^{2}}+\frac{d^{2} \bar{X}_{a}}{d \tau^{2}}+2 \xi_{s} \frac{d \bar{X}_{s}}{d \tau}+\bar{X}_{s}=0 \\
(\delta+1) \frac{d^{2} \bar{X}_{g}}{d \tau^{2}}+\frac{d^{2} \bar{X}_{s}}{d \tau^{2}}+\left(\begin{array}{l}
\phi^{2} \bar{X}_{a}^{4 \phi-2}\left((m+1)^{2}(\delta+1)\right)+ \\
\left(2 \phi \bar{X}_{a}^{2 \phi}(m-1)+\left(\bar{X}_{a}^{2}+1\right)\right)(1+\delta)
\end{array}\right){\frac{d}{2} \bar{X}_{a}}_{d \tau^{2}}+ \\
\left(\begin{array}{l}
\left(\begin{array}{l}
\phi^{2} X_{a}^{4 \phi-3}(2 \phi-1)(m-1)^{2}+ \\
2 \phi^{2} \bar{X}_{a}^{2 \phi-1}(m-1)+\bar{X}_{a}
\end{array}\right)(1+\delta)
\end{array}\right)\left(\frac{d \bar{X}_{a}}{d \tau}\right)^{2}+ \\
2\left(\phi^{2} \delta X_{a}^{4 \phi-2}\left(1+m^{2}-2 m\right)+\delta X_{a}^{2 \phi}(2 \phi m-2 \phi+1)\right) \Delta \frac{d \bar{X}_{a}}{d \tau}+ \\
\left(\phi \bar{X}_{a}^{2 \phi-1}(m-\delta+\delta m-1)+\bar{X}_{a}(\delta+1)\right) \Delta^{2}=0
\end{gathered}
$$


Por último se tem a superfície curva de quarto grau (Eq.6.10) mostrada na Figura 10-2. As equações de movimento têm a forma seguinte:

$$
\begin{aligned}
& \left(\ddot{X}_{s}+\ddot{X}_{a}+\ddot{X}_{g}\right) M_{s}+C_{s} \dot{X}_{s}+K_{s} X_{s}=0 \\
& \frac{\left(256 H^{4} X_{a}^{2} R_{c}^{4}+256 H^{2} R_{c}^{6}-32 H^{2} R_{c}^{2} X_{c}^{4}+X_{c}^{6}\right)\left(M_{a}+M_{s}\right)}{256 R_{c}^{6} H^{4}} \ddot{X}_{a}+ \\
& \left(M_{a}+M_{s}\right) \ddot{X}_{y}+M_{s} \ddot{X}_{s}+ \\
& \frac{\left(256 H^{4} R_{c}^{4} X_{a}-64 H^{2} R^{2} X_{a}^{3}+3 X_{a}^{5}\right)\left(M_{a}+M_{s}\right)}{256 R^{6} H^{4}}\left(\dot{X}_{a}\right)^{2}+ \\
& \frac{256 H^{4} R_{c}^{4} X_{a}^{2}+256 H^{4} R_{c}^{6}-32 H^{2} R_{c}^{2} X_{a}^{4}+X_{a}^{6}}{256 R_{c}^{6} H^{4}} C_{a} \dot{X}_{a}+ \\
& \frac{\left(256 H^{4} R_{c}^{5} g X_{a}-16 H^{2} R_{c}^{3} X_{c}^{3} g\right)\left(M_{a}+M_{s}\right)}{256 R_{c}^{6} H^{4}}=0
\end{aligned}
$$

Rescrevendo a Eq.10.21 e 10.22 em termos dos parâmetros adimensionais, chega-se às seguintes equações adimensionais:

$$
\begin{gathered}
\frac{d^{2} \bar{X}_{s}}{d \tau^{2}}+\frac{d^{2} \bar{X}_{g}}{d \tau^{2}}+\frac{d^{2} \bar{X}_{a}}{d \tau^{2}}+2 \xi_{s} \frac{d \bar{X}_{s}}{d \tau}+\bar{X}_{s}=0 \\
(\delta+1) \frac{d^{2} \bar{X}_{g}}{d \tau^{2}}+\frac{d^{2} \bar{X}_{s}}{d \tau^{2}}+ \\
\frac{\left(256 H^{4} \bar{X}_{a}^{2}-32 H^{2} \bar{X}_{a}^{4}+\bar{X}_{a}^{6}+256 H^{4}\right)(\delta+1)}{256 H^{4}} \frac{d^{2} \bar{X}_{a}}{d \tau^{2}}+ \\
\frac{\left(256 H^{4} \bar{X}_{a}-16 H^{2} \bar{X}_{a}^{3}\right)(\delta+1)}{256 H^{4}} \Delta^{2}+ \\
\frac{512 H^{4} \bar{X}_{a}^{2}-64 H^{2} \bar{X}_{a}^{4}+2 \bar{X}_{a}^{6}+512 H^{4}}{256 H^{4}} \delta \xi_{a} \Delta \frac{d \bar{X}_{a}}{d \tau}+ \\
\frac{\left(256 H^{4} \bar{X}_{a}-64 H^{2} \bar{X}_{a}^{3}+3 \bar{X}_{a}^{5}\right)(\delta+1)}{256 H^{4}}\left(\frac{d \bar{X}_{a}}{d \tau}\right)^{2}=0
\end{gathered}
$$

